By

Bradley Robert John Hannigan

A thesis

Submitted to the Victoria University of Wellington In fulfilment of the requirements for the degree of

Doctor of Philosophy

In Education

Victoria University of Wellington

2010 


\section{Dedication}

This thesis is dedicated to Helen, Bryn, Lily and Otis: My loving family who have supported and inspired me throughout the long thesis journey.

This thesis is also dedicated to the memory of my mentor and friend Dr. Jim Neyland (1953-2010). 


\section{Abstract.}

This thesis argues that there is structural dissonance in university-based initial early childhood teacher education programmes in Aotearoa/New Zealand, and suggests a pedagogy of enacted hope as a countermeasure. In this thesis, structural dissonance is constructed as a form of structural violence, which is based on the contradiction between socioculturalism in the content of IECTE programmes and individualisation in the context in which they are provided.

This theoretical thesis uses Richard Rorty's (1979, 1982, 1989, 1999) neopragmatic assumptions on truth, reality and knowledge to provide a coherent and consistent approach to the argument of structural dissonance and enacted hope. Distinctions between truth and justification, reality and appearance, found and made are rejected, and utility for social justice, language use, and an ironist approach to scholarship are adopted.

This thesis uses philosophical hermeneutics as a methodology for interpreting the textual sources that make up the data drawn upon in this thesis. This methodology is linked to interpretive scholarship, research bricolage, and the constructivist paradigm in qualitative research. The methods used in this thesis 
are an ecological hermeneutic, ideal type method (converted into an interpretive method of textual analysis) and focus groups of student teachers.

This thesis constructed two ideal types. The ideal type for socioculturalism is used to argue that the content of IECTE programmes is heavily influenced by socioculturalism. The ideal type for individualisation is used to argue that the context in which IECTE programmes are provided reproduces individualisation. Socioculturalism and individualisation are shown to be dissonant in the structure of a case IECTE programme in Aotearoa/New Zealand resulting in a situation of structural dissonance.

A pedagogy of enacted hope is then proposed to counteract structural dissonance in the case study IECTE programme in Aotearoa/New Zealand. This pedagogy is constructed using a theory of hope developed through the integration of Ernst Bloch's (1986) philosophy of hope, Rortyan philosophical assumptions and enactivist learning theory. Implications of using the pedagogy of enacted hope are then discussed in relation to the problem of structural dissonance. 


\section{Acknowledgments.}

This thesis would never have eventuated without the guidance and support offered by Victoria University of Wellington. I give particular thanks to the Scholarship Committee who supported this project from the outset and gave my young family the financial security to enable me to tackle such a large project. Thank you to Helen May who first brought me into the early childhood teacher education programme and to Kay Morris-Matthews, along with Helen May for giving me my first break into lecturing.

Thank you to all the inspiring teacher educators I have had the honour to work with over the past few years and the conversations we have had around teacher education. In particular I would like to thank Anita Mortlock, Sarah Te One, Alison Barker, Kayte Edwards, and Mandy Coupe. I would also like to thank all the fabulous student teachers that I have had the honour to work with over the last five years.

I offer special thanks to three people in particular: To the late Jim Neyland for being such an inspirational figure in my academic life. His were the first lectures to really set me on fire and the catalyst for my switch from psychology to educational philosophy. Jim's vision for education was infectious and I thank 
his family deeply for sharing him with me and students like me. His smile and his writing are sorely missed. Thank you to Carmen Dalli who has been instrumental in bringing this thesis to fruition, whose editing skills are second to none, and who has been and continues to be an inspirational figure in early childhood studies. Thank you also to Rob Strathdee for stepping in at the last minute to ensure this thesis would be completed. I have appreciated your piercing questions and your wry smile.

Last, but certainly not least, thank you to my family: To Helen, Bryn, Lily and Otis. Two of my children have never known me when I have not been writing this thesis, and the third has never known me to not be a student (he is nearly ten). Extra special thanks to Helen, my dear partner, who has walked with me and supported me on this journey. I would never have even got to the foot of the mountain if it were not for your love and support. Arohanui ki a koutou katoa! 


\section{Contents.}

Abstract

Acknowledgements

Part One - Introduction.

1.0 Introduction 2

1.1 Thesis overview $\quad 8$

2.0 Structural dissonance, moral hope and reconceptualisation 19

2.1 Structural dissonance $\quad 20$

2.2 Moral hope 33

2.3 Reconceptualisation $\quad 40$

Part Two - Philosophical assumptions and methodology.

3.0 Philosophical assumptions 56

3.1 Pragmatism and neo-pragmatism 58

3.2 A Rortyan perspective $\quad 64$

3.3 Rortyan assumptions $\quad 69$

3.4 Ironist scholarship $\quad 83$

4.0 Methodology and methods 85

4.1 Methodology: Hermeneutics $\quad 87$

4.2 Methodology: Qualitative research 98

$\begin{array}{ll}4.3 \text { Research methods } & 103\end{array}$

Part Three - Structural dissonance in IECTE programmes in Aotearoa/New Zealand.

5.0 Socioculturalism: An ideal type $\quad 119$

5.1 Socioculturalism: Definitions and theories 119

5.2 Socioculturalism: An ideal type 140

6.0 Socioculturalism in the content of IECTE programmes in

Aotearoa/New Zealand 150

6.1 Socio-historical context 152

6.2 Socioculturalism in the common texts used in IECTE programmes in Aotearoa/New Zealand 165

6.3 Socioculturalism in Aotearoa/New Zealand universities 174 
6.4 Socioculturalism in the content of the IECTE programme at a case study university

6.5 Socioculturalism in student teacher's experiences of their IECTE programme at a case study university

7.0 Individualisation in the context of IECTE programmes in

Aotearoa/New Zealand

7.1 Individualisation theory: An ideal type

7.2 Individualisation in the context of IECTE programmes in Aotearoa/New Zealand

8.0 Structural dissonance in IECTE programmes in

Aotearoa/New Zealand

8.1 Dissonance between ideal types

8.2 Structural dissonance in the context of IECTE programmes in Aotearoa/New Zealand

8.3 Structural violence and structural dissonance in IECTE programmes in Aotearoa/New Zealand

\section{Part Four - Reconstruction: A pedagogy of enacted hope.}

9.0 Hope

9.1 A general definition of hope 293

9.2 Hope is a holistic concept 296

9.3 Hope, Bloch (1996) and Rortyan assumption 302

9.4 Theory of hope 314

$\begin{array}{ll}10.0 \text { A pedagogy of enacted hope } & 319\end{array}$

10.1 Hope and education 319

10.2 Enactivist learning theory 328

10.3 Enacted hope $\quad 342$

10.4 A pedagogy of enacted hope challenges structural dissonance in IECTE programmes in Aotearoa/New Zealand 355

11.0 Conclusion 362

11.1 Summary of thesis $\quad 362$

11.2 Limitations and possibilities 369

$\begin{array}{ll}\text { Appendix A } & 374\end{array}$

$\begin{array}{ll}\text { Appendix B } & 375\end{array}$

$\begin{array}{ll}\text { References } & 377\end{array}$ 


\section{List of figures.}

$\begin{array}{ll}\text { Fig. } 1 \text { Grid of ideal types } & 109\end{array}$

$\begin{array}{ll}\text { Fig. } 2 \text { Ideal-type for socio-culturalism } & 140\end{array}$

Fig. 3 Ecological hermeneutic for chapter $6 \quad 152$

$\begin{array}{ll}\text { Fig. } 4 \text { Shifting gazes of state } & 153\end{array}$

Fig. 5 Socioculturalism in compulsory IECTE courses at Auckland $\begin{array}{ll}\text { University (2007) } & 177\end{array}$

Fig. 6 Socioculturalism in compulsory IECTE courses at Auckland University of Technology (2007) 178

Fig. 7 Socioculturalism in compulsory IECTE courses at Massey University (2007)

Fig. 8 Socioculturalism in compulsory IECTE courses at Otago University (2007) 180

Fig. 9 Socioculturalism in compulsory IECTE courses at the University of Canterbury (2007)

Fig. 10 Socioculturalism in compulsory IECTE courses at Victoria University of Wellington (2007)

Fig. 11 Socioculturalism in compulsory IECTE courses at Waikato University (2007)

Fig. 12 Socioculturalism in compulsory practice-based papers at the case study university

Fig. 13 Socioculturalism in compulsory pedagogical papers at the case study university

Fig. 14 Socioculturalism in compulsory academic papers at the case study University

Fig. 15 Ideal type for individualisation

Fig. 16 Ecological hermeneutic for individualisation

Fig. 17 Pairing of ideal types: Individualisation and sociocultural 258

Fig. 18 Ecological hermeneutic for structural dissonance 263

Fig. 19 Ecological hermeneutic for understand hope 292 



\section{Part One}

Introduction 


\section{Chapter One}

\section{Introduction}

Early childhood education has a history emblazoned with hope and the struggle against injustice (Cannella, 1997). Given this rich history there is little reason to believe that the future of early childhood education would not consist of further attempts to construct socially justice in the practices and study of early childhood education. Contemporary writers in early childhood studies have fought against injustice for children in the hope of extending citizenry rights to the very young (e.g., May, 2004; Smith, 1996, 2007; Te One, 2008, 2009). Authors like Ritchie (1994, 1996, 2003) and Stewart and Rawhiti (2004) have written against cultural injustice in the hope that all cultural groups will have a voice in early childhood settings. And others have struggled against dominating discourses in the hope that alternative stories might be given equal attention (e.g. Cannella, 1997; Dahlberg \& Moss, 2005; MacNaughton, 2005; Prochner, 2004).

Teacher education in Aotearoa/New Zealand had been provided in Teacher's Colleges or Colleges of Education since the early decades of the twentieth century (Partington, 1997). Early childhood education got its first diploma level qualification in 1988 after a hard fought campaign that stretched decades (May, 
2009). The struggle of the courageous women and men who battled prejudice, lack of funding and inequality to realise their hopes is not only inspiring, it is a case in point about how this thesis interprets hope as a concept: as looking forward to a better future and acting on the possibility of its realisation. Within this frame, initial early childhood education is an example of fulfilled hopes, as well as a site for ongoing struggle.

The introduction of sociocultural narrative into the policy, practices and reflections of state qualified teachers throughout New Zealand is another example of the struggle for social justice: of hope in action. Throughout the drafting of New Zealand's first early childhood curriculum statement the hope for a better future was present (e.g., Carr, May \& Mitchell, 1991; Carr \& May, 1993). This hope continued through out the consultation process, and into the final version, though as a somewhat watered down form of the original intention (Te One, 2003). The subsequent struggle to gain a degree programme, mentor students in Masters and PhD programmes, and influence government policy (May, 2009) are further examples of hope in action: of realisation through intrepid action and passionate commitment. 
There are currently 21 initial early childhood teacher education (IECTE) providers in New Zealand, 7 of which are universities (Ministry of Education, 2011). This thesis is written within a context where statefunded Teacher's Colleges have merged with Universities, those mergers occured between 1996 and 2007. By focusing on university based IECTE programmes, this thesis studies post-merger universities, and therefore only a small sector within teacher education providers. This thesis focuses specifically on Bachelor of Education (BEd) programmes, as opposed to including the Diploma, Postgraduate Diploma and Bachelor of Arts/Bachelor of Teaching programmes that were also provided in some university settings. Delineating IECTE programmes in this way allowed this research to focus on a qualification that was common across all universities, though it should be recognised that IECTE programmes in Aotearoa/New Zealand are diverse both in terms of the qualifications on offer as well as the method delivery (e.g., centre-based, campus-based, online).

Within this context, passionate teacher educators continue to encourage and inspire new generations of early childhood teachers, in addition to producing high quality research in numerous fields of inquiry (Strathdee, 2005). The role of teacher educators as purveyors of hope and inspiration is never in question throughout this thesis. The arguments set forth are not premised on an absence of hope, but rather on the hope that there is still something more that can be 
said in the struggle for social justice. This thesis is based on the assumption that the historical journey of early childhood education is by no means complete.

This thesis takes a theoretical approach to identify structural dissonance in IECTE programmes in Aotearoa/New Zealand and suggests a pedagogy of enacted hope in IECTE as a way of counteracting that dissonance. This thesis draws on multiple theoretical perspectives and uses neo-pragmatic assumptions to provide a new perspective in the ongoing conversation of social justice and socially just pedagogy in IECTE programmes. The central motif of this thesis is borrowed from peace education: It is the assumption that there needs to be consistency between what is being taught, and how it is being taught (Collinge, 1994). This thesis proposes that the content of IECTE programmes is contradicted by the context in which those programmes are delivered (there is dissonance between what and how), that that dissonance occurs in the structure of IECTE programmes, and that the IECTE pedagogy proposed herein offers a means for transforming that situation.

This thesis highlights structural dissonance between the sociocultural content of IECTE programmes in Aotearoa/ New Zealand and the reproduction of individualisation within them. University based IECTE programmes are considered in this thesis and the term structural dissonance is applied to these other programmes as well due to the requirement that all programmes meet the 
same Graduating Teacher Standards (NZ Teachers Council, 2007), and in doing so they are likely to be similar in a variety of ways (this is discussed in depth in chapters six and seven). Chapter two introduces the concept of structural dissonance and aligns it with the broader category of structural violence (social injustice). The critical (critique) part of this thesis identifies structural dissonance in an IECTE programme. This critical argument is advanced in part three (chapters five to eight). The reconstructive part of this thesis constructs a pedagogy of enacted hope and identifies some possibilities for application of this pedagogy in IECTE programmes. The reconstructive argument is advanced in part four (chapters nine and ten). The concepts used in developing this argument are initially explained below, and in greater detail in corresponding chapters.

This primarily theoretical thesis has been constructed with the aim of reconceptualising IECTE programmes to promote social justice. Social justice is the practice creating equitable relationships between human beings in social spaces, and between human beings and the social spaces they inhabit. One way of looking at reconceptualisation for social justice is as a practice of changing vocabularies to highlight injustices that have not-yet been considered in scholarship or discourse, so that new perspectives on social justice can be formed (e.g., Freire, 1970; Te One, 2009; Viruru, 2001). This thesis constructs a discourse of structural dissonance and counteracts it with a pedagogy of enacted 
hope. Both are new ideas within the fields of early childhood studies and IECTE. This thesis constructs these ideas and then applies them to IECTE programmes in Aotearoa/New Zealand.

Reconceptualisation for social justice is not a new endeavour in early childhood studies. For example, Cannella (1997) pointed out that the concept of childhood is monocultural in developmental discourses, Viruru (2001) pointed out that contemporary images of the child are by and large mono-cultural; and Dahlberg and Moss (2005) pointed out that border-crossing (cross disciplinary scholarship) is necessary to keep the conversation of early childhood and its goals flowing. This thesis joins in this conversation by offering a new way of looking at structural issues in IECTE, focusing on student teachers and their education. A related aim in writing this is to construct a theoretically consistent perspective that can be used to inform future research into teacher education and social justice.

This thesis uses Richard Rorty's (1979, 1982, 1989, 1991a, 1991b, 1998a, 1998b, 1999, 2007) philosophical assumptions to underpin the methodology used, the structure of the argument advanced, the analysis given and to organise the internal coherence of the chapters and parts of this thesis. A more specific introduction of those assumptions will be given below, however, it is important to note at the outset, that this philosophical perspective offers an innovative 
approach to early childhood studies that few scholars have taken up. Most noticeable of those that have are Dahlberg, Moss and Pence (1999) and Walsh (1993) who mentioned Rorty's contingency based approach to knowledge formation, and McArdle and McWilliam (2005) who mentioned Rorty's (1989) figure of the ironist in educational research. This thesis uses Rortyan assumptions as the lynch pin of its approach in a sustained effort of reconceptualisation: Both critical and reconstructive.

This thesis answers three questions. How is there structural dissonance in IECTE programmes in Aotearoa/New Zealand? How might structural dissonance be counteracted in IECTE programmes in Aotearoa/New Zealand? How can a neo-pragmatic research design be used to answer questions one and two? The following section introduces the four parts of this thesis and explains their function in terms of answering each of the thesis questions.

\subsection{Thesis overview}

Structurally, this is a thesis of four parts: Introduction; philosophy and methodology; critique; and reconstruction. This thesis is an example of a scholarship of integration. Scholarship of integration entails "making connections across the disciplines, placing the specialities in larger context, illuminating data in a revealing way, often educating non-specialists, too" (Boyer, 1990, p. 18). Dahlberg, Moss and Pence (1999) have called this border 
crossing. This thesis integrates IECTE discourses with discourses of structural dissonance, Rortyan philosophy, individualisation theory, and enacted hope. The integration of these perspectives opens spaces for further reconceptualisation of IECTE in terms of resisting injustice and encouraging social justice.

Part one offers an introduction to the focus of this thesis, an explanation of the first two research questions, introduction to the concepts of structural dissonance, moral hope and reconceptualist in early childhood studies.

Part two is made up of a chapter outlining the neo-pragmatic assumptions used to answer the third research question, and a chapter that translates the commitment to neo-pragmatism into a research methodology and which introduces the particular research methods used in this thesis. The chapter on neo-pragmatism introduces assumptions of anti-essentialism and antifoundationalism expressed in the writing of American philosopher Richard Rorty $(1979,1982,1989,1999,2007)$, and aligns this thesis with an ironist approach to scholarship, wherein writers take a sceptical approach to both certainty and the vocabularies commonly used to frame contemporary issues, e.g., Beck, 1992; Bloch, 1986; Kuhn, 1962; McArdle \& McWilliam, 2005). 
This thesis uses the term Rortyan assumptions to convey the distinguishing features of Rorty's philosophical position: Anti-foundationalism and antiessentialism (Rorty, 1979, 1982, 1989, 1999, 2007). Anti-foundationalism is the idea that there is no useful distinction to be made between truth and justification, rather, there are only "sentences" (Rorty, 1999, p. 54) that are more or less useful for fulfilling the requirements of particular purposes and for particular communities. Truth, from a Rortyan (1989) perspective, is therefore a contingency of time, place, habits and language use. For this reason, there is little need to search for any unconditional quality called Truth because no such quality exists outside of the fashionable use of certain sentences in the place of others (e.g., we no longer think it useful to use a theological vocabulary to describe the rising sun, we have developed up a new vocabulary for that purpose). Ceasing the need to accurately represent reality offers constructivist theses the opportunity to suggest new metaphors with the aim of convincing others of their utility value.

In Rorty's thinking, anti-essentialism rejects the distinction between found and made, and the distinction between reality and appearances. From this perspective there is no essence of things that can be found by privileged methodologies (e.g., scientific method and the presumption of validity), nor is there an essence of the way things really are against which we can measure what appears before us. Instead there are simply more and less successful metaphors used to describe 
those things that are important to us. Metaphors, if successful, are literalised insofar as they are shared by a majority of the people in a given community (Rorty, 1982). Less successful metaphors are either those that have been passed over or those which have not-yet been picked up and literalised. Antiessentialism grants hermeneutic methodologies a philosophical rationale as it encourages new edifices of knowledge (Rorty, 1979, p. 359) constructed in the service of making the familiar appear strange.

These philosophical assumptions are important not only because they underpin the construction of knowledge claims made in this thesis, but also because they direct the methodologies used to construct that knowledge. Chapter four introduces an ecological interpretation of Gadamerian philosophical hermeneutics (Gadamer, 1975) as a method and methodology for creating an integrative (Boyer, 1990) bricolage (Denzin \& Lincoln, 2005) that is consistent with those neo-pragmatic assumptions. This chapter also introduces a version of Weber's (1949) ideal type method which is used as an analytic tool in part three of this thesis, and the focus group method used in the same part to provide empirical evidence in support of the argument of structural dissonance, as well as to counter the claim that the thesis argument works in theory but lacks empirical evidence. Ideal type theory idealises social and theoretical phenomena and converts those idealisations into research tools that can then be used to interpret the appearance or non-appearance of those phenomena in a 
given research setting. Ideal types for socioculturalism (chapter 5) and individualisation (chapter 7) are constructed in part three.

The term socioculturalism is used here to stand for a collection of sociocultural perspectives that are used to explain development and learning. The suffix -ism is used to denote a connection of related ideas (e.g., the word Buddhism covers Theravada, Mahayana, Vajrayana, Navayana and variations within each of these themes). This thesis applies the suffix -ism to sociocultural in order to construct a general ideal type that can be used as an analytic tool in part three. As a term, socioculturalism is a pluralistic conglomeration of approaches to development and learning that are widely considered to be sociocultural (e.g., Lave \& Wenger, 1991; Rogoff, 1990; Vygotsky, 1978).

This thesis uses a hermeneutic methodology based on Gadamer's (1975) assertion that all understanding consists of the pre-understandings or tradition to which the inquirer belongs, the object (e.g., text, picture, discourse) that is being understood and the application to which the act of understanding is aimed. The fusion of these concerns guides the methodology of this thesis. In chapter four, an ecological hermeneutics is developed by blending Bronfenbrenner's (1979) metaphor of nested contexts (i.e., the micro-system sits within the macro-system, the macro- sits within the exo- etc) with the hermeneutic circle as a method for organising analysis. The hermeneutic circle 
is the practice of relating particular instances to general accounts (Hoy, 1978), parts to the whole (Heidegger, 1962), and questions to answers (Gadamer, 1975). The concept of ecological hermeneutics developed in this thesis uses the metaphor of nested contexts to organise analysis from the general to the specific. For example, chapter 7 on individualisation in the context of the case study IECTE programme analyses the broad socio-historical context, government policy, external regulatory bodies (e.g., the New Zealand Teachers Council), university regulations, course outlines and the feedback from focus groups in order to show individualisation in the context of IECTE programmes in Aotearoa/New Zealand.

Part three of this thesis contains chapters five to eight. This is the phase of the thesis in which the case for structural dissonance is put and where justifications are offered in answer to the first research question. Chapter five establishes an ideal type for socioculturalism based on primary sources in socio-cultural theory (e.g., Lave \& Wenger, 1991; Rogoff, 1990, 2003; Vygotsky, 1978, 1986; Wertsch, 1998). That ideal type model comprises the following dimensions: participation, co-construction, situatedness and community. In chapter six this ideal type is used to show that although IECTE programmes draw on a number of theoretical assumptions, the content of courses, in terms of theoretical perspective, curriculum, teaching competencies, course objectives and 
pedagogical work (the assessed component of individual courses) draws heavily on socioculturalism.

Chapter seven constructs an ideal type for individualisation theory using the work of Bauman (2001), Beck (1992) and Beck-Gernsheim (2002). That ideal type consists of the following dimensions: Disembedding, standardisation, institutional dependency and social fragmentation. Those components are explained in the first part of the chapter and applied to the regulatory context of IECTE programmes in the second. That chapter provides justification for the claim that the context of IECTE programmes reproduces individualisation as structural element in which the content of those programmes is delivered. The final chapter of this part answers the question: how is there structural dissonance in IECTE programmes in Aotearoa/New Zealand? In this chapter the notion of structural dissonance, worked out in chapter two, is applied to the data created in chapters five to seven. The discourses of socioculturalism and individualisation are shown to be dissonant and an ecological examination of that dissonance in the structure of IECTE programmes is presented.

For the most part, this primarily theoretical thesis uses textual data sources, however, in an effort to include an empirical element to this thesis, four focus groups of second and third year students were sought at a case study university. The responses of these students were transcribed and analysed 
using the ideal type models and are reported in chapters six, seven and eight. Generally speaking, the students from the four focus groups voiced a concern about the contradiction between the sociocultural content of their courses and a context reproduced a culture of individualisation (students highlighted elements of the ideal type rather than referring to Beck's (1992) individualisation theory directly). The evidence provided by these student teachers adds empirical strength to the theoretical and text based approach taken in the other parts of this thesis.

The final part of this thesis contains two reconstructive chapters followed by a concluding chapter that reflects on the thesis and its findings. In order to counteract structural dissonance in IECTE programmes in Aotearoa/New Zealand this thesis suggests a pedagogy of enacted hope. This pedagogy is constructed by applying a philosophy of hope to enactivist learning theory. The philosophy of hope is constructed in chapter nine through an integration of German philosopher Ernst Bloch's (1986) hermeneutic of hope with the Rortyan assumptions that underpin this thesis. The philosophy of hope worked out in chapter nine is then fused with enactivist learning theory in chapter ten (Davis, 1996; Varela, Thompson \& Rosch, 1991). This fusion is arguably a novel, and theoretically coherent, approach to solving the problem of structural dissonance through the reconceptualisation of IECTE pedagogical practices. Implications of taking this approach are then discussed before finishing with an indication of 
what a pedagogy of enacted hope in early childhood teacher education might look like in practice.

The final part of this thesis is an exercise in utopian thought or blue skies thinking. It aims to make new inroads into what is possible for the construction of socially just learning spaces in IECTE programmes in Aotearoa/New Zealand. According to Dahlberg and Moss (1999, p. 179):

Utopian thought both provokes and enables radical critique of the status quo through 'confrontation by imagination of whatever exists'. And it gives direction for future change, by 'the exploration by imagination of new modes of human possibility' that enable us to reinvent the future. It both deconstructs the present and reconstructs the future. It provides a provocation to politics, both major and minor [though not only politics], through the act of thinking differently (Dahlberg \& Moss, 1999, p. 179).

This thesis offers a radical critique of IECTE programmes in Aotearoa/New Zealand based on the argument that structural dissonance exists between the content and context of those programmes. It also offers a radical solution to that problem through the suggestion of a pedagogy of enacted hope. Arguably the major contribution of this thesis is in the philosophical coherence of each of its parts, the approach taken to the formation of critique and solution, and the 
breadth of the evidence produced from textual sources along with focus group data.

In 2004, the New Zealand Teacher's Council and the New Zealand Ministry of Education co-published a literature review entitled Research on Initial Teacher Education in New Zealand: 1993-2004: Cameron \& Baker (2004). This was the first systematic overview of initial teacher education undertaken in New Zealand (Cameron \& Baker, 2004). The intention of this literature review was to "inform future policy and practice and identify key areas for further research" (Cameron \& Baker, 2004, p. 3). The key findings of this review were that there were few research projects that follow a theme through to create new knowledge; that research is "over reliant on surveys and questionnaires"; and that there was a clear lack of research studying teacher education programmes carried out at specialised teacher education facilities (Cameron \& Baker, 2004, p. 68). This thesis is firmly located as an attempt to meet those stated needs whilst continuing the theme of struggling against injustice in the hope that more socially just and peaceful educational environments might be constructed.

My own hope for IECTE and early childhood studies is that scholars will continue to reconceptualise the field with new ideas and fresh integrations of perspectives constructed for the consideration of others. This thesis is one more attempt at keeping that conversation alive in the hope that we will find ever 
more useful ways of talking about what we do as teacher educators, and that future audiences will be encouraged to translate our commitments into practice, in the ongoing project of making the world a more just, more peaceful place. 


\section{Chapter Two}

\section{Structural Dissonance, Moral Hope and}

\section{Reconceptualisation}

This chapter introduces the concept of structural dissonance and links it to the concept of structural violence from the field of peace studies. Structural dissonance is a concept constructed in this thesis to describe contradiction within institutional contexts. The concept of structural dissonance developed is used in part three of this thesis to formulate a critical perspective on IECTE programmes in Aotearoa/New Zealand, and in part four as an impetus for further reconceptualisation.

The second section of this chapter uses Bauman's (1993) understanding of morality to construct a moral argument for transforming structural dissonance into more peaceful and just organisational structures. This thesis adopts the assumption that morality entails identifying with the plight of others and acting to make life better (that is, more just and more peaceful) for them. This section introduces the rationale used to justify reconstruction in the fourth part of this thesis as well as advancing the argument that it is morally useful to challenge injustice. 
In the final section of this chapter reconceptualisation is introduced as an important part of the methodology used in this thesis. Consideration of reconceptualisation in early childhood studies is included in this chapter to introduce the particular form of scholarship that is being undertaken. This chapter introduces a general and specific use of the term reconceptualisation in the field of early childhood studies in order to identify the tradition to which this thesis belongs.

\subsection{Structural Dissonance}

This section integrates theories of dissonance from music and social psychology with Galtung's (1996) theory of structural violence to construct the concept of structural dissonance. The term structural dissonance is a softening of the term structural violence: Injustice perpetuated by organised social structures/institutions. By softening the term violence to dissonance I aim to make the concept of structural violence more palatable to early childhood educators whilst at the same time extending Galtung's (1996) original formulation to include contradiction. 


\subsubsection{Dissonance: Integrating music theory and social psychology.}

Synonyms for dissonance include clash, conflict, discord, disharmony, contradiction, and tension. There are also colloquial phrases that approximate the meaning of dissonance, for example up the booai, all over the show, and out of whack. There are also ways of describing the production of dissonance in language, e.g., speaking with a forked tongue, do as I say and not as I do, and the devil is in the detail.

As a background to the concept of structural dissonance this section draws on two particular uses of the word dissonance, derived from music theory and social psychology. Constructing meaning in this way is consistent with Dahlberg \& Moss's (2005) idea of border crossing (using diverse perspectives to form new understandings) as will be explained in section 2.2. The disciplines chosen for this construction offer insight into specific uses of the word dissonance as a theoretical concept within two fields that do not necessarily intersect. By drawing these theoretical perspectives together this thesis constructs an ideal type upon which the notion structural dissonance can be posited as an innovative framework for the study of structural violence in IECTE programmes.

In music theory, dissonance occurs when two or more notes combine to make a sound that is disharmonious, that is, they clash. For example, Hodges (2007) 
observed that dissonant notes give one a feeling that the notes want to turn into something else, "it is almost as if you have caught them in mid-metamorphosis" (para 5). Similarly, for Hanson (2000) dissonance is a "tension that leads to release" (para 5) and may be vertical or horizontal; vertical in terms of discordant notes played together, and horizontal in terms of discordant notes played beside one another in sequence. Hanson (2000) observed further that dissonance adds dramatic intensity to music, but that it is an intensity that longs to be overcome. Dissonance therefore has a negative side (the side of disharmony), but it also has a positive side, the side that inspires counteraction.

Other writers in music theory identify further types of dissonance. For example, Terhardt (1974) stated that dissonance is created through competing pitches; which begged the question of co-operating pitch. Cazdin (1980) noted that dissonance occurs when listeners' expectations of what should occur are violated; which begged the question of harmonising expectations and occurrences. And Rogers (2001) explored the idea that musical theories of dissonance could inform other aspects of culture by identifying a link between the musical writing of Theodore W. Adorno (2002) and critical social theory. These writers are similar in their assertion that dissonance is important as a concept of disharmony, but also that it is a disharmony that leads somewhere (toward harmony or consonance). In music theory, dissonance is a contradiction that has its uses in the broader design of the entire composition. 
This is a useful metaphor for the concept of structural dissonance because it potentially leads to the question of what can be done. It is a metaphor that links parts three and four of this project.

The notion of dissonance has been used in several different approaches to psychology (e.g., Piaget's (1926) idea of cognitive conflict or disequilibrium which leads organisms to seek equilibrium through strategies of assimilation and/or accommodation, and Freud's (1927) notion of dissonance between id and superego as a causal factor in neurosis). This thesis uses the concept of cognitive dissonance constructed by social psychologist Leon Festinger in 1957 to inform the notion of structural dissonance because it makes a useful statement on how people act in contradictory ways when faced with dissonant situations.

Cognitive dissonance "exists when related cognitions are inconsistent - that is, when they contradict each other" (Weiten, 1998). Festinger (1957) proposed that when subjects face inconsistencies in their attitudes, beliefs and experiences they will be motivated to reduce the tension by altering their own beliefs to suit the situation. Examples of dissonant cognitions include statements like the following: 'I love children but I can't stand being near them'; or, 'I consider myself a Vygotskian but the zone of proximal development makes no sense to me'. In each case there is a tension to be overcome. Cialdini, Trost, and Newsom 
(1995) observed that there is wide variation in what people find dissonant, the intensity of the tension perceived, and the need for consistency itself. Studies like Croyle and Cooper (1983) and Elliot and Devine (1994) also support Festinger's claim that discomfort is aroused in dissonant situations and that subjects are motivated to reduce that tension.

In their classic study of cognitive dissonance Festinger and Carlsmith (1959) tested and corroborated two of Festinger's (1957) key theses:

1. If a person is induced to do or say something which is contrary to his private opinion, there will be a tendency for him to change his opinion so as to bring it into correspondence with what he has done or said.

2. The larger the pressure used to elicit the overt behaviour (beyond the minimum needed to elicit it) the weaker will be the above-mentioned tendency (Festinger \& Carlsmith, 1959, p. 210).

Cognitive dissonance is closely linked to socialisation, and dissonant situations or contexts can prompt a change in both attitude and behaviour. Festinger's (1957) work showed that people faced with dissonant situations would change their perspective on a given subject in order to reduce the dissonance they experience (Piaget called this adaptation). Festinger and Carlsmith (1959) 
showed that dissonance exerts a subtle influence on attitude and behaviour that often goes undetected by those affected. The idea that dissonance has the power to subvert authentic expression or undermine congruence in persons is one that points to a potentially sinister aspect to this concept. For this reason, it is a useful perspective to take into the following discussion on structural dissonance.

Musical dissonance and cognitive dissonance share at least two common features noted here, they are catalysts for corrective action and they can have deeper meaning when placed into a wider context (e.g., the entire score in the case of music, or social reproduction in the case of cognition). These features will be revisited in section 2.1.3 after the introduction of Galtung's (1996) notion of structural violence (from which the word structural is borrowed in the concept of structural dissonance).

\subsubsection{Structural violence}

This section uses insights from the discipline of peace studies to provide a definition of structural violence as the parent concept for structural dissonance. Authors such as Dayan $(2005,2008)$ and Ridgeway \& Surman $(2004)$, have borrowed from political and psychological vocabularies to make similar points about contradiction in the field of teacher education. 


\subsubsection{Galtung's notion of structural violence}

Norwegian peace theorist and writer Johan Galtung (1990, 1996, 2004) described three types of violence that are used by many in the field of peace studies and peace education as the touchstone for definitions of violence (e.g., Barash \& Webel, 2002; O'Connell, 1999; Smoker, Davis \& Munske, 1990; Wulf, 1992). Structural violence is the name Galtung gave to one part of this triadic conception, the others being direct violence and cultural violence.

In his threefold typology Galtung $(1990,1996,2004)$ described narrow or direct violence as the most visible form of violence, e.g. physical violence entailing the aim of "somatic incapacitation, or deprivation of health done (with killing as the extreme form) at the hands of an actor [or actors] who intend this to be the consequence" (Galtung, 1990, p. 9). Other examples of direct violence include bullying, assault, rape, and murder, though physical intimidation and neglect might also be added to this by no means exhaustive list.

Structural or indirect violence is a form of violence that occurs where there is no visible, physical actor intending violent consequences. Rather, it is a violence which "comes from the social context itself" (Galtung, 1996, p. 2). Galtung (1996) identified two forms of structural violence: repression and domination. Repression results in the inability to enact personal rights to equality or the inability to participate fully in the construction of one's social/institutional 
context. For example, in New Zealand the Native Schools Act (1867) outlawed the use of Māori language in schools, with the goal of assimilating Māori culture into European culture (MacFarlane, 2000).

Structural domination occurs when organisational/institutional structures rule over (that is, dominates) a person or people. The topic of domination is no stranger to early childhood education literature, particularly in terms of teachers exercising their dominion over children (e.g., Boutte, 2008; Cannela, 1997; MacNaughton, 2005), or governments exercising dominion over early childhood services (e.g., May, 2001, 2009). Structural domination may be intentional or non-intentional, but is a symptom of social and institutional structures rather than the intentions of individual actors, though the two may not necessarily be mutually exlusive. It is argued later in this thesis that the structural context of IECTE programmes in Aotearoa/New Zealand reproduces individualisation. This is a problem when the theoretical content of those courses is sociocultural, as it creates a situation of structural dissonance.

Galtung's (1996) third type of violence is cultural violence, which is "violence that makes direct and structural violence look, even feel, right - or at least not wrong" (p. 196). Examples of cultural violence, include the notion of a just war, capital punishment for heinous crime, and arguments for the right of parents to strike their children. Examples of cultural violence as it pertains to structural 
violence include the exploitation of child workers in developing countries, the repression of minority concerns in a democratic system of government, and, as this thesis adds, the invisibility of individualisation and the subsequent structural dissonance in IECTE programmes.

\subsubsection{Symbolic violence}

In their book Reproduction in Education, Society and Culture, Bourdieu and Passeron (1990) identified pedagogical action (educational practice in social institutions) as a form of "symbolic violence insofar as it is the imposition of a cultural arbitrary by an arbitrary power" (Bourdieu \& Passeron, 1990, p. 5). From this perspective, symbolic violence occurs where-ever educational subject matter (e.g., university papers) is provided as a mandatory component of a nonarbitrary system of education (e.g., approved teacher education programmes). To translate this further: Where particular papers are compulsory for particular courses (e.g., in BEd programmes), and where the content of those papers is decided by some power outside of the student, then, at least according to Bourdieu and Passeron (1990), symbolic violence is present.

Symbolic violence extends from the symbolically powerful to the symbolically weak (i.e., from those who have the power to define to those who are beholden to pick up those definitions). For instance: From universities to individual student teachers, from school teachers to pupils, from older siblings to younger 
siblings. Thus, from Bourdieu and Passeron's (1990) perspective, IECTE is necessarily symbolically violent as it involves the imposition of institutionalised rules and regulations upon individual student teachers (for example, student contracts, graduating teacher standards, prescribed/proscribed courses, reading lists and assessments).

This view of violence adds to Galtung's (1996) triadic notion by honing in on the question of who has the power to make meanings? And how is that power made invisible through the reproduction of mandatory inequalities? Mandatory inequalities are inequalities that seem reasonable given the structure of the institution, and the structure of the rules by which it is regulated, and by which it regulates its own affairs. The idea that violence can be perpetrated in symbolic relationships (e.g., between the university as training provider and student teachers as dependent trainees) raises the suspicion that structural dissonance may appear mandatory, and therefore go unchallenged.

In the context of university education, Bourdieu and Passeron (1990) use terms such as pedagogical authority and pedagogic work. Pedagogical authority is the legitimate authority that has the right to define both the context and content of courses, and as such, reinforces the mandate of the arbitrary power (Bourdieu \& Passeron, 1990, p. 13). For example, imagine yourself as a student teacher about to begin your training. You have already undergone a selection process, you 
receive a list of compulsory courses complete with a timetable, at the first lecture you receive a course outline containing required readings, nonnegotiable regulations (e.g. late work penalties) and assessment details (e.g. content, word count and due date). Using Bourdieu and Passeron's (1990) perspective, you have just come under the influence of pedagogical authority.

Pedagogic work is "a process of inculcation which must last long enough to produce a durable training, i.e. a habitus" (Bourdieu \& Passeron, 1990, p. 31). A habitus is a naturalised way of acting. A habitus combines experience and context and means the same as a person's worldview or perspective, though the contents of the habitus are not always explicit but exist as undisclosed assumptions. Habitus can also refer to a desired perspective set out by institutional authorities. For example, the desired habitus for early childhood teachers is contained in the Graduating Teacher Standards (NZ Teachers Council, 2007) and it is a regulated requirement that all early childhood training providers have courses approved to meet those standards (NZ Teachers Council, 2010). Pedagogic work produces assessable objects by which inculcation into the desired habitus can be ascertained. Pedagogic work consists of all work undertaken by students in their relationship with the university, e.g. attending lectures, tutorials, studio times, contribution to discussions, assignments and teaching practicum. 
Bourdieu and Passeron's (1990) perspective adds a symbolic element to the notion of structure set out by Galtung (1996). That symbolic element informs this thesis by drawing attention to the seemingly non-arbitrary regulations and relationships within universities as social institutions. The next section uses the previous work on dissonance and fuses it with these insights into structural violence.

\subsubsection{Structural Dissonance}

Structural dissonance is a term constructed to help achieve the aims of this thesis, for describing contradictory elements within institutional structures. Recalling that dissonance is synonymous with disharmony and contradiction, structural dissonance means contradiction within institutional settings. The concept of structural dissonance is intended as a subset of Galtung's (1996) depiction of structural violence. It draws on the notion of symbolic violence in the sense that the contradiction within the institutional setting appears to be non-arbitrary and therefore a normal facet of institutional life. This thesis aims to make a particular form of structural dissonance visible and arbitrary. That work is carried out, for the most part, in part three of this thesis.

This thesis studies the contradiction between the content of IECTE programmes in Aotearoa/New Zealand and the context in which they are provided. The argument set out in this thesis is that there is a contradiction between what is 
being taught to student teachers and how it is being taught. This, given the nonarbitrary nature of both content and context in IECTE programmes is framed as a form of structural violence, but softened to the structural dissonance between content and context. Specifically, it is the contradiction between a socioculturally based content and a context that reproduces individualisation. Chapters five to eight unpack this dissonant relationship using ideal types and ecological hermeneutics, providing numerous justifications from multiple levels of the dissonant relationship.

Structural dissonance is linked to structural violence insofar as it perpetuates the inability of student teachers to challenge and change the context in which they are educated: repression (Galtung, 1996). On the other hand, the nonarbitrary design of the training programmes offers no chance for students to coconstruct the curriculum, it is compulsory, pre-formed and externally regulated: domination (Galtung, 1996). Along these lines, the compulsory pedagogical work entrenches pedagogical authority by making participation and submission to authority a non-negotiable element of the programme structure.

Galtung's $(1990,1996,2004)$ work on violence is used mainly as a justification supporting efforts that work toward peace. Similarly, Bourdieu and Passeron's (1990) work on symbolic violence carries with it the will to recognise hidden 
structures of symbolic power, in the hope that more socially just alternatives can be created. The first part of this chapter also showed how dissonance is a means for eliciting transformation (in music and in cognition). The concept of structural dissonance therefore opens out to the possibility of solutions, the impetus for which this thesis defines as moral hope.

\subsection{Moral hope}

Moral hope is a shorthand term for the notion that one of the best things we humans can do is enact our responsibility toward others by making their life better (more peaceful and more just). This assumption will be discussed in the next chapter. This section advances the argument that is useful to introduce the particular notion of morality used in this thesis as a catalyst for reconceptualisation: As a general background justification for the assumption that, given the claim of structural dissonance in IECTE, there is still the possibility that something can be done. Part four of this thesis is therefore an exercise in moral hope.

\subsubsection{What is morality from Bauman's (1993) perspective?}

Bauman (1993) used Levinas' (1998) notion of being for rather than with the Other. The Other, in this case, means beings other than the individual self. By 
way of this definition, Bauman (1993) defined traditional ethics as rule-bound socially constructed codifications. By this account traditional ethics (e.g., Kant, 1785), are both regulatory and historically specific. This thesis uses Bauman's (1993) non-normative conception of morality to avoid discussion of the ethical frameworks that make moral action possible (e.g., Kant's (1785) categorical imperative which sought to make moral action universalisable). Rather morality is cast as the activity of being for the other. Much of Bauman's (1993) work laments the loss of moral agency in the face of societal fragmentation, uncertainty and enforced impersonal ethical codes. At the conclusion of his book Postmodern Ethics, however, his lament turns into hope - the hope that morality can still be meaningful in an often hostile and unforgiving world. This thesis picks up that hope and translates it into the will to overcome structural dissonance in the service of being for the other (in this case the other is student teachers in IECTE programmes).

Bauman's (1993) perspective is useful to this thesis because he set out a framework on morality that explains the meaning of moral justification and subsequently the meaning of moral hope. That framework highlights five theses that are useful to this explanation: Humans are morally ambivalent; moral phenomena are 'non-rational'; morality is aporetic (fraught with difficulty); morality is not universalisable; and morality privileges being for over being with. The remainder of this section explains each of these theses. At the 
conclusion of this section the case for moral hope as a justification for reconceptualisation will be put.

According to Bauman (1993) humans are morally ambivalent (p. 10). Ambivalence means prone to fluctuation. For Bauman (1993) this perspective sits at the crux of the separation of morality and ethics. In Bauman's (1993) view, morality is embodied in face-to-face interactions between people, rather than through codes made by social agents, professional bodies, or philosophers. For Bauman (1993), morality defies rule-based relations, as that is the domain of traditional ethics: It is because humans are morally ambivalent that ethical rules are necessary in the first place. The outcome of this perspective is that morality can not be guaranteed even under conditions of strict ethical regulation. To illustrate this point take for example May's (1997) assertion that the establishment of kindergartens in Dunedin, Christchurch, Wellington and Auckland were an expression of moral concern. Bauman (1993) would counter such an argument by claiming that this concern was ethically based (e.g., Christian ethics) rather than an expression of the face-to-face relationship that underpins the moral encounter.

Moral phenomena are non-rational (Bauman, 1993, p. 11). This means that morality does not follow as means-end trajectory, as moral phenomena "are only moral if they precede the consideration of purpose and the calculation of 
gains and losses" (Bauman, 1993, p. 11). Rationality, at least as far as Bauman (1993) was concerned, highlights the formation of rule-based relationships between human beings. Rational models of morality imply that third party adjudicators of moral activity can be employed to override the face-to-face morality of lived situations. Take for example, Cannella's (1997) attack on developmentalism in early childhood education. In this instance Cannella (1997) hoped to rescue face-to-face relationships from a rationale based on rule/research-based foundations (e.g., developmentally appropriate behaviour). She wished to peel off the ethical (socially constructed) membrane to find the face of children and adults, as well as a place where they could meet.

Morality is aporetic, or fraught with difficulty (Bauman, 1993, p. 11).

Contemporary morality takes place in a context of uncertainty and among many competing and/or contradictory impulses. In our modern, pluralistic society the great diversity of cultural norms offers little in the way of certainty for moral actors. For example, is it moral to offer a hungry Muslim child pork sausages, or a Hindu child chips that are made using beef fat even if you are unaware of cultural mores? Is it moral to offer congratulation to a Māori child by patting them lightly on the head? In each case the moral impulse that is enacted face-to-face does so in a context where no firm rules fit all circumstances. Some people who refer to themselves as Muslim and eat bacon, Hindu people who eat beef burgers and Māori families that offen congratulate 
their children by ruffling their hair. Instead, for Bauman (1993) the moral impulse is the one that worries that it has not been moral enough, rather than one that worries about whether an ethical standard has been maintained.

Morality is not universalisable (Bauman, 1993, p. 12). Bauman (1993) defined universalisation as a particularly Western project of stamping out some forms of moral judgment in favour of a privileged few. Bauman (1993) rejects the idea that there is any such thing as an original or true form of morality against which inferior models can be measured. By saying this, Bauman (1993) rejects the notion of foundations and essences for similar reasons to those advanced in this thesis (see Ch 3). Take for example the idea that children will perform gross motor (and fine motor movements as well) in their own time (e.g., Gerber, 2002), compared to the idea that gross motor movements can be scaffolded and enhanced (e.g. Epstein (2006) and tummy time, or the Jolly Jumper ${ }^{\mathrm{TM}}$ which boasts the improvement of pre-walking skills: www.jollyjumper.com.au). For Bauman (1993,) neither perspective approaches anything like reality in the sense of an essence of human development because there is no universal morality of development to be found. There is no moral standard that can adjudicate on this issue, but rather a set of more or less useful justifications that are employed to give weight to each side of the bargain. One person's morality of care might therefore be another's careless disaster. 
Moral responsibility assumes that "being for the Other before one can be with the Other - is the first reality of self, a starting point rather than a product of society" (Bauman, 1993, p. 13). Being for supposes that moral responsibility is a non-reciprocal event in which action for the Other is offered without hope of reward, distinction or reparation. This is a crucial point because it shifts morality from noun to verb. Specifically, morality consists of what we do when we do not expect to get a return. This notion of non-reciprocal action is central to the writing of Noddings $(1999,2003)$ and Tronto $(2006)$ on an ethics of care in early childhood teacher education. This concept is important in this thesis insofar as it underpins the motivation to highlight structural dissonance as an expression of the moral hope that something can be done to construct IECTE programmes where content and context are congruent. The focus groups, reported later in this thesis, suggest that student teachers are aware that there is contradiction between the content and context of their courses, even if they are not-yet aware that something can be done about it.

Morality is a lived event that finds its material correlate in one person's care for another. This thesis uses Bauman's (1993) framework of morality as a fluid coping, punctuated by a will to care and a rationale for reconstruction (covered in part four). Moral hope is an equally ambiguous and ambitious practice of acting for the other in an uncertain context in ways that are as yet unprecedented, with the goal of making life better for others without hope of 
reciprocation. Whilst moral hope is fraught with difficulty, it is also imbued with a spirit of possibility (see chapter nine for a full explanation of hope). For this thesis, moral hope is the hope for social justice for student teachers in IECTE programmes. This particular rationale is strongly linked to the philosophical assumptions that underpin this thesis in the next chapter.

\subsubsection{Moral hope and reconceptualisation}

A morality based on being for the Other (in this case student teachers in IECTE programmes) and a will to care for the Other in a way that does not revert to this or that ethical code, is central to the overall rationale of this thesis. Moral hope offers justification for reconceptualisation through no other means than to argue that being for student teachers and promoting a will to care is enough reason. As a reason for reconstruction, this thesis anticipates that overcoming structural dissonance is morally useful insofar as it empowers student teachers to play an active and co-constructive role in their education. This thesis is not alone in this assumption, as several writers in early childhood education have attempted (though with different objects of emancipation in mind) to do the same thing: e.g., Cannella (1997); Cannella \& Viruru (2004); Dalli (2006); Dayan (2005); Dahlberg, Moss \& Pence, (1999); Grieshaber \& Cannella (2001); Penn (2004); White \& Nuttall (2007). My hope is that by pointing out structural dissonance and suggesting a way to counter act it students may no longer complain that they are "teaching a child what empowerment, communication 
and belonging are, but you need to feel like you belong from the college you are educated from, for me anyway" (others in the focus group enthusiastically agree).

\subsection{Reconceptualisation in early childhood studies}

As this is a reconceptualist thesis, this section offers a general and specific definition of reconceptualisation in education studies and early childhood studies. Introducing reconceptualisation is important to the coherence of this entire thesis as it sets out the scholastic community to which this project belongs. This thesis is situated in the reconceptualist project of early childhood studies, understanding this project explains the pre-understanding (see chapter 4) that orients this research effort.

\subsubsection{Reconceptualisation in education: A general perspective.}

One, specifically educational way, of thinking about reconceptualisation is to view it as an educational paradigm alongside other educational paradigms. Codd et. al. (2002) in their summary of the Organisation for Economic Cooperation and Development (2001) Scenarios for the Future of Schooling, mapped out five specific educational paradigms. Those five paradigms are: reproduction (carrying on the status quo), re-schooling (teaching to achieve specific 
outcomes), de-schooling (challenging mainstream institutionalised education models ), socio-cognitive (using scientific research and theory to construct new learning theories and applications), and reconceptualist. Codd et. al. (2002) described the relationship between paradigms in the following way: "These competing assumptions... can be understood as five distinct discourses which articulate quite different understandings of teaching and learning with very different social and educational outcomes" (p. 39).

Codd et. al. (2002) defines the reconceptualist paradigm in the following terms:

This discourse is concerned with fundamental questions about the purpose of education itself. In this sense, education is not synonymous with teaching and learning processed A strong emphasis is placed on critical pedagogy in pursuing the aims of education within a democratic and networked society...There is a basic need to rethink the curriculum and broader pedagogical contexts in which teaching and technology is located. In this regard, the discourse seeks to create a more equitable education system and socially just society (p. 44).

This definition highlights two key themes of reconceptualisation in education: First, there is a degree of scepticism about education and education systems. This scepticism questions whether current practices and pedagogies are the 
final story on education and its uses and asks can we make things better? Secondly, it emphasises a concern for equity and social justice. Reconceptualist education views current situations as resources for change. Adopting a reconceptualist perspective encourages this thesis to offers a new lens for looking at IECTE programmes in the hope that social justice for student teachers might be a positive result.

However, in early childhood studies, there is a group of writers who identify themselves as reconceptualists, and their way of writing as reconceptualisation. The following section identifies examples of reconceptualist writer and the projects they have produced to gain insight into reconceptualisation as a research perspective used by scholars in the field of early childhood studies, and as an example of the form of scholarship to which this thesis belongs.

\subsubsection{Reconceptualisation in early childhood studies: Origins}

Jipson \& Johnson (2001) pin the origin of the re-conceptualist tradition in early childhood studies to a conversation between Jipson and Kessler in 1987, and more formally to the first annual Reconceptualising Early Childhood Education conference in Madison, Wisconsin in October 1991 (pp. 1-2). In the same year as that conference, Swadener \& Kessler (1991) produced a special edition of the Early Education and Development journal devoted to the inclusion of "critical, interpretive, feminist and/ or phenomenological" discourses into conversations 
about early childhood and early childhood curriculum (Swadener \& Kessler, 1991, p. 85). Swadener and Kessler (1991) challenged a "lack of recognition or acceptance of alternative theoretical perspectives in early childhood education" (p. 85). In their introduction to the special edition, they identified the 1973 Bergamo Conference as the first instance in which the term reconceptualist was applied to those who promoted alternative perspectives in early childhood studies (alternative to the normal discourse of developmental psychology) (Swadener \& Kessler, 1991). This thesis promotes an alternative perspective on IECTE education by introducing structural dissonance as a critical perspective on IECTE programmes and enacted hope as a reconstructive pedagogy, not in opposition to, but in addition to the currently accepted perspectives in this field of study.

Also in 1991 Critical Perspectives on Early Childhood Education (Weis, Altbach, Kelly \& Petrie, 1991) was published. In this edited book, the authors drew together alternative perspectives regarding issues of teachers voices, gendered pre-schools, and critical approaches to policy development in the early childhood sector. The editors hoped to "suggest new directions for research" (Weis et. al., 1991, p. xii) by offering new ways of conceptualising early childhood issues. These writers were critical of how developmental discourses dominated conversations about children, of teachers and their education, and about parents and families. 
In 1992 Shirley Kessler and Beth Blue Swadener published their edited book Reconceptualising the Early Childhood Curriculum: Beginning the dialogue. In the foreword of this book Mara Sapon-Shevin (1992) provided a good definition of the spirit of the reconceptualist project in early childhood studies:

One way to reconceptualise the early childhood curriculum, the goal of this book, is to ask a different set of questions than have typically been addressed. And perhaps the best way to identify those questions is to ask more people what those questions are, to represent multiple voices, particularly the voices of those most affected and often disregarded (p. viii).

Cannella (2005, p. 21) wrote that the reconceptualist tradition in early childhood studies can be drawn into the single vision of challenging "monocultural ways of being and believing" (p. 21). For the early reconceptualists, challenge and reconstruction went hand in hand. This thesis is situated within that scholastic project through both its structure and its motivation. The following section strengthens that association by identifying this motif in the work of some reconceptualist scholars who use feminist and philosophical discourses to challenge the status quo. 


\subsubsection{Reconceptualisation in early childhood studies: Feminist.}

Cannella (2005) defined reconceptualist scholarship in early childhood studies as the attempt to generate "points of critical consciousness" (p. 21). These points are generated to organise and mobilise resistance in the hope that the social world might become more socially justice for increasingly diverse populations. How this insight is applied to early childhood studies however, is broad and diverse.

Cannella (2005) organises reconceptualist writing into the following categories: cultural, critical, feminist and post-modern (p. 19). This thesis identifies some reconceptualist writing from feminist perspectives before linking this project explicitly to the efforts of postmodern reconceptualists in early childhood studies. Over-viewing some of the uses from feminist and gendered perspectives on reconceptualisation reiterates the theme of resistance and the postmodern reconceptualists relate most closely to this thesis.

From the feminist and gendered perspective on reconceptualisation there are writers such as Maccoby and Jacklin (1989) who identified gender segregation as an issue for childhood development and argued for gender integration. Martin, Eisenbud and Rose (1995) studied children's gender stereotyping in the use of toys, while Tozzo and Golub's (1990) wrote about sex role stereotypes in children's play. Both sets of authors argued for anti-bias education around toys 
and their uses. Writers such as Meade (1982) and MacNaughton (1996) provided evidence that young children reproduce socially received gender differences in their everyday interactions, whilst researchers such as Alloway (1995) and MacNaughton (2000) suggested that if we are to transform gender relations then more study is needed.

Honig (1983) and Miedzian (1991) found strong evidence that gender role stereotypes are in place by the age of four and used this finding to argue that we need to resist gender bias. Whereas Hardcastle-Stanford (1992) and Matsumoto-Grah (1992) have explicitly aligned challenging sexism with a struggle for social justice. Feminist post-stucturalist writers like MacNaughton $(1993,1997,2000,2005)$ have used discourses of power and knowledge to highlight injustices around inclusion, exclusion and gender, whilst advocating an approach that reconstructs power and knowledge on the theme of anti-bias. Writers like Ryan and Oschner (1999) have encouraged teachers to question current gendered understandings of children in their care, in order to recast early childhood settings as spaces for practicing political action for social justice. And Butterworth (1991) and Massey (2008) both advocated for children to be actively involved in the process of recognising and resisting sexism in their relationships with one another. 
Some feminist and gendered writers in early childhood studies are a good example of border-crossing into philosophy in order to make innovative and powerful points in their given field of interest. For example, Rhedding-Jones $(1995,1996)$ used poststructural notions of subjectification of and positioning to point out the strong link between education and socially constructed submission. Whereas, writers like Osgood (2006) have used poststructural philosophy to challenge the construction of professionalism in early childhood education. These writers are quasi-philosophical insofar as they do not write philosophy, but rather they use philosophical writing to formulate their arguments. They are also an example of border crossing between disciplines.

\subsubsection{Reconceptualisation in early childhood studies: Philosophical.}

Philosophical reconceptualists draw on the work of philosophers (particularly post-modern philosophers) to inform their perspective on early childhood studies. This thesis uses Rortyan philosophical assumptions to organise the reconceptualisation in IECTE programmes in Aotearoa/New Zealand in a similar fashion.

Several writers in reconceptualist early childhood studies have used Michel Foucault's (1926-1984) writing to offer insights into early childhood discourses and practices (e.g. Cannella, 1997, 1999; Dahlberg, Moss \& Pence, 1999; Jordan, Cowan \& Roberts, 1995; MacNaughton, 1995, 2000, 2005; Millei, 2005; 
Walkerdine, 1988). Foucault's writing gives those who use his approach the opportunity to challenge unjust power structures and to see how the reproduction of knowledge is closely related to moves in a power game (e.g. who has the power to decide, who is being positioned by that power, what alternative interpretations are being ignored). On this point Foucault (1980) writes:

Knowledge and power are integrated with one another, and there is no point in dreaming of a time when knowledge will cease to depend on power; this is just a way of reviving humanism in a utopian guise. It is not possible for power to be exercised without knowledge, it is impossible for knowledge not to engender power (p. 52).

Other aspects of Foucault's work that lend themselves to reconceptualist scholarship include discourse analysis, archaeology, genealogy, effective history, regimes of truth, subjectification and governmentality. Australian writer Glenda MacNaughton has consistently used Foucault's insights in her work for almost two decades, blending these with her own feminist perspective. In her book entitled Doing Foucault in Early Childhood Studies (2005), she outlined a project aimed at picking up the writing of French post-structural theorists like Foucault, Derrida and Deleuze and using it as a resource for activism in the pursuit of social justice. MacNaughton (2005) used Foucault's 
$(1972,1977,1980)$ writing on history and philosophy to inform an approach to early childhood education with the aim of "making the world a better place" (p. 3). MacNaughton (2005) pointed out that using Foucault in early childhood studies offers new resources for activism and the pursuit of social justice (p. 5). In doing so, she was apologetic to Foucauldian scholars who might find her use of Foucault's work a partial exploration, claiming that her focus is the use of Foucault's writing rather than the representation of his writing, which is work that she claims is already well done (MacNaughton, 2005, p. 5). MacNaughton's (2005) use of Foucault's writing is of interest to this thesis because it is a good example of a prolonged reconceptualisation of early childhood vocabularies and contexts using philosophical perspective as a resource. MacNaughton's (2005) use involved picking up words and concepts developed by Foucault and employing them to challenge the reader to reflect on issues raised, concepts introduced and case studies of teacher activists. Thus, even though she used Foucault as a resource, her aim and methods were by in large pragmatic: She hoped to change habits of both thinking and acting for the sake of social progress. This thesis takes a similar approach.

Other writers who have used Foucault's philosophical work to reconceptualise early childhood studies include: Cannella (1997) who offered a genealogy aimed at deconstructing dominant ideas of children and childhood in order to reconceptualise "early childhood as the struggle for social justice" (p. 157). 
MacNaughton and Smith (2001) who used action research to redistribute power in early childhood research to develop a more equitable distribution, and Cannella and Viruru (1999) who provided insight into how alternative constructions of early childhood studies are made possible by challenging the status quo. Similarly, authors like Dahlberg, Moss and Pence (1999) used Foucault's work to challenge the notion of quality that permeates the regulatory context of early childhood services whilst arguing for a more democratic and revolutionary approach to the question of quality. Other authors that have used Foucault's philosophical writing to reconceptualise early childhood studies include Cohen (2008), Fenech, Sumison \& Goodfellow (2008), Jordan, Cowan and Roberts (1995), Macfarlane, Noble and Cartmel (2004), MacNaughton and Smith (2001), Mozere (2007), Saltmarsh (2009) and Woodrow and Brennan (2001).

Derrida's (1997) post-structural project centred on the idea that texts have a surplus of meaning that goes beyond the sentences collected between the front and back cover of a book. Derrida assumed that meaning is a contestable term and aimed to show how what is not written into the text explicitly can be just as interesting, if not more interesting, than the marks set down on the page. The marks (words) themselves are not independent things with any absolute or real nature of their own, but rather they depend on other marks (words) for meaning, and those depend on others, and those on others and on and on. 
Derridan scholars deconstruct the power structures that form and reform identities and relationships, they care about binaries and positioning, and they seek social justice for the invisible realm of the Other by making otherness a conscious goal of scholarship. Derrida (1997, as cited in MacNaughton, 2005, p. 77) explains:

The very meaning and mission of deconstruction is to show that things - texts, institutions, traditions, societies, beliefs, and practices of whatever size and sort you need - do not have definable meanings and determinable missions, that they are always more than any mission would impose, that they exceed the boundaries they currently occupy.

MacNaughton (2005) used Derrida's writing to encourage early childhood teachers to reinforce a spirit of activism and to challenge the notion that the big fights were over when women got the vote, when early childhood education achieved degree status, and when governments began to take a fiscal interest in early childhood education. Other writers who have used Derrida's philosophical writing include Kaomea (2003) who used Derrida's (1997) literary deconstruction to move beyond surface meanings of words and to make new sense out of a diverse set of textual sources. Trifonas (2006) wrote against permanent essences of problems in philosophy of childhood in order to show that alternative injustices are subverted by the processes of essentialism. Jones 
(2002) used Derridan deconstruction as a tool for understanding how habits can be challenged to encourage new early childhood practices, and Helliener (2001) deconstructed post-war versions of children and childhood to look beyond the privileged images to those images that are hidden or pushed to the periphery. These writers all shared the will to challenge the status quo and a hope for greater degrees of social justice in society and education. They are relevant to this thesis as they are examples of other reconceptualist writers using philosophical writing to develop arguments in early childhood studies.

Reconceptualists using the writing of Deleuze \& Guatarri (1987) are less prolific than the users of Foucault and Derrida in early childhood studies, but there is growing recognition of their work. MacNaughton (2005) used parts of Deleuze and Guatarri's (1987) work, particularly their work on rhizo-analysis which she described as "a way to explore the politics of a text in order to create new texts" (MacNaughton, 2005, p. 120). Rhizo-analysis links texts and happenings in disciplines that do not seem connected, to argue for the new understandings that can emerge from new symmetries. This, according to Deleuze and Guatarri (1987, p. 7) is because "a rhizome ceaselessly establishes connections between semiotic chains, organisations of power, and circumstances relative to the arts, sciences, and social struggles." 
Other authors like Sellars (2009) and Sellars and Honen (2007) use rhizoanalysis to map out non-linear pathways between texts and subjects. These authors argue that there is still a lot of room for re-conceptualisation in the space where philosophy and early childhood studies meet. The power of rhizome analysis is in making connections that might otherwise not be made. It allows researchers to make hidden connections visible and is a powerful resource for discoursing new approaches to realising social justice in communities of practice, for example, in recognising structural dissonance in the context of IECTE programmes in Aotearoa/New Zealand. Similarly, Olsson (2009) uses the work of Deleuze and Guattari (1987) to challenge closed ended conceptions of children and childhood by using a metaphor of movement to convey a sense of broad horizons as yet unknown.

In addition to the big three post-structuralists other writers branch out into alternative philosophical perspectives in order to re-conceptualise early childhood studies. For example, White \& Nuttall (2007) and White (2007) have used the writing of Bakhtin $(1984,1986)$ to argue for new terms for describing inclusion and dialogue in early childhood discourses. Grace and Tobin (1997) used Bakhtin's (1984) ideas to re-conceptualise the way early childhood studies views itself and its social practices. In terms of theses, three examples of philosophical reconceptualisation in Aotearoa/New Zealand are Farquhar's (2008) use of Ricoeur's (1992) narrative theory to critically explore the formation 
of identity in early childhood contexts; Gibbon's (2006) use of Heidegger (1962) to explore the interconnection between discourses of technology and play in early childhood settings; and Duhn's (2006) use of Foucault (1991) to map out the territory of childhood in Aotearoa/New Zealand.

This thesis uses Rortyan philosophical assumptions to construct a critique of IECTE programmes in Aotearoa/New Zealand and to suggest a pedagogy of enacted hope as a useful reconstruction of what IECTE programmes might look like in the future. The following chapter sets out those Rortyan assumptions.

\subsection{Summary}

This chapter has introduced structural dissonance and outlined a justification based on the moral hope that resistance and reconstruction need only the hope that life can be made better for others as a result. The reconceptualist perspective adopted by this thesis has been introduced and the central motif of critique and reconstruction has been identified. The reconceptualist tradition to which this thesis is a contribution was also detailed. These elements set the scene for the subsequent parts of this thesis. 


\section{Part Two}

Philosophical assumptions and methodology 


\section{Chapter Three}

\section{Philosophical assumptions}

This chapter introduces Rorty's philosophical writing and draws from it several assumptions which are used to approach to questions of truth (validity), reality (and representations) and knowledge (particularly the creation of new knowledge) which is taken up throughout this thesis. In a review of early childhood studies and initial early childhood teacher education (IECTE) literature there was very little evidence that the philosophical assumptions set out by American neo-pragmatic philosopher Richard Rorty have been used to inform research in early childhood studies or IECTE (outside of mention by Dahlberg, Moss \& Pence, 1999, pp. 2, 118).

This chapter is called philosophical assumptions because it deals with subjects that traditionally concern professional philosophers, namely: truth, reality and theory of knowledge. It is, however, more accurate to call them quasiphilosophical assumptions because this thesis does not focus on a problem in philosophy; rather, it applies philosophical discourse to the topic of structural dissonance in IECTE. The difference here is subtle but important: This thesis uses rather than creates a philosophical perspective. 
Adopting Rortyan assumptions gives this thesis philosophical coherence.

Following Rorty (1989), this thesis is not going to "argue against the vocabulary I want to replace, I am going to try to make the vocabulary I favour look attractive" (p. 9), or at least, plausible. For this reason, this thesis is not interested in arguing that Rortyan assumptions are more adequate for describing what is going on in IECTE than other sets of assumptions, or that Rorty is in any way useful for getting to the essence of the problem of structural dissonance. Instead, this chapter argues that using Rortyan assumptions makes a certain type of reconceptualisation possible - one that focuses of vocabularies of usage, contingency and an ironist reconstruction of social metaphors.

The first section of this chapter introduces pragmatic philosophy in order to situate Rorty's neo-pragmatic approach within this wider set of concerns. Neopragmatism is then introduced against that backdrop. The second section introduces Rorty and some characteristics of his philosophy before identifying his assumptions on truth, reality and theories of knowledge. This chapter ends by identifying with the figure of a research ironist (see section 3.4) as a neopragmatic reconceptualist and an explanation of how these assumptions influence the parts of this thesis. 


\subsection{Pragmatism and neo-pragmatism.}

Pragmatism is a set of philosophical statements that are strung together to side step certain philosophical problems that occupy mainstream philosophy based on the assumption that there is no practical benefit in continuing those conversations (Rorty, 1979). For example, questions that distinguish between truth and justification, reality and appearance, and poetry and knowledge. At this general level, pragmatic philosophy focuses on functions, habits and actions, and makes use of two kinds of philosophical distinction: the distinction between past and future ways of acting, and the distinction between more and less useful ways of acting. These distinctions are set against a background assumption that social salvation is most likely to be wrought by human effort, rather than divine providence. Pragmatists believe that it is up to us humans to make the world a better place for one another to inhabit.

For Rorty (1990) pragmatism is the name given to a philosophical movement that aims to change the subject of dialogue from accuracy of representation toward making the world a better place. Menand (1997) sums up this sentiment by defining pragmatism as "an effort to unhitch human beings from... a useless structure of bad abstractions"' (p. xi). 
The key figures in pragmatic philosophy include Saunders Peirce, William James and John Dewey. These figures are American, and pragmatism is often characterised as a uniquely American school of philosophical thought (Menand, 1997; Murphy, 1990). The writing of Saunders Peirce is commonly held as the origin of the American tradition of pragmatic philosophy (James, 1907). Peirce (1904) described the pragmatic perspective as one which entails "a certain maxim of logic" (as cited in Menand, 1997, p. 56) that seeks to trace the practical consequences of any thought, utterance, doctrine or action, as opposed to how well a thought, utterance, doctrine or action represents reality. For Peirce (1904), reasoning and thinking are varieties of action, they are something we humans do, they are ways in which we humans behave: They are habits. Belief for Peirce (1878), was therefore a habit of thought. Using this logic, pragmatists argue that if belief is merely a habit of thought then it has little, if anything to do with the accurate representation of reality. Pragmatists think that we can drop the problem of appearance or reality (the question of whether objects or issues are real or just appear to be real) and still have something useful to say to one another (e.g., Rorty, 1979). This thesis uses this insight to unhitch itself from questions concerning the reality or appearance of structural dissonance, in favour of arguing that talking in this way is useful because it makes structural dissonance visible and counter action possible. 
For pragmatic theologian and psychologist William James (1907) the acid test for any problem is the question: does it make any practical difference? Or in other words does holding a belief make a difference to my practice? Under the condition of pragmatism, James (1907) wrote that "theories thus become instruments, not answers to enigmas, in which we can rest" (as cited in Menand, 1997, p. 98). James (1907) based his account of pragmatism in intrapersonal psychology; at the place where old opinions meet new experiences. James (1907) preached a pragmatism that does not hold what is true for us and what is better for us apart (as cited in Menand, 1997, p. 109), but collapses the two into a single vision. On this account, truth (as well as reality) exists as a distribution of possible perspectives and their potential for utility (James, 1909). This view is unsettling to those who would prefer to think of truth and reality as absolute qualities that can be found given the correct method (e.g., Plato and Kant). James' (1907) insight is important to this thesis because it sets out a pragmatic challenge in terms of theoretical construction: namely, does it make a difference to practice? This thesis will argue that structural dissonance makes a difference to practice in IECTE programmes and that a pedagogy of enacted hope has the potential to make a difference as counter action.

Dewey (1929), like James, elevated experience to the position where metaphysicians (those who claim reality has an absolute essence that can be found) placed truth. In doing so he placed the demand of practical utility ahead 
of the quest for accurate representation. The main difference between Dewey and James on this count is that where James was content to talk of individual psychology, Dewey emphasised community and social progress. However, both privileged action over the quest for truth or reality. Dewey's pragmatism was Darwinian in its assumption that social utility is the arbiter of human evolution. Dewey used the concept of progress (e.g., progressive education) as a metaphor for purpose in human history, as he applied the pragmatic distinction of old versus new. Dewey, like Peirce and James before him offered a naturalised version of philosophy that drops otherworldliness (metaphysics) to focus on the question: what are the most useful ways we can act? Dewey characteristically answered that question with one word: democratically. Pragmatism is, on the account given above, a philosophical perspective based on maxims of practical effect, a running together of truth and utility, focus on experience, the consequences of action and the dialectic of old versus new. Rorty, who considered himself a pragmatist and a disciple of Dewey (Rorty, 1999, p. xvi), has summed up pragmatism as anti-representationalism: which he explained as "the spectator account of knowledge and the consequent abandonment of the appearance/reality distinction" (Rorty, 1990, p. 2). For Rorty pragmatism is "simply anti-essentialism applied to notions like 'truth,' 'knowledge,' 'language,' 'morality,' and similar objects of philosophical theorising" (Rorty, 1982, p. 162). Anti-essentialism is the suspicion that reality 
has no constant essence, but rather it is a social construct made by humans for humans. This view will be expanded upon in section 2.3.

For Rorty (1982), pragmatism is a conscious attempt to get out from under the vocabulary left by Plato (who granted access to unconditional and absolute values) and humanised by Kant (who valorised human reason as the arbiter of truth). According to Rorty (1999), "if there is anything distinctive to say about pragmatism it is that it substitutes the notion of a better human future for the notions of 'reality', 'reason' and 'nature'"' (p. 27). Pragmatism is therefore the practice of dropping the project of discovering a true representation of reality, whilst picking up the hope that we can find the strength to work together to make better (more peaceful and socially just) societies.

\subsubsection{Neo-pragmatism}

The prefix neo- means new. Neo-pragmatism is a new form of pragmatism, related to, but different from, the traditional form. Rorty (1999) described the difference between pragmatism and neo-pragmatism in the following way:

"It is customary to distinguish the classical pragmatists - Pierce, James, and Dewey - from such living neo-pragmatists as Quine, Goodman, Putnam, and Davidson. The break between these two is the so-called linguistic turn. This was the turn philosophers took when, dropping the topic of experience and picking 
up that of language, they began talking their cue from Frege rather than from Locke" (p. 24).

The turn away from experience and toward language and its uses underpins the neo-pragmatic approach to philosophy. Menand (1997) described this as the distinction between first and second generation pragmatism. In the first generation he placed the individuals identified by Rorty as classical pragmatists (e.g., Peirce, 1904; James, 1907; and Dewey, 1929), in the second generation he places the people Rorty called neo-pragmatists (e.g. Rorty, 1979; and Putnam, 1995). According to Menand (1997) the date of the birth of second generation pragmatism is quite precise: 1979, the year Rorty published Philosophy and the Mirror of Nature.

To further differentiate neo- from traditional pragmatism Rorty (1999) wrote, "we new pragmatists talk about language instead of experience, or mind, or consciousness, as the old pragmatists did "(p. 95).

The neo-pragmatic approach taken in this thesis focuses on vocabularies and their use whilst adopting the anti-metaphysical approach to philosophy characteristic by first generation pragmatists, and the anti-epistemological approach to philosophy that is characteristic of Rorty's (1979, 1982, 1989, 1999, 2007) philosophical writing. These terms will be further explained in section 3.3. 


\subsection{A Rortyan perspective.}

Rorty was born in New York in 1931. He completed his PhD entitled The Concept of Potentiality at Yale University in 1956 and began his career as a professional philosopher at Princeton University. In 1979, with the publication of Philosophy and the Mirror of Nature, Rorty signalled a significant shift in pragmatic thought, away from habits of experience to the vocabularies we use

(Rorty, 1979, p. 8). Leaving his position at Princeton, he moved to the University of Virginia to become Professor of Humanities. By 1989, with the publication of Contingency, Irony and Solidarity this shift was complete. Rorty ended his days as Emeritus Professor of Comparative Literature at Stanford University, until his death in 2007.

Rorty was an anti-philosopher who used philosophical writing to make his point. He argued for the end of analytic philosophy, sketching out in its place a post-philosophical culture (one in which philosophy is seen as just another type of literature among the many types available) (Rorty, 1979, p. 372). Rorty (1989) hoped to do away with the figure of the scientist, as the vanguard of the human species and replace it with Harold Bloom's strong poet as a person "capable of telling the story of their own production in words never used before" (p. 28). The poet, for Rorty, is one who excels in making new metaphors. Within this 
frame, Rorty argued that inquiry (philosophical and scientific) can be thought of as metaphor making, and that discovery is really a project of consensus building wherein those metaphors are literalised. From this perspective, reconceptualisation is the process of offering new metaphors for consideration. Rorty's (1999) self description goes as follows: "If there is anything to the idea that the best intellectual position is one which is attacked with equal vigour from the political right and the political left, then I am in good shape" (Rorty, 1999, p. 3). Rorty goes on (Rorty, 1999, p. 4): “The left's favourite word for me is complacent, just as the right's is irresponsible." However, Mendieta (2006) offers a useful description of Rorty in the introduction to his edited collection of interviews with Rorty: Take Care of Freedom and Truth Will Take Care of Itself. In that introduction Mendieta (2006) wrote the following:

"Richard Rorty is a uniquely American anomaly... His work is cosmopolitan, ecumenical, multilateralist, trans-American, anti-imperial, and confessedly ethnocentric, so that it can be critical of his moral community, both antischolastic and antidisciplinary. He is utopian, hopeful, and optimistic without being reckless, unrealistic, and antidemocratic" (pp. xi, xii). 


\subsubsection{Rortyan philosophy.}

Rortyan philosophy is the sum total, and useful parts, of Rorty's writing concerning philosophy and philosophical questions. As a pragmatist, Rorty made it his stock and trade to drop the philosophical problems/distinctions that had occupied traditional Anglophone philosophers (Rorty, 1999, pp. xii, xxii), e.g., distinctions between truth and justification, reality and appearance, discovered and made. The implications of his position open themselves to application in a great number of diverse fields of inquiry in much the same way as MacNaughton (2005) has picked up Foucault's assumptions on power and knowledge and used them in her writing. On the topic of utility, Rorty (1999) pointed out: "any philosophical view is a tool which can be used by many different hands" (p. 22). This approach is consistent with the reconceptualist perspective set out in the previous chapter.

This thesis uses Rorty's philosophical writing to map out the philosophical assumptions that underpin this research, particularly Philosophy and the Mirror of Nature (1979), Consequences of Pragmatism (1982), Contingency, Irony and Solidarity (1989), Philosophy and Social Hope (1999), and Philosophy as Cultural Politics (2007).

To further illuminate Rorty's approach to philosophy it is useful to identify how his work relates to the work of other philosophers. In this way the reader gets 
an idea of where Rorty is situated in the broader philosophical landscape. Again, Mendieta (2006) offers a useful insight into Rorty's philosophical perspective, consequently it is quoted at length.

"Rorty is anti-Platonist, that is, he rejects the appearance-essence, or contingenteternal distinction that is fundamental to Platonism. He is anti-Aristotlian, that is, he rejects the convention-nature distinction. He is also anti-Thomist, that is, he rejects the natural law-human law distinction. He is also an anti-Kantian, that is, he rejects the noumena-phenomena, analytic-synthetic, a priori-a posteriori distinctions. He is also anti-Cartesian, that is, he rejects the mindmatter, innate-acquired distinctions. He is anti-Hegelian, that is, he reject the notion that there is a logic of history, and that this logic is the nature of reason, and that this reason is tied to freedom. He is also anti-Marxist, that is, he rejects the idea that all history is the history of class struggle, and the notion that the ruling ideas are the ideas of the ruling classes... Rorty is avowedly proHumean, that is he endorses the education of moral sentiment over the alleged power of reason. He is pro-Derridean, that is, he endorses the ways in which deconstruction is another name for jostling and redescription, brilliant bricolage, and a form of polytheistic criticism. He is pro-Davidson, that is, he endorses the ways in which Davidson's view of language is a form of panrelationalism, in which triangulation means submitting to the authority of reasons that are offered as justifications rather than as ways of finding something outside and beside what is merely human. He is pro-Wittgenstein, 
that is, he endorses the ways in which language use is tied to forms of life, and how changing ways of talking and describing the world entail changing practical relations. He is also pro-Heideggerian, but he endorses only the Heidegger who is interested in language as poetic novelty, the one who offers metanarratives that allow us to see how we may begin to be disenchanted with old mythologies and begin to articulate new languages and narratives. He is also pro-Habermasian, that is, he endorses the kind of shift from monological subjectivity to intersubjectivity and communicative rationality that Habermas has so eloquently described" (pp. xv, xvi).

I would also add that he is consistently pro-Dewey, that is, he sees himself as a continuation of the Deweyan tradition which unhooks itself from assumptions that can no longer be deemed useful (even some of his own - see Rorty in Brandom, 2000). He is also pro-Gadamer, at least as far as Gadamer views understanding as an interaction between pre-understanding, text (this includes utterances), and intended application.

This section has taken a very broad overview of Rorty's position in order to construct a consistent and internally coherent approach to the formation of new knowledge claims in the field of IECTE studies. 


\subsection{Rortyan assumptions.}

Rorty (1999) claimed that pragmatists usually "define ourselves in negative terms. We call ourselves 'anti-Platonists' or 'anti-metaphysicians' or 'antifoundationalists'"' (p.xvi). The Rortyan method adopted in this thesis is to explain what I am against (anti-) and what I am for (pro-) in its place. There are two parts of this section that use that method: anti-metaphysics/antiessentialism- pro-utility (3.3.1 and 3.3.2), and anti-epistemology/antifoundationalism - pro-constructivism/abnormal discourse (3.3.3 and 3.3.4). A third part explains and aligns this thesis to the Rortyan figure of the ironist researcher/scholar. These assumptions underpin the methodology and methods used in this research, analysis of data, and the subsequent justification of structural dissonance in IECTE, and the pedagogy of enacted hope.

\subsubsection{Assumption one: Anti-metaphysics, anti-essentialism.}

Metaphysics is a branch of philosophy that investigates Reality-As-It-Is or first principles. Anti-metaphysics is the conviction that there is no such thing as Reality-As-It-Is or a first principle, that these things are made by people, formed in language, and prone to change (Rorty, 1999). Metaphysics is the tradition of identifying objects beyond physical appearance e.g. Truth, Reality, Justice, Human Rights. Anti-metaphysics is the tradition of saying truth, reality, justice 
and human rights are things we humans do, that is, they are products of human interactions, histories and hopes (Rorty, 1982).

Essentialism is the belief, often held by metaphysicians, that there is an essence to be found that is unconditional, absolute, and unalloyed. Anti-essentialism is the belief that such essences do not exist independently of human needs (Rorty, 1999). For example, essentialists like to think that there is something specific and objective that we can call childhood, they might make statements like the essence of childhood is play, or they might come up with statements like children's rights are universal. Anti-essentialists respond that childhood is a social construction (e.g., Cannella, 1997), and that rights are products of social history rather than ahistorical and absolute. By taking an antimetaphysical/anti-essentialist position, this thesis does not maintain that structural dissonance has an essence or that the essence of the contradiction being studied is structural dissonance. Rather, it takes the view that structural dissonance is one metaphor among many that can be used to describe contemporary practices in IECTE programmes, which is in itself, an expression of human hope that less contradictory, more just approaches to IECTE are possible.

$\mathrm{Neo/pragmatic} \mathrm{philosophy} \mathrm{is} \mathrm{an} \mathrm{anti-metaphysical/anti-essentialist} \mathrm{endeavour.}$ Pragmatists think that there is no such thing as truth as an absolute and 
unconditional quality of things or people, and that there is little use in attempting to define or represent it. This thesis picks up that assumption. "Pragmatists - both classical and neo - do not believe that there is a way things really are. So they want to replace the appearance-reality distinction with that between different descriptions of that world and ourselves which are less useful and those which are more useful" (Rorty, 1999, p. 27). In the place of this quest for true representation of reality Rorty (1999) suggested a version of utility based on "our ability to trust and cooperate with other people, and in particular to work together so as to improve the future" (p. xiii). Rorty's approach to utility is not a quest for certainty, but a quest for how best to cope with the contingencies of human life. This is the crux of the argument between essentialists and anti-essentialists: the former think that certainty is possible, the latter think that agreement (or fruitful disagreement) is the only goal we can hope to achieve. This thesis assumes that latter.

According to Rorty (1999), "for pragmatists, there is no such thing as a nonrelational feature of $\mathrm{X}$, anymore than there is such a thing as the intrinsic nature, the essence, of X" (Rorty, 1999, p. 50). X is always understood using language, language is a human construction, and human constructions are relative to time, place and participants. Therefore, so too is the manner in which we understand $X$. If $X$ is education, then those approaches to education that identify essential skills or key competencies are buying in to the idea that 
education has a set of non-relational features or essences. This thesis does not take that view. For neo-pragmatists essential skills and key competencies are one way among many to talk of education. From this perspective, the question is: does our way of talking about education make for more just and peaceful relationships between human beings? Rather than, how well does education represent an essence.

According to Rorty (1999), "there is nothing to be known about an object except what sentences are true of it... We anti-essentialists try to substitute the picture of language as a way of hooking up objects to one another for the picture of language as a veil interposed between us and objects" (p. 55). What Rorty is getting at here is that language has no way of corresponding to reality (i.e., truth), because reality is constructed of sentences that refer only to other sentences and not to objects as they exist unconditionally (that is, outside of our human uses). For example, the sentence learning is a situated activity would not, on Rorty's account, refer to the way things really are, rather it refers to the fact that this metaphor for learning has currently achieved more popularity than alternative metaphors in a given community, for the particular purpose of coming to some form of agreement on what it means when we talk to each other about learning. 
In place of unconditionality, Rorty used contingency. For Rorty (1989) “truth can not be out there - cannot exist independently of the human mind - because sentences cannot exist, or be out there. The world is out there, but descriptions of the world are not... The world does not speak. Only we do" (pp. 5, 6). On this account, where truth is articulated it is a truth that is made rather than found. Essentialists maintain that truth can be found and that it is possible to draw up a correct criterion for finding it. A typical Rortyan reply to this assertion is that it makes no sense to engage in this type of sense making activity because it is no longer useful to talk in such a way, just as scientists no longer find it useful to talk in the terms used by theologians. To this the essentialist may reply: then you are a relativist. To which Rorty (1999) would retort:

"I think it is important that we who are accused of relativism stop using the distinctions between finding and making, discovery and invention, objective and subject... we must repudiate the vocabulary our opponents use, and not let them impose it on us... We pragmatists shrug off charges that we are relativists or irrationalists by saying that these charges presuppose precisely the distinctions we reject" (pp. xviii, xix).

Rorty's (1982, p. 166) approach to philosophy is not relativistic, he does not believe that anyone believes that all positions are equally valid. He thought, 
instead, that some ways of speaking are more useful than others for helping us create more socially just and less violent communities (Rorty, 1982, p. 167). Clearly not all sentences that humans can utter are up to this task.

According to Rorty, there is no useful distinction between truth and justification, just as there is no useful distinction between appearance and reality, or found and made. These distinctions are part and parcel of a vocabulary he has gone out of his way to drop (see Philosophy and the Mirror of Nature, 1979). Rorty talked instead of metaphors and re-descriptions where others talk of objectivity and correspondence to reality. He opted for a conversational version of truth, offering the following as an alternative to the metaphysical desire for essences:

We call something fantasy rather than poetry or philosophy when it revolves around metaphors which do not catch on with other people - that is, around ways of speaking or acting which the rest of us cannot find a use for... Conversely, when some private obsession produces a metaphor which we can find a use for, we speak of genius rather than of eccentricity or perversity (Rorty, 1989, p. 37).

These anti-metaphysical/anti-essential assumptions inform this thesis by allowing it to bypass the question of whether the reconceptualisation being put 
forward corresponds to reality or not. From a neo-pragmatic perspective the question of correspondence to reality makes like sense. Instead, like Rorty, this thesis asks if the reconceptualisation put forward is useful for the purpose of constructing a more socially just context for student teachers in IECTE programmes in Aotearoa/New Zealand.

\subsubsection{Utility.}

In a general sense, utility is "a matter of adjusting the relation between an object and other objects, a matter of putting an object in a profitable context" (Rorty, 1999, p. 65). Rorty is saying that usefulness is aligned with attaining the best result. There are many alternatives available that could suffice as profitable contexts, from downright exploitation (e.g., child labour in England's industrial revolution) right through to the hope for social justice. For Rorty, "hope for social justice is nevertheless the only basis for a worthwhile human life" (Rorty, 1999, p. 204). This assumption fits the reconceptualist tradition of resistance and the will for social justice by drawing utility and social justice into a single vision. Further to this point, Rorty (1999) wrote "my candidate for the most distinctive and praiseworthy human capacity is our ability to trust and cooperate with other people, and in particular to work together so as to improve the future" (p. xiii). 
Rorty (1989) also followed the traditional pragmatic line by defining utility as socially useful:

The view I am offering says that there is such a thing as moral progress, and that this progress is indeed in the direction of greater human solidarity. But that solidarity is not thought of as recognition of a core self, the human essence, in all human beings. Rather, it is thought of as the ability to see more and more traditional differences (of tribe, religion, race, customs, and the like) as unimportant when compared with similarities with respect to pain and humiliation - the ability to think of people as wildly different from ourselves as included in the range of $u s$ (p. 192).

This thesis uses the assumption of social utility as a rationale for identifying structural dissonance in IECTE programmes, as a philosophical orientation to the notion of moral hope introduced in the previous chapter, and as the impetus for suggesting a pedagogy of enacted hope (introduced in chapter 10).

\subsubsection{Assumption two: Anti-epistemology, anti-foundationalism.}

Epistemology is a branch of philosophy that studies knowledge and beliefs, particularly the nature of knowledge and the means of its production. A fairly literal definition of epistemology is theory of knowledge. Epistemology depends on metaphysics for the assumption that there is an unconditional object called 
knowledge in the first place. Epistemologists hold that this object called knowledge has a structure, and, that that structure can be used as the foundation to discover more knowledge on a given subject. Anti-epistemology is the conviction that no such structure or object exists outside of contingency and human uses (Rorty, 1979).

Foundationalism is the attempt to establish a structure/foundation and apply this to diverse subjects in order to establish objectivity. Anti-foundationalism is the conviction that objectivity is just a word used by people who like to talk about foundations and as such it does not exist outside of language and the communities to whom such a language makes any sense (Rorty, 1999). From the perspective of Rortyan scepticism, epistemology is an attempt by professional philosophers to keep themselves in work after metaphysics was disintegrated by physics. Rorty (1979) credits Emmanuel Kant as the creator of epistemology noting that "it was not until after Kant that the philosophyscience distinction took hold" and that:

The eventual demarcation of philosophy from science was made possible by the notion that philosophy's core was theory of knowledge, a theory distinct from the sciences because it was their foundation... Without this idea of a theory of knowledge, it is hard to imagine what philosophy could have been in the age of modern science... Kant, however, managed to transform the old notion of 
philosophy - metaphysics as queen of the sciences because of its concern with what was most universal and least material - into the notion of a most basic discipline - a foundational discipline. Philosophy became primary no longer in the sense of highest but in the sense of underlying (pp. 131-132).

Rorty (1979) argued that "the theory of knowledge is a desire for constraint - a desire to find foundations to which one might cling, frameworks beyond which one must not stray, objects which impose themselves, representations which cannot be gainsaid" (p. 315). Rorty therefore equated being anti-epistemological with being anti-foundational, the two being different ways of arriving at the same point.

The difference between Rorty and epistemologists is that Rorty does not try to establish certainty through his assumptions, whereas epistemologists do. To Rorty $(1979,1989,1999)$ the idea that objectivity is possible or that there is a way to be objective is a relic of those assumptions he believed we would benefit from dropping. Like Rorty (1979), this thesis assumes that we can drop these ways of talking with no harmful consequences; that we can drop the quest for foundations of knowledge and still have something potentially useful to say to our respective communities. 
For Rorty (1979), we are being epistemological when we do the following: assure ourselves that there are foundations of knowledge which are "truths because of their causes rather than the arguments given for them (p. 157); when we think that knowledge mirrors (accurately represents) nature/Reality as it is; when we try to prescribe knowledge through a "permanent ahistorical framework for inquiry" (p. 257); when we assume that "all contributions to a given discourse are commensurable" (p. 316): can be brought under a set of rules; when we think that being rational is the same as finding common ground (p. 318); and, when "we understand perfectly well what is happening but want to codify it in order to extend, or strengthen, or teach, or ground it" (p. 321). This thesis rejects these assumptions and for this reason is anti-epistemological in its approach to the question of structural dissonance in IECTE programmes in Aotearoa/New Zealand. Taking this perspective has methodological consequences as discussed in the following chapter.

The anti-foundationalist argument is that there is nothing to be found except the words/metaphors that we have made, and the consensus these words have inspired in different communities over time. On this account, if there is to be a foundation then it is at best a shifting one, one that takes on different forms in different epochs, for different audiences. 
In assuming that there is no such thing as correspondence to reality in the first place, let alone better or worse ways for corresponding, the focus of this thesis shifts away from attempts at discovery toward attempts to reconceptualise IECTE programmes in a way that has the merit of utility to a given audience (in this case, those early childhood practitioners and theorists interested in social justice). By dropping the metaphor of finding and picking up the metaphor of making, the onus shifts from justifying correspondence to reality to justifying the utility of sentences and concepts. The outcome of adopting this philosophical assumption is that this thesis is an example of what Rorty (1979) called abnormal discourse. In this thesis abnormal discourse is a synonym for reconceptualist writing wherein new perspectives are integrated and implicated in scholarship within particular fields of inquiry.

\subsubsection{Normal and abnormal discourse.}

A normal discourse is one that is accepted by the mainstream of a given community (e.g., in chapter five the argument is advanced that sociocultural theory is a normal discourse used in the content of IECTE programmes today). An abnormal discourse is one that is not commonly used by the mainstream of a given community, but which may, in future, with luck and/or good management, become a normal discourse. Examples of discourses that were abnormal to the contexts in which they were written include Rousseau's (1762) idea that childhood is a developmental stage distinct from adulthood, Holt's 
(1965) discourse on how children fail, and Cannella's (1997) deconstruction of the concept of childhood.

In Philosophy and the Mirror of Nature (1979) Rorty used Thomas Kuhn's (1962) argument that normal science is the practice of furthering an already established research paradigm and extends it to discourse in general, and philosophical discourse in particular. A paradigm is normal when "research is directed to the articulation of those phenomena and theories that the paradigm already provides" (Kuhn, 1962, p. 24). A paradigm is revolutionary when it has become uneasy about anomalies in normal science to the point where an altogether new paradigm is established; one in which research no longer articulates the paradigm of the normal science but changes the worldview altogether, that is, it begins a new paradigm, or forces a paradigm shift (Kuhn, 1962).

Rorty (1979) converted the term normal science into normal discourse and revolutionary science in abnormal discourse. For Rorty (1979), a vocabulary counts as normal discourse when it "is conducted within an agreed-upon set of conventions about what counts as a relevant contribution, what counts as answering a question, what counts as having a good argument for that answer or a good criticism of it" (p. 320). An abnormal discourse is "what happens when someone joins in the discourse who is ignorant of these conventions or 
who sets them aside" (Rorty, 1979, p. 320). Rorty identified the drive to be epistemological as the drive to the produce normal discourse. Alternatively, he called the drive to describe the familiar in unfamiliar terms the practice of producing abnormal discourses.

According to Rorty (1979), "the product of abnormal discourse can be anything from nonsense to intellectual revolution" (p. 320). The challenge, therefore, is to create an abnormal discourse that is useful for the purposes of achieving social justice within a given field of interest, in a way that is coherent, consistent and reasonable to the community to which the discourse is addressed. If this discourse is deemed useful then it becomes normalised insofar as the vocabulary set forward is picked up and used by a given community. This thesis is an abnormal discourse insofar as it constructs new possibilities for conversation on the topic of social justice by introducing the notion of structural dissonance and suggesting a pedagogy of enacted hope. Quality, from this perspective, extends from the plausibility of the argument set out and its utility in terms of supporting the development of a more socially just programme for IECTE students. 


\subsection{Ironist scholarship}

In Contingency, Irony, and Solidarity (1989) Rorty sketched the ironist a figure who has lost faith in both metaphysics and epistemology. This thesis identifies strongly with that figure. Rorty (1989) used the concept of final vocabulary to describe theoretical projects that promote certainty and the closure of the possibility. According to Rorty (1989), we adopt a final vocabulary when we cling to one particular vocabulary (to describe ourselves, others, our world, purpose etc.), and can not resort to anything other than circular arguments when that vocabulary is challenged. In opposition to that project, Rorty (1989) cast his figure of the ironist as one who fulfils three conditions:

(1) She has radical and continuing doubts about the final vocabulary she currently uses, because she has been impressed by other vocabularies, vocabularies taken as final by people or books she has encountered; (2) she realises that argument phrased in her present vocabulary can neither underwrite nor dissolve her doubts; (3) insofar as she philosophises about her situation, she does not think that her vocabulary is closer to reality than others, that it is in touch with a power not herself (p. 73).

This thesis is an example of ironist scholarship, of the type set out by Rorty (1989). From that ironist perspective, this thesis does not hold out any hope that 
the vocabulary used here is a final vocabulary. However, holding that view does not mean that the proposed vocabulary is not useful, or justifiable, but rather that its author is also open to using other vocabularies, vocabularies notyet read, or perhaps that have not-yet been written, in future. The vocabulary of structural dissonance and enacted hope worked out in this thesis is not intended to stifle the urge to move beyond those vocabularies. The attempt to be normative contradicts the ironist goal of keeping conversation open.

This thesis does, however, hope that the vocabularies and perspectives woven together in these chapters will be interesting enough that others will make use of them to approach structural dissonance in IECTE programmes. This thesis offers a new way of talking about IECTE programmes by drawing together vocabularies, philosophical assumptions and text. The Rortyan assumptions used in this thesis permeate methodology as well as the way in which truth claims are constructed and justified (i.e., as moves within a broader conversation rather than as certainties attained by a privileged method). Using these assumptions across all chapters enables a coherent and consistent approach to the construction of new vocabularies and their application to the study of structural dissonance in IECTE programmes in Aotearoa/New Zealand. 


\section{Summary}

This chapter has introduced the neo-pragmatic perspective taken in this thesis by defining neo-pragmatism in relation to traditional pragmatic writers.

Rortyan neo-pragmatism has been introduced and situated within a wider context of philosophical perspectives. The key assumptions of anti-metaphysics, anti-essentialism and anti-epistemology, anti-foundationalism have been explained and the figure of the ironist has been used to describe the approach to scholarship undertaken in this thesis. The next chapter introduces the methodology and methods used in this thesis. 


\section{Chapter Four}

\section{Methodology and Methods}

This chapter outlines the methodology and research methods used in this thesis. The methodology adopted to organise data generation and analysis is a Rortyan version of Gadamer's (1975) philosophical hermeneutic blended with an ecological structure promoted through the writing of Bronfenbrenner (1979).

The first part of this chapter sets out Gadamer's (1975) philosophical hermeneutic and Rorty's (1979) inversion of that hermeneutic approach. The research design used in this thesis is integrative (Boyer, 1990) and draws on the bricolage and constructivist perspectives in qualitative educational research (Denzin \& Lincoln, 2005). The methods employed in this thesis consist of an ecological approach to philosophical hermeneutics, a Rortyan perspective on Weber's (1949) ideal type method (used subsequently as a tool for textual analysis in chapters five to eight), and four focus groups of year two and three IECTE student teachers from a case study New Zealand university. 


\subsection{Methodology: Hermeneutics.}

The methodology of this thesis is based on the concept of understanding set out by Gadamer (1975) in his book Truth and Method. This thesis converts Gadamer's (1975) philosophical hermeneutic into a methodology by proposing that those elements which Gadamer thought constitutes all understanding can also be employed to construct new understandings. Gadamer's perspective is then further reconceptualised using Rorty's $(1979,1989)$ ironist hermeneutics.

\subsubsection{Hermeneutics: A general perspective.}

Hermeneutics is a set of techniques for understanding and interpreting text/s or utterances. It is both a means by which understanding takes place (Gadamer, 1975) and a method for distinguishing truth from interpretations (Hirsch, 1967), depending on the philosophical assumptions one subscribes to. The former approach adopts an anti-epistemological perspective whereas the latter is epistemological (insofar as it holds there is a distinction to be made between reality and appearances). Hermeneutics is, therefore, a tool that can be, and has been, used in a number of ways, epistemological and anti-epistemological. This thesis takes an anti-epistemological approach which is consistent with the philosophical assumptions outlined above. 
Another way of understanding the hermeneutic approach to research is offered by Ricoeur (1974) who delineated between hermeneutics of suspicion and hermeneutics of understanding. Hermeneutics of suspicion is a critical project whereby injustices are identified and a way forward to emancipation is set out (e.g., MacNaughton, 2005). Hermeneutics of understanding is a constructivist project whereby new understandings are encouraged through the integration of diverse perspectives (e.g., Dahlberg, Moss \& Pence, 1999).This thesis uses both styles of hermeneutic inquiry: it is suspicious of structural injustice in IECTE programmes and aims to produce a new pedagogical approach in this context.

As a research methodology hermeneutics is a disconnected grouping of diverse perspectives on the interpretation and understanding of textual sources (Bleicher, 1980). Hermeneutics is diverse in much the same way that qualitative research contains a number of diverse and divergent paradigms (Denzin \& Lincoln, 2005), or the history of science is a history of paradigmatic change (Kuhn, 1962), or the history of early childhood education is inflected with the changing gazes of state (May, 1997, 2001).

Bleicher (1980) identified four specific genre in hermeneutics: The first is hermeneutical theory which "focuses on the problematic of a general theory of interpretation as the methodology of the human sciences" (p. 1). This hermeneutic theory is structure bound, positivistic/objectivist and 
epistemological. For Bleicher (1980) the paradigm figure of hermeneutic theory was Betti (1962) who pronounced that the only true and objective meaning of a text is that which the author originally intended. On this account there was a distinction between appearance and reality which only entering the psychological space of the author, context included, could divine.

Bleicher's (1980) second category is philosophical hermeneutics, which rejects objectivity as the goal of hermeneutic inquiry and draws attention to the foreunderstandings of the interpreter/researcher. This approach casts the hermeneutic act as one that necessarily involves ontology (being) in the ongoing interpretation of texts and utterances. This approach to hermeneutics rejects the quest for certain understanding and focuses on those elements that contribute to a person's understanding. Paradigm figures in this approach are Heidegger (1962) and Gadamer (1975). Within this frame, Gadamer (1975) believed he had formulated an universalisable approach to understanding.

The third category is critical hermeneutics, which situates interpretations in a context of socio-historical power relations and emphasises the power of interpretation to change the world and bring about emancipation (Bleicher, 1980). Critical hermeneutics is another name for what Ricoeur (1974) called the hermeneutics of suspicion. Critical hermeneutics treats commonly accepted social discourses with suspicion and looks for the power relations that privilege 
one text over another in different social contexts. According to Bleicher (1989), the paradigm figure in this perspective is Habermas, who championed a hermeneutics which highlights intersubjectivity over the objectivity/subjectivity binary, and who sought out the traces of distorted communication which circulate in the collective unconscious of our native language/s.

Bleicher's (1980) final category of hermeneutic inquiry is phenomenological hermeneutics in which interpretations of literal meanings are investigated in terms of the hidden meanings that are also conveyed within (and beneath) a text. Bleicher's (1980) paradigm case in this field is Ricoeur (1974) who translated Freud's notion of human unconscious to describe hidden levels of meaning operating within a single piece of text. Each of these perspectives on hermeneutics has its own particular way of going about the interpretation of textual sources. As noted, this thesis uses Gadamer's (1975) philosophical hermeneutics as the basis of its methodology. This is detailed in the following section.

\subsubsection{Gadamerian hermeneutics.}

Gadamer's (1975) philosophical hermeneutics borrowed heavily from Heidegger's (1962) philosophy of Being/being as the precondition for all understanding. Gadamer used Heidegger's notion of foreunderstanding to propose that the perspective of the interpreter/researcher influences the 
interpretation of textual sources. Using that methodology: Reconceptualisation and Rortyan assumptions are the foreunderstandings that guide this thesis. From the perspective of philosophical hermeneutics, these foreunderstandings are methodologically important to disclose. Gadamer's (1975) hermeneutics revolves around the idea that the person reading a text (the interpreter) is just as important as the words that the text itself contains: both are partners in the co-construction of understanding.

Gadamer (1975) used the idea of horizons to describe spheres of influence at work in the act of interpretation/understanding: (i)There is the horizon of the text which is, for the purposes of interpretation, considered a complete and coherent entity in its own right, divorced from its author and open to new interpretations. (ii)There is the horizon of pre-judgment (Heidegger's foreunderstanding) which brings the life-world (Husserl, 1936) of the interpreter/researcher into the hermeneutic equation. And (iii) there is the horizon of application (why the text was consulted in the first place, and the purpose the text will be put to). Understanding, for Gadamer (1975), occurs through the fusion (integration) of these horizons.

\subsubsection{Horizon of the text.}

According to Gadamer (1975), a text is not interpreted against the authors original meaning (e.g., Betti, 1962; Hirsch, 1967), or in relation to the context in 
which it was written: "what is fixed in writing has detached itself from the contingency of its origin and its author and made itself free for new relationships" (Gadamer, 1975, p. 357). This means that that the quest to find a true or intended meaning of a given text can be set aside in favour of asking the more pragmatic question: what can this text be used for? In Gadamer's view, multiple readings of a single text are not only possible, but to be expected, as readers differ and their perspectives change over time. On this point Gadamer (1975) remarked: "the understanding of something that is written is not a reproduction of something that is past, but the sharing of a present meaning" (Gadamer, 1975, p. 354). The meaning in the case of this thesis is open and flexible. This perspective supports reinterpretation, multiple uses and reconceptualisation.

Although the text is open to multiple interpretations, Gadamer (1975) points out that it must also be considered complete, that is, considered an authoritative or important text in a given discipline or context. This consideration ensures that the hermeneut is consulting texts that are appropriate not only to the task at hand, but to the literary context to which those texts belong (e.g., academia). For the most part, this thesis uses primary texts on neo-pragmatism, socioculturalism, individualisation, enactivism and hope in the construction of the thesis argument. It is for this reason that the following chapter uses original key texts to describe socioculturalism rather than relying on secondary texts. 
Where secondary texts are used, they are used in support of, or introduction to, the primary sources.

\subsubsection{Horizon of the interpreter.}

According to Gadamer (1975), the horizon of the interpreter contains the perspective to which the interpreter belongs (e.g. their philosophical assumptions, cultural identity, the research community with which they identify). Gadamer's (1975) hermeneutic perspective rests on the assumption that "all understanding inevitably involves some prejudice that gives the hermeneutical problem its thrust" (p. 239). That prejudice is the pre-judgment or foreunderstanding that the interpreter brings to the act of understanding. Thus, it is assumed that "the interpreter's own thoughts have gone into reawakening the meaning of the text" (Gadamer, 1975, p. 350). This thesis approaches textual sources from the perspective of a neo-pragmatic ironist who thinks that the business of reconceptualisation in IECTE is not-yet over. If I were to approach my textual sources believing that the author's original intention is the only true interpretation, and that the possibilities for redescription should be countered where ever possible, the way of reading socioculturalism, individualisation, Rorty and key texts in IECTE programmes adopted in this thesis would be quite different to the present case (i.e., adopting anti-epistemological assumptions would be contradictory and there would be a great deal of writing to justify that a true and absolute interpretation has been 
found). Furthermore, that way of reading texts would contradict the philosophical assumptions used which would weaken the internal consistency of this project.

\subsubsection{Horizon of application.}

The third of Gadamer's (1975) horizons is the horizon of application. This is the reason why the text is being consulted in the first place and the particular use for which a given text or fragment of text is intended to fulfil. This thesis has introduced its horizon of application in chapter two: The proposition of structural dissonance in IECTE programmes and the hope that something can be done about it. For Gadamer (1975), “understanding always involves something like the application of the text to be understood to the present situation of the interpreter" (p. 274). The inclusion of application into hermeneutic inquiry is arguably Gadamer's greatest innovation in the field of philosophical hermeneutics. Previously, Heidegger (1962) had brought only the ontology of the interpreter and the ontology of the text into conversation. The horizon of application is consistent with the neo-pragmatic assumptions (see section 4.2) underpinning this thesis, especially where utility is given primacy over the search for essences or foundations. Methodologically, this means not only the words of the text, nor the foreunderstandings of the interpreter go into the act of understandings, but also the task at hand, the reason for consulting the text in the first place. 
Hermeneutics, from a Gadamerian stand point, is the dialogical practice of entering into conversation with texts and between texts, between interpreters and between applications. Following Heidegger (1962), Gadamer (1975) used the hermeneutic circle to organise conversation and to aid the integration of sources. The hermeneutic circle is the technique of moving between the whole and the parts, and back to the whole again. Heidegger (1962) thought of the hermeneutic circle as the relationship between individual and the whole of Being, whereas Gadamer (1975) used the term to mean the technique of relating specific texts to the broader application at hand. This thesis uses the hermeneutic circle as a strategy for organising inquiry, meaning that throughout this thesis interpretive discussion moves from the general to the specific through out the structure of the chapters, and in the sections that make up the chapters. In section 4.3 this general hermeneutic strategy is converted into a specific method for inquiry and reconceptualised as ecological hermeneutics.

\subsubsection{A Rortyan appropriation.}

A Rortyan (1979) appropriation of Gadamer's philosophical hermeneutic, of the type outlined in Philosophy and the Mirror of Nature, highlights two important aspects of Gadamer's work whilst rejecting his presumption that the system he proposes can be universalised. The first is the idea of conversation as edification: That hermeneutics is a conversation that encourages ever more 
diverse perspectives, texts, and applications resulting in the construction of new edifices of knowledge; new vocabularies for re-describing the world. The idea of edifice is important here because it replaces the need for a foundation. An edifice is a structure to which one can cling in order to formulate new spaces for new conversations, or reconceptualisations (Rorty, 1979).

For Rorty (1979), edification:

Stands for [the] project of finding new, better, more interesting, more fruitful ways of speaking"... consisting in "the poetic activity of thinking up new aims, new words, or new disciplines, followed by, so to speak, the inverse of hermeneutics: the attempt to reinterpret our familiar surroundings in the unfamiliar terms of our new inventions (p. 360, brackets added).

Hermeneutics as the practice of edification is aligned to adopting an antiepistemological stance to methodology. In this regard, being antiepistemological is not merely the rejection of foundations, but also an expression of hope in the enduring nature of human conversation. This thesis is methodologically bound to carry on the conversation of reconceptualisation for social justice in early childhood studies in general and IECTE in particular. 
In Philosophy and the Mirror of Nature (1979), Rorty argued against the epistemological worldview, asking that we reject the notion of theory of knowledge or foundation of knowledge, as we dropped the idea that the world is flat, or the sun revolves around the earth. Without advocating that hermeneutics should be the successor subject to epistemology (Rorty, 1979, p. 315). Rorty argued that "hermeneutics is an expression of hope that the cultural space left by the demise of epistemology will not be filled" (Rorty, 1979, p. 315). From this perspective, there is little point in arguing against the many alternative methodological perspectives that are available (nor is there any point in the next section arguing against the research methods not used in this thesis). The question of difference in each is merely a question of philosophical orientation. To claim that the methodology (and methods) adopted herein are better than any other at finding the truth of structural injustice would be a contradiction between philosophy and methodology. For a similar reason this thesis rejects Gadamer's (1975) claim to the universability of his approach and instead understands it as one approach among many (see Rorty, 1979, p. 380).

A second idea for Rorty (1979) was that hermeneutics meant synthesis: Bringing together sentences and perspectives in the hope that something new and useful might emerge as a result. Rorty's hope was that this type of synthesis might bring about as yet un-thought of edifices that have the power to woo future audiences and change the way we talk about the things that are important to us, 
or open up the possibility of talking about altogether new subjects as we continue our conversations. On this point, Rorty (1979) wrote: "edifying discourse is supposed to be abnormal, to take us out of our old selves by the power of strangeness, to aid us in becoming new beings" (p. 360). Rorty's (1979) ironist hermeneutics, on this count, whilst it shares an open approach to knowledge formation, is an inversion of the Gadamerian project. Gadamer (1975) claimed that hermeneutics is the process of making the strange appear familiar, where-as in Rorty (1979) it is the process of making the familiar appear strange. This thesis takes up the later claim as it reconceptualises IECTE programmes in Aotearoa/New Zealand along the lines of structural dissonance and enacted hope. Both propositions have the net effect of making the familiar appear strange.

\subsection{Methodology: Qualitative Research.}

This section links the methodology used in this thesis to broader perspectives on qualitative educational research. The links in this section are important because they identify hermeneutics as a legitimate research methodology amid alternative approaches. The alternative approaches are recognised but not introduced in any depth, they are highlighted for the purposes of contextualisation; through the articulation of difference. This section links this 
thesis to integrative scholarship, and the bricolage and constructivist research paradigms in qualitative research. The three parts of this section explain those terms.

\subsubsection{Integrative scholarship.}

Integrative scholarship is a research practice that brings together multiple sources into a single scholarly project (Boyer, 1990). In his book Scholarship Reconsidered: Priorities of the Professoriate, Boyer (1990) argued that the simple dichotomy of teaching and research had outlived its usefulness in the modern university. He proposed that the idea of scholarship within universities be given a "broader, more capacious meaning, one that brings legitimacy to the full scope of academic work" (Boyer, 1990, p. 16). To this end, he concluded that: "The work of the professoriate might be thought of as having four separate, yet overlapping, functions. These are: the scholarship of discovery; the scholarship of integration; the scholarship of application; and the scholarship of teaching" (Boyer, 1990, p. 16).

Using scholarship of integration, as an academic metaphor, highlights a commitment to the multiplicity that is at the heart of Rorty's neo-pragmatism, Gadamer's philosophical hermeneutic and the reconceptualist perspective in early childhood studies. The metaphor of depth, or expert use, of a single 
research method is replaced in this thesis by multiple methods being brought into conversation with multiple perspectives: Multiple border crossings.

\subsubsection{Research bricolage.}

To further extend this idea of integration, this thesis identifies with Denzin \& Lincoln's (2005) metaphor of the research bricoleur. A bricoleur is a quilt maker, a maker of bricolage; a person skilled at combining many parts in the service of the whole. In another sense the bricoleur is a mat weaver; a maker of whāriki (mats). This is a metaphor that holds great currency in early childhood education given that the New Zealand curriculum statement for early childhood education is Te Whäriki (Ministry of Education, 1996). As a document Te Whāriki (Ministry of Education, 1996) bases its structure on a metaphor of weaving together strands and principles: It is itself a form of bricolage.

Denzin \& Lincoln (2005) identified several types of research bricoleur:

"interpretive, narrative, theoretical, political, methodological" (p. 4). This thesis integrates the interpretive, theoretical, methodological types of bricoleur into a unified approach to research. The interpretive bricoleur brings together a variety of methods and interpretations with a number of possible effects. Likewise, the theoretical bricoleur brings together multiple theoretical perspectives in an attempt to create an alternative approach to a given subject or question. This thesis weaves diverse philosophical and theoretical 
perspectives together to reconceptualise IECTE programmes in terms of structural dissonance and enacted hope. The methodological bricoleur brings multiple methods of data collection and analysis to bear on their research effort. This thesis combines hermeneutics, ideal type theory and focus groups as methods of inquiry. The result is a multifarious abnormal discourse.

The notion of weaving multiple perspectives to form a unified whole; a bricolage, is not only in line with the Rortyan philosophical assumptions presented in the previous chapter, and the hermeneutic approach set out above, but is a normal mode of operation for Rorty in his writing. Mendieta (2006), in the introduction to his edited collection of interviews with Rorty, called him an "ingenious mixer and masterful producer of modern bricolage" (p. xi). It was Rorty's style to draw writers (of philosophy, literature, history etc.) together into conversations that support the point he wished to make at the time. For this reason, the metaphor of qualitative research bricolage sits well with the assumptions that underpin this thesis.

\subsubsection{Constructivist research.}

As a general theoretical framework for understanding the diverse possibilities encompassed under the umbrella term qualitative research, Guba \& Lincoln (2005) borrow Kuhn's (1962) notion of paradigms and paradigm shifts. The different research paradigms diverge not only in their basic beliefs over such 
questions as being, knowledge, and methodology, but they also differ in specific issues such as criteria of quality, ethics, and the position of the inquirer (Guba \& Lincoln, 2005, pp. 195, 196). The research paradigms outlined by Guba and Lincoln (2005) are: positivism, postpositivism, critical theory, constructivism, and participatory practices.

This thesis identifies with the constructivist paradigm of qualitative research. For Guba and Lincoln (2005), the constructivist paradigm encompasses the following assumptions: realities are co-constructed, findings are created and involve the researcher as participant, methodology is hermeneutical (interpretative), quality means authenticity/internal coherency, ethics are process driven (goodness is in the authenticity of the construction itself), and the inquirer's voice is "as facilitator of [a] multi-voice reconstruction" (p. 196).

Constructivism is conducive to neo-pragmatism because it does not assume that there is an object called knowledge that can be found, or a real world that can be discovered, anymore than it thinks that the world is flat is a useful metaphor for modern day sailors. According to Guba \& Lincoln (2005), "constructivists... tend toward the anti-foundational" (p. 204), they have little use for epistemology in the sense that knowledge has a certain structure that must be protected, maintained, and reproduced. Rather, constructivists take it upon themselves to create abnormal discourses, build edifices, and draw new 
vocabularies into existing conversations. Identifying this paradigm in qualitative research supports the legitimacy of the methodology set out above.

\subsection{Research methods.}

The primary methods for data collection and interpretation used in this thesis are ecological hermeneutics, a Rortyan approach to ideal type theory and focus groups. This section introduces those methods and their uses.

\subsubsection{Using Gadamer and ecological hermeneutics.}

Ecological hermeneutics is a method developed in this thesis through the integration of Gadamer's (1975) hermeneutic fusion, the hermeneutic circle and insights from Bronfenbrenner's (1979) ecological theory. This section identifies how these are applied as a method of data collection and analysis.

Gadamer (1975) did not intend his approach to philosophical hermeneutics to be a method for understanding, he thought he had found the universal means by which all humans arrive at understanding. However, this thesis converts Gadamer's insights into a method of inquiry. It does so by switching his approach from a passive theory (one which describes understanding) to an active theory (one which enables the construction of new understandings). The 
distinction here is between an approach that seeks to explain understanding and one that uses that explanation to construct new knowledge. The elements of Gadamer's hermeneutic fusion are then transformed into elements that can be manipulated and rearranged to produce innovative understandings within research contexts. This approach is aligned to the Rortyan attempt to make the familiar appear strange.

In this thesis, the horizon of the text includes philosophical writing, theoretical perspectives, policy documents, curriculum artefacts and transcribed responses from focus group meetings. The horizon of foreunderstanding has been identified in chapter two in the section on reconceptualisation, and throughout chapter three in terms of the philosophical assumptions that underpin this thesis. In terms of method, those particular parts of this thesis are important because they set out how and why the fusion of horizon occurs, as well as what counts as successful fusion (i.e., a coherent and innovative reconceptualisation of IECTE programmes). In chapter 2, the application of this thesis was introduced as resistance to injustice and the hope for social justice.

This thesis integrates Bronfenbrenner's (1979) ecological theory with the hermeneutic circle to construct a method of organising data in chapters six, seven and eight. Bronfenbrenner used the Russian doll as a metaphor for the nesting of contexts within which individuals and groups of individuals are 
situated. This metaphor was used to show the different layers of contexts within which everyday human development occurs. Bronfenbrenner described these layers as systems and named them micro-, meso-, exo-, macro-, and chrono-. The content of these systems is not important to the method of ecological hermeneutics, but the metaphor of nested contexts is. In chapters six to eight, the interpretation of texts pertaining to the content and context of IECTE programmes is organised ecologically. Analysis moves from the general socio-historical context, to policy external to the university, to internal university policy and finally to findings from the focus groups. Movement from the general to the specific is therefore organised ecologically.

\subsubsection{Ideal type method.}

As noted above, this thesis uses a variation of Weber's (1949) ideal type method as a theoretical tool for showing socioculturalism in the content of an IECTE programme and individualisation in the context of that programme. This is an important tool because it supplies a means for justifying the thesis of structural dissonance. The logic of part three of this thesis is as follows: 1. Define socioculturalism - show socioculturalism in the content of IECTE programmes.

2. Define individualisation - show how individualisation is reproduced in the context of IECTE programmes. 3. Show how socioculturalism and individualisation are dissonant - show how content and context of IECTE programmes are structurally dissonant. Ideal type theory offers the means by 
which socioculturalism and individualisation can be defined as well as the method by which their presence in content and context is justified.

The theory of ideal types is part of the sociological method developed by German sociologist Max Weber (1864-1920). Weber constructed ideal type method in his essay entitled 'Objectivity in Social Science and Social Policy' (first published in English in Shils \& Finch's (1949) Max Weber - On the Methodology of the Social Sciences). In this essay, Weber coined the term ideal type to describe "an ideal picture of events" (Weber, as cited in Rogers, 1969, p. 17) that is "arrived at by the analytical accentuation of certain elements of reality" (Weber, as cited in Rogers, 1969, p. 17). What this means is that the ideal type "is not a description of reality but it aims to give unambiguous means of expression to such a description" (Weber, as cited in Rogers, 1969, p. 17). Weber's ideal type is a tool (or construction) that can be used to analyse complex social phenomena. Analysis is achieved by asking the question: how closely does a context match the ideal type?

According to Weber (as cited in Rogers, 1969, p 17), the ideal type is "formed by the one-sided accentuation of one or more points of view and by the synthesis of a great many diffuse, discrete, more or less present and occasionally absent concrete individual phenomena, which are arranged according to those onesidedly emphasised viewpoints into a unified analytical construct." On this 
account, ideal types are created (rather than found or discovered), by bringing a number of nameable elements together into an intensified, idealised depiction. Weber (as cited in Rogers, 1969, p. 17) went on to say "in its conceptual purity, this mental construct cannot be found empirically anywhere in reality. It is a utopia." By utopia, Weber meant a place that does not exist - the ideal type is not an empirical, or even a grounded (theory-style) construction, but rather, it is a theoretical construction - the construction of an idealised idea.

The ideal type method applies the simple description (ideal type) to a complex situation (e.g., institutional structure). The simple description is Weber's (1949) one-sided accentuation and the complex situation is, in this case as in Weber's, a particular social process (e.g., IECTE programmes). Ideal type analysis works by comparing the simple description to the complex situation, asking, in Weber's (1969) words, what is "the extent to which this ideal-construct approximates to or diverges from reality?" This thesis uses that method to construct ideal types for socioculturalism and individualisation and asks Weber's question.

\subsubsection{Using ideal types in this thesis.}

Following Rorty $(1979,1989,1999)$, this thesis has a deep suspicion of Weber's belief that objectivity is attainable, his assumption that the true form of social processes/conditions can be found, and his assertion that reality exists as an 
essence to be discovered. This thesis uses Weber's method as a way of interpreting the content and context of IECTE programmes. This renovation is achieved by rejecting the distinction between interpretation and understanding, as well as the will to accurately represent reality. Thus, where Weber wanted to use his method to show real qualities of social institutions and their processes, this thesis uses his method to show how IECTE programmes can be interpreted using the vocabulary and concepts used to construct the ideal types.

The ideal types used in this thesis are constructed from key texts associated with each category, namely: Out of the primary texts of socio-cultural writers such as Vygotsky (1986), Rogoff (1990, 2000), Lave and Wenger (1991), and Wertsch (1998); and out of the primary texts of individualisation theory i.e. Beck (1992), Beck \& Beck-Gernsheim (2002), and Bauman (2001). The perspectives (in the form of language) of these authors are integrated to construct ideal types that contain key words that act as abbreviations for broader theoretical concepts. The method of analysis used in this thesis is interpretive insofar as the ideal type is used to justify claims of socioculturalism in the content and individualisation in the context of IECTE programmes. For the purposes of analysis the ideal types are organised using the following grid (fig. 1). The empty boxes in this grid will be filled by interpreting sociocultural theories (chapter 5) and individualisation theory (chapter 7). 


\begin{tabular}{|l|l|l|}
\hline & Socioculturalism & Individualisation \\
\hline View of people & & \\
\hline Ideal social structure & & \\
\hline Social agency & & \\
\hline $\begin{array}{l}\text { Participatory } \\
\text { framework }\end{array}$ & & \\
\hline
\end{tabular}

Fig 1. Grid of ideal types.

\subsubsection{Focus groups.}

As noted earlier (see 1.0) this is a theoretical thesis. However, focus groups are used to provide empirical support the thesis of structural dissonance in IECTE programmes in Aotearoa/New Zealand. Focus groups were used to counter the possible assertion that even though there is theoretical and textual evidence that structural dissonance exists, there is no empirical evidence to support this. This thesis used focus groups made up of year two and three student teachers in an IECTE programme with one university.

The focus group method was chosen because focus groups are particularly useful in generating "large quantities of material from relatively large numbers of people in a relatively short time" (Kamberelis \& Dimitriadis, 2005, p. 903). Focus groups were used as a point of contact with student teachers' experiences gaining access to group meanings and shared experiences (Bloor, Frankland, Thomas \& Robson, 2001, p. 4). Focus groups are often used for gaining initial insight into a topic, and are often followed by depth interviews of individual members (Bloor, Frankland, Thomas \& Robson, 2001). This thesis used focus 
groups to collect the responses and conversations of second and third year university students enrolled in an IECTE programme, but did not follow this up with in-depth interviews. The data generated from the focus groups was sufficient for the purposes of this thesis, namely, to analyse the language generated in student conversations using the ideal types for evidence of discourses associated with socioculturalism and individualisation.

Duncan \& Marotz-Baden (1999) observed that focus groups are useful for identifying how multiple perspectives fit together into a combined local perspective. Focus groups are often used in educational research to gauge group reactions to educational programmes (e.g., Nordstrom, Wilson, Kelsey, Maretzki \& Pitts, 2000), and this thesis has adopted a similar approach. According to Krueger \& Casey (2000) the goal of focus group research is to include between 10-15 respondents in order to get elicit a good number of responses. The focus groups at the case study university numbered between 6 (for the smallest group) and 11 (for the largest group). This number of respondents worked well because it gave everyone a chance to speak and allowed for conversations to emerge beyond the scope of the initial question. It also allowed for easy return to the research agenda (questions) when conversation strayed from the topic of students' experiences of their IECTE programme. 
Using the focus group method for the empirical component of this study fits well with the linguistic turn taken in other parts of this thesis because the data type generated by focus groups is language (Creswell, 1998). Responses from each of the four focus groups were recorded and then transcribed by the researcher to form a text which could then be analysed. The transcriptions were coded based on the ideal type grid set out above and particular quotations were used in chapters 6 to 8 of this thesis as justifications for the proposition of structural dissonance in IECTE programmes.

\subsubsection{Focus group method.}

The focus group method was applied as follows: In the first instance ethical approval was sought for conducting focus groups at an IECTE degree providing institution and was approved by the Faculty of Education Ethics Committee on 26/02/2007 (see Appendix A). Considerations of confidentiality, anonymity, informed consent, voluntary participation and deception were all met. Information sheets and informed consent sheets were constructed to meet the guidelines for research that involves human subjects.

Participants were recruited through posters pinned up around key student areas (lockers, café, early childhood education notice board) inviting second and third year early childhood student teachers to participate in focus groups to discuss their experience of their teacher education programme. The day before 
the focus groups were to commence, students were given a personal invitation to participate in the research in three lectures containing second and third year initial early childhood student teachers. Students were also given the opportunity to have any questions they may have answered over the lunch break and throughout the morning of the first focus group.

Two focus groups an afternoon over two afternoons (total=4) were offered and accepted by student participants. The total number of participants over the four focus groups was 32. Those focus groups took place in a room set aside on the campus of the case study university. The researcher waited outside the room at the appointed times to welcome participants and guide them to the focus group area.

Focus groups began five minutes after the advertised time to allow for participants who might have been running late, and so as not to disturb the flow of the group. No participants arrived after the advertised time. Participants were verbally thanked for volunteering their time and handed an information sheet which identified the project and ethical considerations (e.g., privacy, the right to terminate participation, confidentiality and anonymity: see Appendix B). The researcher read through the sheet and answered any questions. No participants had questions, but they were all told that if questions did arise they could contact either myself or my supervisors on the numbers at 
the bottom of the information sheet. Participants were then walked through the consent form and invited to sign at the bottom if they agreed to the clauses. All participants signed the form.

Participants were then given a sheet of six questions to look at and told that these would be the questions we would be discussing in the focus group. Participants were also informed that supplementary questions may be used to extend or clarify conversation on a particular topic. Participants were invited to note down some initial responses before the focus groups began. Those notes were useful as conversation starters and ensured that participants were given time to reflect on their experiences before commenting. Those questions were:

1. How would you describe your experience of teacher education so far?

2. What do you enjoy the most about your experience as a student teacher?

3. How does this make you feel?

4. What do you enjoy least about your experience as a student teacher?

5. How does this make you feel?

6. How do you think that your educational experience could be improved?

In each of the focus groups conversation tended to move away from the topic and several supplementary questions were asked in order to re-focus discussion. I have accounted for this in my reporting of statements generated in 
focus group discussions by highlighting the general question or the supplementary question to which the statements were addressed.

A recording device was placed in the centre of the table and each question was put to the group in sequence allowing as much time as participants required to answer to each one. The ensuing conversation was recorded, transcribed and then analysed using the ideal types for socioculturalism and individualisation theory. The focus group method proved difficult to transcribe in places with participants often talking over one another resulting in some of the data being lost to noise. There was also a tendency across the groups for one or two participants to take over the conversation leaving little space for more quiet members of the group to voice their opinions. In hindsight I think that using an interview method with single participants would help to account for these difficulties.

Once transcription was complete, sentences in the transcripts were coded using coloured highlighters into either sociocultural statements, individualisation statements, statements of dissonance, or neutral statements based on the themes conveyed by the speakers. Statements that related to each of the ideal types were then organised into groups according to the aspects of each ideal type to which they aligned. Those statements were then used in chapters six, seven and 
eight to provide empirical evidence to advance the argument of structural dissonance.

\subsubsection{Discussion of focus group method.}

Using the focus group method in this thesis raises a methodological issue in relation to the tension between philosophical assumptions and hermeneutic methodology on the one hand, and the empirical project of accurate representation on the other.

The philosophical assumptions used in this thesis make little sense of the claim that there can be more or less accurate representations of reality. This perspective challenges the data generated by the focus groups in terms of the participants own ability to represent the reality of their experience, and in terms of whether or not the sentences uttered by participants bare any wider (generalisable) significance in relation to IECTE programmes in Aotearoa/New Zealand. The philosophical assumptions used in this thesis make both concerns obsolete by proposing that both concerns presuppose a vocabulary that I have argued, echoing Rorty $(1979,1989,1999)$, that we can well do without. From this perspective, the value of the sentences generated in the focus groups does not exist in their ability to represent the reality of the situation, or to provide insight into a general(isable) dilemma, but rather, it exists in their ability to provide 
examples of particular themes (namely, socio-culturalism, individualisation, and structural dissonance).

Methodologically, once the words left the lips of the participants they opened themselves to new associations and new interpretations (Gadamer, 1975). From this perspective, there is no question over the author's original intentions because that is the very question that Gadamer (1975) was at pains to avoid. This thesis has adopted that approach. A consequence of using this methodology is that the participants' motivation for joining the focus groups does not come under scrutiny, meaning that whilst it is possible that only those students with an axe to grind participated, that is not a concern for the interpretation of focus group data. Interpretation instead hinges on thematic analysis (namely, associating the sentences with the ideal types for socioculturalism, individualisation, and the theme of structural dissonance). A second methodological consequence is that the sentences collected in the focus group sessions are assumed open to reinterpretation based on fusion with the reconceptualist preunderstandings used herein, and an application to ideal type analysis in general, and the argument of structural dissonance in particular. This treatment of the focus group data challenges epistemological understandings of the focus group method by presenting an antiepistemological alternative to data interpretation and its uses. 
In terms of the difference that philosophical assumption and methodology make to my use of the focus group method, the net result circulates around how sentences are used to premise arguments of socio-culturalism, individualisation, and structural dissonance. By avoiding the need to accurately represent reality, and by opening the sentences generated in the focus groups to reinterpretation, this thesis side steps the positivist assumption that something real has been found, and replaces it with the pragmatic assumption that the generated can have uses beyond those perceived by the original speakers. In this thesis the data generated in the focus groups are useful not as empirical truths, but as sentences derived from alternative sources (i.e., the mouths of student teachers), and as such, provide another means of philosophical justification.

\section{Summary}

This chapter has set out the research methodology and methods used in this thesis. Links to philosophical assumptions were identified and the particular uses of research methods have been described. The methodology and methods set out in this chapter will be used in the next part of this thesis to justify the proposition that IECTE programmes in Aotearoa/New Zealand are structurally dissonant. 


\title{
Part Three
}

\section{Structural dissonance in}

\author{
IECTE programmes in
}

Aotearoa/New Zealand. 


\section{Chapter 5}

\section{Socioculturalism: An Ideal Type}

This chapter constructs an ideal type for socioculturalism, as a first step in investigating socioculturalism in the content of an IECTE programme. This chapter is divided into two parts. The first part identifies definitions and theories of socioculturalism from primary texts within this tradition. The second part draws on those definitions and theories to construct an ideal type. Much like MacNaughton (2005) in her use of Foucault, this thesis apologises to socioculturalists for not providing an exhaustive overview of socioculturalism and sociocultural theories. Like MacNaughton (2005), I believe that others (such as Wertsch, 1991 and John-Steiner and Mann, 1996) have made a much better job of this. This present chapter constructs an ideal type for socioculturalism by integrating general and specific conceptualisations of socioculturalism with the parameters set out on the ideal type grid (see Fig. 1).

\subsection{Socioculturalism: Definitions and theories}

This chapter is based on the methodological consideration that the texts consulted for hermeneutic construction should be considered complete, authoritative and important to the context to which they belong (Gadamer, 
1975). This section begins with some general definitions of socioculturalism before turning to the primary texts of key sociocultural theorists in order to construct a database of vocabulary and concepts that will be used to construct an ideal type in the next section.

\subsubsection{Socioculturalism: General perspectives}

In a general sense, sociocultural theories of development assume that participation and participants are socially engaged, socially interactive and socially constructed. This means that the social and cultural world in which we find ourselves lends us the words by which we define ourselves. Gadamer (1975) called these words our pre-judgement, Heidegger (1962) our foreunderstandings. Generally speaking, socioculturalists assume that human development occurs through social and cultural interaction, specifically the formation of relationships (e.g., Bruner, 1975; Chaiklin \& Lave, 1993; Cole, 1985; Tharp \& Gillmore, 1988). This group of theorists understand learning to be dependent on social contexts (e.g., Altman \& Rogoff, 1987; Kublin, Wetherby, Crais \& Prizant, 1989, p. 287; Nuttall \& Edwards, 2007). Other writers pick up on the claim that human experience is developed and mediated by socially constructed tools, signs and actions (e.g., Rogoff, 1992; Smith, 2003; Wertsch, 1991), and use this as a means for social justice.

From some perspectives, socioculturalism is a movement that resists the 
dominant discourse of developmentalism exemplified by Bredekamp's (1989) notions of developmentally appropriate practice (e.g., Fleers, 1995).

Socioculturalism, on this account, uses sociocultural theory as a means of resistance in the hope that something more can be made of human interactions (i.e., learning, facilitation, social peace). Socioculturalism in education acts as a set of discourses that make the social and cultural components of experience and learning primary pedagogical concerns (e.g., Lave \& Wenger, 1991; Nuttall, 1997; Rogoff, 1990, 2003 and Wertsch, 1998), rather than focusing on intrinsic and individual psychological development (e.g., Piaget, 1926). Socioculturalism is therefore a way of describing and explaining behaviour that has been used to oppose individualised accounts of human development (Fleer, 1995).

Lave (1991) defined socio-cultural theory as the theoretical claim that "learning, thinking and knowing are relations among people in activity in, with, and arising from the socially and culturally constructed world" (p. 67). Minick, Stone and Forman (1993, p. 6) sketched out a vision of socioculturalism that highlighted the cultural impact of social institutions, language development as a social and institutional practice, interpersonal relationships within shared contexts, and the social nature of both belief and cognition. Other writers like Wood, Bruner and Ross (1976) operationalised socioculturalism to develop pedagogies that express the importance of society and culture in teaching and learning (e.g., scaffolding). 
Writers like Leont'ev (1981) and Saxe (1991) argued that all problem solving is a sociocultural event in which institutional, cultural, social and situational forces not only impact perception of problems, but also place limitations on the available possibilities for solution. This perspective is similar to the problemsolving approach to early years education advocated by Dewey $(1900,1902)$. Other socio-cultural writers, such as Eckhoff and Urback (2008), have linked socioculturalism to childhood imagination by proposing that experience, imagination and emotion actively expand learning. Others again, like Siu and Lam (2005), have applied sociocultural ideas to technology education in the early years and have observed that the background of parents and children, social expectation and society's perception of technology and its uses, are all important factors in ascertaining the potentials of educational experiences.

These authors are similar on two counts. The first is that they understand that context directly influences the course of development. The second is that each of these authors have a common point of theoretical reference, namely, the writing of Lev Vygotsky (1896-1934). These authors, however, are not alone in identifying Vygotsky as the origin of sociocultural theory, others include Damon (1984), Kozulin (2001), Lantolf (2000), Moll (1990), Slavin (1983, 1987), and Tudge and Rogoff (1989). The next section on key theorists begins with Vygotsky $(1978,1986)$ for this very reason, drawing on aspects of his theoretical perspective before drawing on other influential theorists who have offered 
alternative interpretations of socioculturalism.

\subsubsection{Sociocultural theory.}

Vygotsky was the Russian Marxist philosopher and psychologist who, along with his colleagues in the 1920's and 1930's, first systematised sociocultural theory (John-Steiner \& Mann, 1996). Much of his work was not translated into English until the late 1970's, but since that time it has taken the interest of social theorists, psychologists, and in particular, educationalists (John-Steiner \& Mann, 1996). In particular, Wertsch (1991) highlighted three major themes that reoccur throughout Vygotsky's writing: That mental functions originate from social sources; that human action is mediated by social tools and shared language; and that developmental analysis is the best method for highlighting social and cultural influences.

According to Vygotsky (1978), “every function in the child's cultural development appears twice: first, on the social level, and later, on the individual level" (p. 57). Vygotsky (1978) called the mechanism for this process: internalisation. He believed that children (and humans in general) are socially and historically situated beings. For Vygotsky (1978, p. 56), this approach meant that learning, even from the earliest experiences, is not purely object-directed, but rather, it is directed by the reactions of others and interactions with others in the person's social context. Along these lines, Vygotsky (1978) thought that 
"the internalisation of socially rooted and historically developed activities is the distinguishing feature of human psychology" (p. 57). Human development and learning, on this account, is determined by the social and cultural context in which a person is situated.

By taking this particular line, Vygotsky (1978) avoided separating human development and learning. He perceived the human condition as an active, open ended, dialectically driven social and historical phenomenon where learning and development are folded into one another. Vygotsky's (1978) sociohistorical method includes the principle that "to study something historically means to study it in the process of change" (p. 65). With this insight, Vygotsky (1938/1978) challenged theories that proposed that development leads learning (e.g., Piaget) and confirmed Dewey's (1938) idea that learning is a matter of using social tools (e.g. signs and symbols) and their use. The upshot of Vygotsky's approach to human development was that it navigated a path between universalism and individualism by using history to carve off the hubris of the former, and society to do away with the isolation of the latter. It is this turn toward the social as a way to explain questions of learning and development that is emblematic of Vygotsky's (1978) version of psychology (Wertsch, 1995).

Central to Vygotsky's (1978) innovation in psychological thought is the notion 
of the zone of proximal development. For Vygotsky $(1978$, p. 86) the zone of proximal development (ZPD) is the difference between a person's independent problem solving skills and the possible level that could be reached with the help of others. Through the notion of ZPD, Vygotsky (1978) proposed that "what children can do with the assistance of others might be in some sense even more indicative of their mental development than what they can do alone" (p. 85). Along these lines, Vygotsky (1978, p. 88) emphasised the role of imitation in learning, by proposing that human development is enhanced when people work together for common goals. This position is similar to Dewey's (1938) idea that learning is made meaningful through cooperation with others.

According to Vygotsky (1978), “human learning presupposes a specific social nature and a process by which children grow into the intellectual life of those around them" (p. 88). From a Vygotskyan perspective, therefore, learning is a socially embedded process brought about "when the child is interacting with people in his environment and in cooperation with his peers"' (Vygotsky, 1978, p. 90). Further to this point, Vygotsky (1986) wrote about a "unique form of cooperation between the child and the adult that is the central element of the educational process" (p. 169). Clearly then, it was Vygotsky's assertion that humans are social beings whose perception of the world and its contents is synonymous with being in a world of culturally mediated perceptions, languages and contents. 
Vygotsky and Luria (1930, p. 4) claimed that sociocultural development is the "cultural growth of behaviour. It is based on the mastery of devices and means of cultural behaviour and thinking." Socioculturalism is, therefore, a framework that describes not only the situations that humans find themselves in, but also the activities that humans engage in within those situations. Vygotsky (1981) believed that human development occurs from the outside in and that "humans master themselves from the outside" (p. 141). Society and culture, on this view, profoundly influence human development and learning.

Authors like Leont'ev (1981), Luria (1976), Rogoff (1990) and Wertsch (1984, 1985) claim that Vygotsky is the proto-socioculturalist. However, the real influence of Vygotsky's writing was not simply in the discourses that he personally produced, but also in the discourses that his work inspired, for example, Bakhtin (1981), Leont'ev (1981), and Zinchenko (1985). This thesis picks up the work of four Western writers who have been influential in further developing Vygotsky's socio-historical perspective and in further expanding the vocabulary on socioculturalism identified in Vygotsky's perspective. Those writers are Jean Lave and Etienne Wenger, Barbara Rogoff and James Wertsch. These authors have been chosen because they offer related but significantly different perspectives on socioculturalism. Taking this broader view of socioculturalism allows the integration of a group of perspectives under the banner of socioculturalism offering a richer set of resources than if only one 
author (e.g., Vygotsky) was used. The remainder of this section will overview the perspectives set out by these authors as a data set from which socioculturalism as an ideal type will be constructed.

In their book Situated Learning: Legitimate peripheral participation Lave and Wenger (1991) drew on Vygotsky's idea that learning is socially and historically constructed to formulate a perspective on learning that draws together community and participation. Their vision of learning as a situated activity runs as follows:

Learning viewed as situated activity has as its central defining characteristic a process that we call legitimate peripheral participation. By this we mean to draw attention to the point that learners inevitably participate in communities of practitioners and that the mastery of knowledge and skill requires new comers to move toward full participation in the socio-cultural practices of a community (p. 29).

Lave and Wenger (1991) rescued the notion of apprenticeship from a relational conception of master and student tied into an object-based notion of mastery, and to broaden its meaning to include all of culture, history and the construction of social spaces. To this end, these authors developed a sociocultural theory of learning that embraced both generality (in the notion that all 
learning is situated) and specificity (in the understanding that the situations in which learning occurs are diverse and possibly endlessly varied). To achieve this, Lave and Wenger (1991) developed the notion of legitimate peripheral participation which they defined as a "constitutive element" (p. 35) of learning in general. Lave and Wenger (1991) described peripheral participation in the following terms:

Peripherality suggests that there are multiple, varied, more- or less-engaged and -inclusive ways of being located in the fields of participation defined by a community. Peripheral participation is about being located in the social world. Changing locations and perspectives are part of actors' learning trajectories, developing identities, and forms of membership (pp. 35, 36).

For Lave and Wenger (1991), legitimacy is a facet of a particular social interface that either empowers participants as they move into fuller forms of participation in a given community, or disempowers participants, where a community works to keep participants from full entry until the time is deemed (usually by the community) to be right. Lave and Wenger (1991) draw upon a Marxist tradition of viewing development as social practice to propose that their notion of legitimate peripheral participation is less a grand theory aimed at an accurate representation of reality, but is rather, an analytic tool for exploring interconnections "through time and across cultures" (p. 39). 
Socioculturalism, for Lave and Wenger (1991) highlights the situatedness of human activity, the movement from peripheral to full participation in those situations, and the relationship between settings and persons, contexts and human action.

Lave and Wenger's (1991) theory is important to include because it sets out a sociocultural project that integrates the social world with the transformation of individual participants within particular social and cultural contexts. To this end, they place "emphasis on connecting issues of sociocultural transformation with the changing relations between new comers and old-timers in the context of a changing shared practice" (Lave \& Wenger, 1991, p. 49). For Lave and Wenger (1991), identity, practice and knowing are inherently social practices. From this perspective, when attempting to understand people, practices and/or learning, it is necessary to understand also the social, cultural and historical contexts to which people, communities and social institutions belong. The particular insight that Lave \& Wenger (1991) offer this thesis, in terms of understanding socioculturalism, is that not only are people embedded within society, but they are part and parcel of what their setting entails.

Lave and Wenger (1991) also introduce the notion of communities of practice. A community of practice is a "set of relations among persons, activity, and world, over time and in relation with other tangential and overlapping communities of 
practice" (Lave \& Wenger, 1991, p. 98). For example, if we were to refer to IECTE as a community of practice, we would be referring to those persons involved in the endevour of early childhood teacher education (students, teachers, administration, policy makers), those involved in the pedagogical experience (students, lecturers, tutors, course coordinators, administrators, policy makers) and those whose work in other disciplines (e.g. economics, social development, teachers council, early childhood settings, professional bodies) intersects that community. This means that sociocultural communities are not necessarily bound by space but rather by common concern or common history.

The point of Lave and Wenger's (1991) sociocultural theory is not that we merely learn in relation with others, but that we humans transform, reproduce and change ourselves within a wider context of social and historical relationships. For Lave and Wenger (1991), learning is a situated activity wherein participants move from peripheral toward full and active participation within a given community of practice, which is itself related to broader communities of practice within the wider social world. In my view, Lave and Wenger (1991) offer a tool for sociocultural analysis; one that can be used to investigate social practices in terms of legitimate participation (i.e., who can and who can not move from the periphery to the centre of a community of practice), and in social settings in terms of how communities of practice use rules to 
include and exclude persons from participation.

Wenger (1999) went on to develop the idea of communities of practice into a sociocultural theory of learning in his book Communities of Practice: Learning, meaning and identity. The theme of this book is that communities construct themselves through shared practices and reifications (documents, texts, policies etc), and that communities are established through mutual engagement (doing things together), joint enterprise (negotiating activity/meaning), and a shared repertoire (communal artefacts/reifications) (Wenger, 1999, p. 73). In Wenger's (1999) view, communities of practice not only influence how we come together in common practice, but also how we form an identity in relation to that practice, the shared meanings through which that practice is invoked, and even the practices by which new meanings are integrated into the given communities.

A third author, Barbara Rogoff offered another take on sociocultural theory that also builds on Vygotsky's socio-historical theory. This thesis uses two of Rogoff's books in particular to contribute to a database of vocabulary from which an ideal type for socioculturalism can be constructed. The first book is Apprenticeship in Thinking: Cognitive development in social context published in 1990. The second book is The Cultural Nature of Human Development published in 2003. 
In Apprenticeship in Thinking Rogoff (1990) set out a "framework for conceptualising the development of mind in socio-cultural context" (p. 7). Rogoff's (1990) approach used Vygotsky's work to emphasise understandings of the social nature of development using apprenticeship as a metaphor for learning relationships. The central theme of this book is Rogoff's (1990) idea that guided participation is a key concept for the collaboration and sharing that underpins human development (but with a particular emphasis on child development). This approach is closely related to Vygotsky's zone of proximal development insofar as development depends on social connection. On this point Rogoff (1990) wrote: “Children use social resources for guidance - both support and challenge - in assuming increasingly skilled roles in the activities of their community" (p. 8). The idea of development as a form of social participation is echoed by Lave and Wenger (1991) when they linked development within social contexts with movement from peripheral to full practice.

Rogoff's (1990) use of apprenticeship as a metaphor framed children's cognitive development as a relationship between novice and skilled partners, a notion that echoed Bruner's (1961) idea of cognitive apprenticeships. However, she expanded this insight with the declaration that: "it is essential to view the cognitive activities of individuals within the cultural context in which their thinking is embedded" (Rogoff, 1990, p. 42), and not simply as an interaction 
between two isolated individuals. This notion of embeddedness is important to the sociocultural perspectives constructed by both Rogoff (1990) and Lave and Wenger (1991). For Rogoff (1990), the cultural context extends beyond the institutions in which children learn (e.g., early childhood settings, schools) to include broader social and historical practices which influence the development of a person (e.g. language, economics, human rights). In Rogoff's (1990) view, both novice and skilled partners (e.g., parents, teachers, older or more experienced participants) are embedded within contexts that extend beyond the formal face-to-face interaction.

According to Rogoff (1990), guided participation is encouraged in communities and settings through the development of intersubjectivity. Intersubjectivity entails the mutual understanding that is developed between people over time. Intersubjectivity emphasises "that understanding happens between people; it cannot be attributed to one person or the other in communication" (Rogoff, 1990, p. 67). Communication is the bridge that Rogoff (1990) used to connect novice and skilled participants by linking "familiar skills or information and those needed to solve new problems" (p. 66). Rogoff's (1990, p. 100) point was that children, embedded within cultural historical contexts, through a process of collaboration increasingly take on more responsibilities for managing situations as they become familiar with particular tasks. Rogoff (1990) suggested that the phenomenon of guided participation is a world-wide 
phenomenon, which embraces diverse contents, contexts and outcomes. Unlike Lave and Wenger (1991) she did not propose guided participation as an analytic tool (as in Wenger, 1999), but rather, she aimed to draw attention to contextual influences as powerful conditions for teaching and learning from a sociocultural perspective.

Rogoff (1990) linked cognition with social interaction. She echoed Vygotsky in proposing that "the collaborative process seems to lead to a level of understanding unavailable in solitary endeavour or non-collaborative interaction" (Rogoff, 1990, p. 178). Rogoff's (1990) socio-cultural theory embedded individuals in broader social and cultural contexts. Development, from this perspective, is a process of mutual engagement in culturally significant practices whereby learning is a function of becoming ever more proficient in socially and historically mediated skill sets (i.e., those skills which are important to the context in which the learner is embedded). The outcome of Rogoff's (1990) view is that the space between participants and their context/s diminishes to the point that it disappears altogether, for learning is an interdependent affair that links persons and contexts into a single but richly diverse whole.

In The Cultural Nature of Human Development Rogoff (2003) maintained her sociocultural view that "people develop as participants in cultural 
communities" (p. 3), and that "children everywhere learn skills in the context of their use and with the aid of those around them" (p. 69). However, she added the assertion that "in the emerging socio-cultural perspective, culture is not an entity that influences individuals. Instead, people contribute to the creation of cultural processes and cultural processes contribute to the creation of people" (Rogoff, 2003, p. 51). On this account, participants and contexts co-specify one another. The novice in this case also takes on the role of skilled participant in the sense that the personal history of the novice (in a partial way) co-determines the character of the cultural context itself. Rogoff (2003) summed up this sentiment in the following fashion: "humans develop through their changing participation in the socio-cultural activities of their communities, which also change" (p. 11). From this sociocultural perspective, development occurs through the creation of relationships both human and environmental.

Rogoff (2003) moved beyond Vygotsky's socio-historical approach to develop an appreciation of the forward/future facing aspect of communities that are in the process of becoming other: that are involved in an ongoing process of change. Another way to say this is that: Participants and contexts co-determine one another in ways that transform not only relationships between persons, but also relationships between people and their environments, and their personal and communal histories. The idea that humans develop in cultural contexts that change with time and place opens the possibility for a forward facing 
dimension of history (Bloch, 1986). This forward aspect contains relationships between persons and settings that have not-yet-been-achieved, modes of participation that are not-yet-conscious, and social and cultural settings that are yet to be constructed.

Rogoff (2003) noted that "cognitive development is an aspect of the transformation of people's participation in socio-cultural activities" (p. 237). But it is also plausible that she is also making the point that participants themselves transform activities, contexts and cultures as they interact, make choices, and develop together in unprecedented directions and in ways that may also break completely with the social and cultural spaces to which their histories belong. Socioculturalism is therefore not only bound to the past and the present, but also contains an element of what has not-yet-become (Bloch, 1986). For this reason, socio-cultural theory, as a theory of unfinished activity opens onto the vista of hope. This theme will be further developed in chapter ten. Suffice it to say that from Rogoff's (2003) perspective, sociocultural theory is as much to do with transformation as it is to do with interpreting or describing society.

In 1998, James Wertsch published Mind as Action (though he had written several books on sociocultural theory prior to this, e.g., Wertsch, 1984, 1985, 1991. In this book, he set out a sociocultural research agenda focusing on agents and their use of cultural tools. Wertsch (1998) claimed that "the task of a 
sociocultural approach is to explicate the relationships between human action, on the one hand, and the cultural, institutional, and historical contexts in which the action occurs, on the other" (p. 24). This claim builds on an assumption, which is common to Dewey, Vygotsky, Lave and Wenger and Rogoff: That human development can not be effectively understood in terms of the individual alone, but instead, it must be viewed in terms of the activities of human agents within their cultural context. That said, Wertsch (1998) advocated a view that, "one of the tasks of sociocultural analysis... is to find a way to avoid the pitfalls of ... individualistic reductionism" (p. 21). Holding that view encouraged Wertsch (1998) to not only argue against the pitfalls of viewing individuals in isolation, but also to position sociocultural theory in the space where individual and society interface, and to argue for an understanding of sociocultural theory that has its basis in human action (p. 23).

By human action, Wertsch (1998) meant mediated action. Mediated action occurs as agents within socio-cultural contexts use cultural tools (e.g., artefacts, language, ritual) for diverse purposes. According to Wertsch (1998), "almost all human action is mediated action" (p. 25). This assertion opens another vista in sociocultural analysis by focusing analysis on agents and their use of culturally mediated tools rather than on interactions between agents and the settings in which they are situated. Wertsch (1998) viewed his project as a continuation of the perspective put forward by Vygotsky (1986), insofar as participants within a 
culture use the tools of that culture, e.g., language, social structures, objects. Wertsch's (1998) emphasis on utility and activity aligns him well will pragmatic philosophers such as Dewey and James.

In terms of the transformational qualities of mediated action, Wertsch (1998) explained that "the introduction of novel cultural tools transforms the action" (p. 42). Wertsch (1998) gives the example of the switch from bamboo poles to aluminium poles in Olympic pole vaulting and the influence this had on pole vaulting practice. However, we might just as easily use examples such as the implementation of Te Whâriki in 1996, or introducing a new toy to a preschool sandpit. In each example, the introduction of the tool makes new action possible; the tool itself, complete with its culturally appropriate uses, becomes the catalyst for change within each setting. By itself, it is only a potential, but in human hands that potential is realised. The point Wertsch (1998) makes is similar to Rogoff's (2003) notion of co-determination, wherein development is viewed as an interaction between learners, their communities and the cultural tools used in diverse contexts. In both cases, transformation is not only possible, but a necessary aspect of activity in sociocultural domains, and in both cases development is situationally embedded but at the same time potentially culturally transformative.

According to Wertsch (1998), cultural tools do not operate as value independent 
artefacts: Issues of power (who created them and why) and authority (who sanctions particular uses) permeate their production and consumption within diverse sociocultural contexts. For example, the New Zealand early childhood curriculum is a tool used by early childhood teachers for a number of purposes within early childhood settings (e.g., planning, assessing, informing practice). This document is not a neutral tool, but was constructed out of a series of assertions that have been privileged over possible alternatives (e.g., developmental theories over post-structural considerations of power and knowledge: MacNaughton, 2005), it has power over practice insofar as its use is audited by the Education Review Office, and it also provides a degree of authority that teachers can use to justify their practice to parents, to the Teachers Council, and to each other. Wertsch (1998) makes the point that "by invoking the appropriate cultural tools [within a given sociocultural setting] it is possible for one's actions to take on a kind of power and authority" (p. 72, brackets added). In this view, sociocultural theory not only accounts for development and transformation, but also involves a hermeneutics of suspicion (Ricoeur, 1974) regarding how cultural tools are used by agents to exert power (both over others and for the purposes of self determination). 


\subsection{Socioculturalism: An Ideal Type.}

In this section, an ideal type for socioculturalism is constructed as a one-sided accentuation of the vocabulary set out above. This section explains the ideal type for socioculturalism in greater detail, working through each of the parts. The ideal type grid is set out on the following page, using the headings discussed in 4.3.1.

\begin{tabular}{|l|l|}
\hline View of people & Socioculturalism \\
\hline Ideal social structure & $\begin{array}{l}\text { Embedded/Situated (culture, history, time, place), } \\
\text { agents of change, connected to contexts }\end{array}$ \\
\hline Social agency & Contextualised, supports equitable transformation \\
\hline $\begin{array}{l}\text { Participatory } \\
\text { framework }\end{array}$ & $\begin{array}{l}\text { Inclusive, communicative, community-based, } \\
\text { relationship-based. }\end{array}$ \\
\hline
\end{tabular}

Fig. 2. Ideal-type for socioculturalism

\subsubsection{Socio-culturalism: A view of people.}

As noted, soci-culturalism views people as beings embedded within wider social and historical networks (e.g., Vygotsky, 1978, 1986; Lave \& Wenger, 1991; Rogoff, 1990, 2003; Wenger, McDermott \& Snyder, 2002; Wertsch, 1998). For this reason, to understand a person or group of people, it is necessary to also take into account considerations of cultural experience, the history of that experience in the life of the person and in the life of their culture, and the actual physical and social spaces that the person or people inhabit (Lave \& Wenger, 1991). 
From this perspective, people are not merely figures set against a background of social, cultural and historical importance: The social, cultural and historical contexts to which the person belongs are part and parcel of that person or people (Rogoff, 2003). Within this framework the idea of the independent individual makes little or no sense (Rogoff, 1991).

Socioculturalism focuses on human activity (Vygotsky, 1978, 1986; Wertsch, 1998). Humans are viewed as agents that both change and are changed by their environments (Rogoff, 2003). Likewise, specific tools (e.g., language, artefacts, habits) are integrated into the life experience of persons. Human development from this perspective is the product of human activity within contexts, history (personal and contextual), in relationship with other human beings. For socioculturalism, humans are actively involved in the shaping and re-shaping of their own experience (Rogoff, 2003), and the contexts in which they are situated whilst at the same time they are shaped and reshaped by those contexts and wider networks of action (e.g., natural disaster, change of government, employment). From this perspective humans are viewed as contextually situated, interconnected and part and parcel of wider relationships and histories of experience. 


\subsubsection{Socio-culturalism: Ideal social structure.}

Sociocultural analyses of institutions has focused on participation (e.g., Lave \& Wenger, 1991; Rogoff, 1990; Wenger, 1999; Wenger, McDermott \& Snyder, 2002). Institutions act as social, cultural and historical contexts to which people belong in varying degrees (Lave \& Wenger, 1991). People's interactions with one another within institutions, interactions between those who are more experienced in the context and those who are new to it, and the relationship between the culture of the institution and the culture of participants are all areas of interest to sociocultural perspectives (e.g., Rogoff, 2003; Wenger, 1998). Institutions are viewed as matrixes of social and cultural interactions where diverse participants are brought into dialogue with one another and with the wider institutional culture (e.g., Wenger, McDermott \& Snyder, 2002). For this reason, at the interface of participant and institution there is diversity, especially insofar as diverse participants interact with institutional cultures in multiple ways. Take, for example, participant responses to the death of a loved one. Anglicised European cultures have a very different view of funeral arrangements than Māori or Islamic people. For most Muslims, the funeral happens on the day of the death; Māori will leave the body to rest in the home and the funeral (tangi) will last a period of three days, and for most Anglicised Europeans the body of the deceased will stay at a funeral home until the day of burial or cremation. 
Given that participants within institutions belong to a number of social and cultural contexts (e.g., ethnicities, sports affiliations, cultural groups, hobby communities, political affiliations), and that there is also a great diversity within people's personal experiences of living in those contexts, socioculturalism embraces, and indeed expects diversity as a matter of course (Lave \& Wenger, 1991; Rogoff, 1990, 2003). A sociocultural perspective on institutional structure encourages the acceptance of diversity within the institutional culture, for instance through charters that recognise and encourage multicultural perspectives, and through team building activities that bring people from diverse backgrounds into dialogue with one another in the pursuit of shared goals. Acceptance of diversity may also be achieved through the celebration/authentication of events important to particular participants within an institution for example Holi for Hindu people, Ramadan for Muslims, Christmas (in both the religious and the secular sense), and Matariki (Māori new year). Socioculturalism maintains an inclusive stance toward diversity insofar as diversity is encouraged within socio-cultural frameworks of analysis (e.g., as applied in many contemporary early childhood education settings).

\subsubsection{Socioculturalism: Social agency.}

Social agency is a key focus of socioculturalism (Rogoff, 1990; Wertsch, 1998). Socio-culturalism, although it is a tool for describing and explaining activities and events within social and cultural settings, can also be used as a tool to 
encourage the distribution of power and authority among participants within social contexts (Wertsch, 1998). Control is exerted through the relationships between participants, the contexts to which they belong, and their history within a given context. Control is embedded in the rules by which the context is formed and maintained (e.g., purpose, regulations, best practice). It is also embodied in the activity of experienced participants as they interact with one another, and with those who are new to the context (Lave \& Wenger, 1991). Over time, as they gain experience, new participants also gain a greater degree of autonomy as they become accustomed to the practices, expectations and procedures inherent in that context. For example, first year university students might reasonably be expected to be more dependent on library staff than third year students when it comes to the use of research databases. Over time, power (in terms of the ability to research) moves into the hands of students as they become more accustomed to using the databases (which can be considered cultural tools in a university context). Lave and Wenger (1991) describe this as a centripetal movement toward full participation.

Although power is distributed within social and institutional contexts it should be noted that power is not necessarily distributed evenly (Bourdieu \& Passeron, 1990). Some participants have more authority than others within various sociocultural contexts (e.g., lecturers, priests, head teachers, bank managers, company directors and so on). Socioculturalism is, therefore, not necessarily a 
tool for achieving equal distribution of control in different contexts. It is a lens through which relative degrees of participation may be analysed (Wenger, 1999). The distribution of power and authority is one concern that is highlighted when using a sociocultural lens (Wertsch, 1998) and as such it opens on to the possibility of transforming social relationships for social justice purposes (e.g., Smith's (1966) work on children's rights, and Te One's (2009) PhD thesis on rights in early childhood settings). Through a sociocultural lens, humans are social agents, therefore social agency, in terms of relations between people and the contexts in which they are embedded, is a central concern (e.g., Fleer, 1995).

Social cultures are developed through the action of social agents who both transform and are transformed by their context (Rogoff, 2003; Wenger, 1998). It is arguable as to whether this leads to equity for all participants within a given context, suffice it to say that this is a topic that might attract the attention of sociocultural researchers interested in explaining the cultural determinants of social agency (e.g., Wenger, McDermott \& Snyder, 2002).

If socioculturalism is itself a cultural tool, and if this tool, like all cultural tools (Wertsch, 1991, 1998) is available to mediated action, then the tool itself can undergo the same sort of transformations that all tools do when they are picked up and used. The pole remains a pole when it is used to hold open a gate, the 
curriculum remains a legal document when it is used as a fan on a hot day, and the dump truck remains a dump truck even when it is used as a doorstop. It is the use that transforms the object. This thesis argues that although socioculturalism is commonly used to explain and describe phenomena, it has also been used to inspire cultural change (e.g., to challenge developmental discourses: Fleer, 1995). From this perspective, socioculturalism supports social agency for the transformation of social and cultural spaces.

\subsubsection{What is a sociocultural view of participatory frameworks?}

Socioculturalism identifies participation as a key attribute of social, cultural and historical development (Lave \& Wenger, 1991; Rogoff, 1990, 2003; Vygotsky, 1938/1978). Socioculturalism describes the construction of mutually beneficial communities where participants are encouraged to form bonds of belonging and a sense of shared identity (Wenger, 1998). For socioculturalism, issues of more or less, central or peripheral, inclusive or exclusive, mark central concerns when it comes to explaining the role of participation in social settings (e.g., Lave \& Wenger, 1991). For this reason, socioculturalism explains participatory frameworks as being community oriented, wherein communities are formed and re-formed through co-mutual action between participants, and between participants and the contexts in which they are embedded. Communication is a key means by which participation occurs (Lave \& Wenger, 1991; Rogoff, 1990; Vygotsky, 1938/1978; Wertsch, 1998). 
In IECTE programmes communication takes many forms including official texts (e.g. induction texts, curriculum, workplace rules), regulations, lines of authority (e.g. director, manager, supervisor, teacher), between participants at each of those levels, through the use of jargon, and in the explanations of shared habits of action (e.g., talking to infants before during and after their nappy change). Sociocultural notions of embeddedness, participation and inclusion may be used to encourage communication between people, institutions and cultural contexts. That interaction is, to varying degrees, open insofar as participants and their contexts may be transformed as a result of that communication. For example, when a Muslim child enrols in an early childhood centre and they are the only Muslim child (or the only child from a particular tradition in Islam, e.g., Shi'i or Sunni), it can be expected that two things may happen. First, the child will be introduced to the culture of the particular centre (e.g., spaces that have specific functions, activities that are organised for certain times, games and songs that children already at the centre know). Over time, it can be expected that the child will transform some of their own habits as a direct result of interacting with this new context. Second, the centre as a community will transform by introducing aspects of Islamic culture to the setting and the other participants in that setting (e.g., respect for Ramadan, recognition of halal (food regulations) and an understanding of Silat (prayer) and its role in the day-to-day life of Muslim children). In this example, 
through communication and interaction, transformation is a two-way event. The participatory framework is co-mutual in theory.

A sociocultural framework of participation involves a concerted effort aimed at inclusivity and developing a sense of belonging (Rogoff, 1991; Wenger, 1998). The concept of inclusivity in this case uses a rationale of shared activity, shared language, and shared space to organise interactions within social contexts. The key to this aspect of socioculturalism is in the degree to which diverse participants and their social and cultural histories are included in diverse social settings. Inclusion in this case means that not only do people from diverse social and cultural backgrounds have equal access to social and institutional contexts, but also that they are given the opportunity to express their identity without censure. Socio-cultural researchers such as Rogoff (2003) have informed us that inclusion itself is a notion that has different meaning to different cultural groups, so for the most part it is best considered a negotiated event.

\section{Summary}

This chapter has used sociocultural texts to construct an ideal type for socioculturalism. The components of that ideal type included understandings of people as embedded/situated (culture, history, time, place), agents of change, and connected to contexts; participatory and co-constructed social structures; contextualised, equitable and transformative understandings of social agency; 
and inclusive, community based and communicative participatory frameworks. The concepts incorporated in this ideal type are used in the following chapter to justify the claim that the content of IECTE programmes is greatly influenced by socioculturalism. 


\section{Chapter Six}

\section{Socio-culturalism in the content of IECTE programmes in}

\section{Aotearoa/New Zealand.}

This chapter uses the ideal type for socioculturalism developed in the previous chapter to interpret the content of an IECTE programme in Aotearoa/New Zealand. The point of this chapter is to show the variety of ways that socioculturalism influences content, as the first step in showing how structural dissonance occurs within an IECTE programme. Analysis in this chapter is organised using the ecological hermeneutic introduced in chapter four (see section 4.3.1). The first part of this chapter uses May's $(1997,2001)$ idea of the shifting gazes of the state to make the point that the focus of early childhood education has moved from the individual to the social. This is the sociohistorical level of the ecological hermeneutic (see fig 3).

The next part of the chapter analyses texts that are external to the university but which influence the content of IECTE programmes: Graduating Teacher Standards (NZ Teachers Council, 2007) and the New Zealand Early Childhood Education Strategy (Ministry of Education, 2002). Following that analysis, this thesis studies two core texts used in IECTE programmes in Aotearoa: The early 
childhood curriculum - Te Whāriki (Ministry of Education, 1996), and the assessment handbook Kei Tua o te Pae (Ministry of Education, 2004 - 2007). They are core texts because they relate directly to the Graduating Teacher Standards (NZ Teachers Council, 2007) stipulation that graduating teachers "have knowledge of the relevant curriculum documents of Aotearoa New Zealand" (NZ Teachers Council, 2007, S1:c) and that graduating teachers "have knowledge of a range of relevant theories, principles and purposes of assessment and evaluation" (NZ Teachers Council, 2007, S2:b).

Following the analysis of core texts this chapter investigates the content of the 2007 course outlines of the seven New Zealand universities that offer IECTE programmes. The sociocultural content of each IECTE programme is highlighted as specific examples of what I am calling socioculturalism in IECTE programmes. Multiple sites are used in this analysis in order to show that the case study university is not unique among IECTE programmes offered in Aotearoa/New Zealand. Following that, the 2007 programme from one case study IECTE provider is analysed in depth, focusing on the achievement objectives of each course, the pedagogical work (assessed work) and required readings for each course. Finally, the findings from the focus groups, concerning the content of IECTE programmes, are introduced. This will show that there is also empirical evidence that supports the argument being advanced. 
The parts of this chapter work together to provide evidence to support the claim that the content of IECTE programmes in Aotearoa/New Zealand is greatly influenced by socioculturalism.

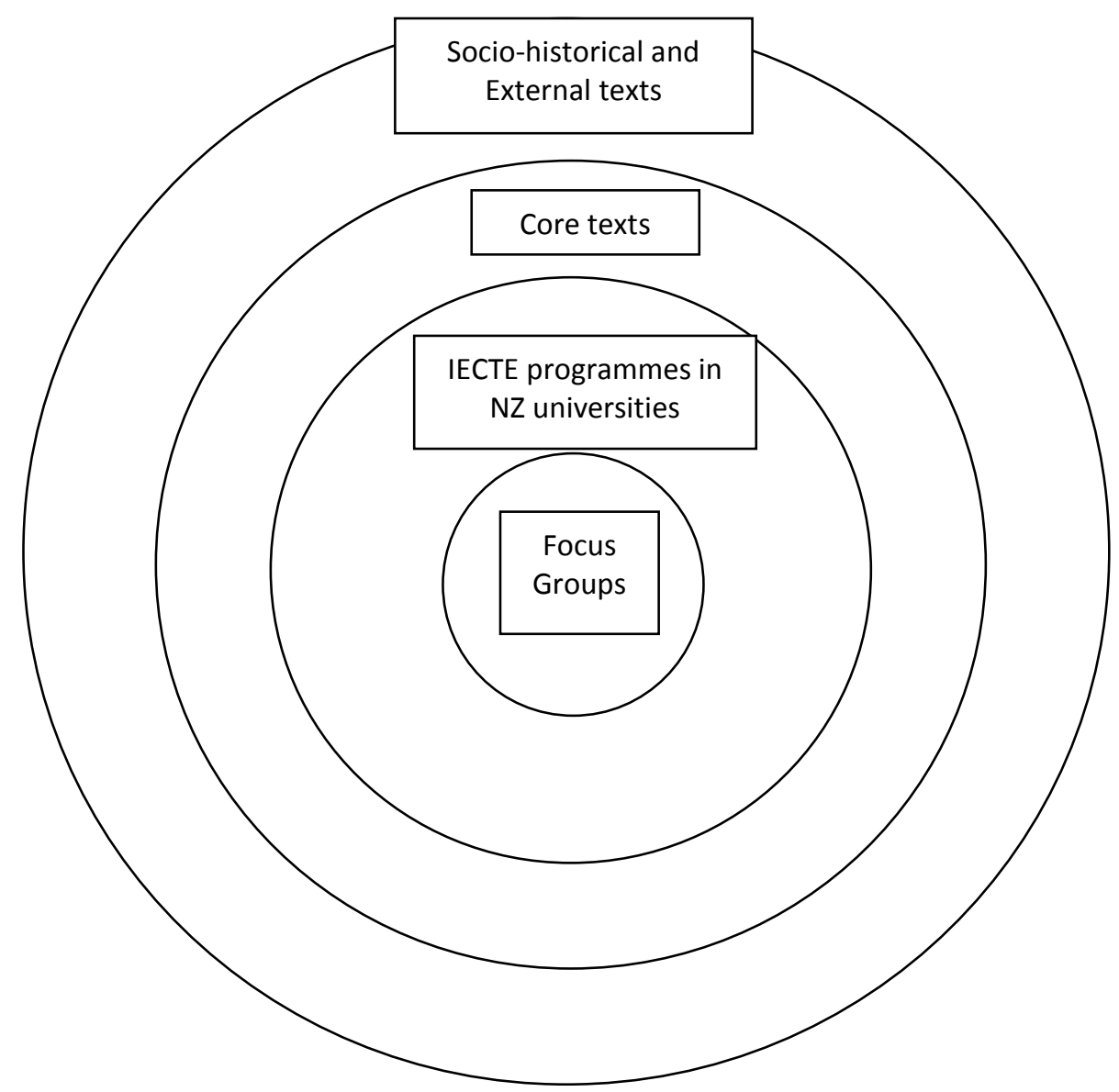

Fig. 3. Ecological hermeneutic for chapter 6.

\subsection{Socio-historical context.}

In her historical analysis of early childhood education in Aotearoa/New

Zealand, May (2009) used the notion of gaze as a metaphor for understanding how society has viewed early childhood education over time. Following May (1997, 2001), this thesis defines gaze as the official/mainstream/general 
perspective on early childhood education. This thesis does not argue that alternative gazes on early childhood education have not emerged in each of May's $(1997,2001)$ epochs, but rather, that for the purposes of analysis, May's $(1997,2001)$ metaphor is useful as it shows movement away from individualistic to social agenda over time. The following chapter points out the irony that contemporary institutional structures socially enforce the individualisation of persons, resulting in the fragmentation of social settings.

May (2005, p. 23) identified six historical gazes: Survival, moral, physical, psychological, equity, and economic and asserted that the progression of each gaze is chronological, with overlaps and unresolved concerns, meaning that in many instances the gazes are overlaid upon one another. May (2004) used the following depiction to illustrate her chronology of shifting gazes:

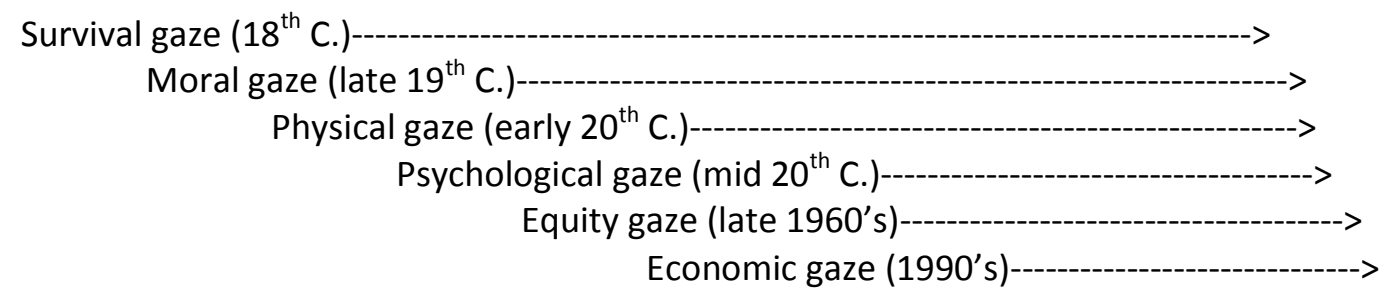

Fig. 4. Shifting Gazes of State (May, 2004, p. 75).

This thesis divides May's (2004) metaphor of gazes into two categories: individual focused and society and culture focused. The survival, moral, 
physical and part of psychological gaze takes the individual, as the basic element of analysis. In this group, the overarching idea is that if one looks to individuals and their development in a systematic and deliberate fashion then society will benefit as a result. Wertsch (1998) called this individualistic reductionism. The survival gaze responded to the high mortality rate of children in the $19^{\text {th }}$ century, particularly in England, but also throughout Europe (May, 1997). With this gaze individual lives of individual children were the key focus of legislation (e.g., Children's Protection Act, 1890) and efforts at early childhood care (e.g., Thomas Coram's foundling schools).

The moral gaze, whilst concerned with the creation of a better society (May, 1997), responded to the problem of immorality by rescuing children from the immoral influences of their social context. The first Free Kindergarten in New Zealand is a case in point where "they wanted to lay hold of the little ones, who came into the world burdened with evil tendencies" (Dunedin Free Kindergarten Association, 1891, p. 11, as cited in May, 1997, p. 69). The goal, in this case, was to save individual souls from damnation through Christian virtue and the inculcation of moral habits. The physical gaze, drawing on early child development literature as justification, reacted less to the moral behaviour of a person and more to the development of a healthy, normal body (May, 1997).

The psychological gaze straddles the individualistic and sociocultural divide. In 
pre-1980's in NZ, psychology had dropped the religiously infused notion of soul to pick up the more secularly appropriate notion of mind. At the same time behavioural psychologists like B.F Skinner (1968) maintained a focus on the things that bodies do, Freud's (1923) psychoanalytic psychology brought a concern for the wellbeing of children's subconscious selves. Freud's intrapersonal psychology influenced not only his daughter Anna Freud, who worked with children rather than neurotic adults as her father had, but also Susan Issacs whose Malting House School provided research evidence in favour of a free play approach to education (e.g. Intellectual Growth in Children, 1930). New Zealander Moira Gallagher was strongly influenced by Issacs' work (May, 1997), as was Gwen Sommerset, who was to become the intellectual matriarch of the Playcentre movement in New Zealand. Both women had a lasting influence on early childhood education in New Zealand (May, 1997, 2001).

More relevant to contemporary early childhood education in Aotearoa/New Zealand, and highlighting the movement from the individual to the social in child development discourses, is the movement from Piaget's (1935/1971) personal constructivism to Vygotsky's (1978) social constructivism. Piaget's (1935/1971) personal constructivism centred on the biological development of individual children and the biological basis of learning (e.g., children learn differently at different stages of development). Piaget (1935/1971) held that a child understands the world through their own actions on that world and their 
subsequent experiences: That is, children personally construct their understandings of the world through acting on that world with the resources that they possess as biological beings who adapt to their environment.

The shift from using Piaget to using Vygotsky is a historical fact in New Zealand discourses of child development. For example, Smith (1998), in her fourth edition of Understanding Children's Development, a text used in human development papers at one New Zealand university, remarked that "earlier editions of this book placed a great deal of emphasis on the theory of Swiss psychologist Jean Piaget" (p. 5). In the fourth edition only 17 pages mention Piaget's work whilst thirty eight pages are devoted to Vygotsky, and a further seven to Rogoff. The shift from Piaget to Vygotsky is indicative of the dominance of socio-cultural discourses in contemporary early childhood education and development.

May's (2001) final gazes evoke a social perspective in their rationale for early childhood education. The equity gaze is linked with what she calls liberation politics, where groups within New Zealand society (e.g., Māori: Ritchie, 1993) advocated against exclusion and assimilation on the one hand and for inclusion and self-determination on the other. During the time that May characterises as the equity gaze past wrongs began to be righted. In regards to Māori issues of equity, this began with Lange government's recognition of the Treaty of 
Waitangi (1840) as New Zealand's founding document which led to changes in the charters and strategies of Crown agencies (e.g., Ministry of Social Development, Ministry of Education, Ministry of Health), and opened space for the development of programmes aimed at the reinvigoration of Māori culture (i.e., the Kohanga Reo movement). The equity gaze, though sharing common ground with individualism and personal liberty, shifted the focus toward a social and cultural vista. For example, in 1984, in summing up the government's position on issues of culture William Renwick, the then Director General of Education, stated that "concern for cultural diversity and cultural respect... [are issues] to be faced to in every aspect of our lives as New Zealanders" (Renwick, as cited in May, 2001, p. 185).

This shift toward what Wertsch (1998) would call social reductionism is the shift away from viewing the individual as an isolated agent toward viewing humans as essentially social agents. This social reductionism continued into the 1990 's and 2000's in the form of an economic reasoning that situated early childhood education within a broader national project for economic sustainability. For example, the ten year strategic plan for early childhood education: Pathways to the Future: Ngā Huarahi Arataki (Ministry of Education, 2002) stated at the outset "our social, educational and economic health can only benefit from efforts and resources focused on young New Zealanders. We cannot leave to chance the quality and accessibility of early childhood 
education" (p. 1). Economic sustainability, on this account, benefits the entire country, and it is a significant tool for establishing national prosperity.

The above analysis, using May's $(1997,2001)$ metaphor of shifting gazes offers justification for thinking that the socio-historical context of contemporary New Zealand early childhood education, and subsequently IECTE programmes is societally focused. This is not to say that focus on the individual is lost. This is certainly not the case (e.g., Ministry of Education, 1996, 1998, 2002, 2004). Rather, it points out that over the course of time, descriptions of early childhood education and its uses have taken a sociocultural turn where by individuals are viewed as embedded within inclusive social settings and intricately linked to the communities in which they feel they belong.

At this general level in the ecological hermeneutic, the contemporary sociohistorical context of the content of IECTE programmes in Aotearoa/New Zealand socioculturalism has an important influence. This discussion has shown how the gaze that directs early childhood education has come to view people as embedded within their social context; has come to value inclusion and diversity; and has come to encourage active participation within social and socio-economic settings. 


\subsubsection{Socioculturalism and the Graduating Teacher Standards.}

The Teachers' Council of New Zealand is mandated by the Education Act (1989) to encourage best teaching practice, issue practicing certificates to registered teachers, maintain standards for qualifications that lead to registration; and approve quality teacher education courses (part 10b, 139AE). In 2007 the Teachers Council published the Graduating Teacher Standards (2007). The purpose of Graduating Teacher Standards (2007) is to "describe what a teacher at the point of graduation from an initial teacher education programme will know, will understand, will be able to do, and the dispositions they will have that are likely to make them effective teachers" (NZ Teachers Council, 2007, p. 2). This document regulates the content of IECTE programmes. For this reason, this thesis examines the Graduating Teacher Standards (NZ Teachers Council, 2007) in the content of IECTE programmes.

IECTE programmes in Aotearoa/New Zealand are expected to "develop a graduate profile for each programme that will be aligned with the Graduating Teacher Standards" (NZ Teachers Council, 2007, p. 2). The Teachers Council (2007) stipulates that "the profession will expect that the Provisionally Registered Teachers entering their school or early childhood services will meet the Graduating Teacher Standards" (Teachers Council, 2007, p. 2). This stipulation influences the construction of IECTE programmes by ensuring that 
teacher education institutions provide evidence to the Council that will give assurance that the Graduating Teacher Standards will be met by all graduates (NZ Teachers Council, 2010).

Within the Graduating Teacher Standards (2007), there are three categories of competencies that IECTE providers are expected to develop through their teacher education programmes: professional knowledge, professional practice, and professional values and relationships. Professional knowledge contains the first three standards: Graduating teachers must know what to teach; know about learners and how they learn; and, understand how contextual factors influence teaching and learning. Professional practice contains a further two standards: Graduating teachers must use professional knowledge to plan for a safe, high quality teaching and learning environment; and, use evidence to promote learning. And professional values and relationships contain the final two standards: Graduating teachers must develop positive relationships with learners and the members of learning communities; and, be committed members of the profession (NZ Teachers Council, 2007).

According to the Graduating Teacher Standards (NZ Teachers Council, 2007), it is essential that graduating early childhood education teachers have knowledge of Te Whāriki (Ministry of Education, 1996). Discussion of Te Whāriki (Ministry of Education, 1996) is undertaken in the following section. This curriculum is 
commonly held to be a sociocultural curriculum document (e.g., Carr \& May, 1993; Cullen, 1996, 2003; May, 2001; Nuttall, 2003). Making knowledge of Te Whāriki (Ministry of Education, 1996) a prerequisite for graduating early childhood teachers means that the content of IECTE programmes in Aotearoa/New Zealand are necessarily sociocultural. Furthermore, within the context of IECTE programmes, an understanding of relevant learning theories, theories of development and pedagogies, whilst not exclusively sociocultural is also necessarily sociocultural in great part. This is because Te Whāriki (Ministry of Education, 1996) is framed using a socio-cultural perspective on development, teaching and learning (Nuttall, 2003).

Graduating teachers are expected to "have an understanding of the complex influences that personal, social, and cultural factors may have on teachers and learners" (NZ Teachers Council, 2007, p. 1). This document understands humans as being connected to the contexts of which they are an integral part. Social agency, within this frame, is localised to the communities to which teachers and learners belong, and to human interactions within those multifaceted contexts. Understanding teachers and learners is therefore a matter of understanding the sociocultural contexts within which they are embedded and to which they feel a sense of belonging. 
A more specific link to sociocultural assumptions in teacher education is standard six which requires that "graduating teachers develop positive relationships with learners and the members of learning communities" (NZ Teachers Council, 2007, p. 2). On the one hand there is the recognition that education is about forming relationships, and on the other is the notion of learning communities. Graduating teachers are required to:

a. "Recognise how differing values and beliefs may impact on learners and their learning.

b. Have the knowledge and dispositions to work effectively with colleagues, parents/caregivers, families/whānau, and communities.

c. Build effective relationships with their learners.

d. Promote a learning culture which engages diverse learners effectively.

e. Demonstrate respect for te reo Māori me ngā tikanga-a-iwi in their practice" (NZ Teachers Council, 2007, p. 2).

Recognition of diversity, assumptions that teachers and learners are embedded in multiple contexts, a focus on building relationships, a commitment to inclusion and participation and a respect for culture are all hall marks of socioculturalism as this thesis understands it. That IECTE programmes are required to develop these competencies in graduating student teachers, combined with a requirement to use sociocultural curriculum and assessment 
tools, means that the content of IECTE programmes, if they are to be certified by the New Zealand Teachers Council (and the Committee on University Academic Programmes) need necessarily to incorporate sociocultural ways of understanding the world.

\subsubsection{Socioculturalism and the New Zealand early childhood strategy.}

The New Zealand strategic plan for early childhood education is Pathways to the Future: Ngā Huarahi Arataki (Ministry of Education, 2002). This strategy was advanced by the Labour-led government that created it as "a journey towards increased participation, improved quality and stronger relationships" (Ministry of Education, 2002, cover). Although aspects of that strategy were retrenched by the incoming National government in 2009, the strategy was still influential to the context of IECTE programmes during the time of data collection for this thesis (2007-2008). The strategy not only aimed to increase participation, meet the needs of individual communities, promote collaborative relationships and "be more responsive to the needs of children, parents, families and whānau" (Ministry of Education, 2002, p. 3), but it also aimed to "increase the numbers of registered teachers" (Ministry of Education, 2002, p. 14).

Socio-cultural notions of participation (Ministry of Education, 2002, p. 11), inclusivity (Ministry of Education, 2002, p. 14), cultural responsivity (Ministry of Education, 2002 p. 15), co-construction (Ministry of Education, 2002, p. 17) 
and scaffolding (through the now terminated Centres of Innovation action research project), permeate this document. Pathways to the Future (Ministry of Education, 2002) provides links to the socio-cultural content of Te Whāriki (Ministry of Education, 1996), specifically stating the assumption that: "children's learning and development are fostered if the well-being of their family and community is supported; if their family, culture, knowledge and community are respected; and if there is a strong connection and consistency among all aspects of the child's world" (Ministry of Education, 2002, p. 16). Pathways to the Future (Ministry of Education, 2002) aims to build stronger links to communities, community groups and support networks in an effort to improve participation and quality, and promote collaborative relationships. For these reasons, Pathways to the Future (Ministry of Education, 2002) is a strategy that reflects a dominant framework of socioculturalism as it is focused on improving outcomes through forming effective relationships between children, centres, teachers, family, whānau and external interest groups (e.g. schools, health and social services). Improving life for individuals by improving the quality of their context is implicitly linked to Vygotsky's (1978) idea that the external context directs human development.

I have argued that the improvement of social and cultural contexts through quality early childhood education is a primary focus of policy in contemporary early childhood education policy. This focus assumes that the contexts in which 
children are embedded have a lasting influence on their development. I have also argued that teachers have an important role to play in the lives of children as they work to construct inclusive environments that encourage the participation of children and their families in early childhood services.

\subsection{Socioculturalism in the common texts used in IECTE} programmes in Aotearoa/New Zealand.

IECTE programmes in Aotearoa/New Zealand are diverse in their content (see section 7.3), however all use the early childhood curriculum - Te Whāriki (Ministry of Education, 1996) and the early childhood assessment handbook Kei Tua o te Pae (Ministry of Education, 2004-2007). This thesis calls those texts common texts.

\subsubsection{Socioculturalism and the New Zealand early childhood curriculum.}

Te Whāriki (Ministry of Education, 1996) is a socio-cultural curriculum (Carr \& May, 1993, 2001; Nuttall, 2003). As a curriculum document, it draws on a number of theoretical discourses in addition to socio-culturalism (namely Piaget's personal constructivism - particularly in the exploration strand which proposes that "the child learns through active exploration of the environment" (Ministry of Education, 1996, p, 16); Erikson's psycho-social theory of 
development - in the assumption that children develop through stages with specific developmental needs such as the idea that infants need security for socio-emotional development (Ministry of Education, 1996, p, 22); and Bronfenbrenner's (1979) socio-ecological theory of nested contexts (Ministry of Education, 1996, p, 20). However, a large part of the content of Te Whāriki (Ministry of Education, 1996) is heavily influenced by socioculturalism. This section identifies those influences in the text of Te Whāriki (Ministry of Education, 1996) as further defence of the claim that socioculturalism heavily influences the content of IECTE programmes.

The stated focus of Te Whāriki (Ministry of Education, 1996) uses a sociocultural vocabulary. For example, the curriculum aspiration for children is as follows: "to grow up as competent and confident learners and communicators, healthy in mind, body, and spirit, secure in their sense of belonging and in the knowledge that they make a valued contribution to society" (p. 9). Whilst it is also asserted that the curriculum "is about the individual child" (Ministry of Education, 1996, p. 9), the child is not understood as an entity isolated from social and cultural context, but rather, the curriculum uses sociocultural understandings of the children being embedded within familial contexts and multiple communities (Ministry of Education, 1996). Providing a case in point for the argument of sociocultural assumption, Te Whāriki (Ministry of Education, 1996) clearly states the following: 
This curriculum emphasises the critical role of socially and culturally mediated learning and of reciprocal and responsive relationships for children with people, places, and things. Children learn through collaboration with adults and peers, through guided participation and observation of others, as well as through individual exploration and reflection (p. 9).

Te Whäriki (Ministry of Education, 1996) consists of four principles: empowerment/whakamana, holistic development/kotahitanga; family and community/whānau tangata; and, relationships/ngā hononga. Three out of those four principles are based on sociocultural assumptions of embeddedness and connection. Within this principle "the child's whole context, the physical surroundings, the emotional context, relationships with others"' (Ministry of Education, 1996, p. 41) contribute to a child's development. This principle requires adults working with children to not only understand child development, but also to have "a clear understanding of the context in which they are working" (Ministry of Education, 1996, p. 41). Bi-cultural considerations are also highlighted as well as the assertion that "children should be encouraged to understand and respect the different cultures which make up our society" (Ministry of Education, 1996, p. 41). These socio-cultural concerns for the contexts (physical and social) in which children are embedded, the formation of strong communal relationships and the importance of cultural 
inclusion relate positively to the ideal type for socioculturalism worked out in the previous chapter.

The principle of family and community/whānau tangata emphasises that:

Children's learning and development are fostered if the wellbeing of their family and community is supported; if their family, culture, knowledge and community are respected; and if there is a strong connection and consistency among all the aspects of the child's world (Ministry of Education, 1996, p. 42).

Furthermore, teachers are directed to foster culturally appropriate communication, community participation in ECE programmes and a commitment to Māori language, culture and communities. These commitments further strengthen the link between socioculturalism and the early childhood curriculum in Aotearoa/New Zealand.

The principle of relationships/ngā hononga values "co-operative aspirations, ventures and achievements" (Ministry of Education, 1996, p. 43). Socio-cultural learning theories are encompassed in this principle as well as the learning environments will encourage "active and interactive learning opportunities for children to have an effect and to change the environment" (Ministry of Education, 1996, p. 43). The development of transformative relationships, focus 
on co-operation, and the importance of relationships between children and adults strongly links Te Whäriki (Ministry of Education, 1996) with socioculturalism.

Interwoven with the principles are the five strands and their associated goals, which arise from the principles (Ministry of Education, 1996, p. 15). Those strands are: well-being/mana atua, belonging/mana whenua, contribution/mana tangata, communication/mana reo, and exploration/mana aotūroa. Because contemporary New Zealand notions of health and well-being are holistic (see Ministry of Education, 1999; Ministry of Health, 2000) well-being necessarily encompasses social well-being/taha whānau and links to others and the wider community. Belonging/ mana whenua is socio-cultural insofar as it encourages "connecting links with the family and the wider world are affirmed and extended" (Ministry of Education, 1996, p. 15). Contribution/mana tangata picks up on the transformative notion of sociocultural theory identified iby Rogoff (2003), and communication/mana reo highlights the importance of language development, use of symbols, and shared understandings that is at the heart of Vygotskyan (1986) social constructivism. The only strand that appears non-sociocultural is exploration/mana aotūroa, which is based on a more personal constructivist (Piagetian) understanding of children and development as children "develop working theories for making sense of the 
natural, social, physical, and material worlds" (Ministry of Education, 1996, p. 16).

Socio-culturalism heavily influences Te Whāriki (Ministry of Education, 1996) from the introduction right through to the learning outcomes. My analysis of the vocabulary used in this document found that sociocultural concepts are used consistently throughout the document, for example the word culture/cultural appears 45 times in the text, context appears 32 times, community appears 45 times, relationship/s appears 59 times and the word social/ly appears 63 times (the words individual, individuals and individually appear a total of 56 times). The evidence outlined offers support to the proposition that the content of IECTE programmes in Aotearoa/New Zealand is heavily influenced by socioculturalism, insofar as Te Whäriki (Ministry of Education, 1996) is a core text used in IECTE programmes at all New Zealand universities.

\subsubsection{Socioculturalism and Kei Tua o te Pae (Ministry of Education, 2004).}

It is central to the graduating teacher standards: that students "have knowledge of relevant theories, principles and purposes of assessment and evaluation" (NZ Teachers Council, 2007, p. 1). Kei Tua o te Pae (2004) is a core text for understanding the use of sociocultural assessment in early childhood settings. 
According to the Ministry of Education (1996), "the purpose of evaluation is to make informed judgements about the quality and the effectiveness of the programme" (p. 29). However, Carr (2003) has stated that Te Whāriki (Ministry of Education, 1996) itself gave little real guidance on how that situated assessment should occur. Carr, May and Podmore (1998) have observed that from the mid-1990s early childhood services were required to keep records of assessment procedures for external auditing. The lack of concrete explanation and example in Te Whāriki (Ministry of Education, 1996) over how sociocultural assessment might take place coupled with mandatory accountability, led to the development of Kei Tua o te Pae: Assessment for Learning (Ministry of Education, 2004).

In developing Kei Tua o te Pae (2004), the Ministry of Education cited in its rationale the development of "a resource to support and guide assessment practice that is embedded within the dynamics of teaching and learning and the context of Te Whāriki" (Ministry of Education, 2006, p. 3). As a resource, Kei Tua o te Pae (2004) was targeted at learning communities and their ongoing professionalisation (Ministry of Education, 2004, p. 2), drawing, from the outset, upon a sociocultural reservoir of language. Similar to scaffolding, or tuakana/teina notion of integrated participation, Kei Tua o te Pae (Ministry of Education, 2004) uses the platform of exemplars to identify quality assessment practices to assist teachers and student teachers to develop their own 
assessment practices.

Explicit links to sociocultural theory are made in the exemplars to "indicate that there is a learning community involved in both curriculum and assessment. The learning community includes children, families, whānau, teachers and others" (Ministry of Education, 2004, p. 1:3). A link to Vygotsky is made on page 16: "arguing that belonging and participating in 'what we all do here and what we value' is a prerequisite for individual learning" (Ministry of Education, 2004, p. $1: 16)$.

Book two of Kei Tua o te Pae (Ministry of Education, 2004) focuses specifically on sociocultural assessment, whilst book five highlights the importance of inviting multiple participants into "a particular community designed to foster children's learning" (p. 5:2). This particular exemplar emphasises the importance of developing learning communities and draws directly on Wenger (1999, p. 271) for its rationale, going on to state "it is helpful to think of the early childhood setting as a learning community constructed through the everyday responsive and reciprocal relationships that develop between those who belong to it" (Ministry of Education, 2004, p. 16).

Sociocultural assessment practices aim to empower learners in their contexts and enable them to develop learning dispositions (Katz, 1993) that encourage 
them to bring their own lived experiences to bear on local educational settings. Katz (1993) identified five learning dispositions: taking an interest, being involved, persisting with difficulty or uncertainty, communicating with others, and taking responsibility. In her book, Assessment in Early Childhood Settings: Learning Stories, Carr (2001) identified learning dispositions as "responsive and reciprocal relationships between the individual and the environment" (p. 22). Carr (2001) provided a sociocultural perspective on learning dispositions wherein "learning dispositions are... located in activities, in places, and in communities" (p. 35).

It is because the idea of learning dispositions leads to the development of learning stories as a socio-cultural assessment tool that they are worth mention in the context of this thesis. For Carr (2001) learning stories "illustrate the domains of learning dispositions in action" (p. 95); this necessarily involves protecting and enhancing the early childhood setting as a learning community:

“Assessment will protect and enhance the centre as a learning community in whatever way the community defines learning and provides for it. Assessment will be about participation: it will be of the learner-in-action-mediational-means in terms of mediational means that are locally available" (Carr, 2001, p. 94).

Learning stories and learning dispositions are key concepts in Kei Tua o te Pae 
(Ministry of Education, 2004), and assessment is crucial to the measurement of both learning and quality, and quality learning experiences are essential to both Te Whāriki (Ministry of Education, 1996) and Pathways to the Future (Ministry of Education, 2002). Focus on embeddedness, relationship building, contextual influences, participation and cultural appropriateness are all factors that firmly link Kei Tua o te Pae (Ministry of Education, 2004) to socioculturalism.

This discussion has shown that the core texts used throughout IECTE programmes are heavily influenced by socioculturalism. Both texts view people as being intricately connected to familial, community and cultural contexts. Both documents encourage participation, relationship building, and the coconstruction of knowledge, learning spaces and assessment, and both texts provide a communicative, community based perspective that encourages and supports equitable transformation (of persons and places).

\subsection{Socioculturalism in New Zealand Universities}

This section now considers the next layer of the hermeneutic ecology to identify the influence of socioculturalism in the compulsory papers of Bachelor of Education (Early Childhood) courses in seven New Zealand universities. The 2007 programme outlines (found online) for each university are used as the data 
set upon which analysis is performed. These texts were chosen because of their accessibility, their relevance to the programmes they summarise, and their function as guiding documents describing the content of IECTE programmes in each of the universities. These courses reflect the sociocultural emphasis of external agencies (i.e., the New Zealand Teachers Council and the New Zealand Ministry of Education) and the socio-cultural impetus of the New Zealand early childhood curriculum and assessment guide. They are important to survey as they provide further textual evidence that socioculturalism heavily influences IECTE programmes in Aotearoa/New Zealand.

\subsubsection{Socioculturalism and IECTE programmes in New Zealand universities.}

At present there are seven New Zealand universities offer a three year Bachelor of Education (Early Childhood) programme: Auckland University, Auckland University of Technology, Massey University, Otago University, University of Canterbury, Victoria University, and Waikato University. This section shows that in 2007 each of them used socioculturalism as a core for their IECTE programmes. This section will focus on the compulsory courses for the campus based Bachelor of Education degree (BEd). The universities outlined in this section are organised into alphabetical order for the purposes of analysis.

Each university followed a similar format of course construction: practical courses, pedagogical courses and academic courses. Practical courses were 
courses that include sections of teaching practice in ECE settings or reflection on that practical experience. Pedagogical courses were campus-based courses concerned with curriculum and assessment, professional teaching practice, and cultural studies. Academic courses were campus-based courses which are closely aligned to sociology, history, politics, and philosophy. However, it should be noted that practical courses contained both pedagogical and academic components to greater and lesser degree depending on the course. Likewise, pedagogical courses contained both academic aspects and practical and reflective applications, whilst academic courses may encompass pedagogy and an application to practice.

Methodologically, this thesis uses a grid for each university to organise the foci of all compulsory courses within each of the three types of courses (practice based, pedagogical and academic). All courses used Te Whāriki (Ministry of Education, 1996) as a core document and were reconciled with Graduating Teacher Standards (NZ Teachers Council, 2007).

\subsubsection{Socio-culturalism in IECTE: Auckland University.}

Relationships and relationship building, contextual influences on teaching and learning (embeddedness), the construction of effective learning environments and the promotion of diversity key aspects of my interpretation of the Auckland University IECTE BEd programme. A focus on participation and 
macro-influences in some papers contributes to the sociocultural perspective

that underpins this programme. Sociocultural theory was used throughout the

programme with explicit mention in the first year courses.

\begin{tabular}{|c|c|c|c|c|}
\hline Level & Practice-based & Pedagogical & Academic & Ideal type \\
\hline 100 & $\begin{array}{l}\text { Developing } \\
\text { professional } \\
\text { relationships in } \\
\text { ECE settings. }\end{array}$ & $\begin{array}{l}\text { Construction of learning } \\
\text { environments; } \\
\text { understanding diversity; } \\
\text { using sociocultural } \\
\text { assessment tools; } \\
\text { understanding Māori } \\
\text { culture; developing a } \\
\text { sociocultural approach to } \\
\text { understanding children's } \\
\text { wellbeing; curriculum } \\
\text { areas. }\end{array}$ & $\begin{array}{l}\text { Diversity in } \\
\text { education and } \\
\text { developmental } \\
\text { theory; } \\
\text { understanding } \\
\text { diversity and } \\
\text { teaching } \\
\text { practice. }\end{array}$ & $\begin{array}{l}\text { Inclusive, } \\
\text { contextualised, } \\
\text { relationship } \\
\text { based. }\end{array}$ \\
\hline 200 & $\begin{array}{l}\text { Constructing } \\
\text { learning } \\
\text { environments; } \\
\text { managing } \\
\text { relationships in } \\
\text { ECE settings }\end{array}$ & $\begin{array}{l}\text { Social science (improving } \\
\text { participation, belonging and } \\
\text { cultural understanding); } \\
\text { relationship building with } \\
\text { infants; cultural identity, } \\
\text { languages and literacy; } \\
\text { development of holistic } \\
\text { learning environments; } \\
\text { curriculum areas. }\end{array}$ & $\begin{array}{l}\text { Integrating } \\
\text { teaching, } \\
\text { learning and } \\
\text { assessment; } \\
\text { understanding } \\
\text { the citizenry } \\
\text { rights of } \\
\text { learners. }\end{array}$ & $\begin{array}{l}\text { Participatory, } \\
\text { connected to } \\
\text { contexts, } \\
\text { relationship } \\
\text { based, agency } \\
\text { focused. }\end{array}$ \\
\hline 300 & $\begin{array}{l}\text { Extending and } \\
\text { deepening } \\
\text { relationships in } \\
\text { diverse } \\
\text { contexts. }\end{array}$ & $\begin{array}{l}\text { Contextual influences on } \\
\text { play; play and citizenship; } \\
\text { play and society; } \\
\text { ethical/political/social } \\
\text { dimensions of learning } \\
\text { environments. }\end{array}$ & $\begin{array}{l}\text { Macro } \\
\text { influences on } \\
\text { education; } \\
\text { socio-historical } \\
\text { approaches to } \\
\text { understanding } \\
\text { educational } \\
\text { contexts; } \\
\text { contextual } \\
\text { influences on } \\
\text { teacher practice. }\end{array}$ & $\begin{array}{l}\text { Relationship } \\
\text { based, } \\
\text { contextual, } \\
\text { inclusive, } \\
\text { agency } \\
\text { focused. }\end{array}$ \\
\hline
\end{tabular}

Fig. 5 Socioculturalism in compulsory IECTE courses at Auckland University (2007).

\subsubsection{Socioculturalism in IECTE: Auckland University of Technology.}

Specific focus on bi- and multi-cultural contexts of teaching and learning, understanding contextual influences on children, their parents and early 
childhood settings, and use of sociocultural theories of learning and

development are hallmarks of this programme. ECE settings, teachers and

children and their families were viewed as being embedded within diverse

sociocultural contexts. Sociocultural theory was used in each course particularly

in the third year.

\begin{tabular}{|c|c|c|c|c|}
\hline Level & Practice-based & Pedagogical & Academic & Ideal type \\
\hline 100 & $\begin{array}{l}\text { Linking ethical } \\
\text { and regulatory } \\
\text { contexts with } \\
\text { reflective } \\
\text { practice. }\end{array}$ & $\begin{array}{l}\text { Māori customs and } \\
\text { language; } \\
\text { maintaining healthy } \\
\text { and safe } \\
\text { environments; } \\
\text { curriculum and } \\
\text { young children; } \\
\text { socio-cultural } \\
\text { learning and } \\
\text { relationship building } \\
\text { with young children. }\end{array}$ & $\begin{array}{l}\text { Sociocultural } \\
\text { development; } \\
\text { learning in socio- } \\
\text { cultural contexts; } \\
\text { developing respectful } \\
\text { relationships with } \\
\text { parents/whānau. }\end{array}$ & $\begin{array}{l}\text { Contextual } \\
\text { connections, } \\
\text { participation } \\
\text { focused, } \\
\text { inclusive, } \\
\text { relationship } \\
\text { based. }\end{array}$ \\
\hline 200 & $\begin{array}{l}\text { Documentation; } \\
\text { reflect on } \\
\text { practice in } \\
\text { relation to } \\
\text { DOP's. }\end{array}$ & $\begin{array}{l}\text { Working with parents } \\
\text { and families; critical } \\
\text { assessment of } 7 \\
\text { curriculum areas in } \\
\text { relation to infants, } \\
\text { toddlers and young } \\
\text { children. }\end{array}$ & $\begin{array}{l}\text { Learning theories in } \\
\text { cultural contexts; } \\
\text { working with children } \\
\text { with special needs; } \\
\text { child development in } \\
\text { New Zealand; } \\
\text { advocacy \& } \\
\text { wellbeing. }\end{array}$ & $\begin{array}{l}\text { Co- } \\
\text { constructive, } \\
\text { contextual } \\
\text { connections, } \\
\text { inclusion. }\end{array}$ \\
\hline 300 & $\begin{array}{l}\text { Contexts of } \\
\text { student } \\
\text { learning; policy } \\
\text { and regulation } \\
\text { relating to } \\
\text { communities } \\
\text { and families. }\end{array}$ & $\begin{array}{l}\text { Historical and current } \\
\text { approaches to } \\
\text { curriculum, use of } \\
\text { sociocultural } \\
\text { assessment tools; a } \\
\text { sociocultural } \\
\text { approach to second } \\
\text { language, music and } \\
\text { arts development. }\end{array}$ & $\begin{array}{l}\text { Sociocultural } \\
\text { perspectives in ECE; } \\
\text { critical approaches to } \\
\text { teaching philosophies, } \\
\text { learning theories, } \\
\text { professional practice; } \\
\text { designing effective } \\
\text { learning environs. }\end{array}$ & $\begin{array}{l}\text { Community } \\
\text { based, } \\
\text { contextual } \\
\text { connections, } \\
\text { agency } \\
\text { focused, }\end{array}$ \\
\hline
\end{tabular}

Fig. 6 Socioculturalism in compulsory IECTE courses at Auckland University of Technology (2007). 


\subsubsection{Socioculturalism in IECTE: Massey University (Palmerston North).}

A focus on inquiry into social and cultural contexts of children and their

parents, socio-political contexts in which ECE programmes operate and

appreciation of the cultural contexts in which children and their families are

embedded are hallmarks of this programme. This programme highlighted

inclusivity, social teaching and learning and emphasis on children's

participation.

\begin{tabular}{|c|c|c|c|c|}
\hline Level & Practice-based & Pedagogical & Academic & Ideal type \\
\hline 100 & $\begin{array}{l}\text { Functions and } \\
\text { responsibilities } \\
\text { of teachers in } \\
\text { learning } \\
\text { environments. }\end{array}$ & $\begin{array}{l}\text { Introduction to Māori } \\
\text { language; principles } \\
\text { and practices of Te } \\
\text { Whäriki (1996) (the } \\
\text { role of adults in } \\
\text { children's learning); } \\
\text { arts and maths in } \\
\text { ECE. }\end{array}$ & $\begin{array}{l}\text { Learning, learning } \\
\text { styles, teaching } \\
\text { strategies; social } \\
\text { cultural and political } \\
\text { contexts of ECE in } \\
\text { NZ. }\end{array}$ & $\begin{array}{l}\text { Relationships, } \\
\text { contextual, } \\
\text { supporting } \\
\text { equity, } \\
\text { cultural. }\end{array}$ \\
\hline 200 & $\begin{array}{l}\text { Strategies for } \\
\text { fulfilling } \\
\text { responsibilities } \\
\text { in ECE settings. }\end{array}$ & $\begin{array}{l}\text { Social and cultural } \\
\text { issues for Māori } \\
\text { learners; social } \\
\text { science, maths, } \\
\text { science and health } \\
\text { and physical } \\
\text { education. }\end{array}$ & $\begin{array}{l}\text { Sociocultural } \\
\text { assessment and } \\
\text { teaching and learning; } \\
\text { inclusive pedagogy } \\
\text { and building } \\
\text { networks; children's } \\
\text { construction of } \\
\text { knowledge and } \\
\text { contextual influences. }\end{array}$ & $\begin{array}{l}\text { Inclusive, } \\
\text { connected to } \\
\text { context, co- } \\
\text { construction. }\end{array}$ \\
\hline 300 & $\begin{array}{l}\text { Critical inquiry } \\
\text { into children's } \\
\text { social, political } \\
\text { and cultural } \\
\text { contexts and } \\
\text { the ethical and } \\
\text { social aspects of } \\
\text { teaching } \\
\text { practice. }\end{array}$ & $\begin{array}{l}\text { Programme } \\
\text { planning and } \\
\text { sociocultural } \\
\text { assessment in } \\
\text { learning contexts; } \\
\text { arts; curriculum } \\
\text { integration. }\end{array}$ & $\begin{array}{l}\text { Socioecological } \\
\text { perspective on } \\
\text { children and their } \\
\text { development; } \\
\text { analysis on national } \\
\text { and international } \\
\text { ECE programmes; } \\
\text { inclusive education } \\
\text { and the } \\
\text { development of } \\
\text { inclusive settings. }\end{array}$ & $\begin{array}{l}\text { Contextual, } \\
\text { participatory, } \\
\text { inclusive. }\end{array}$ \\
\hline
\end{tabular}

Fig. 7 Socioculturalism in compulsory IECTE courses at Massey University 


\subsubsection{Socioculturalism in IECTE: Otago University.}

A focus on contextual influences of ECE programmes, socio-cultural contexts of

children, their families and teachers, the social and cultural foundations of

education and human development are all hallmarks of this programme. Socio-

historical analysis, social constructivism and use of bi-cultural and multi-

cultural perspectives on participation link this programme closely to

socioculturalism.

\begin{tabular}{|l|l|l|l|l|}
\hline Level & Practice-based & Pedagogical & Academic & Ideal type \\
\hline 100 & $\begin{array}{l}\text { Professional } \\
\text { and } \\
\text { regulatory } \\
\text { context of } \\
\text { ECE. }\end{array}$ & $\begin{array}{l}\text { Introduction to Te } \\
\text { Whāriki (1996); } \\
\text { language and literacy } \\
\text { development in the } \\
\text { early years; ECE in the } \\
\text { NZ context; Māori } \\
\text { language and customs. }\end{array}$ & $\begin{array}{l}\text { Teachers in } \\
\text { sociocultural } \\
\text { contexts; social } \\
\text { foundations of } \\
\text { education; human } \\
\text { development in } \\
\text { sociocultural } \\
\text { contexts. }\end{array}$ & $\begin{array}{l}\text { Contextual, } \\
\text { embedded, } \\
\text { contextualised, } \\
\text { communicative. }\end{array}$ \\
\hline 200 & $\begin{array}{l}\text { Knowledge } \\
\text { recognition } \\
\text { and } \\
\text { promotion of } \\
\text { complex } \\
\text { learning. }\end{array}$ & $\begin{array}{l}\text { Analysis of Te Whāriki } \\
\text { (1996); quality } \\
\text { education and care of } \\
\text { children; developing } \\
\text { collaborative } \\
\text { relationships with } \\
\text { children and parents; } \\
\text { Māori language and } \\
\text { learning and } \\
\text { (cognitive, } \\
\text { behavioural, } \\
\text { social } \\
\text { constructivist); } \\
\text { socio-historical } \\
\text { context of ECE in } \\
\text { NZ. }\end{array}$ & $\begin{array}{l}\text { Relationship } \\
\text { based, co- } \\
\text { constructed, } \\
\text { contextualised. }\end{array}$ \\
\hline 300 & $\begin{array}{l}\text { Implementing } \\
\text { and } \\
\text { evaluating } \\
\text { integrative } \\
\text { programmes } \\
\text { for learning. }\end{array}$ & $\begin{array}{l}\text { Implementation of Te } \\
\text { Whāriki (1996) in bi- } \\
\text { and multi-cultural } \\
\text { settings; professional } \\
\text { practice in diverse } \\
\text { contemporary } \\
\text { contexts; individual } \\
\text { research project; Māori } \\
\text { language and customs. }\end{array}$ & $\begin{array}{l}\text { Practical } \\
\text { implications of } \\
\text { research and } \\
\text { educational } \\
\text { theory; research } \\
\text { methods in ECE. }\end{array}$ & $\begin{array}{l}\text { Supports } \\
\text { equity, } \\
\text { inclusive, } \\
\text { connected to } \\
\text { contexts. }\end{array}$ \\
\hline
\end{tabular}

Fig. 8 Socioculturalism in compulsory IECTE courses at Otago University (2007). 


\subsubsection{Socio-culturalism in IECTE: University of Canterbury.}

A focus on relationship building, contextual influences on children, families

and development, socio-cultural assessment and emphasis of bi- and multi-

cultural settings is a hallmark of this programme. Links between quality and

cultural awareness, promotion of children's participation, awareness of

diversity and a focus on inclusivity link this programme to socioculturalism.

\begin{tabular}{|c|c|c|c|c|}
\hline Level & Practice-based & Pedagogical & Academic & Ideal type \\
\hline 100 & $\begin{array}{l}\text { Professional } \\
\text { practice and } \\
\text { self- reflection. }\end{array}$ & $\begin{array}{l}\text { Developing } \\
\text { relationship building } \\
\text { skills; understand bi- } \\
\text { and multi-cultural } \\
\text { responsibilities; } \\
\text { regulatory context of } \\
\text { ECE; curriculum, } \\
\text { diversity and effective } \\
\text { learning environments; } \\
\text { Māori language \& } \\
\text { culture. }\end{array}$ & $\begin{array}{l}\text { Learning, learning } \\
\text { styles, teaching } \\
\text { strategies; social } \\
\text { cultural and } \\
\text { political contexts } \\
\text { of ECE in NZ. }\end{array}$ & $\begin{array}{l}\text { Relationship } \\
\text { based, } \\
\text { contextual, } \\
\text { communicative, } \\
\text { inclusive. }\end{array}$ \\
\hline 200 & $\begin{array}{l}\text { Self-reflection } \\
\text { and centre } \\
\text { management. }\end{array}$ & $\begin{array}{l}\text { Adult/child learning } \\
\text { relationships; quality } \\
\text { and culturally aware } \\
\text { learning experiences; } \\
\text { planning for learning in } \\
\text { bi-cultural settings; } \\
\text { curriculum and } \\
\text { assessment. }\end{array}$ & $\begin{array}{l}\text { Sociocultural } \\
\text { assessment and } \\
\text { teaching and } \\
\text { learning; inclusive } \\
\text { pedagogy and } \\
\text { building } \\
\text { networks; } \\
\text { children's } \\
\text { construction of } \\
\text { knowledge and } \\
\text { contextual } \\
\text { influences. }\end{array}$ & $\begin{array}{l}\text { Relationship } \\
\text { based, supports } \\
\text { equity, } \\
\text { inclusive, co- } \\
\text { construction, } \\
\text { contextual. }\end{array}$ \\
\hline 300 & $\begin{array}{l}\text { Self-reflection, } \\
\text { the Treaty of } \\
\text { Waitangi and } \\
\text { continued } \\
\text { professional } \\
\text { development. }\end{array}$ & $\begin{array}{l}\text { Developing inclusive } \\
\text { practices; development } \\
\text { of reciprocal } \\
\text { relationships in ECE } \\
\text { settings; working } \\
\text { collaboratively; Māori } \\
\text { language and culture. }\end{array}$ & $\begin{array}{l}\text { Action research; } \\
\text { developmental } \\
\text { context of the } \\
\text { curriculum. }\end{array}$ & $\begin{array}{l}\text { Supporting } \\
\text { equity, } \\
\text { inclusive, } \\
\text { relationship } \\
\text { based, } \\
\text { inclusive. }\end{array}$ \\
\hline
\end{tabular}

Fig. 9 Sociocultural in compulsory IECTE courses at the University of Canterbury (2007). 


\subsubsection{Socioculturalism in IECTE: Victoria University of Wellington.}

A focus on building professional and inclusive relationships, enhancing a sense of belonging, encouragement of community involvement in ECE and a sociocultural perspective on human development are hallmarks of this programme. Use of socio-historical analysis, a focus on constructing responsive bi- and multi-cultural settings, and an emphasis on the participatory rights link to socioculturalism.

\begin{tabular}{|l|l|l|l|l|}
\hline Level & Practice-based & Pedagogical & Academic & Ideal type \\
\hline 100 & $\begin{array}{l}\text { Professional } \\
\text { relationships within } \\
\text { ECE settings; } \\
\text { Developing } \\
\text { relationships with } \\
\text { parents/whānau. }\end{array}$ & $\begin{array}{l}\text { Exploring Te } \\
\text { Whāriki (1996); well } \\
\text { being and } \\
\text { belonging needs; } \\
\text { culture and Māori } \\
\text { language and } \\
\text { protocols. }\end{array}$ & $\begin{array}{l}\text { Sociocultural } \\
\text { perspective on } \\
\text { child development; } \\
\text { socio-historical } \\
\text { analysis of ECE in } \\
\text { NZ. }\end{array}$ & $\begin{array}{l}\text { Relationship } \\
\text { based, } \\
\text { community, } \\
\text { inclusive, } \\
\text { supporting } \\
\text { equity. }\end{array}$ \\
\hline $\begin{array}{l}\text { Practices for } \\
\text { building inclusive } \\
\text { relationships with } \\
\text { parents and } \\
\text { whānau; relating } \\
\text { links with the } \\
\text { wider community. }\end{array}$ & $\begin{array}{l}\text { Language and } \\
\text { communication in } \\
\text { diverse contexts; } \\
\text { music and } \\
\text { expression in } \\
\text { diverse contexts; } \\
\text { curriculum areas; } \\
\text { language } \\
\text { acquisition and } \\
\text { Māori culture. }\end{array}$ & $\begin{array}{l}\text { Children's rights } \\
\text { and socio- } \\
\text { contextual } \\
\text { issues. }\end{array}$ & $\begin{array}{l}\text { Supporting } \\
\text { equity, } \\
\text { relationship } \\
\text { based, } \\
\text { communicative, } \\
\text { inclusive. }\end{array}$ \\
\hline 300 & $\begin{array}{l}\text { Leadership and } \\
\text { community } \\
\text { involvement; } \\
\text { regulatory contexts of } \\
\text { ECE; context and the } \\
\text { development of } \\
\text { quality programmes. }\end{array}$ & $\begin{array}{l}\text { Facilitating and } \\
\text { extending } \\
\text { children's } \\
\text { thinking } \\
\text { processes. }\end{array}$ & $\begin{array}{l}\text { Socio-emotional } \\
\text { development in } \\
\text { sociocultural } \\
\text { settings; } \\
\text { advocacy for } \\
\text { children in } \\
\text { diverse settings. }\end{array}$ & $\begin{array}{l}\text { Contextual, } \\
\text { community, } \\
\text { supporting } \\
\text { equity, } \\
\text { inclusive, } \\
\text { participatory. }\end{array}$ \\
\hline
\end{tabular}

Fig. 10 Socioculturalism in compulsory IECTE courses at Victoria University of Wellington (2007). 


\subsubsection{Socioculturalism in IECTE: Waikato University.}

A focus on bi-culturalism in ECE settings, use of sociocultural theories of human development, and emphasis on belonging, social wellbeing, relationships and participation are all hallmarks of this programme. Use of sociocultural assessment tools, links to the wider community, focus on developing cultural and multi-cultural relationships all link this programme strongly to socioculturalism.

\begin{tabular}{|c|c|c|c|c|}
\hline Level & Practice-based & Pedagogical & Academic & Ideal type \\
\hline 100 & $\begin{array}{l}\text { Links between } \\
\text { theory and } \\
\text { teacher practice. }\end{array}$ & $\begin{array}{l}\text { Cultural studies } \\
\text { (intro to Māori } \\
\text { language and } \\
\text { culture); personal } \\
\text { and professional } \\
\text { relationship building, } \\
\text { health and children's } \\
\text { wellbeing. }\end{array}$ & $\begin{array}{l}\text { Influence on } \\
\text { family, } \\
\text { educational } \\
\text { settings and mass } \\
\text { media on } \\
\text { children; } \\
\text { philosophical } \\
\text { perspectives in } \\
\text { ECE programmes. }\end{array}$ & $\begin{array}{l}\text { Inclusive, } \\
\text { relationship } \\
\text { based, } \\
\text { connected to } \\
\text { context. }\end{array}$ \\
\hline 200 & $\begin{array}{l}\text { Links between } \\
\text { theory and } \\
\text { teacher practice. }\end{array}$ & $\begin{array}{l}\text { Art and creativity; } \\
\text { participation in } \\
\text { learning } \\
\text { environments (maths } \\
\text { and technology); } \\
\text { language acquisition; } \\
\text { Māori language and } \\
\text { culture. }\end{array}$ & $\begin{array}{l}\text { Philosophy and } \\
\text { theory in ECE } \\
\text { (focusing on } \\
\text { sociocultural } \\
\text { relationships); } \\
\text { theoretical } \\
\text { frameworks and } \\
\text { practice } \\
\text { (sociocultural). }\end{array}$ & $\begin{array}{l}\text { Participatory, } \\
\text { embedded, } \\
\text { relationship } \\
\text { based, } \\
\text { inclusive, } \\
\text { supporting } \\
\text { equity. }\end{array}$ \\
\hline 300 & $\begin{array}{l}\text { Links between } \\
\text { theory and } \\
\text { practice - } \\
\text { developing a } \\
\text { personal } \\
\text { teaching } \\
\text { philosophy. }\end{array}$ & $\begin{array}{l}\text { Developing and } \\
\text { assessing quality } \\
\text { ECE programmes; } \\
\text { managing } \\
\text { transition to } \\
\text { school. }\end{array}$ & $\begin{array}{l}\text { Facilitation of } \\
\text { belonging and } \\
\text { contribution } \\
\text { within socio- } \\
\text { cultural contexts } \\
\text { for the } \\
\text { development of } \\
\text { social wellbeing. }\end{array}$ & $\begin{array}{l}\text { Co- } \\
\text { construction, } \\
\text { connected to } \\
\text { context, } \\
\text { participatory. }\end{array}$ \\
\hline
\end{tabular}

Fig. 11 Socioculturalism in compulsory IECTE courses at Waikato University (2007). 
The content of these IECTE programmes are all greatly influenced by socioculturalism. The words used in the online programmes for the 2007 year drew heavily on the vocabulary and concepts outlined in the ideal type for socioculturalism. To further deepen this analysis of socioculturalism in IECTE programmes, this thesis makes a case study of the course outlines of one New Zealand university. The following section presents the findings of that case study.

\subsection{Socioculturalism in the content of the IECTE programme at a}

\section{case study university}

In order to assess the influence of socioculturalism in a more detailed way, this section analyses the course outlines of compulsory courses in the BEd (ECE) programme at one New Zealand university. The compulsory courses at this university are made up of three types of courses: practice-based courses which are the courses that structure and assess teaching practice; pedagogical courses, which are curriculum studies courses; and academic courses, which are education courses from the Bachelor of Arts programme. This section analyses each type of course in turn, identifying the influence of socioculturalism in the text of course outlines pertaining to the course aims and objectives, the course work (pedagogical work: Bourdieu and Passeron, 1990), and required course 
readings. The following analysis uses grids to chart the contents of each course using the 2007 course outlines from the case study university.

\subsubsection{Socioculturalism in the content of practice-based papers}

Socioculturalism exerts great influence on the content of practice-based papers in the objectives of courses, the pedagogical work undertaken in courses and in the required readings in the case study university. The practice-based courses encourage the formation of relationships and connections between children, adults, families/whānau and the wider community. These courses facilitated the development of learning communities through participation, shared experience and transformative pedagogical action. These courses used Te Whāriki (Ministry of Education, 1996) as a core text in describing not only the purpose of education, but also as a guide to the development of educational programmes for use in multicultural early childhood settings. They also aimed to acquaint student teachers with forms of socio-cultural assessment and encourage the development of professional partnerships within the sector.

The pedagogical work undertaken in these courses emphasised that learners (and teachers) are embedded in diverse socio-cultural contexts. Focus was on both inclusion and understanding diversity in ECE settings. Student teacher observations were contextualised in particular settings and served to communicate a shared sense of social agency (one that encourages student 
teachers to reflect on how their practice empowers children and their families/whānau). Broader socio-political contexts were considered in relation to the early childhood settings in which the students are embedded. A central theme of the pedagogical work was the understanding that children and their contexts are embedded in multiple social and cultural networks. Teaching practice emphasised the social construction of knowledge and aims to empower children through the co-construction of both the content and the context of their education.

The sociocultural readings (e.g., Duffy, 1998) used in these courses emphasised relationship building, the formation of connections within settings, and methods of improving participation (of both children and adults). The readings linked individual children's development with the learning environments in which they are embedded, and offered guidance on the application of sociocultural assessment tools. The vocabulary of these courses: the objectives, pedagogical work and required readings drew heavily upon socioculturalism. 


\begin{tabular}{|c|c|c|c|}
\hline Course & Objectives & Pedagogical work & Required readings \\
\hline 112 & $\begin{array}{l}\text { Development of } \\
\text { professional skills } \\
\text { through human } \\
\text { relations; using Kei Tua } \\
\text { o te Pae (2004-2007) for } \\
\text { assessment. }\end{array}$ & $\begin{array}{l}\text { Contextual influences } \\
\text { that brought students to } \\
\text { ECE; educational } \\
\text { influences; analysis of } \\
\text { conversations with } \\
\text { children; contextual } \\
\text { analysis focused on } \\
\text { relationship formation. }\end{array}$ & $\begin{array}{l}\text { Duffy (1998) on relationship } \\
\text { building and Reid (2002) on } \\
\text { using learning stories. }\end{array}$ \\
\hline 113 & $\begin{array}{l}\text { Practicum focusing on } \\
\text { professional } \\
\text { behaviours, } \\
\text { relationships with } \\
\text { adults, relationships } \\
\text { with children. }\end{array}$ & $\begin{array}{l}\text { Practice narrative } \\
\text { observation and aim to } \\
\text { contextualise children } \\
\text { within wider social } \\
\text { networks as a means for } \\
\text { understanding them. }\end{array}$ & N/A \\
\hline 213 & $\begin{array}{l}\text { Practicum focusing on } \\
\text { working in partnership } \\
\text { with parents, whānau } \\
\text { and caregivers in ECE. }\end{array}$ & $\begin{array}{l}\text { Narrative observation } \\
\text { focusing on working with } \\
\text { parents, whānau and } \\
\text { caregivers in ECE. }\end{array}$ & $\mathrm{N} / \mathrm{A}$ \\
\hline 214 & $\begin{array}{l}\text { Developing } \\
\text { professional } \\
\text { partnerships, analysis } \\
\text { of environmental and } \\
\text { contextual issues, } \\
\text { developing parental } \\
\text { and community } \\
\text { relationships. }\end{array}$ & $\begin{array}{l}\text { Reflection on student's } \\
\text { values and beliefs when } \\
\text { working with, whānau } \\
\text { and caregivers; } \\
\text { contextualising the child } \\
\text { using learning stories, } \\
\text { scaffolding for future } \\
\text { action; reflective practice } \\
\text { on human relations. }\end{array}$ & $\begin{array}{l}\text { Carr (2001) on learning } \\
\text { stories; Dalli (1997) on ECE } \\
\text { settings as sites of parental } \\
\text { support; Greenfield, Quiroz, } \\
\text { Rothstein-Fisch and } \\
\text { Trumbull's (2001) work on } \\
\text { linking home and school; } \\
\text { Morrow and Nigel (2004) on } \\
\text { relationships with parents. }\end{array}$ \\
\hline 312 & $\begin{array}{l}\text { The artistry of teaching; } \\
\text { teachers' ability to } \\
\text { connect with the wider } \\
\text { community; facilitate } \\
\text { curriculum led } \\
\text { practices; participation. }\end{array}$ & $\begin{array}{l}\text { Understanding the } \\
\text { regulatory and statutory } \\
\text { context of ECE; } \\
\text { demonstration of teacher } \\
\text { competencies. }\end{array}$ & $\begin{array}{l}\text { Keesing-Styles (2000) on } \\
\text { improving parental } \\
\text { participation; Smith (2006) } \\
\text { on linking collaboration with } \\
\text { children's wellbeing. }\end{array}$ \\
\hline 315 & $\begin{array}{l}\text { Construction and } \\
\text { delivery of quality ECE } \\
\text { programmes focusing } \\
\text { on context, transition } \\
\text { and socio-cultural } \\
\text { assessment. }\end{array}$ & $\begin{array}{l}\text { Research report on } \\
\text { children's learning, } \\
\text { professional } \\
\text { development, early } \\
\text { childhood settings. }\end{array}$ & $\begin{array}{l}\text { Anning (2004) on co- } \\
\text { construction of learning } \\
\text { environments; Cullen (2001) } \\
\text { on assessment in a socio- } \\
\text { cultural curriculum; Wien, } \\
\text { Coates, Kealing and Bigelow } \\
\text { (2005) encouraging a } \\
\text { connection to place. }\end{array}$ \\
\hline
\end{tabular}

Fig. 12 Socioculturalism in compulsory practice-based papers at the case study university. 


\subsubsection{Socioculturalism in the content of pedagogical papers}

The objectives of the pedagogical courses focused on forming positive learning environments through the development of positive, reciprocal relationships between children, adults, families/whānau and the wider community. Programmes highlighted the importance of inclusivity and assumed that children, adults and families/whānau are embedded in social and cultural contexts that contribute to both well-being and a sense of belonging. Programmes aimed to enhance participation and encourage the expression of diversity in terms of culture and commitment to the wider communities to which children and their families/whānau belong through the development of reciprocal relationships. Specific focus was given to bi-cultural issues and strategies for the inclusion of Pasifika cultures in centre practices.

Pedagogical work highlighted the importance of context in teaching practices and learning. Sociocultural teaching strategies surrounding the use of Vygotsky's (1986) notion of the zone of proximal development were assessed, as was the application of socio-cultural assessment tools. Curriculum areas were linked to social and cultural considerations to encourage participation and a sense of belonging. Assessments encouraged the co-construction of knowledge through the application of sociocultural learning theories in diverse settings. Bi-cultural considerations were examined and a commitment to the Treaty of Waitangi was explored and used to inform teaching practice. 
Pedagogical work in the pedagogical courses assessed the degree to which students could use Te Whāriki (Ministry of Education, 1996) to inform, guide and reflect on their teaching practice.

The sociocultural readings in the required readings focused on co-construction, adult/children relationships, contexualisation, strategies for inclusiveness, the celebration of diversity and encouragement of inclusive practices in ECE. The pedagogical courses linked pedagogy with community in the construction of learning environments to encourage participation, communication, belonging and a shared sense of community. Therefore, in great part, the content of pedagogical courses at the case study university drew on a sociocultural vocabulary to describe the aims and objectives of learning, to organise the assessed pedagogical work and to highlight key texts for consideration.

\begin{tabular}{|l|l|l|l|}
\hline Course & Objectives & Pedagogical work & Required readings \\
\hline 111 & $\begin{array}{l}\text { Overview of children's } \\
\text { learning and Te } \\
\text { Whäriki (1996). }\end{array}$ & $\begin{array}{l}\text { Review 4 articles regarding } \\
\text { Te Whäriki (1996); poster on } \\
\text { a play context; test on an } \\
\text { observation in the zone of } \\
\text { proximal development }\end{array}$ & $\begin{array}{l}\text { Dockett (1997) on adult } \\
\text { support of children's play; } \\
\text { Richie (2003) and Carr } \\
\text { and May (2000) on Te } \\
\text { Whāriki. }\end{array}$ \\
\hline 112 & $\begin{array}{l}\text { Understanding how } \\
\text { the culture of a setting } \\
\text { influences children's } \\
\text { wellbeing and } \\
\text { belonging; enhancing } \\
\text { positive cultures in } \\
\text { settings. }\end{array}$ & $\begin{array}{l}\text { Linking the nurture of } \\
\text { wellbeing and belonging to } \\
\text { quality teaching practices; } \\
\text { preparing food in diverse } \\
\text { cultural contexts; test. }\end{array}$ & $\begin{array}{l}\text { Quality in Action (1998); } \\
\text { Church (2006) on creating } \\
\text { sense of community; } \\
\text { Pugh (2001) on } \\
\text { collaborative \& } \\
\text { relationships; Swick \& } \\
\text { Freeman (2004) on } \\
\text { peaceful communities. }\end{array}$ \\
\hline
\end{tabular}




\begin{tabular}{|c|c|c|c|}
\hline 113 & $\begin{array}{l}\text { Introduction to the } \\
\text { study of culture; } \\
\text { reflection on student's } \\
\text { own and other } \\
\text { cultures; expression of } \\
\text { the Treaty of Waitangi }\end{array}$ & $\begin{array}{l}\text { Understanding the Treaty } \\
\text { of Waitangi; reflection on } \\
\text { the role of culture in } \\
\text { everyday life. }\end{array}$ & \\
\hline 211 & $\begin{array}{l}\text { Focus on art, language } \\
\text { development and the } \\
\text { communication strand } \\
\text { of Te Whāriki (1996). } \\
\text { Understanding } \\
\text { Vygotsky (1986) theory } \\
\text { of language } \\
\text { acquisition. }\end{array}$ & $\begin{array}{l}\text { Studies of art and } \\
\text { communication; studies of } \\
\text { children's literature; } \\
\text { application of language } \\
\text { acquisition theory. }\end{array}$ & $\begin{array}{l}\text { Eales (1996) on Vygotsky } \\
\text { and art; Hamar (2005) on } \\
\text { infant literacy from a } \\
\text { socio-cultural perspective; } \\
\text { Guylon and Terrini (2002) } \\
\text { on linking learning } \\
\text { environments and } \\
\text { empowerment; Terrini } \\
\text { (2005) on scaffolding in } \\
\text { art education. }\end{array}$ \\
\hline 212 & $\begin{array}{l}\text { Focus on diverse } \\
\text { cultural environments } \\
\text { for music and physical } \\
\text { development. } \\
\text { Importance of cultural } \\
\text { factors for children's } \\
\text { expression r and } \\
\text { learning. }\end{array}$ & $\begin{array}{l}\text { Understanding musical } \\
\text { composition in diverse } \\
\text { cultures; understanding } \\
\text { the value of physical } \\
\text { movement and designing } \\
\text { learning environments. }\end{array}$ & $\begin{array}{lr}\text { Achilles (1999) on creating } \\
\text { music } & \text { environments; } \\
\text { Poest, Williams, Witt and } \\
\text { Alwoods (1990) on } \\
\text { scaffolding } & \text { children's } \\
\text { large } & \text { muscle } \\
\text { development. } & \end{array}$ \\
\hline 213 & $\begin{array}{l}\text { Extend and support } \\
\text { skills in Māori } \\
\text { language and customs } \\
\text { for ECE programmes. }\end{array}$ & $\begin{array}{l}\text { Conceptual analysis of } \\
\text { either whānaungatanga } \\
\text { (interdependence), } \\
\text { tuakana/teina (a Māori } \\
\text { equivalent to scaffolding), } \\
\text { manaakitanga (respect for } \\
\text { others), or kotahitanga } \\
\text { (being together); increasing } \\
\text { Māori language in centres. }\end{array}$ & $\begin{array}{l}\text { Chang (1994) on cultural } \\
\text { and linguistic continuity } \\
\text { for the young; Royal- } \\
\text { Tangaere (1997) on a } \\
\text { Māori interpretation of } \\
\text { the zone of proximal } \\
\text { development; Irwin (1994) } \\
\text { on contextualising Māori } \\
\text { educational policy. }\end{array}$ \\
\hline 214 & $\begin{array}{l}\text { Focuses on the rights } \\
\text { of children to active } \\
\text { and equitable } \\
\text { participation in } \\
\text { communities; } \\
\text { developing strategies } \\
\text { for inclusion for Māori } \\
\text { and Pasifika children. }\end{array}$ & $\begin{array}{l}\text { Cultural analysis of a } \\
\text { learning story; role play } \\
\text { using only in Māori } \\
\text { language; reflective journal } \\
\text { on personal feeling of } \\
\text { inclusions and exclusion. }\end{array}$ & $\begin{array}{l}\text { Gerritsen (2000) on } \\
\text { diversity; Sapon-Shevin } \\
(1996) \text { on celebrating } \\
\text { diversity and community; } \\
\text { Villegas and Lucas (2002) } \\
\text { on culturally responsive } \\
\text { teachers. }\end{array}$ \\
\hline 311 & $\begin{array}{l}\text { Focuses on the role of } \\
\text { adults in } \\
\text { understanding and } \\
\text { extending children's } \\
\text { thinking processes. }\end{array}$ & $\begin{array}{l}\text { Linking maths to socio- } \\
\text { cultural pedagogy; linking } \\
\text { technology with context; } \\
\text { powerpoint on a topic in } \\
\text { science. }\end{array}$ & $\begin{array}{l}\text { Bickmore-Brand and } \\
\text { Gawned (1990) on } \\
\text { scaffolding in mathmatics; } \\
\text { Mactier (2006) on co- } \\
\text { construction } \\
\text { knowledge; Paley (1986) } \\
\text { on child participation. }\end{array}$ \\
\hline
\end{tabular}

Fig. 13 Socioculturalism in pedagogical papers at the case study university. 


\subsubsection{Socioculturalism in the content of academic papers}

The academic courses drew heavily on a socio-cultural vocabulary in the description of course aims, in the pedagogical work that is assessed and in the required readings for each course. The aim of these courses was to encourage students to consider the socio-historical contexts in which they are embedded and the diversity of sociocultural contexts that operate at any one time in ECE settings. These courses highlighted the importance of inclusive practices for the formation of learning communities, the importance of participation and belonging for effective teaching and learning, and the centrality of context in building relationships between children, adults and family/whānau in ECE settings.

The pedagogical work undertaken in the academic papers required students to contextualise theorists and theoretical perspectives in ECE, national and international ECE settings and advocacy groups for children. Students focused on facilitating a sense of belonging and wellbeing for children and building positive relationships with parents/whānau and caregivers. In these papers students were required to demonstrate an understanding of embeddedness, participatory rights and the value of developing trusting relationships with children, adults, external agencies and the wider community. 
The required readings provided insight into socio-historical contexts, participatory rights and the development of communities of learners, reciprocal relationships and social connectedness. The course outlines for the academic papers used a sociocultural vocabulary to describe aims and objectives for students, pedagogical work that is required to meet the terms of each paper and required readings. 


\begin{tabular}{|c|c|c|c|}
\hline Course & Objectives & Pedagogical work & $\begin{array}{l}\text { Required } \\
\text { readings }\end{array}$ \\
\hline 153 & $\begin{array}{l}\text { Encourages critical } \\
\text { analysis of socio- } \\
\text { historical and political } \\
\text { contexts of ECE in NZ } \\
\text { and Europe. }\end{array}$ & $\begin{array}{l}\text { Book review or biography } \\
\text { of historical figure focusing } \\
\text { on contextual influences; } \\
\text { contextual analysis and } \\
\text { comparison of the origins } \\
\text { of } 2 \text { ECE services. }\end{array}$ & $\begin{array}{l}\text { May }(1997,2001) \text { on } \\
\text { the socio-historico- } \\
\text { political contexts of } \\
\text { ECE services in NZ } \\
\text { and Europe. }\end{array}$ \\
\hline 154 & $\begin{array}{l}\text { Understanding of } \\
\text { developmental } \\
\text { approaches in ECE; } \\
\text { observation of children } \\
\text { in ECE settings. } \\
\text { Recognises that all } \\
\text { children develop } \\
\text { within social and } \\
\text { cultural contexts. }\end{array}$ & $\begin{array}{l}\text { Overview of a theorist and } \\
\text { their key ideas; observation } \\
\text { and running record; socio- } \\
\text { historical comparison of } \\
\text { two developmental } \\
\text { theorists; review of Carr's } \\
\text { (1997) article on learning } \\
\text { dispositions. }\end{array}$ & $\begin{array}{l}\text { Carr (2001) on } \\
\text { learning dispositions. } \\
\text { Smith (1998) on } \\
\text { children's } \\
\text { development from a } \\
\text { socio-cultural } \\
\text { perspective. }\end{array}$ \\
\hline 253 & $\begin{array}{l}\text { Appraise cultural, } \\
\text { political and } \\
\text { pedagogical contexts of } \\
\text { ECE in NZ and } \\
\text { internationally; } \\
\text { children's rights and } \\
\text { contemporary issues in } \\
\text { ECE. }\end{array}$ & $\begin{array}{l}\text { Portfolio of social issue; } \\
\text { contextual analysis of } 2 \\
\text { contemporary ECE } \\
\text { services; seminar on a } \\
\text { contemporary ECE service } \\
\text { and its socio-historical } \\
\text { context. }\end{array}$ & $\begin{array}{l}\text { Hart (1997) on } \\
\text { children's } \\
\text { participation; John } \\
\text { (2003) on children's } \\
\text { rights and power } \\
\text { sharing; Mitchell and } \\
\text { Reid-Walsh (2002) on } \\
\text { children's cultural } \\
\text { spaces. }\end{array}$ \\
\hline 356 & $\begin{array}{l}\text { Examine adult/child } \\
\text { relationships; explore } \\
\text { the interface between } \\
\text { good teaching practice } \\
\text { and emotional and } \\
\text { social wellbeing in } \\
\text { diverse socio-cultural } \\
\text { settings. }\end{array}$ & $\begin{array}{l}\text { Adult responsibilities } \\
\text { within Te Whāriki (1996); } \\
\text { journal focusing on issues } \\
\text { of belonging and } \\
\text { contribution; seminar on } \\
\text { relationship building, } \\
\text { socio-emotional wellbeing, } \\
\text { or linking diverse contexts. }\end{array}$ & $\begin{array}{l}\text { Derman-Sparks } \\
\text { (1989) on removing } \\
\text { bias from ECE } \\
\text { contexts; Hanna } \\
\text { (2006) on children } \\
\text { and parents learning } \\
\text { together; Pollard } \\
\text { (1996) on learning as } \\
\text { a social activity. } \\
\end{array}$ \\
\hline 358 & $\begin{array}{l}\text { Overviews advocacy } \\
\text { for children in a } \\
\text { democratic context; } \\
\text { develop skills to } \\
\text { advocate on behalf of } \\
\text { children. }\end{array}$ & $\begin{array}{l}\text { The role of adults as } \\
\text { advocates; contextual study } \\
\text { of an advocacy group and } \\
\text { the strategies they employ; } \\
\text { analysis of media releases } \\
\text { on child specific issues. } \\
\text { Drawing up a press release } \\
\text { to be used for advocacy on } \\
\text { a child specific issue. }\end{array}$ & \\
\hline
\end{tabular}

Fig. 14 Socioculturalism in the compulsory academic papers at the case study university. 
Socio-culturalism was an integral part of the BEd (ECE) programme at the case study university. The content that student teachers were expected to learn across the courses, the pedagogical work that student teachers were expected to complete in order to meet the requirements of each course, and the literature that student teachers are expected to read as part of the course requirements were all heavily influenced by socioculturalism and sociocultural theory. These findings support the proposition that the content of IECTE programmes Aotearoa/New Zealand is heavily influenced by socioculturalism.

In IECTE programme outlines and the course outlines of the case study university socioculturalism is the dominant discourse. The content of these programmes and courses encourages student teachers to acknowledge children as social beings connected to multiple communities. They emphasise the contextual influences on learning and development and highlight participation, inclusivity, communication and relationship building as appropriate pedagogical methods for early childhood education in Aotearoa/New Zealand.

\subsection{Socioculturalism in student teacher's experiences of their IECTE} programme at a case study university.

The final level of the ecological hermeneutic is the empirical findings from focus 
groups carried out at a case study university. The focus groups are used to add an empirically based component to this thesis. Over the four focus groups it was clear that socioculturalism dominated the content of IECTE programmes, for example, when asked about the importance of cultural values on participant, responded that "to be a teacher you have to be culturally aware", which meant that teachers were expected to understand the important influence that culture has on both development and learning. When describing the content of the courses another student observed that "there is a lot of sociocultural theory... we know that it's important". Other members of the group agreed.

When student teachers were asked what they enjoyed most about their IECTE experiences, students across all four focus groups responded that it was the sociocultural aspects such as relationships, community, embeddedness, belonging and the opportunities to participate in their context (though few of the latter were reported by participants). One typical response was: “I like meeting everyone, making contacts and learning through others, not necessarily the lecturers, the students too". Another typical response was summed up by a student in a different group when she talked about the importance of building relationships and a sense of companionship: "that's one of the good things because you are in small classes, getting to know other students really well, which is really nice, making friends and all that". 
Much of the the students' focus, in terms of positive experiences, revolved around the practice of socioculturalism in their classroom context. Students found they had more affinity with their lecturers when content matched context, for instance, when asked about how she experienced the teaching on her course she responded "the lecturers that are good and the lectures you learn the most in, are the lectures that are related back to everyday life". These students were highlighting the importance of context in their own learning and voiced their support of intimate teaching spaces where relationships and connections could be formed not only between students, but also between students and teaching staff. For instance, when participants were asked what they enjoy about their course one participant highlighted the teacher-student relationship by observing that "with the small classes you get to know the teachers better". The other participants voiced their approval that this was a positive aspect in their education.

Some participants in the focus groups pointed out the importance of lecturers using sociocultural teaching methods to implicate themselves within the context in which they are teaching. For example one participant said, "I like that the lecturers have had experience themselves in early childhood education so they are following their own experiences, they haven't just learnt this theory, they haven't learnt just concepts and stand up in front of us and preach it". The 
other participants in the group agreed and indicated that real learning occurs for them when teachers and learners are embedded within the same social space, rather than separated by ownership of conceptual knowledge. The point here is not that teaching style needs to change, it is that this group of student teachers believed that for learning to be made more meaningful for them the delivery had to match the message. This theme is picked up in chapter eight.

Student teachers found value in situations where they felt the university recognised their unique needs and in situations where there was an emphasis on relationship building, though all four groups reported that there was little opportunity to pursue these sociocultural factors in class-time. For instance, when asked what she thought of group work, one participant said, "yeah I like working in groups most of the time... the objectives are put there and everybody takes their share and does their part in producing whatever we have got to produce." However, all groups stressed that there was not much group work, and some respondents also intimated that they would rather do individual projects because then there is control of the overall quality. This finding will be revisited in the next chapter.

One particular group was made up entirely of Samoan students for whom English is a second language. For them the problems they faced involved a sense that their culture and language were not valued by their programme of 
study (see discussion of this in chapter 8). However, these students also placed great value in those occasions when the sociocultural content they were absorbing was matched by socioculturalism in their learning context. For example, when asked how they feel about their experience at the case study university one student stated, "I was quite pleased today, you know, this is the practice that is done in the College [university] that I agree with, you know, it was like 'if English is your second language, go into theatre 2 because you get an extra half an hour". Another student described what she thought was effective teaching given that English is her second language: “But she speaks slowly... If you ask a question she explains more and shows you on the board how to at least write an essay. Yeah, we feel better. You go home really happy, the next day you want to come back to school, if you're not happy you don't want to go back to school". These students are expressing a desire that their culture and social/linguistic practices be included in the institutional setting of the university. These students are expressing their hope that socioculturalism may have an influence beyond the content of their courses to encompass the context in which those courses are being provided.

\section{Summary}

This chapter has used an ecological hermeneutic to justify the proposition that socioculturalism heavily influences the content of IECTE programmes. Analysis began with the sociohistorical context of contemporary IECTE programmes 
highlighting the movement from individual based to social based rationales for early childhood education. Te Whāriki (Ministry of Education, 1996), the Graduating Teacher Standards (NZ Teachers Council, 2007) and Kei Tua o te Pai (Ministry of Education, 2004) were all shown to draw heavily on socioculturalism in terms of their content. Analysis of seven IECTE programmes highlighted the great extent to which IECTE programmes use socioculturalism in the content of all compulsory courses within the programmes. Analysis of course outlines at a case study university supported the claim that the content of IECTE programmes in Aotearoa/New Zealand draw heavily on socioculturalism and evidence from the focus groups also supported this claim. This chapter has presented one side of structural dissonance in IECTE programmes. The next chapter constructs the other side of that pairing: Individualisation. 


\section{Chapter 7}

\section{Individualisation in the context of IECTE programmes in}

\section{Aotearoa/New Zealand.}

This chapter advances the argument that the context in which IECTE programmes are provided reproduces individualisation. This chapter is important to this thesis because it defines and identifies the second pairing in the thesis of structural dissonance. This chapter is organised into two sections: The first section constructs an ideal type for individualisation using the theoretical writing of Bauman (2001), Beck (1992), and Beck \& Beck-Gernsheim (2002). The second section uses the ecological hermeneutic method (used in chapter 6) to organise interpretative analysis of the regulatory context in which IECTE programmes are provided based on the ideal type worked out in the first section.

It is useful to distinguish between individualism and individualisation.

Definitions of individualism vary by place and time (Lukes, 1973). Writers like Emerson (1847-1924) linked individualism with self reliance, which in turn can be linked to the Western liberal project of autonomy and self-creation (Taylor, 1989). Wilde (1891) equated individualism to self-expression and personal creativity, whereas writers like Hayek (1949) aligned individualism with the 
social will to limit coercive power resulting in free market philosophies and democratic social structures. In the field of early childhood education studies Woodhouse (2008) has defined individualism as "a belief in the primary importance of the individual and the virtues of self-reliance and personal independence" (p. 135). Individualisation, as this thesis uses the term, is not the same as individualism: Individualisation occurs when social institutions enforce individualism through standardisation and dependency. Under the condition of individualisation, being an individual is no longer a choice.

The liberal idea of individualism as self-creation and personal rights has been used extensively in early childhood studies (e.g., Dunn \& Cutting, 1999; Ministry of Education, 1996; Smiley \& Dweck, 1994; Spodek \& Saracho, 1994; Te One, 2009). But individualisation theory has not been used as part of a critical lens in the field of IECTE studies, though Dahlberg and Moss (2005) do pick up the reconstructive side of Beck's (1992) argument against the fragmentation of modern Western society. In the broader field of early childhood education studies, the word individualisation is synonymous with teaching techniques that encourage individualism (self-reliance, autonomy and self-expression). For example, McCormick, Wong \& Yogi (2003) wrote about individualisation in early childhood and special needs settings but defined individualisation as “maximising every child's opportunities for optimal learning" (p. 214). Likewise, Sheerer (1997) in her paper on using individualisation and scaffolding 
to improve in-service ECE learning, aligned individualisation with individual assessment of persons and their skills. This thesis adopts neither of those approaches, but uses Beck's (1992) individualisation theory to show individualisation in the context of IECTE programmes in Aotearoa/New Zealand.

Individualisation theory is a sociological theory popularised by Ulrich Beck (1992) in his book Risk Society: Towards a new modernity, and further developed in his book Individualization (Beck \& Beck-Gernsheim, 2002). Individualisation theory provides a new lens for the description of the institutional context of IECTE programmes in Aotearoa/New Zealand. The word individualisation is a piece of technical vocabulary Beck (1992) used to describe the complex social processes of late modern, post-industrial nations (such as Germany, Great Britain and New Zealand. This section uses the writing of Beck (1992), Beck \& Beck-Gernsheim (2002) and social theorist Zygmunt Bauman (2001) to construct an ideal type for individualisation theory.

\subsection{Individualisation theory: An ideal type}

This section introduces individualisation theory as a research perspective, as a social theory, and as an ideal type. The ideal type is a "one-sided accentuation" 
(Weber, as cited in Rogers, 1969, p 17) of individualization insofar as it does not critically engage with individualization theory (e.g., Atkinson, 2007 who challenged Beck's (1992) notion of a classless society). This approach leads to what critics might call a romanticised version of Beck's theory, however, the point of this section is not to engage with Beck over his description of reality, but rather to use his approach as part of a broader critique of structural dissonance in IECTE programmes in Aotearoa/New Zealand. Beck's (1992) theory is reduced to an ideal type and applied to the interpretation of texts in the context IECTE programmes. Given the philosophical assumptions that underpin this thesis and the methodological approach taken herein, that sort of one-sided accentuation is consistent with the other parts of this thesis.

\subsubsection{Individualisation as a research perspective.}

Individualisation theory has a relatively recent history in sociology, but individualisation has a much longer history given that from the time of writers such as de Tocqueville (1835) the question of individuals in society held special interest. Regarding the origins of individualisation theory, Bauman (2001) identified Norbert Elias's (1991) posthumously published The Society of Individuals as the turning point of social theory; one that transformed the popular distinctions between the individual and/versus society and made the theory of individualisation possible: 
Elias replaced the and and the versus with the of and in doing so he changed the imaginaire of the two forces locked in a mortal, yet unending battle of freedom and domination, into that of a reciprocal conception: society shaping the individuality of its members, and the individuals forming society out of their actions while pursuing strategies plausible and feasible within the socially woven web of their dependencies (Bauman, 2001, p.45).

However, it was not until Beck (1986/1992) published Risk Society: Towards a new modernity that individualisation emerged as a coherent theoretical perspective in its own right. In this book, Beck (1992) outlined his thesis of reflexive modernity: a modern world characterised by the side effects of progress ecological side effects, social/economic side effects, and individualisation (the side effect of de-traditionalising social connections and granting autonomy primacy in social relations). Beck (1992) described the innovation of his approach in the following way:

Many people associate individualisation with individuation $(=$ personalisation $=$ uniqueness $=$ emancipation). That may be true. But perhaps the opposite is also true..... In contrast to those inquiries, which are primarily concerned with consciousness, identity, socialisation and emancipation, the main question [of individualisation theory] is: how can individualisation be understood as a change of life situations and biographical patterns? (p. 128). 
Beck's (1992) theory of individualisation departs from liberal accounts of the self-empowered free individual to create a picture of institutional structures that make individualism a fate rather than a choice. Under the condition of individualisation, social institutions exert almost total control over a fragmented, non-mobile, preoccupied populace. Beck and Beck-Gernsheim (2002) described individualisation as a sociological project established as an alternative to popular discourses of globalisation ("globalisation denotes the processes through which sovereign national states are criss-crossed and undermined by transnational actors with varying prospects of power, orientations, identities and networks" (Beck, 2000, p. 11)). Specifically: "if the globalisation debate took up the territorial bias, the individualisation debate has probed and criticised the collective bias of the social sciences"' (Beck \& BeckGernsheim, 2002, p. xxi).

Beck's (2002) assumption was that analysis of society is equally possible from the perspective of the societal (as in class-systems) and from the terms of agents themselves (individuals). To premise this proposition, Beck (2002) made a distinction between new and old sociology. According to Beck, the new sociology asks questions like "what would happen if these individuals wanted a different society, or even a different type of society?" (Beck \& BeckGernsheim, 2002, p. 12). The old sociology cuts off this line of questioning by maintaining that "individuals can only be or become individuals within 
society" (Beck \& Beck-Gernsheim, 2002, p. 12). Arguably, one of Beck's (2002) intentions, therefore, was to create a new perspective in sociological theory by allowing "conflicts between individuals and society to be analysed from the standpoint of individuals" (Beck \& Beck-Gernsheim, 2002, p. 14).

Research produced from the perspective of individualisation theory offers an alternative story of social institutions and those who live within their spheres of influence than those which give primacy to society in their analysis. Examples of scholars who have used individualisation theory in their work are: Côté and Schwartz (2002) who assessed the influence of individualisation on the formation of identity in adolescents; Ferge (2002) who used individualisation theory to analyse changes to welfare state provisions; Schwartz, Cote and Arnett (2005) who used individualisation theory to study identity formation in adolescents; and Gillies (2005) who used individualisation theory to challenge meritocracy practices in the United Kingdom.

\subsubsection{Individualisation as a social theory.}

Individualisation means institutionalised individualism (individualisierung) (Beck \& Beck-Gernsheim, 2002, xxi), a term first developed by Talcott Parsons (1978) in the context of religious studies. Beck and Beck-Gernsheim (2002) gave the following definition to describe what they proposed the word individualisation entails: 
“Central institutions of modern society - basic civil, political and social rights, but also paid employment and the training and mobility necessary for it - are geared to the individual and not to the group. Insofar as basic rights are internalised and everyone wants to or must be economically active to earn their livelihood, the spiral of individualisation destroys the given foundations of social existence. So - to give a simple definition - 'individualisation' means disembedding without reembedding" (pp. xxi, xxii).

Social theorist/philosopher Zygmunt Bauman simplifies things further stating:

“To put it in a nutshell, 'individualisation' consists in transforming human 'identity' from a 'given' into a 'task' - and charging the actors with the responsibility for performing that task and for the consequences (also the sideeffects) of their performance: in other words, it consists in establishing a de jure autonomy (although not necessarily a de facto one)" (Bauman, in Beck \& BeckGernsheim, 2002, p. xv).

Both Beck and Bauman maintained that contemporary Western societies are characterised by individualisation, and that this culture is becoming the shared experience of those living in the post-industrial world. Beck (2002) pointed out that "it is the individualisation and fragmentation of growing inequalities into separate biographies which is a collective experience" (Beck \& Beck-Gernsheim, 2002, p. xxii). From this perspective, individualisation might be thought of as a 
sociocultural condition of modern Western societies. Bauman (2005)

wholeheartedly agrees with Beck's analysis, differentiating himself only by using the term liquid modernity where Beck has used second modernity.

Beck and Beck-Gernsheim (2002) went on to note that individualisation means both the "disintegration of previously existing social forms" (e.g., class), and a modern social condition wherein "new demands, controls and constraints are being imposed on individuals" (p. 2). In the context of individualisation, "one has to win, know how to assert oneself in the competition for limited resources and not only once, but day after day" (Beck \& Beck-Gernsheim, 2002, p. 3). Essentially, and here is the crux of the matter, individualisation processes "not only permit but they also demand an active contribution by individuals", or to put it another way, "individualisation is a social condition which is not arrived at by a free decision of individuals" (Beck \& Beck-Gernsheim, 2002, p. 4). It is a default setting, an "iron cage" (Weber, 2002, p. 121), a set of circumstances over which individuals have little if any control. The invisibility of individualising processes in institutional discourses, to a large extent, results from the normalisation of those processes in modern life. Further on in their work Beck and Beck-Gernsheim (2002), as in Beck (1992) use individualisation, in conjunction with the thesis of a risk society to argue for new social formations of local action on local issues (sub-politics). This thesis does not follow that line but instead focuses specifically on individualisation theory. 
Bauman (2001) supported Beck's (1992) thesis of individualisation and observed that life conditions (social context) and life narratives (the stories people tell about their successes and failures, hopes and fears etc.), "undergo a process of relentless individualisation" (p. 6). In regard to living within this context he stated:

In our 'society of individuals' all the messes into which one can get are assumed to be self-made and all the hot water into which one can fall is proclaimed to have been boiled by the hapless failures who have fallen into it. For the good and the bad that fill one's life a person only has himself or herself to thank or to blame (Bauman, 2001, p. 9).

Individualisation, and the socially conditioned quest for a life of one's own, coincide in the gatekeeper role education plays in the context of personal success:

For it is after all only possible to pass through formal education by individually succeeding by way of assignments, examinations and tests. Formal education in schools and universities, in turn, provides individual credentials leading to individualised career opportunities in the labour market (Beck \& BeckGernsheim, 2002, p. 32). 
Individualisation the process by which biographical patterns are institutionalised (Beck, 1992, p. 131). On this account, institutions shape the way that people live without granting the opportunity for participation in the way in which those institutions shape their lives. Personal choices are made within a rubric of pre-formed institutional contexts. Under the condition of individualisation "the private is not what it appears to be: a sphere separated from the environment. It is the outside turned inside and made private, of conditions and decisions made elsewhere, in the television networks, the educational system, in firms, or the labour market, or in the transportation system, with general disregard of their private, biographical consequences" (Beck, 1992, p. 133). Thus, institutions act to standardise biographies by creating contexts of institutional dependency: life in an individualised society is therefore a matter of managing multiple dependencies and living up to institutionalised expectations. In this context making a life of one's own, given the great diversity of opportunities (and threats) available, is a matter of learning to live by the rules of the institutions upon which individuals are personally dependent.

As a social theory Beck's individualisation theory has been criticised for suggesting that individualisation results in a society that is beyond traditional class structures, as individualisation processes disembed individuals from traditional class structures (e.g., Breen, 1997; Blossfield, Mills \& Bernandi, 2006). Other writers like Atkinson (2007) accuse Beck of constructing “a 
primarily conceptual critique" (p. 356), devoid of empirical evidence. This thesis does not enter into these debates except to cite Beck (2007) as a useful response to these critiques. Using the assumptions that underpin this thesis, the argument over whether a metaphor represents reality or just an appearance makes no sense. It is the theoretical perspective that is important here, as it is used to form an ideal type to analyse the context of IECTE programmes, not the adequacy Beck's (1992) theory in representing reality or truth in absolute terms.

\subsubsection{An ideal type for individualisation theory?}

Beck (1992) identified three 'theses' to organise his theory of individualisation: Disembedding, standardisation and institutional dependency. This section unpacks each thesis. These theses are then used as the ideal type for individualisation.

Beck (1992) claimed that under the condition of individualisation people are disembedded from traditional social and cultural affiliations such as class. According to Beck (1992) this is because "the individual himself or herself becomes the reproduction unit for the social in the lifeworld" (p. 130). Affiliations to social class or social collectives take a back seat to the task of personal survival in a context determined by the rules of institutions, constant change and market forces. According to Beck (2002), disembedding means relinquishing historical connections in the pursuit of personal survival in 
multiple contexts:

"With the decline of class and status groups the individual must become the agent of his or her own identity making and livelihood. The individual, not his or her class, becomes the unit for the reproduction of the social in his or her lifeworld. Individuals have to develop their own biography and organise it in relation to others" (p. 203).

On Beck's (1992, 2002) account, disembedding occurs at a societal level, as individuals forge an identity of their own through the various commitments they have rather than in relation to a particular stable sociocultural point of origin. Whilst sociocultural understandings of embeddedness integrate multiple contexts and transformations (e.g., Rogoff, 2003), individualisation theory maintains that those multiple commitments are managed by individuals who are in the process of working out their own personal biographies as they actively create $a$ life of their own. Many of those commitments are formed out of the relationship that individuals have with the various social institutions to which they belong. For example, individual contracts formed with banks, credit agencies, educational institutions, medical facilities, landlords, councils, employers, and tax departments, in addition to commitments to the immediate family or persons for whom the individual is directly responsible. 
For Beck $(1992,2002)$ managing one's personal biography is only one side of the disembedding process. The other side, the one that separates individualisation from the more emancipatory categories of individualism and individuation, is the assertion that under the condition of individualisation individuals not only manage their personal biographies, but they also manage risk. Under the condition of individualisation, the risk of success or failure falls squarely on the shoulders of individuals themselves. For Beck (1992, 2002) and Bauman (2001) the paradox is that autonomy leads to greater risk on the part of individuals as they manage their own biographies in a context where the institutions on which people depend demand personal accountability as a condition of inclusion.

Beck's (1992) notion of disembedding does not mean that individuals are isolated from their contexts. It means that the contexts in which individuals construct and re-construct their personal biographies make personal demands of individuals, which, for the most part, individual actors must meet individually. In other words, the social institutions that reproduce individualisation create demands on individuals for which the individual alone bares the final, and often legal, responsibility. Individuals may of course enlist communal help to meet those demands but in terms of institutional accountability (e.g., educational assignments), those demands must be met on one's own.

The second thesis of individualisation is standardisation. Beck (1992, p. 130) 
observed that the "differentiation of socio-biographical situations is accompanied at the same time by a high degree of standardisation. Or more precisely, the very same media which bring about an individualisation also bring about a standardisation". The institutions to which people belong may be varied, but Beck (1992) maintained that the internal rules that govern the relationship between individuals and each institution are standardised, formalised and for the most part non-negotiable. For example, consider the forms that a prospective student must complete in order to enter university study. These forms are examples of standardisation given that they are administered to all prospective students, particular answers invoke standardised responses from a university (e.g., entry qualifications, residency), and the forms are nonnegotiable regarding the content they require.

Beck and Beck-Gernsheim (2002) called standardisation the paradox of individualisation where "the legal norms of the welfare state make individuals (not groups) the recipients of benefits, thereby enforcing the rule that people should organise more and more of their own lives" (p. 23).

Beck (2002) goes on to explain: "This simultaneous individualisation and standardisation of our lives is not simply a private experience. It is institutional and structural" (p. 203). On this account, the contexts in which personal biographies are constructed standardise the relationships between individuals 
and the institutions to which they belong. Participation in this frame is not a matter of moving from peripheral to full participation as per Lave and Wenger's (1991) version, but is always peripheral, as participation is managed in a standardised manner by institutionalised mechanisms removed from the lived contexts of individual actors (e.g., in board rooms and lawyer's offices). For example, a first year student entering university to study early childhood education enters after completing the standardised enrolment forms to the required standard, and participates in a number of compulsory courses that have been preformed and standardised (e.g., objectives, assessments, course readings). Participation in this respect is a matter of coping with standardised requirements. By the third or fourth year students have moved no closer to full participation in the co-creation of their learning programmes. They are still peripheral participants whose obligations are standardised by the institution in which the programme is undertaken.

Thirdly, linked to both disembedding and standardisation, Beck (1992) claimed that "there are no longer merely private situations, but also always institutional. They have the contradictory double face of institutionally dependent individual situations" (p. 130). Beck (1992) went on to assert that because individuals are dependent on the labour market, dependency on the institutions that perpetuate and support the market (particularly the job market) increases. Education institutions are a primary vehicle for individualisation in post- 
industrial Western societies (Beck, 1992, pp. 87, 90, 93, 94, 130, 131). Beck's (1992) point is that individualisation means individual dependency on institutional contexts whose operation is well beyond the control or individuals alone, for example "education, welfare state regulations and support, possibilities and fashions in medical, psychological and pedagogical care. Dependency on the market [and its institutions] extends into every area of life" (p. 203).

Beck's (1992) vision of modern society is based on the "institution-dependent control structure of individual situations [whereby] individualisation becomes the most advanced form of societalisation dependent on the market, law, education and so on" (p. 131). Individualisation cuts off the possibility of autonomy through enforced dependency on the institutions that appear nonarbitrary to modern living e.g., banks, schools, the Inland Revenue Department. For the most part the rules by which the institutions exert control are both nonnegotiable and standardised: "individualisation delivers people over to an external control and standardisation" (Beck, 1992, p. 132). On this account, personal biographies are necessarily entwined with social institutions on which daily existence depends in large part. To this end Beck (1992) observed:

Individualisation thus means precisely institutionalisation, institutional shaping and, hence the ability to structure biographies and life situations politically. The 
actual shaping usually occurs unseen as a latent side effect of decisions explicitly related to intra-organisational matters (education system, labour market, work, etc) (p. 132).

Individualisation reproduces a culture characterised by disembedding, standardisation and institutional dependency. On this point Bauman (2001) concluded that individualisation "divides instead of uniting, and since there is no telling who might wake up in what division, the idea of 'common interests' grow ever more nebulous and in the end becomes incomprehensible" (p. 24).

The fragmentation of societal structures makes concerted effort for social and institutional change difficult and nigh on impossible. That fragmentation, coupled with the personalisation of risk in a context of ambient uncertainty serves to anaesthetise citizen action for social change. For example, who could imagine citizens rising in protest against banks charging interest on mortgages, the government raising the goods and services tax to $15 \%$ or power companies returning multi million dollar profits. Who could imagine students rising against the university to put an end to assessment or compulsory courses? We might be able to imagine some people getting together to protest, but by and large such action for reform on a societal scale is just fancy - why? According to individualisation theory personal risk, standardised institutional dependencies and the ethic of a life of one's own result in a fragmentation borne of self interest 
and a sense of fatalism. For this reason the reign of institutionalised individualism goes largely unchecked, even, as this thesis argues in the context of IECTE programmes, unseen.

This thesis claims that the institutional context in which IECTE programmes are provided reproduces a culture of individualisation and in the next section uses the ideal type set out in fig. 15 and ecological hermeneutics to justify this claim.

\begin{tabular}{|l|l|}
\hline & Individualisation \\
\hline View of people & Disembedded, self interested, autonomous \\
\hline Ideal structure & Standardised, externally controlled, homogenous \\
\hline Social agency & Institutionally dependent, fragmented \\
\hline Participatory framework & Limited, self interested \\
\hline
\end{tabular}

Fig 15. Ideal type for individualisation.

\subsection{Individualisation in the context of IECTE programmes in}

\section{Aotearoa/New Zealand}

This part of the chapter applies the ideal type for individualisation to the context in which IECTE programmes in Aotearoa/New Zealand are provided. The argument being presented here is that the context in which IECTE programmes in Aotearoa/New Zealand are provided reproduces individualisation. This chapter uses an ecological hermeneutic similar to that used in chapter 6 as a structure for unfolding that argument (see fig. 3). This 
begins with an analysis of broader contemporary societal norms in Aotearoa/New Zealand in order to show that in a general sense, the theory of individualisation is applicable to the New Zealand context. That section is followed by analysis of educational policy and the regulations for the provision of IECTE programmes in order to show that individualisation is reproduced in the regulatory context of IECTE programmes. Next, policy at the case study university is analysed in order to show how the site in which IECTE programmes are provided reproduces individualisation as an arbitrary requirement for participation in the programmes. The final two levels of analysis are the regulations identified in the course outlines of courses at the case study university and reports from the focus groups regarding their experience of individualisation. 


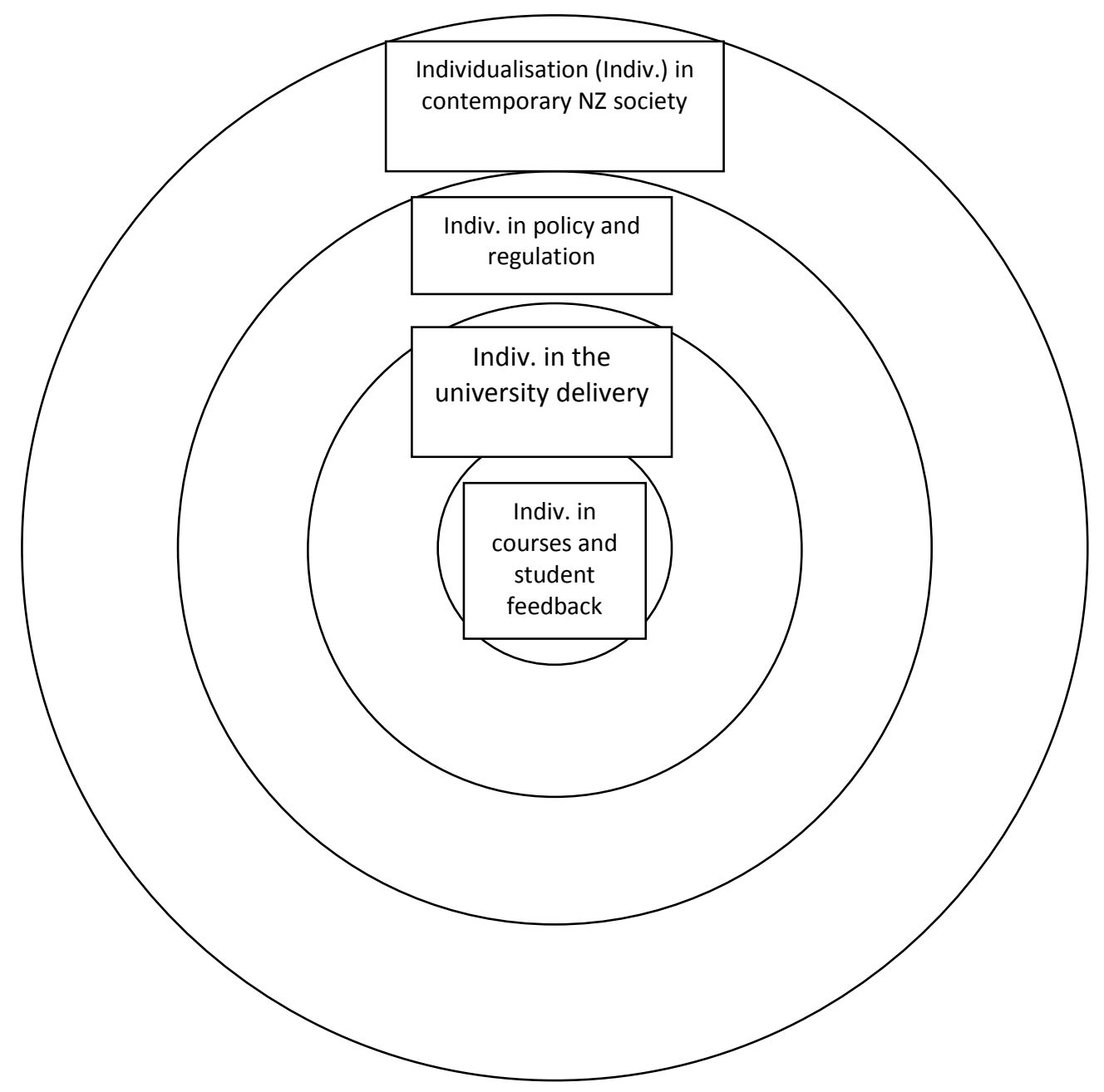

Fig. 16 Ecological hermeneutic for individualisation.

\subsubsection{Individualisation and contemporary New Zealand society.}

It is incredibly difficult living in New Zealand (in any Western country)

without forming dependency on social institutions. It is possible, but nigh on impossible, especially for those with families to support and who can not disappear into the bush to live an alternative existence. A short inventory of 
social institutions in New Zealand will show that individualisation is an integral part of this wider context. Examples of social institutions include: Inland Revenue Department, the health system, compulsory schooling (primary and secondary: which also have social benefits), Transit New Zealand, Accident Compensation Corporation, tertiary education institutions, banks and finance houses, phone and power companies, New Zealand Qualifications Authority, the legal system, policing, insurance companies, the Department of Internal Affairs. These social institutions have at least two things in common: they are each intricately implicated in the social structure contemporary New Zealand, and they are all powerful conveyers of individualisation (though this is not necessarily their only function).

The Inland Revenue Department establishes a context of individual accountability and institutional dependency by providing individuals with standardised personal tax numbers which correlate to them and to them only. These tax numbers are compulsory and non-negotiable for all wage and salary earners, students who wish to get a student loan or allowance, and anyone who receives any form of government subsidy (e.g., working for family tax credit, ACC payments, unemployment or sickness benefit). New parents are given three months from the registration of the birth of their child/ren (individualisation begins early) to have a personal tax number for their new 
addition in order to qualify for family tax credits. That tax number will be assigned to the child throughout their lifespan.

In the health system once registration (of name) is complete a baby becomes an individual entity and a personal, and standardised, medical file is created containing a history of diagnosis, treatment, and prognosis. In order to access less expensive health care the child will need to be enrolled with a Primary Health Organisation (Ministry of Health, 2009a), where they will also be expected to participate in the National Immunisation Register (Ministry of Health, 2009b). This dependency on the health system is standardised, personalised and appears to be a non-arbitrary fact of modern living. In New Zealand, schooling is compulsory for children aged 6 to 15 (New Zealand Education Act, 1989). Once at school children are individualised through the creation of portfolios which track individual achievement and nonachievement. Testing is performed on an individual basis, and although students may share a classroom during key tests (e.g., National Standards) the results they generate are theirs and theirs alone, as is the risk of achievement and non-achievement. Data on academic achievement serves to make individual children visible to interested groups such as Boards of Trustees or special education services. Tests are standardised, the data produced is standardised and depending on the result (i.e. if the result is lower than 
expected) tests can lead to a greater degree of institutional dependency (e.g. specialised lessons or classes).

Likewise, the National Certificate in Educational Achievement (NCEA) individualises students to the point that all work that counts toward the NCEA qualification is individually assessed and grades are assigned to individual students in a standardized, externally constructed format. At this level, education delivers the key message of individualisation: the risk of success or failure belongs to the student alone as they manage their personal biography. Individuals are dependent upon the institution they are enrolled in (e.g., college, high school, correspondence school) in order to fulfil the requirements of NCEA. The grades that individual students attain will have direct bearing on the ability to enter higher education, thus enhancing personalising risk, individualising consequences and further necessitating institutional dependency as students forge the foundations of a life that will soon be their own (with all the personal risk and opportunity that entails).

Owners of motor vehicles will know that Transit New Zealand is another force of institutional individualisation. New Zealand has one of the highest rates of motor vehicle ownership in the world. Individualisation begins with a person gaining a licence to drive on New Zealand roads (licences are highly individualising as they are constructed of a picture of the licensee, their name, 
date of birth, and a particular licence number that applies to that person and that person only). Tests are standardized and individuals are wholly dependent on their own efforts and the will of the licensing authority to gain their drivers license. Owning a car furthers that individualisation insofar as car ownership is standardised through forms, payments, the need for a licence and set durations of registration. Car owners are dependent on Transit New Zealand to register their vehicles lest they incur fines for which they are personally fiscally responsible.

Banks and finance houses, insurance companies, phone and power companies; all of which appear entirely necessary to a successful modern life, reproduce individualisation in contemporary New Zealand society. Bank accounts bearing long strings of numbers identify individuals and are arguably the basis for establishing oneself as a home owner, recipient of student allowance, and in most cases, as an employee (given that for the latter two examples a bank account is necessary for receiving payments). Likewise, insurances are also taken out in name (though also in partnership), individuals and partners are assigned highly personalised numbers, and in the case of premium payments, claims, or excess payments, individuals and individual partners are personally responsible. Insurance is a primary means of protecting the life of one's own from the ambient uncertainty of modern living (e.g., life insurance, health insurance, earthquake insurance, car insurance etc.). 
This analysis has shown that it is normal for people living in contemporary New Zealand to be dependent on multiple institutions in the day to day management of commitments and personal biographies. The scope of those institutions is far reaching and accounts little for social status or class, all are equal, standardised and made dependant on those social institutions for the resources and services they provide. It is within this context of multiple and standardised commitments that the life of one's own becomes a personal obsession, to the point that opportunities for altruism and real participation in that institutionalised context become at best neglected and at worst impossible.

\subsubsection{Individualisation and educational policy in Aotearoa/New Zealand.}

At the next level of the ecological hermeneutic are the policies and regulations which are external to the university, but which regulate the university and its internal policies. This section analyses three particular policies and identifies how they reproduce individualisation in the regulatory context of IECTE programmes.

Educational policy forms the broad context in which IECTE programmes operate. It provides stipulations for the construction of programmes (e.g., NZ Teachers Council, 2010) and designation of the utility/function of those programmes within the context of New Zealand's broader social aims (e.g., Ministry of Education, 2002). The first part of this section analyses three 
documents: the New Zealand Education Act (1989), the New Zealand Tertiary Education Strategy (2007-2012) and the New Zealand Tertiary Education Strategy (2010-2015). These three documents set the general context within which IECTE programmes are situated. The 2007-2010 Tertiary Education Strategy is used because it highlights policy direction for universities at the time of the case study. The 2010-2015 Tertiary Education Strategy is used because it highlights a move toward a more concerted reproduction of individualisation in the context of IECTE programmes, particular as the rationale of economic uncertainty is employed.

The second part of this section analyses the forces that directly influence or regulate IECTE programmes (i.e., the Early Childhood Strategy, 2002-2012; the New Zealand Vice Chancellors Committee; and the New Zealand Teachers Council). All of these sources were chosen for analysis because of their regulatory relevance to the context in which IECTE programmes are provided.

\subsubsection{Individualisation in the Education Act (1989).}

The New Zealand Education Act (1989) reproduces individualisation in education in general by regulating for the compliance of individual students, placing the consequences of non-compliance on individuals and their personal caregivers. For example, the New Zealand Education Act (1989) defines a 
student as "a person enrolled at a school or institution" (p. 33): as an individual person situated in a context of institutional dependency.

The New Zealand Education Act (1989) regulates the definition of student as an individual person, provides impetus for the standardisation of individual students through prescribing shared rights and responsibilities applicable to all in equal measure, and offers little if any participatory rights in the negotiation of those standards (e.g. the contents of one's personal responsibilities). Institutional dependency is legally enforced for the eleven years of compulsory education. From the age of five, children are socialised into an institutional relationship wherein the content of that relationship is prescribed in the form of school charters, curriculum, testing schedules, and as of 2010, National Standards testing. The Act (1989) perpetuates the absence of democratic participation in the construction of educational outcome statements and objectives, a focus on standardised outputs for which individual children are personally responsible/liable, set in a context where there is a biographical risk of failure are characteristics of this system.

Principals and Boards of Trustees have the right to the exclude individuals from educational institutions (Education Act, 1989, p. 80) based on their personal biographical details. The Act also requires that an individual's personal and demographic details be recorded as evidence of attendance and kept available 
for scrutiny (Education Act, 1989, p. 94). The effect of the NZ Education Act (1989) then, intentional or not, is that being an individual is mandated, expected, non-negotiable, and compulsory. The New Zealand Education Act (1989) legitimates a context where individualisation is a normal mode of operation for this system. As an Act of Parliament there is very little scope for individuals to re-negotiate the content of different sections of the Act, there is limited scope for alternative interpretations of the parts of the Act, and there is scant chance of any escape from individual accountability for success and failure. The New Zealand Education Act (1989) promotes individualisation in the context of social educational institutions by ensuring, through its content, that individualism is a fate rather than a choice.

\subsubsection{Individualisation in the Tertiary Education Strategy (2007-2012).}

The Tertiary Education Strategy (2007-2012) is significant to the regulatory context of IECTE programmes because it "provides a direction for all tertiary education" in New Zealand (Ministry of Education, 2007, p. 3). More specifically, given the high demand for qualified early childhood teachers the strategy is also relevant in its aim to "reduce skills shortages through improving the relevance of tertiary education to the needs of the labour market" (Ministry of Education, 2007, p. 6). This close relationship between tertiary education in general, the labour market, and economic prosperity is a theme that is played out throughout this document (e.g., pp. 3, 4, 5, 8, 9, 13, 14). 
A focus on economic outcomes, linked to the labour market, and the development of personal knowledge for economic advantage (achieving a sustainable life of one's own) are characteristics of what Beck $(1992,2002)$ calls the social reproduction of individualisation. Skill accumulation is a key mode of individualisation, as it links personal biography success in a context of increased uncertainty/competition e.g., an economy in recession. The expectation here is that the more skills an individual possesses, the greater the chances of personal biographical success. Linking success to lifelong learning promotes individualisation by encouraging institutional dependency in the form of matriculation. Matriculation invokes at the outset the importance of one's individual biography regarding entry criteria, it uses standardised forms and procedures to manage entry and it reinforces a context of institutional dependency (given that the individual is now subject to the rules and regulations of the tertiary institution).

It cannot be argued that the Tertiary Strategy (2007-12) is solely individualising, as it also outlines a number of socio-cultural initiatives (e.g., a focus on supporting Māori and Pasifika cultural perspectives and traditions in education (p. 4); the strategic goal of building a national identity (p. 9 ); and, "building skills and competencies for social and cultural development" (p. 24). However, a focus on enhancing the personal wellbeing of individuals and their family groups in a context that is increasingly competitive, the goal of creating a 
seamless system where individuals can move from one context of institutional dependency to another (Ministry of Education, 2007, p. 12), and employment of a rhetoric that strongly links success in the labour market with personal educational outcomes (Ministry of Education, 2007, p. 35) contributes to the normalisation of individualisation in the strategic context of IECTE programmes in Aotearoa/New Zealand.

\subsubsection{Individualisation in the Tertiary Education Strategy (2010-2015).}

This strategy signals a change of direction as the National government works to "make tertiary education more relevant and more efficient, so that it meets the needs of students, the labour market and the economy" (Ministry of Education, 2010, p. 2). The link between personal success in education, entry into the workforce and economic prosperity are a key theme of this document (e.g., pp. $2,3,6,7,10,15,16,22,23)$. Like its predecessor, it entrenches the ethic of a life of one's own where success is a personal affair as one strategically manages one's personal biography in the hope of achieving economic security in an increasingly competitive environment.

The Tertiary Education Strategy 2010-2015 identifies a need for higher productivity in the workforce and assumes that higher skills will increase productivity (Ministry of Education, 2010, p. 7). Accordingly, it is believed that "there is a significant wage premium for people who complete higher-level 
study, particularly bachelors degrees" (Ministry of Education, 2010, p. 11). This focus on the fiscal outcomes of education and the strong link being forged between education and the labour market form a context in which a successful life of one's own demands institutional dependency as a primary means. Again, matriculation into tertiary educational institutions bears all the hallmarks of individualisation, as discussed in 7.2.2.2.

Similar to the 2007-2012 strategy, there are also social and cultural components invoked, for example, focus on Māori and Pasifika participation, development of culturally responsive pedagogies and the encouragement of multicultural perspectives. However, in saying that, the Government "expects students to take responsibility for their own performance" (Ministry of Education, 2010, pp. $15,20)$, and will reward those who are successful in this endeavour. Students will be encouraged to enter tertiary education directly from school, contributing to further institutional dependency as individuals piece together their personal biographies, ready to vie for success in the labour market. In the ways outlined above the New Zealand Tertiary Education Strategy 2010-2015 not only reproduces individualisation in the context of IECTE programmes in Aotearoa/New Zealand, it enforces it. 


\subsubsection{Individualisation and the New Zealand Vice Chancellors' Committee.}

The New Zealand Vice Chancellors' Committee (NZVCC) plays an important role in regulating university programmes including IECTE programmes. The NZVCC contributes to a context of individualisation through the personalised award of scholarships and university based certificates (i.e., degrees) it individual persons; it establishes standardised criteria for course approval and course accreditation, it assesses the quality of learning programmes (in a standardised manner) and advises universities on entrance criteria (NZ Education Act, part 19, 241).

The NZVCC has a direct influence on IECTE programmes at New Zealand universities carrying out the roles outlined above. The NZVCC contributes to a context of individualisation by awarding scholarships to individual persons: Scholarship forms require personal details referenced to an individual's enrolment details and academic record (personal biography), statements of personal need (sometimes including a personal budget), and statements of individual post-study aspirations are also required for some scholarships (e.g. William Georgetti Scholarship). The NZVCC also allows international students entry to New Zealand universities based on personal merit and credentials. The non-arbitrary nature of personal accountability is reproduced through the standardisation of criteria. 
Leaving aside those functions of the NZVCC that individualise students through making personalisation an institutional demand (see NZVCC, 2009, p. 59), this thesis focuses on the Committee on University Academic Programmes (CUAP) and its role in the reproduction of individualisation in the regulatory context of IECTE programmes.

CUAP is the external body responsible for the accreditation of university courses and it is a "key component in the hierarchy governing the rational development of academic programmes" (NZVCC, 2009, p. 10), alongside the internal processes of the individual universities. CUAP reproduces a context of individualisation by standardizing requirements for the development of courses and entrenching not only institutional dependency, but also an institutionalised dependency on an external governance body. This last point is important because CUAP prevents localised co-construction of courses and acts as non-arbitrary external control managing course prescriptions and subsequent course content. That control acts as a barrier to the full participation of students in the content and context of their own education (I will expand on this last point in the next chapter).

The effect of CUAP's influence on IECTE programmes is regulatory. It is an external quality mechanism that influences the degree of institutional dependency experienced by students in the content of their courses, acts as an 
external control on content of the pedagogical work within the course structure, and provides rules by which courses operate not only eliminating possibility of local co-construction, but also entrenching institutional control of lived educational experiences (see for example NZVCC, 2009, pp. 17-25). This, combined with the personalisation of risk (i.e., each student is personally responsible for passing or failing courses), the strong relationship between gaining a qualification and entry into the labour market, and the importance of work to succeeding in a life of one's own reproduces individualisation in the context of IECTE programmes in Aotearoa/New Zealand.

\subsubsection{Individualisation and the New Zealand Teachers Council.}

The New Zealand Teachers Council plays an important role in the context of IECTE insofar as it oversees the quality of IECTE programmes (in conjunction with the NZVCC in universities); provides advice on programme content via best practice; and issues competency guidelines for graduating teacher (i.e., Graduating Teacher Standards (NZ Teachers Council, 2007). These standards are a tool for standardising educational outcomes and influence the content of IECTE programmes by setting out a requirement for compliance (NZ Teachers Council, 2010). Significant to this thesis is the fact that those standards, although encouraging a sociocultural approach to early childhood education, reproduce individualisation through the focus on competencies that individuals must not only develop, but express in their history of personal practices. The 
non-arbitrary nature of those standards, as they apply to all prospective graduates, adds to enforced institutional dependence as students seek entry into the labour market and success in the quest for a life of one's own. This is not possible unless the competencies are signed off as being met.

The New Zealand Teachers Council reproduces individualisation in the context of IECTE programmes by making individuals accountable for meeting the standards set out by the Teachers Council; by standardising the programmes in which student teachers undertake their education; by enforcing institutional dependency on approved providers; and by making personal biographies a key component in both entry to and successful exit from courses.

The New Zealand Teachers Council is legally mandated to provide professional leadership to teachers and schools and act as a registering body for New Zealand teachers (Education Act, 1989). Across all levels of pre-tertiary education it is also mandated to encourage best teaching practice, issue practicing certificates to registered teachers, maintain standards for qualifications that lead to registration (i.e., IECTE programmes), approve quality teacher education courses (Teachers Council, 2010), develop a code of ethics for teachers (Teachers Council, 2004), act as a disciplinary authority in cases of teacher misconduct, set reporting criteria for serious misconduct, identify researching priorities, coordinate police vetting of teachers, and 
provide guidelines for teacher competency (Education Act, 1989, part 10b, 139AE). In this role, in the context of IECTE programmes, the New Zealand Teachers Council works with CUAP on the acceptance and assessment of learning programmes (NZVCC, 2009).

IECTE programmes depend on the Teachers Council to approve courses and must demonstrate the programmes effectiveness in relation to the graduating teacher guidelines (Teachers Council, 2010). Programmes must obtain reapproval from the Teachers Council every five years (Teachers Council, 2010). In addition major changes to programmes and particular courses within programmes must meet with the approval of the Teachers Council (Teachers Council, 2010), and CUAP (as outlined above). Institutional dependency and the externalisation of institutional control through standardisation contribute to the reproduction of individualisation in the context of IECTE programmes. These are the unavoidable conditions in which IECTE programmes in Aotearoa/New Zealand operate.

\subsubsection{Individualisation and internal university regulations.}

This section takes another step in on the ecological hermeneutic (fig. 6) to analyse policy documents (at a case study university) and the generic prescriptions set out in the course outlines. This section argues that individualisation is reproduced within broader university regulations and in 
specific course regulations in IECTE programmes. It is important to note, even at this late stage in analysis, that lecturers are also individualised under this context (particularly in terms of the regulatory criteria they must meet, the institutions they are dependent on for their livelihood, and the Performance Based Research Funding scenario in which they operate and by which they are held individually accountable).

This analysis identifies some of the ways that universities reproduce individualisation through their internal regulations and policies. In general terms, universities are geared toward disembedding/personalisation (e.g., through the generation of student ID numbers, assessment practices and academic scripts, Student Conduct agreements and offers of study), standardisation (e.g., enrolment forms, assessment policies, course prescriptions), and institutional dependency (no degree without a provider). This thesis acknowledges individualisation in the broader context of teacher education faculties (e.g., in the experience of teaching staff) but narrows its focus to student teachers' contexts and experiences in a case study university.

The internal policies and statutes of the case study university institutionalise personal risk and individual accountability for students by making the individual a highly visible entity (e.g., the Student Conduct Policy, the Academic Policy, and the Assessment Policy). Individual responsibility is reinforced in the 
way the university goes about its daily business (e.g., the use of student ID numbers throughout its administration and student services, and individualised assessment practices where each individual is responsible for the quality of their own pedagogical work, as well as the fees that individual students are expected to pay). The forms (texts) the university uses upon enrolment serve to induct individuals into the university structure through the requirement that individuals fill out standardised forms which require highly personal details and some of which must be accompanied by officially verified documentation (e.g., birth certificate, academic transcript).

\subsubsection{Individualisation and university policy at a case study university.}

University policy reflects the external context in which universities in New Zealand operate and outlines the rules by which the internal mechanisms of each university are enacted. University policy is non-arbitrary insofar as it is non-negotiable except by the official procedures of academic boards. By entering the university students agree to the rules and regulations of the institution and personally sign their agreement on their offer of study. Students are given no opportunity upon entry to participate in the formation of the rules by which their context is constructed. Instead they are absorbed into an institutional structure that standardises personal accountability and entrenches institutional dependency. In this context students personally bear the risk of 
success and failure (in terms of impact on their personal biography) in a game where universities not only hold, but administer all the cards.

University policies and statutes include Academic Policy, Facilities Management Policy, Finance Policy, Governance Policy, Research Policy, Staff Policy, and Student Policy. Individualisation occurs in a number of ways throughout these policies and often in conjunction with elements of university wide regulations (e.g., security, academic standards, governance). For example, the Academic Board Statute creates a committee whose function is to advise the academic council on matters relating to courses of study, awards, and other academic matters. The Academic Board Statute contributes to the reproduction of individualisation through the direction it gives to other university mechanisms (e.g., induction, assessment, graduation) all of which disembed individuals through the personalisation of risk, follow standardised formats and entrench institutional dependency.

Another academic policy that contributes to individualisation in the context of IECTE is the Limitations on Courses and Programmes Statute which creates scarcity within programmes by capping student numbers. Entry to courses with limitations on numbers becomes a highly personalised affair, as participants are assessed and offered entry based on individual merit and personal biographical history. However, once there, the risk is only intensified for those students who 
do not meet the standards of the institution upon which they are dependent, the outcome of which has real effect on both personal biography and opportunities in the labour market.

Upon enrolment in teacher education courses, individuals must provide evidence from personal artefacts such as passport and birth certificate, personalised school results and/or other personalised tertiary results, and pass a highly personalised Police vetting process. The resulting offer of study for students whose personal biography is successful is again highly individualized coming in to force by the application of an individual's signature, and is a contract between the individual student and the university. It is an artefact of both personal responsibility and institutional dependency.

Other policies like the Student Protest Policy describe institutionally sanctioned boundaries for protest action taken by students on university property. Student Protest Policy reinforces and reproduces individualisation in the context of IECTE by serving as a constant reminder to protest groups that when dealing with the institution of their education, student protesters are highly visible individuals who are personally responsible for all of their behaviours.

Conduct policies contribute to the reproduction of individualisation by making the individual accountable to the university. Under the general Conduct Policy, 
complaints that are levelled at individuals within the institutional structure are dealt with through formal and standardised processes (i.e., all complaints focus on an individual: It is the conduct of that individual that comes into question). Likewise, the Student Conduct Statute aligns conduct and misconduct with an individual student's actions. A copy of the Student Conduct Statute accompanies the offer of study form and is agreed to by all students at the outset of their relationship with the university. These forms are signed by individuals and serve the multiple function of forming an individual (though standardised) contract between the student and the university, invoking a culture of personal responsibility at the outset, and providing yet another way that individual students are made dependent on the institution.

Throughout these policies and statutes the individual is constructed as a legal, biographical, autonomous, self responsible and self interested person. There is no alternative. Individualisation is ensconced in the rules and regulations that shape many important functions of the university (e.g., enrolment, research, assessment). The individual is disembedded from familial ties and social class (Beck, 1992), is assigned a student identification number and assumes the identity of one student among many. Individual rights, responsibilities, accountabilities and assessments are all standardised and apply to all students equally. University wide policies and statutes create the wider context in which IECTE programmes operate. The rules and functions contained in policies and 
statute help to form a context of institutional dependency and in so doing reproduce individualisation in the context of IECTE programmes.

The Statute for the Degree of Bachelor of Education (Teaching) Early Childhood also disembeds individuals from their familial ties (and social class) to cast them as candidates. Candidates are classed into subgroups (e.g., candidates with diplomas, candidates with current kindergarten registration, candidates with no prior early childhood education). Successful candidates are then integrated into the institution and as a result become wholly dependent upon the institution and its regulations for the achievement of their qualification, and subsequent entry into the labour market.

\subsubsection{Individualisation and course outlines at a case study university.}

Course outlines are a non-negotiable interface between students as a group of individuals and the institution. Course outlines contain advice on where to go for more information on topics like conduct, and answers questions like "what is plagiarism?" Course outlines also contain important information on assessment and learning objectives, and therefore act as a standardised conduit for achievement. They are also repositories of useful information about obligations, what to do when assignments go missing, how to apply for aegrotat, penalties for late work, and the grievance processes. Course outlines are artefacts of standardisation insofar as they contain rules that apply to all 
students in equal measure. They are also technologies of dependency wherein institutional rules regarding participation, assessments and academic standards are set out in a standardised form as rules to which individual students are held personally accountable. Those rules are non-negotiable and link to other agencies in the broader context of IECTE programmes (e.g., CUAP and the Teachers Council).

At the times when there is the most risk of success and failure - i.e., handing in an assignment and sitting a test, it is the individual that must front up, the work must be their own, and students must use their student ID number and standardised forms and formats. Late penalties reinforce the fact that the individual stands by their efforts alone (though extensions may take into account personal contextual influences i.e., bereavement). This is the same for everyone; it is standardised across the university in academic policy, in the assessment procedures, in penalty policies for late work, and in the final academic transcript.

In terms of institutional dependency, course outlines are powerful artefacts. They contain the rules for participation in courses with little room for negotiation of the contents of what counts as a rule and what does not. Individuals are held accountable for their own success and failure on the exact terms set out by the university in the assessment schedule. This culture of 
personal accountability is standardised to all individuals, who are each themselves caught within the social process of achieving the life of one's own, often marked by entry into the labour market, in a context of increasing uncertainty. The course outline is the link between pedagogical authority, pedagogical work, and personal success. In terms of IECTE programmes the course outline is a generic expression of a universities internal policies and regulations in programmes that have met Teachers Council and CUAP approval. From this perspective, course outlines are a technology that reproduces individualisation in the context of IECTE programmes.

The inability to negotiate the contents of course outlines, combined with the risk of failure, adds to individual dependency on the institution. There is little on offer in terms of co-creation in the structure and contents of the course outline. Individuals are given scant choice in the formation of their pedagogical context, instead, that context is preformed. Course outlines are an extension of institutionalised individualism in IECTE programmes. They set the rules and conditions for success and are non-arbitrary in that regard.

The analysis in this section has shown that the course outlines disembed students from their socio-cultural contexts through the standardisation of course contents, course prescriptions and pedagogical outputs (assessment). The policies of the university standardise the relationship between the 
institution and individual students, and through that standardised relationship they enforce institutional dependency. The course outlines are highly individualising texts as they prescribe the content of pedagogical work in a standardised manner, and make individual students not only individually accountable, but also institutionally dependent to the point that co-construction of educational contexts makes way for surviving externally mediated, nonarbitrary assessment criteria. That preoccupation with personal survival in an institutionally controlled context where success is governed by how well a student meets a predetermined criteria of written expression means that education, for many, is a task not a collaboration. Simply put education is a blunt instrument.

Other experiences such as the student union, class groups, and tutorial groups may be a counter balance to individualisation in the context of IECTE programmes, however, those social aspects occur within a larger context of individualisation which makes individual accountability a primary concern and social interaction a secondary consideration. This idea is picked up in the next section where student teachers reflect on their experience of group work in a highly individualising context. 


\subsubsection{Individualisation and student teachers.}

The final section of this chapter reports on findings from the focus groups held at the case study university. This is the most intimate of all the levels of the ecological hermeneutic. It is intimate because it contains sentences from student teachers regarding their experience of IECTE. Their sentences are interpreted using the ideal type for individualisation.

When asked what they enjoyed most about their courses no students responded in the terms of ideal type for individualisation. As noted in chapter 6, respondents nearly wholly identified sociocultural aspects of their courses as the most enjoyable aspects of their IECTE programmes. This section is divided up into responses detailing disembedding, standardisation, institutional dependency and general statements on personal risk and standardisation.

\subsubsection{Disembedding}

All focus groups expressed disembedding as a negative experience in their education. For example one student, when asked about her experience of group work in the university setting stated:

“I think it should reflect how we really live, we don't just go out and do something and then not see those people again. In our life everything is integrated, you know, you get to see the unity. Why can't that be part of where 
we are living? I mean this is our family in that kind of whanau sense, why can't it reflect what we do at home?"

Another student, when asked what quality learning means to her observed:

"I think also another frustrating thing is, I mean in this course there are a lot of adult students and like people who have got families of their own, but sometimes it seems like the lecturers are teaching little kids, like young kids, you know but people have a lot of input you know, it's a bit degrading sometimes".

The contextual disembedding that is part and parcel of individualisation not only detracts from these student's experiences, but also challenges their understandings of good educational practice.

When asked about their least enjoyable experiences, some students felt that their own life experience was of little value in a highly theoretised context. For example, one participant observed “you kind of feel like you can't have your own opinions because if you express that and it's not what they think [other participants agreeing] they fail you". In relation to the same question another participant stated, "the course is sort of dumbed down, it doesn't take into account previous experience, and I don't think that they adapt a course, they 
just have it set, whether you come from school or a life full of experience they don't alter it". These observations were particularly poignant for the respondents in light of the socio-cultural practices that they are expected to reproduce in their own teaching praxis. On this topic, another student summed up the general feeling of the groups when she observed "there are people who just learn through life by reading, and not just experiencing through life and seeing it or feel it themselves for them to know". This last comment matches the general distinction that respondents perceived between their experience of IECTE as a learning context and the real world.

The focus group comprised of Samoan students felt this disembedding from their culture and devaluing of their social histories most profoundly of all groups. For example, when given space at the end of the focus group session to raise any further points, one student stated "because our language is different we think we are left out (yeah) even when the classes have discussion the tutors still treating us the same as the Pākehā". In this case, disembedding goes handin-hand with standardisation, however another student made an even clearer point “I raised my hand the last Tuesday night and I asked if I don't understand it, can I make it in Samoan words? But I can't write it down in English, it's not my first language, the year before, last year, it was written in Samoan. Now that's why there is hardly any Island culture in the course, in the, in the college, you know it's because of the language". The feeling of being disembedded is 
accompanied by a perception of inequality in the experience of these students. For example, when asked how they feel about their experiences one student answered "sometimes we feel like we're left out, you know" and another answered "really a majority of everything we are given is in English and not in our language".

These students felt the disembedding of individualisation in the context of their IECTE programme. One student talked about feeling disembedded as she formed her own early childhood philosophy based on the theoretical perspectives of others: “I mean they talk about articulating our philosophy half of that is me! Me, you know, my experience". This was a common theme across the focus groups - that those histories of experiences and contexts in which they are embedded were not important in the context of their education, even though the content of what they are learning proclaims the virtues of recognising the histories of experiences and contexts in the children they teach.

\subsubsection{Standardisation}

There are two sides to the standardisation felt by student teachers. On the one side is the standardisation of requirements for courses and their degrees that puts everyone in the same boat regardless of personal socio-historical issues (except for disability which is provided for in university statute). On this side of the equation, there is the recognition of outputs (e.g., institutional expectations) 
that apply to all student teachers alike. On the other side, is the standardisation of the requirements that sees student teachers reproducing a subject matter that is not only expected of them but necessary for them to become professionally recognised early childhood teachers.

The standardisation of course requirements is strongly linked to the disembedding discussed above. Students spoke openly about their experiences of being standardised when the conversation turned to the topic of being assessed, for instance, one participant said, “you kind of feel like you can't have your own opinions because if you express that and it's not what they think (other participants agreeing) they fail you". Another student agreed, saying, "if I was to write an assignment to agree with what they are saying, and just have a few references I'd probably get an A+, but if I was to do against it and have heaps of references that said I don't agree with this person, da, da, da, then she would write that 'I didn't like the criteria'". In regards to standardisation and lack of choice one student reported, "we don't even choose the papers or anything, there's not even options you know, if you've got an interest in something, to follow that through, we just have to do this, this, and this". These students expressed a feeling of being dominated by a system where they have little hope of co-creation in the context of their learning. 
On the other side, is the reproduction of a subject matter to which students feel they have little to contribute other than ensuring that their acceptance of that canon is recognised. For example when asked about the links between home and study one student stated, "what I'm learning now is the labels they are putting on what I already learnt, you know it's these actual structures of things, you know, there's a belief that you're following". Another student concurred saying, "that's the way I get through now, you've just got to say what they want you to say, write what they want you to write, and then you get a good mark". One student summed this feeling up in the following way "honestly, once you know the jargon, you just do it". These students believed that the institution is what it is and that they have to fit in with it or perish. The way in which their context standardises their responses to questions of early childhood theory and practice disturbs them on one level (an intellectual level) but the pragmatics of getting through and gaining their qualification far out-weigh the need to make their influence known.

In the case of the student teachers in the Samoan focus group, standardisation was viewed as an inflexibility on the part of the institution in recognising their culture and language in terms of the pedagogical work required. For example when asked about the issues they face one participant answered, "I find that with the English language its got this proper side to it, it's the same with other languages as well, but you have to use the proper words and you know, they 
say it to be writing in the academic, that's how we should be writing because we are in a university". Another student agreed stating, "I mean we have no choice, we have to learn English and we have to write in English, because I guess the majority are English". These statements highlight the disembedding from cultural influences (language and its uses) that is typical of individualisation. This sentiment was summed up by another student in the following way "I think the university is more interested in the majority than the minority". Students viewed this level of standardisation as oppressive and showed a great degree of fatalism when describing their experiences.

\subsubsection{Institutional dependency}

Institutional dependency was a given for all four focus groups. Respondents recognised the need to give the university what it asked for in the required format as they depended on it for gaining their qualification. For example, one student from the Samoan group, when asked aboutwhy she enrolled in the course remarked, "for me it is getting a qualification, here in New Zealand you can not get a high quality, I mean a job or a good paying job, you know, but because we are Islanders and English is our second language you won't get something that gets the dollars". Another stated, "we' re doing a whole bunch of stuff around being professional, and like getting prepared for like teacher registration, like that's, that's, I'm really concerned with personally". Others in the focus group agreed and there was a sense that each person was highly 
dependent on the institution for passing or failing, and as a result attempts at participating in the co-creation of their context were largely to be avoided.

Another face of this institutional dependency is an ambient feeling that any attempt at being critical of the institution would result in increased personal risk. One student observed the following when asked why she didn't pursue her grievances, "knowing what they would do, they would probably try and kick me out, probably fail me and kick me out [agreement from other participants], it's so risky isn't it, and nobody knows whose doing what". A student from another group agreed when she stated, "it's too scary, they know you and your classes and you like see these people all the time. These teachers aren't just going to be gone the next year; they are going to be your teacher the next year and they're going to know your name, and they are going to hold it against you". Thus, in the face of a standardised dependency on the institution students felt there to be little if any benefit for them personally in seeking cocreation of their context. Another student summed this up in the following way “You can't change the system because it's just - mental". These students felt powerless to effect change in their own context because the external control of their situation is too powerful to challenge individually or as a group.

The risk of passing and failing a course is taken personally by the student respondents who viewed their time at their teacher training institution as 
necessary to their later employment opportunities. The reason for this fatalistic attitude is simple according to one student when asked what she could do about perceived unfair treatment, "you don't want to put yourself in a position where you're going to shoot yourself in the foot because it's just like we've been saying, you are going to see these teachers the next day and the next year". Answering the same question, another student talked about the sense of isolation she felt, "I don't think that there is anyone else that I can talk to because I just think that it would bounce back on me in a negative way". Their believed dependence on the institution was complete as they felt disembedded from contexts external to the institution, entered into standardised relationships within a standardised programme of study, and made personally dependent on their context to the extent that they feel that participation is limited to regurgitating words that the institution deems it important to hear: "honestly, once you know the jargon, you just do it".

The analysis undertaken in this section has shown that student teachers feel disembedded from their lives outside of the university and forced into a standardised programme with its predetermined requirements. At the same time, these students feel dependent upon the institution in which they are training to the point that they do not want to 'rock the boat' by complaining or making a fuss. This fear of participation is a symptom of individualisation in so far as individualising processes make student teachers highly visible to the 
institution upon which they are dependent for success in the life of their own. In this regard, individualisation incapacitates communal resistance from the outset by cutting off the possibility of democratic change to a system that is preset, apparently non-arbitrary, and structured in such a way that failing it is personal failure, and success within it is personal achievement.

\section{Summary}

This chapter has constructed an ideal type for individualisation and used the hermeneutic ecology method to organise analysis of documents and regulatory bodies within the context of IECTE education. This chapter has offered evidence supporting the claim that the regulatory context of IECTE programmes in Aotearoa/New Zealand reproduces a culture of individualisation. This analysis forms the second half of the pairing for structural dissonance, recalling that socioculturalism was the first part of the pairing. In the next chapter, the thesis of structural dissonance is advanced by using the hermeneutic ecology to show contradictions between socioculturalism in the content and individualisation in the context of IECTE programmes of Aotearoa/New Zealand. 


\section{Chapter 8}

\section{Structural Dissonance in IECTE programmes in}

\section{Aotearoa/New Zealand.}

This chapter advances the argument for structural dissonance in IECTE programmes in Aotearoa/New Zealand by analysing the contradiction between socioculturalism in the content, and individualisation in the context of those programmes. This chapter uses the ecological hermeneutic introduced in chapter 4 and the ideal types set out in chapters 6 and 7 to argue that IECTE programmes in Aotearoa/New Zealand are structurally dissonant.

The philosophical assumptions used in this thesis set out an approach that focuses on how language is used, that approach also adopts an ironist perspective to questions of truth and reality (see 3.4). For this reason, asking whether structural dissonance is a reality or just appears to be reality, or asking whether structural dissonance is a contemporary truth or just a result of particular justifications are redundant lines of inquiry (see Ch 3). From the neopragmatic perspective adopted in this thesis it is more relevant to ask how compatible are the vocabularies that are being used in content and context? Or how can 
the justifications that are put forward for structural dissonance help to improve conditions in IECTE programmes?

This chapter begins with an analysis of the dissonance between the ideal types set out in the previous three chapters. This largely theoretical analysis aims to show that socioculturalism and individualisation are non-compatible to the point that as theories they are dissonant. The second section highlights points in the ecological structure of IECTE programmes where that dissonance is evident as structural dissonance. The chapter ends with student teachers' reports of dissonance in IECTE, a re-statement of structural dissonance based on the case put forward in this chapter, and a link to the notion of structural violence.

As the final chapter in this part of the thesis, the argument is advanced that structural dissonance occurs at multiple levels of the ecology of IECTE programmes in Aotearoa/New Zealand. 


\subsection{Dissonance between the ideal types.}

\begin{tabular}{|l|l|l|}
\hline & Socio-culturalism & Individualisation \\
\hline View of people & $\begin{array}{l}\text { Embedded/situated (culture, } \\
\text { history, time, place); agents of } \\
\text { change; connected }\end{array}$ & $\begin{array}{l}\text { Disembedded, self } \\
\text { interested, autonomous }\end{array}$ \\
\hline Ideal structure & $\begin{array}{l}\text { Participatory, co-constructed, } \\
\text { encouraging diversity }\end{array}$ & $\begin{array}{l}\text { Standardised, externally } \\
\text { controlled, homogenous }\end{array}$ \\
\hline Social agency & $\begin{array}{l}\text { Shared control, supports } \\
\text { equitable transformation }\end{array}$ & $\begin{array}{l}\text { Institutionally dependent, } \\
\text { fragmented }\end{array}$ \\
\hline $\begin{array}{l}\text { Participatory } \\
\text { framework }\end{array}$ & $\begin{array}{l}\text { Inclusive, communicative, } \\
\text { community based }\end{array}$ & $\begin{array}{l}\text { Limited, self interested, } \\
\text { biographical }\end{array}$ \\
\hline
\end{tabular}

Fig. 17 Pairing of ideal types: Individualisation and socioculturalism.

Returning to the musical metaphor introduced in chapter 2 , the chords that socioculturalism and individualisation strike are not harmonious. Using the ideal type model, which was developed in the previous chapters, it is apparent that these perspectives are opposite in several ways (see fig. 17). For instance, socio-culturalism views people as embedded and situated within social networks of connection (e.g., Lave \& Wenger, 1991), as being formed through interaction with those contexts (Vygotsky, 1978), and as being socially and culturally oriented in both behaviour and the use of cultural tool (e.g., Wertsch, 1998). Individualisation theory, on the other hand, views people as essentially self-interested, embedded within institutionally standardised contexts, and institutionally dependent (e.g., Beck, 1992). Likewise, the ideal structure (social and/or institutional) for socio-culturalism is participatory with persons moving from peripheral to full participation over time (e.g., Lave \& Wenger, 1991; 
Rogoff, 1990), with space for the co-construction of contexts and the content of those contexts (e.g., Rogoff, 2003). Individualisation processes leave little space for co-construction as contexts are pre-constructed, standardised, and externally controlled (Beck \& Beck-Gernsheim, 2002).

The ideal type for socioculturalism encourages the transformation of social contexts with a view to inclusion and the construction of communities (e.g., Rogoff, 2003), whereas individualisation reproduces social contexts where individuals are dependent on institutions, participation in the construction of contexts is limited by the structure of institutions themselves, and where the primary motivation of people is biographical success/safety (e.g., Bauman, 2001; Beck \& Beck-Gernsheim, 2002). It is difficult to hold social and historical connection to be of utmost importance in a context where social institutions promote self interest and individual autonomy. Likewise, it is difficult to put into practice the virtues of participation and co-construction if at the same time one is enmeshed in a context that enforces standardisation and institutional dependence through external mechanisms of control.

At the level of vocabulary, recalling that the vocabulary used was chosen from key texts on both socioculturalism and individualisation, the words associated with each appear opposing, for example: embedded/disembedded, coconstructed/externally controlled, collaborative/institutionally dependent, 
relationship-focused/self interested. At the level of vocabulary, and in terms of the theoretical perspectives that support those vocabularies, the concepts employed oppose each other. They are dissonant. Their meanings and intentions contradict with one another. At the level of ideal types it is therefore justifiable to assert that because the content of IECTE programmes draws on a socio-cultural vocabulary, and because the structure of the context in which that content is delivered is regulated by a vocabulary of individualisation, then a situation of structural dissonance is present.

Recalling that Beck (1992) used individualisation theory to argue for new forms of citizenship, i.e., sub-politics: wherein localised pressure groups lobby for institutional and social change on local issues. One issue here is the empowerment of students as citizens of their learning context. Bauman (2001) has observed that "the other side of individualisation seems to be the corrosion and slow disintegration of citizenship" (p. 49). Self-reliance and personal accountability in a context where social institutions enforce individual dependency through standardisation have a hidden cost. Bauman (2001) identified that cost as the loss of citizenry participation whereby persons are not, or much less) able to play a key role in the democratic co-construction of their social environment. Under the condition of individualisation, individuals are impotent in the institutional settings they inhabit: They are subordinated to externally constructed institutional contexts. 
Citizenship is itself not a simple concept to unfold (e.g. Faulks, 2000; Heater 1999; Marshall, 1950) where scholars talk of multiple conceptions of citizenship (e.g., Heater, 1999; Magnette, 2005; Marshall, 1950). Citizenship is a term that encompasses the notion of rights and responsibilities (Marshall, 1950) as well as an active participation in the co-construction of the social context of which citizens are a part. It is this participatory aspect of citizenship that Bauman (2001) claimed is eroded by individualisation.

Individualisation erodes citizenry participation by personalising risk and opportunity (in pursuit of the life of one's own), standardising institutional dependency and demanding individual compliance to externally controlled regulations. Socioculturalism, on the other hand, promotes citizenship through a focus on participatory relationship building, co-construction and transformation of shared contexts and the empowerment of communities of actors as they work together to negotiate social practices.

Dayan (2008) made a similar point regarding contradiction in IECTE programmes in the context of practicum supervision in Israel, where she stated "the most commonly favoured approach to working with children is a childcentred humanist democratic approach, and the predominant approach in working with students is behaviourist" (p. 160). Dayan's research is similar to that undertaken in this thesis in that she identified a contradiction between 
approaches to pedagogical content and the delivery (and assessment) of that content. Dayan pointed out that practicum supervisors expect their students to work with children in a humanistic-democratic way, but work with the student teachers in a behaviouralist manner. The one practice contradicts the other. Dayan (2008) pointed out that "the inconsistency of the approaches used with children and with students hampers the students' learning" (p. 160). She also pointed out that picking up alternative concepts might improve this situation.

The argument advanced in this thesis is similar to Dayan's (2008) insofar as both are saying that inconsistency (which I am calling structural dissonance) is a problem in IECTE programmes. Dayan was saying that inconsistency hampers student development, I am saying that contradiction creates a context of structural dissonance which is itself a form of structural violence (see chapter 2). This thesis uses structural dissonance as a critical lens for viewing IECTE programmes in Aotearoa/New Zealand. However, we both hope for the same thing: Dayan hoped for more consistency and I hope for less contradiction; we both write from a belief that a more socially just approach to IECTE is possible. 
8.2 Structural dissonance in the context of IECTE programmes in Aotearoa/New Zealand.

Using the ecological hermeneutic it is possible to see the contradiction (dissonance) between socio-culturalism and individualisation at a number of levels of the ecology of IECTE. At each level of the ecology (see fig. 18) there is a distinct dissonance characterised by contradiction. This section explains how and where that dissonance occurs throughout the ecological structure set out below.

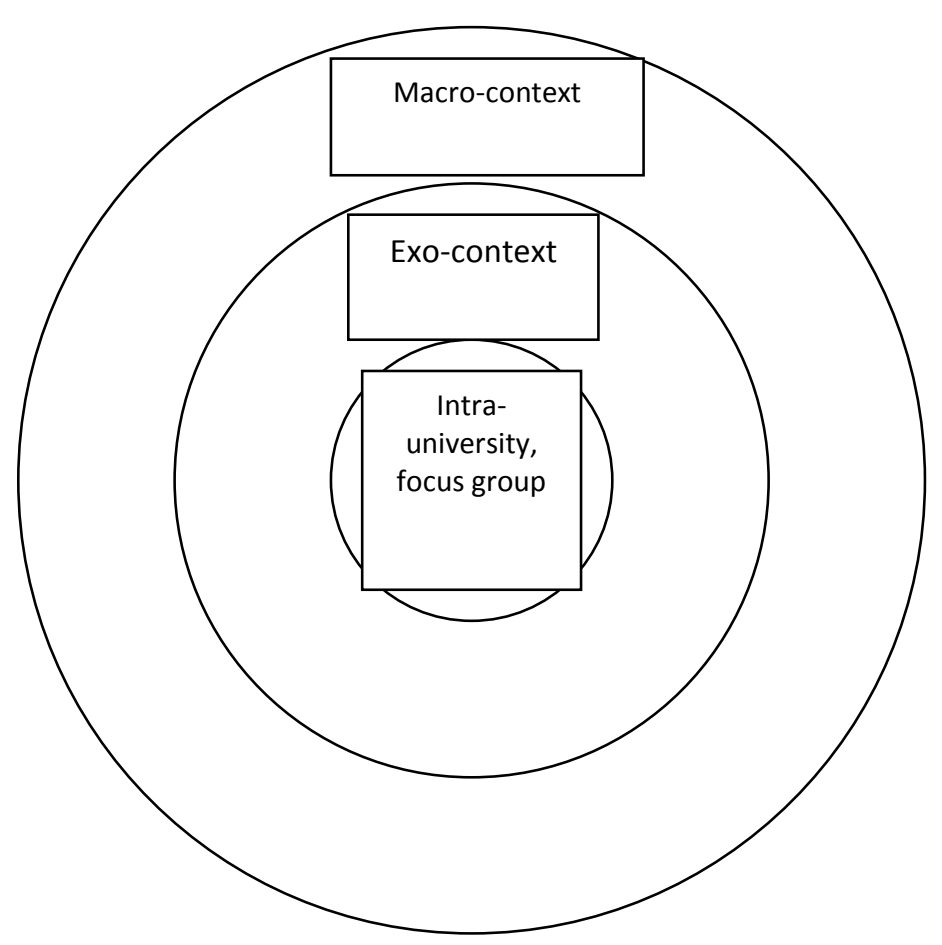

Fig. 18 Ecological hermeneutic for structural dissonance. 
Analysis begins at the macro-level of where socioculturalism in socio-historical context of IECTE and the wider societal reproduction of individualisation collide. Analysis of the structural dissonance at this level shows contradiction between the socio-cultural content of core texts in IECTE programmes (Ministry of Education, 1996, 2004, 2007), and individualising texts in the context of IECTE (the Education Act, the Tertiary Education Strategies (Ministry of Education, 2007; Ministry of Education, 2010), aspects of the Graduating Teacher Standards (NZ Teachers Council, 2007) and the NZVCC (particularly CUAP). The final part of this section identifies the dissonance in course outlines and reports structural dissonance in the experiences of student teachers at the case study university.

\subsubsection{Structural dissonance in the macro-context of IECTE programmes.}

At the macro-level there is dissonance between the socio-historical shift toward sociocultural theories of teaching and learning in the content of IECTE programmes and the institutionalised individualism (individualisation) that is characteristic of life in contemporary New Zealand society. One way to look at this dissonance is to say that the content of IECTE programmes hopes to create a more socially just world by focusing attention on relationship-building, empathy for diversity and developing an ethic of participatory transformation, whereas, processes of individualisation attempt to construct autonomous selfinterested individuals capable of managing multiple institutional dependencies 
and standardised institutional relationships (see 7.4.3). These commitments are mutually exclusive enough to be dissonant, like opposing chords struck simultaneously.

A perspective that places community, cooperation and participation at the centre of its approach to education cannot, without contradiction, be produced in institutions that encourage the personalisation of risk and institutional dependency with out some degree of dissonance. Why? Because, it would be self-contradictory, one either focuses on participatory relationship building or sets up institutions that demand personal accountability and dependency through external control. The movement toward socioculturalism that May (1997, 2009), Ritchie (2003) and Smith (1998) identify could also be viewed as a shift away from those perspectives in early childhood education that isolate individuals from the social and cultural contexts in which they are embedded: a shift away from social forces such as individualisation. From this perspective, the content of IECTE programmes can also be seen as an attempt to contradict the forces of individualisation, which may in turn heighten the sense that something in the structure of IECTE is dissonant.

Sociocultural content on the one hand and a society that reproduces individualisation on the other: This is the dissonant mismatch that this thesis identifies in IECTE programmes in Aotearoa/New Zealand. From this 
perspective the larger stories of what early childhood education hopes to achieve, and how universities provide the programmes that will train teachers to achieve them, are by and large contradictory. Dissonance is the result of that contradiction. Structural dissonance resonates throughout the ecological structure of IECTE programmes in Aotearoa/New Zealand. The next section identifies that dissonance in the macro-structure of IECTE programmes in Aotearoa/New Zealand.

\subsubsection{Structural dissonance in the exo-context of IECTE programmes.}

One level in from the general macro-level on the ecological hermeneutic is the exo-level (fig. 17). At this level agendas are formulated and made into regulatory requirements by agents and agencies external to the university. On the side of individualisation, the previous chapter identified the NZ Education Act (1989), the NZ Tertiary Strategy 2007-2012 and 2010-2015, and aspects of the Graduating Teacher Standards (NZ Teachers Council, 2007) and the NZVCC (particularly CUAP). On the side of socioculturalism is the early childhood curriculum (Ministry of Education, 1996), elements of the Early Childhood Education Strategy (Ministry of Education, 2002), and aspects of the Graduating Teacher Standards (NZ Teachers Council, 2007). On the side of individualisation there is a drive toward personal accountability underpinned by notions of individuals as autonomous and self-responsible (e.g., Ministry of Education, 2010, p. 15). There is standardisation in the form of legal definition (e.g. the 
word student refers to an individual person), the application of regulations (funding, entry, graduating standards), and in the relationship of dependency that exists between individual persons and the institutions in which they undertake their education (e.g., approved provider stipulations, externally regulated course prescriptions, and prescribed graduate standards).

On the other side, socioculturalism understands students as humans necessarily embedded within familial, communal and societal contexts (e.g., Ministry of Education, 1996, p. 19). From a sociocultural perspective it is not possible to understand what it means to be a person without understanding the social and cultural relationships from which that person constructs their sense of self (e.g., Mead, 1934; Vygotsky, 1978). From this perspective, personal accountability (including accountability for a life of one's own) clashes with the will to belong, relate and correspond with others who are embedded within the context of their shared social space. In the context of IECTE programmes in Aotearoa/New Zealand, individual student teachers are personally accountable to the universities in which they train. The personalisation of accountability and the individualisation of risk is dissonant with the sociocultural approach to education espoused in their programmes of study: Particularly as student teachers are encouraged to build links between their students and their wider communities (Ministry of Education, 1996, p. 14), encourage well-being through support of their students' families and cultural community (Ministry of 
Education, 1996, p. 14) and encourage participation through the co-construction of learning environments.

IECTE programmes are provided in a context where the relationship between students and the university is standardised by regulations external to the university itself. For example, Graduating Teacher Standards (NZ Teachers Council, 2007) provide a standardised template-based set of key competencies that students must be shown to meet before they are able to graduate from courses. Those key competencies are used in some teaching practice placements as standardised criteria against which individual students are measured, and subsequently made personally accountable. Another example of this standardisation occurs in the compulsory nature of the CUAP-approved courses that make up the majority of the BEd degree. This standardised structure of IECTE programmes is coupled with a policy drive for greater degrees of personal accountability tying government funding for qualifications to individual student success (e.g., Ministry of Education, 2010). This coupling creates a context where entry standards are applied not only on academic lines but also on economic ones. In the future it is plausible that programmes will be encouraged to accept only those students who meet a standardised criterion ,those who have proven their ability to pass courses. 
Standardisation of the type outlined above contradicts the sociocultural focus on co-constructive participation and the mutual transformation of social contexts (e.g., Rogoff, 2003). Student teachers are expected to encourage openended exploration and participation among children, between teachers, between teachers and children, between teachers and parents/caregivers and between children, teachers, parents/caregivers, and the wider community (Ministry of Education, 1996, 1998, 2002; also see Ch 6). But there are no official documents that bind universities to ensure the same for student teachers. Institutionalised standardisation of the sort engaged in by universities leaves no space for the negotiation of what those standards entail or how those standards might be transformed by those who are being standardised. On this count, there is dissonance between the content of IECTE programmes and the context in which they are provided.

The exo-context of IECTE programmes entrenches the reproduction of institutional dependency. For example, the New Zealand Teachers' Council publishes a booklet listing approved providers of IECTE programmes. Those providers undergo a quality approval process to ensure that their programmes will lead to registration (NZ Teachers' Council, 2010, p. 3). The by-product of that quality control is that students seeking their qualification, and later, registration, are entirely dependant on the institution that provides it. That dependency begins when students fill out the enrolment form and does not end 
until their qualification has been conferred. This institutional dependency is standardised and is applied to all students in equal measure, but it serves to reproduce individualisation by simultaneously personalising responsibility and risk, whilst providing a link between personal success to success in a life of one's own.

Institutional dependency coupled with external control of the contextual conditions in which that dependency occurs (e.g., NZ Teachers Council, CUAP) contradicts sociocultural focus of contextual co-construction, collaboration and community (in the sense of shared transformation): Student teachers are given little choice in the papers that make up their degree, little participation in the structure that the compulsory component of the degree enforced upon them, and as the data showed in the previous chapter, little chance to negotiate and transform the pedagogical context in which they find themselves.

\subsubsection{Structural dissonance in course outlines used in IECTE programmes.}

The previous chapter of the thesis has argued that the context that students find themselves in, in terms of the actual physical environment in which they undertake study, is constructed by influences far outside the immediate environment. It is a context that is constructed in board rooms, by committees and by people whom students (and the lecturers of courses) may have never met. The university context in which IECTE programmes are delivered is pre- 
formed, externally constructed and above all reproduces a culture of individualisation. This section focuses on the official course outlines used in IECTE programmes as a case in point.

Course outlines in IECTE are an interesting irony. They are the documents which most directly enforce individualisation for student teachers, in the form of the rules to which they are individually bound (and accountable). But they are also the place where socioculturalism makes its demands in the form of pedagogical output. In course outlines individualisation and socioculturalism simultaneously exist. Individualisation appears in the course assessment statement which informs the student about course regulations pertaining to individual accountability (e.g., grading scale, late submission of work, requests for extension, academic integrity and attendance requirements). This material is usually presented as housekeeping at the beginning of a course. And, as chapter 6 showed in detail, much of the pedagogical work stated in the course outlines in IECTE programmes was sociocultural in nature (insofar as pedagogical work was being used to assess student comprehension of socio-cultural themes in issues concerning early childhood education, e.g., assessment, pedagogy, curriculum and perspectives on human development).

Course outlines and the course regulations they contain, reproduce the culture of individualisation by foregrounding the individual responsibilities of students 
in a standardised manner. It is not by chance that this information is sited at the front of the documents and usually dealt with in the first class. The disembedding of individuals from their socio-familial setting is achieved through a standardised requirement that individuals are personally accountable for their own academic progress, but have little choice in the direction that progress might take given the level of prescription in the course structure. The point here is that students enter a paradoxical relationship where-by the choice of subject matter is controlled and assessed by the institution, but the subject matter itself is based on a framework of participation, relationship-building and empowerment. Plainly there is dissonance in the structure of the course outlines.

Within the context set out by the course outlines, the onus is on the individual to highlight issues in their personal biography that influence their performance within the course structure (e.g., disability). Furthermore, students are assessed on an individual basis, even in terms of group work where results of assessment are ascribed to individual participants. The risk of success or failure falls firmly on the shoulders of individual student teachers, and success or failure in this case means attaining an institutionally accepted standard (e.g., Standards for Graduating Teachers (NZ Teachers Council, 2007) or a passing grade in the assessments in each course. Individuals are wholly dependent on the tertiary education institution for the provision of each particular course, 
including compulsory non-negotiable assessments. Course outlines establish a standardised set of rules and regulations that make the individual and their efforts highly visible and highly personalised.

The course outline is an artefact of contradiction insofar as it imposes personal accountability on individual students by way of course regulations; it presents a standardised and non-negotiable structure for assessment and relates required pedagogical work to the pre-fashioned course objectives; which is bolstered by the fact that without attaining a pass in each course students will be unable to graduate, and have to return to redo the course (increasing the personal cost of study) in order to gain their qualification. Whilst at the same time the content students are expected to learn, produce and have assessed draws upon sociocultural themes of inclusion, participatory rights, holistic well-being, coconstruction, collaboration and reciprocal relationships.

\subsubsection{Structural dissonance and student teachers' experiences.}

The thesis of structural dissonance is supported by the reports of student teachers in the four focus groups. At a general level, there was dissonance between those aspects of the course that student teachers enjoyed most and disliked the most. Student teachers reported that those aspects of their course that they found most enjoyable were those which developed socio-cultural capacities such as participation, co-creation, belonging and community. They 
also reported that the aspects they disliked the most were those that constitute individualisation (disembedding, standardisation, institutional dependency, and an environment of personal risk). This highlights the distinction student teachers made between elements of their education that drew them together as a community and those elements that fragment them and dominate them through a culture of personal accountability and external control.

Student teachers reported that they experienced contradiction in their courses of study. One student, in a discussion about the way IECTE courses are structured and the pressures placed upon students by the university asked the other students in her group: "do you find it frustrating that when you go to a centre and our curriculum states that we are here to empower children and you want them to express themselves and you know, it's a real contradiction because you can't do that here [at the university]... yeah, so you're two different people". This comment was met with widespread agreement. Students felt that they had to be two different people because the socio-cultural teacher that they are expected to become is so wildly different from the institutionally styled individual that the university creates through processes of individualisation. Encouraged to empower whilst feeling disempowered in their own educational context, the experience of student teachers in this focus group is one of contradiction based on the dissonance between the structure of 
the course content and the structure of the context in which that material is delivered.

A different focus group spoke on the topic of belonging as they talked about their experience of IECTE. As the students were talking about how they felt about their experience at the case study university one student framed their dissatisfaction in the following way: "you're teaching a child empowerment, communication and belonging, but you need to feel like you belong to the institution you are educated in, for me anyway". Again the rest of the group agreed with this sentiment and pointed out that there is a contradiction between how the university as an educational institution treats them as students and how they are expected to treat the children with whom they work in their educational setting. Again, this is further evidence of dissonance in the structure of IECTE courses.

Many of the student teachers in the focus groups had plenty to say about the contradiction between the content they were learning and the context of their own education. One student offered the following remark in a frustrated tone: "they tell us that all children are capable learners so therefore they are able to use knives and you are able to trust them to use big heavy hammers that are real and not plastic, and things like that you know, let them go onto their furthest development and all this stuff, and with us, I mean it's completely the 
opposite end of the scale, I mean 'here's the playdough, you can play with it for two hours, then at the end of that you can come and talk to me about how you felt'"'. Other students in this group agreed. The point they made was that the compulsory nature of courses they took as part of their degree and the nonnegotiable nature of the course content contradicted the socio-cultural values of co-construction and participation. Students in this group felt a marked sense of frustration that there seemed to be one rule for what they are supposed to do with children and another rule for how the university taught them what to do with children.

Another student summed up this feeling when asked if she could think of any examples of contradiction, "it happens pretty much all the time. Well we all know about it. They should be teaching us in the same way they expect us to be working with our children. It happens in all papers". This student is pointing to a contradiction that results from structural dissonance between content and context in IECTE programmes. The other students agreed with this appeal for harmony between what is being taught and how it is being delivered. Another student in that group then gave the following example to illustrate that point "I can think of one that happened yesterday when we were looking at art, like painting and things like that, and it was very directional 'and this is what you will produce'... no chance to experiment and things like that, just, 'this is what you will do, this is what will happen'... it's very prescriptive and prescribed". 
These students are taking issue with the standardisation and institutional dependency that accompanies individualisation. It is an issue with them because it contradicts the teaching practices that they themselves are expected to adopt.

Students in another focus group talked about the way in which they experienced inflexibility in the teaching programme. Given that they were expected to follow children's emergent interests they found it hard to reconcile a course where there was little chance to negotiate programme content. In this conversation one student remarked : "It's like they've had this [course] going for like three years and they thought this is how it is, let's just teach everyone the same. Which goes against what they're teaching us [laughter and agreement from other participants], yeah, it should be like constantly reflecting on their own practice and updating it". These comments suggest that what students perceive as an inability by lecturers to be flexible in the courses they teach is really a result of the inflexibility of the context in which those courses are provided, particularly in terms of CUAP and academic board limitations on what can be changed in courses and NZ Teachers Council stipulations on what must be covered (and what has been accredited).

In the context that students saw as dominated by personal accountability even the group work involved in some of the courses was perceived by some of the 
students that discussed this more socio-cultural element of their education saw it as a negative in a context that is dominated by personal accountability. The contradiction here was between the relationship-building potential of group work and the individualised impact that working in groups may have on personal performance. On this topic one student stated: "It's frustrating because you do gravitate to a group of people for an assignment, because you know that they will get the job done, but it doesn't necessarily mean that you are opening up relationships or really wanting to know that person, you just know that they will get the job done, I actually find it quite negative". This mercenary stance toward forming groups of learners can also be seen as a by-product of a culture of individualisation where students are aware that personal performance is the difference between pass and fail - this difference is connected to the pursuit of $a$ life of one's own and the benefits that passing papers entails for the individual student. When asked about the sense of community she felt at the institution one participant observed, "we work in groups doing things, but the group activities don't really build relationships". In this way the structure of IECTE programmes contradicts socioculturalism so completely that even the sociocultural activities within the programme are warped by the demands of individualisation.

The curriculum that student teachers are expected to put into action focuses on doing. This is to say that the curriculum focuses on activities, the links between 
activities and the social and cultural history that underpins those activities (e.g. Ministry of Education, 1996, pp. 9, 10, 15, 16, 19). This sociocultural focus on communal action echoes Wertsch's (1998) theory of sociocultural action, however, in their own education some students voiced resentment at a pedagogical format that expounds a pre-established content and the contradiction that this entails. For example, when asked about negative educational experiences one participant remarked, "just being told something is not really thinking, or active, or active learning, you're just sitting there". Other students picked up on the contradiction in pedagogical style pointing out that they are expected to communicate with children in a way that encourages their holistic wellbeing, participation and respect while they felt that the same socio-cultural approach was not being taken in their own education. For example, a typical statement made across the groups was, "Half the time they treat you like children, they talk down to you". This feeling of imputed inferiority may be a result of the powerlessness students feel as a result of a heightened sense of personal accountability in a context that demanded dependency through standardisation.

The group of Samoan students also voiced what they perceived as contradiction between what they were being taught and how they were being taught it. For this group language was a particular issue and they talked about how important language is within a sociocultural perspective on early childhood 
education (particularly deriving from Vygotsky's (1978) theory of development). Given this importance one student remarked: “It's funny that they tell us to go to early childhood and to promote the child's first language, but should we be doing that as students here as well? I mean, it's just confusing". These students felt particularly disembedded from their social community through the standardised structure of their IECTE programme. The mixed message these students were being given is a by-product of the structural dissonance that occurs when course content and the contextual rules that govern the delivery of that content contradict one another. Another student in this group illustrated this point when talking about her negative experiences: “They say we can do it in the centre [speak Samoan] so we should be able to do it here too, instead of mentioning you can do it at the centre and here you have to use just one language". Though it must be added that the case study university did have in place Pasifika learning support, Samoan tutors and the option for students to hand in assignments in Samoan language. The point remains, however, that these students reported they did not feel supported.

A feeling of dissonance ran deep in the group of Samoan students. They were trying to express themselves in their second language and trying to understand why they were expected to help others express themselves in their first language when they were not able to. The students in this focus group believed that teaching and learning are mutually inclusive concepts, in much the same 
way that ako in Māori means both teach and learn. One student teacher summed up this sentiment when commenting on the negative experiences of her education: “It should start from the college of teachers, it's a teachers' college isn't it?" The assumption being made here is that teachers should be taught the way that they are expected to teach others. From this perspective teaching and learning should be a harmonious event. However, this is not the case as the content of IECTE programmes in Aotearoa/New Zealand and the context in which they are provided are structurally dissonant.

Out of that dissonance came a feeling of fatalism and disempowerment that was echoed by participants in each of the focus groups. In one of the groups conversation turned from what their ideal early childhood education might look like to how they could create changes now, and whether they felt they could participate in the negotiation of their educational context. One student said: "I think they [the university] need to be more flexible with the course, and adapt it depending on the group and the group's experience... and to recognise not just formal qualifications but life experiences as well, take those into account". This version of what IECTE might look like combats disembedding and standardisation, it also challenges institutional dependency, and looks, at least on the surface, like emancipation for student teachers. However, this sentiment was not held by all students, some students argued the futility of their situation, for example, when asked if there were any other comments they 
would like to make at the end of a focus group session, one participant remarked: “We know we can't change anything but we just wanted to say [something]." The opportunity to have their say was enough for most students to gain a sense of participation, even though this research was explained to them as being completely separate from the case study university.

When the subject of end-of-course evaluations was raised with each of the groups it was met with a degree of scepticism. On the face of things one could relate the course evaluation forms to participation in the ongoing shaping of IECTE courses. However, there is a subtle but important distinction to be made here. Course evaluations are past-focused (regressio: Bloch, 1986). They refer to what has already taken place, and therefore is unchangeable, at least for those respondents that pass the course in question. The rhetoric that supports the course evaluation forms might seem to draw upon the socio-cultural themes of participation and co-construction but in actuality they are merely ways of reporting the past. Students who contribute to their course by filling out the course evaluation form, in all honesty, are commenting on practices that they will no longer be participants in. Formally, the ability to change the programme is there if the feedback is used to inform following year, however, that does not help students in the following year to co-construct their context, it has still been pre-formed. On this theme, when asked about what they felt they could do about their negative experiences one student commented, “But why can't we do 
that now, why can't we change things now when it is actually affecting you? Well, what can you do?"

The culture of personal accountability that permeates IECTE programmes, combined with a standardised delivery of content (pre-determined by external agents, i.e., CUAP and NZ Teachers Council), and an entrenched dependency on the university (and its multiple structures) results in a context of submissive reception to programme content. This is especially so where learning the programme content is concerned, particularly in terms of making the institutionally determined aspects of context a personalised occupation (i.e., personal accountability, acceptance of standardisation, dependency on the university). The content of IECTE uses a vocabulary of co-operation, codetermination, equity and empowerment as a guide for pedagogy and theoretical premise. However, the context, or rather, the manner in which the content is delivered runs in the opposite direction: Toward the erosion of participation and contextual co-construction, toward personal capitulation, and toward the repression of diversity and diverse participation in the coconstruction of educational contexts. 


\subsection{Structural violence and structural dissonance in IECTE programmes in Aotearoa/New Zealand.}

To conclude this chapter, the link between structural violence and structural dissonance is re-stated in order to point out the moral hope that something can and should be done (see $\mathrm{Ch}$ 2). Structural violence is a form of violence where there "is no visible, physical actor intending violent consequences, but rather it is a violence which comes from the social context itself" (Galtung, 1996, p. 2). This and the previous three chapters have premised the claim of contradiction that substantiates the thesis of structural dissonance in IECTE programmes in Aotearoa/New Zealand. The contradiction is one between students as empowered co-creators of their educational context and disempowered receivers of a pre-determined and highly structured education. In Galtung's (1996) terms, I have been arguing that student teachers are repressed by a structure where there is no specific actor which can be taken to account. Rather, it is the entire system, or structure that is brought into question.

Within the courses themselves there is little room for negotiation or coconstruction/transformation (Rogoff, 2003) because the assessments, their weightings, and their relation to pre-formed course objectives are decisions that have been made long before the student teachers are handed their course 
outlines. Courses are for the most part compulsory and ready-made for consumption leaving no space for negotiation or co-creation. It is ironic therefore that a highly standardised individualising institutional structure is being used to reproduce sociocultural pedagogies for teaching the nation's children. Surely sociocultural insights on development do not only apply to children, but are also relevant to adults and adult education programmes. Surely it is also possible that socioculturalism can and should be taught through sociocultural means. Writers like Fleer \& Robbins (2004) have stated in their work that such a connection is necessary. Ridgeway and Surman (2004) agreed with the need for consonance in their paper entitled Practice What We Preach. So too did Galtung (1996) in his classic Peace by Peaceful Means (at least at the theoretical level of institutions having an onus to ensure consistency throughout their practices). This thesis also agrees with these authors. Returning to the motif introduced at the very beginning of this thesis - it is important that what we teach and how we teach are telling the same story, for if there is anything to be learnt from socioculturalism it is this: We humans learn from our contexts as well as from each other and from books. Surely, if we hope to produce sociocultural teachers, then using the logic of socioculturalism, we have to role model the pedagogies we expect. This thesis has argued that because of the institutional context in which IECTE programmes are provided, we do not currently do this very well. 
There are beneficial uses of dissonance, for example, to challenge inequitable situations or to break vicious cycles of domination and/or repression (e.g., Freire, 1970; MacNaughton, 2005; Neyland, 2010; Postman \& Weingartner, 1971). However, that dissonance is different to the notion of structural dissonance advanced in this thesis. Dissonance for social justice is not the same as structural dissonance. Structural dissonance has been shown to be an ambient contradiction between the content and context of IECTE programmes; it is not inclined toward emancipation, but rather, the repression of coconstructive and participatory faculties for student teachers. So whilst it may be argued that some dissonance is good or useful, this thesis argues that structural dissonance is not.

As discussed in chapter 2, the question of whether or not to overcome any form of violence is a moral one. This chapter and the thesis thus far has argued that structural dissonance, as a form of structural violence, is being reproduced in degree-based IECTE programmes at universities in Aotearoa/New Zealand. The question now is what can be done. An answer to this question will be suggested in the fourth and final part of this thesis.

\section{Summary}

This part of the thesis has advanced the argument that there is structural dissonance in IECTE programmes in Aotearoa/New Zealand. Ideal types were 
constructed through the integration of textual sources and used to interpret the content and context of IECTE programmes using the method of ecological hermeneutics. This chapter has used that evidence to o premise the proposition of structural dissonance in IECTE programmes in Aotearoa/New Zealand. 


\section{Part Four}

\section{Reconstruction: A}

pedagogy of enacted

hope. 


\section{Chapter Nine}

\section{Hope}

So far this thesis has argued that structural dissonance is a type of structural violence where the content and context of IECTE programme are contradictory. This chapter is a first step in moving beyond the identification of this problem to suggest what might be done to overcome that situation. The reconceptualisation offered in this and the following chapter is an ironist example (Rorty, 1989) of blue skies thinking aimed at suggesting an alternative conception of IECTE programmes in order to counteract structural dissonance. This thesis does not argue that IECTE programmes, in a state of structural dissonance, are devoid of hope: Hope is abundant even in individualisation. Neither is it arguing that there should be more hope in IECTE programmes: Hope is abundant there too. The argument advanced in this chapter is that we can do a better job of aligning the context in which IECTE is provided with the social hope that socioculturalism describes.

This chapter is an example of blue skies thinking (May, 2009) as opposed to the reproduction of concepts grounded in the reality of present practices. Recalling that this thesis is based on Rorty's (1999) assumption that truth (and reality) are 
a function of the sentences that we use to form agreements in the communities to which we belong, rather than correspondence to reality, the idea that the present can be essentially real is suspect. From the perspective used in this thesis, the term reality of the present refers only to those sentences that are currently used to describe the things that are important to us and the consensus our particular communities have found on the usefulness of those sentences. From an ironist perspective (see chapter 3), those sentences are final vocabularies that can and should be superseded (Rorty, 1989). Blue skies thinking, in this frame, is also synonym for the ironist project of constructing new vocabularies to use in place of the old.

The goal of this chapter is to offer a philosophy of hope as a hermeneutic method for constructing a pedagogy of hope that can be used to create more socially just and less structurally dissonant relations within IECTE programmes The following chapter will then focus on the use of hope in education with particular emphasis on Freire's Pedagogy of Hope (1994). This goal uses Rorty's (1999) sentiment that social justice is one of the most useful conversations that philosophers, educators and culture at large can have. The second chapter of this thesis outlined the moral impetus that faces those who recognise injustice in an area of practice. Chapter two and part three of this thesis advanced the thesis of structural dissonance as a form of social injustice. This chapter is an attempt to open up space for further conversation of what might be done to 
improve the lot of student teachers in IECTE programmes by suggesting a notion of hope that is holistic and philosophically coherent with the rest of this thesis.

This chapter uses the ecological hermeneutic method to move from the general to the specific in terms of hope theory (see fig. 19). Discourses of hope and education are left out of this chapter and used to introduce the following chapter in which the theory of hope worked out in this chapter is applied to pedagogy. This chapter inverts the critical hermeneutic ecology used in part three (chapters 6, 7 and 8), transforming it into a reconstructive tool. In part three, the ecological hermeneutic method was used to organise critical analysis of socioculturalism in the content and individualisation in the context of IECTE programmes. Part four constructs an understanding of hope through the integration of multiple perspectives on this subject, organised from the general to the specific (as outlined in Ch 4). 


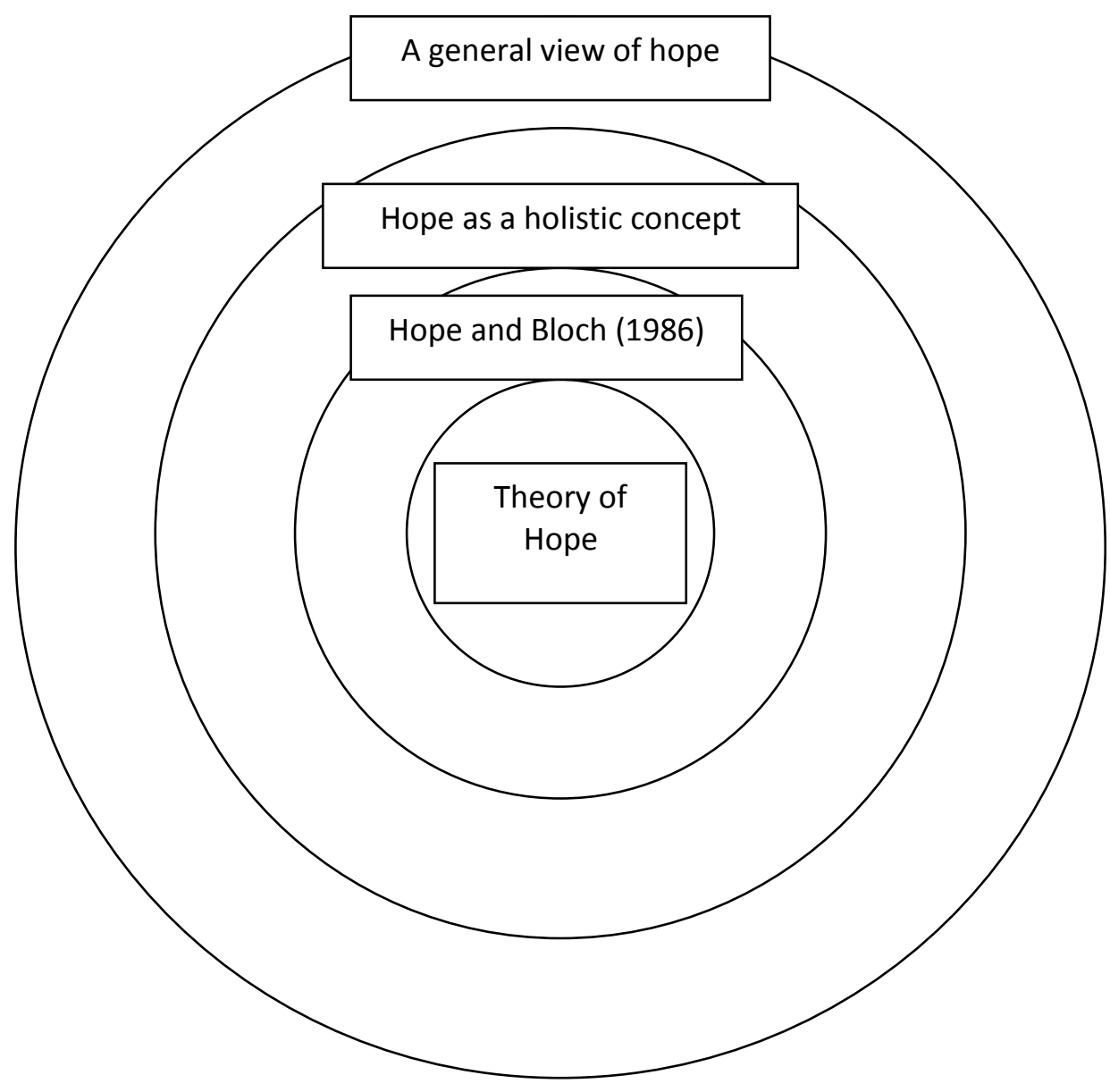

Fig. 19 Ecological hermeneutic for understanding hope.

The first part of this chapter is about hope as a philosophical and pedagogical concept. Hope is a word that people commonly use in a wide variety of settings to express their wishes, dreams, needs and wants. This chapter uses a specific understanding of hope to express the blue skies ironist reconceptualisation of IECTE programmes in Aotearoa/New Zealand, constructed as a response to structural dissonance in the those programmes. This section introduces a general understanding of hope before drawing together a hermeneutic of hope 
(constructed in section 9.1.2.4) which will be used in place of epistemology (theory of knowledge).

\subsection{A general definition of hope.}

From a general standpoint this thesis defines hope as looking forward to a better future and acting on the possibility of its realisation. This formulation contains four inter-related parts: looking forward, a better future, acting and the possibility of realisation. This formulation is similar to that of 13th century Dominican monk Thomas Aquinas when he wrote of hope as "a future good that is arduous and difficult - but nevertheless possible - to obtain" (Aquinas, in Shade, 2001, p. 43). Hope and education are intricately related, relevant to one another, and compatible (e.g., Freire, 1994). The following discussion draws these two topics together as a background to the pragmatic theory of hope advanced in the next section.

Hope looks forward, but the future focus of hope is not necessarily a temporal direction; hope also looks to those aspects of the past that have not yet worked themselves out, or which might offer new life and new perspective in the present (e.g., Taylor, 1989 who argues for the rehabilitation of history into the present by virtue of its unfinished elements). Education looks forward in all of 
these ways: it takes the past and offers new interpretations (e.g., history and social sciences), it uses the resources of the present to create innovation (e.g., technology and art), and it imagines the world of tomorrow (e.g., English and science).

Hope looks to the better in conditions. What this means is that hope provides positive inspiration as a condition of its vision. The object of hope is goodness (which is in itself a subjective term) and it finds this goodness in its subject (whether past, present or future), for example the child who longs for sweet things to eat or the student teacher that eagerly awaits a grade for an essay on which they worked particularly hard. Hope looks out upon brighter vistas, toward the better life, toward finer things (whatever that may mean to a given audience). Educational policy, curriculum statements and course outlines all contain statements of what they hope to achieve - descriptions of the better place to which they tend, e.g., building the lifelong foundations of success (Ministry of Education, 2002), or the aspiration that children "grow up as competent and confident learners and communicators, healthy in mind, body, and spirit, secure in their sense of belonging and in the knowledge that they make a valued contribution to society" (Ministry of Education, 1996, p. 9).

Hope, if it does not inspire action, is an end unto itself. It is a symbolic aspiration, an abstract dreaming. The notion of hope developed in this chapter 
is the idea that hope is an activity, a praxis and a process, and as such has highly practical applications, particularly as a pedagogy for peace. Education is abundant in the activity of hope. In early childhood education, teachers in centres work towards the empowerment of children, their holistic development, community inclusion and the formation of reciprocal relationships. Mere knowledge of these principles is not enough - the hope of their implementation is dependent on the actions of teachers and learners in diverse contexts (e.g., Wertsch, 1998). The condition for the realisation of these principles is constructed through work, that is why student teachers go out for teaching practice and are assessed in the field: to see their abstract hopes put into action. Education, like hope, is something we do, not merely something we learn from books, and, as will be unfolded in this chapter, is at its best when it is something that we do together.

Finally, the object of hope must be possible otherwise it is wishful thinking (i.e., "I wish that money lenders would stop charging interest" as opposed to "I hope I can find a lender with a low rate"). The possibility of realisation grants hope and hopeful activity the vital energy required to make change. In the case of student teachers, all respondents in the focus groups expressed the hope of gaining their degree and becoming registered teachers. All of them thought that this was possible and all had no doubt that with hard work they would someday graduate. Other students used their education as a tool for becoming a 
better teacher, some for becoming a better researcher, others for gaining employment that would otherwise not be possible. In each case, hope was active and the possibility of its realisation was a real possibility to each of the respondents. With this in mind the general definition of hope this thesis uses is as follows: looking forward to a better future and acting on the possibility of its realisation.

\subsection{Hope is a holistic concept.}

In order to flesh out this general definition and also to link the concept of hope to research and discourses in a variety of disciplines, this section uses Durie's (1994) idea of a four sided house as a metaphor through which to construct a holistic idea of hope (spiritual, mental, physical and social). Explaining hope as a holistic concept creates a link to the holistic underpinnings of Te Whäriki (Ministry of Education, 1996). This link offers insight into not only hope as a useful subject, but hope as a useful subject for early childhood education. Drawing philosophy of hope and IECTE programmes into conversation is the work of the final chapter of this thesis.

From a theological perspective, and representing spiritual wellbeing (taha wairua) in this chapter, hope is one of the three theological virtues attributed to 
St Paul in the Christian tradition (along with love and faith) (1 Corinthians 13:13). Some theologians argue that hope is the predominant theme of the New Testament (e.g., Bultmann \& Rengstorf, 1963; Polkinghorn, 2002; Moltmann, 1967). In Romans, hope is the key to salvation (Romans, 8: 24, 25), and in Colossians it is Christ that is "the hope of glory" (Colossians 1: 27). In his book, Sickness Unto Death, the 17th century theologian Søren Kierkegaard (1849/1941) in outlining "the sin of despair" (p. 208), identified hope as a counterpoint to despair (pp. 171, 172), which Kierkegaard regarded as the disease of the soul.

Perhaps the most powerful use of hope in theology can be found in Jürgen Moltmann's (1967) Theology of Hope. In this book Moltmann (1967) argues that "from first to last, and not merely in epilogue, Christianity is eschatology, is hope, forward looking and forward moving, and therefore also revolutionising and transforming the present" (Moltmann, 1967, p. 16). Moltmann (1967) goes on to argue that "hope alone is to be called 'realistic', because it alone takes seriously the possibilities with which all reality is fraught" (p. 25). For Moltmann (1967) hope is essential to faith, and Christian hope in particular has no place in accepting the status quo. Instead, for Moltmann (1967) it is hope that:

Constantly provokes and produces thinking of an anticipatory kind in love to man and the world, in order to give shape to the newly dawning possibilities in 
the light of the promised future, in order as far as possible to create here the best that is possible, because what is promised is within the bounds of possibility. Thus it will constantly arouse the 'passion for the possible', inventiveness and elasticity in self-transformation, in breaking with the old and coming to terms with the new (Moltmann, 1967, pp. 33-35).

For Moltmann (1967) therefore, hope is the foundation of the spiritual life and being hopeful is a mark of not only a realised Christian, but also spiritual wellbeing.

Psychology and hope are easy bed fellows. For instance, in Erik Erikson's (1963, p. 239) psychosocial theory of human development, hope is the first of his psychosocial strengths: the outcome of infantile conflict between trust and mistrust: hope is the earliest and primary virtue to a healthy life, hope must remain, even where confidence fails and trust is broken (Erikson, 1963). Alternatively, Ezra Stotland (1967) is widely acknowledged as a pioneer in the study of hope in the discipline of goal theory. Stotland (1967) identified hope as a combination of the importance of particular goals and the probability of their achievement. For Stotland (1967), the higher the probability of reaching one's goal, the higher the level of hopefulness experienced by the subject; where goal directedness is assumed to be a good thing - a sign of wellbeing. From this 
assertion psychologists began their affair with the goal-related aspects of hope, which educational psychology picked up in due course (e.g., Ames, 1992).

Other uses of hope in psychology include C.R. Snyder's (1994) The Psychology of Hope, which proposed that hope is something that needs developing in children as well as in adults, involves setting challenging yet doable goals, and is accomplished with guidance, friendship, and cooperation. Snyder's (1994) thesis was that hopelessness is at the root of mental disease and that hope heals the hopeless. This book is followed by Snyder's (2000) Handbook of Hope: Theory, measures, and applications which added clinical evidence to his perspective. Gilman, Dooley and Florell (2006) linked hope with increased academic outcomes finding that adolescent students with higher levels of hope reported a higher grade point average, greater life satisfaction and social adjustment (p. 166). William F. Lynch (1974) in his book Images of Hope: Imagination as healer of the hopeless, maintained that the development of hope is a key element in treating mental illness. The findings of a number of studies in this field agree. For example, Bland and Darlington (2002, p. 61) argued that hopefulness “appears to be central to a family's coping with the impact of mental illness. And Westburg (2003) found that hope is particularly useful in the treatment of "elderly people as they experience a decline in their independence" (p. 16). 
From a biological perspective, Norman Cousins (1989) published his groundbreaking book Head First: The biology of hope. In this book, Cousins reflected on his career as a medical practitioner arguing that "if negative emotions could bring about biological change on the downside, positive emotions could create effects on the upside" (p. 12). In his classic experiment, Cousins found that by taking two blood samples at a 5 minute interval and doing nothing but thinking hopeful thoughts between samples "there was an average increase of $53 \%$ in the various components of my immune system from a low of $30 \%$ in the precursor NK (natural killer) cells, to a high of about $200 \%$ in the antibody coated T cells" (p. 253).

Cousin's (1989) work is used widely in contemporary nursing studies alongside texts such as: Groopman's (2005) research which found that hope “can block pain by releasing the brains endorphins and enkephalins, mimicking the effects of morphine" (pp. iv, 170); Arnaert, Filteau and Sourial's (2006, p. 137) report that hope has a positive effect on the recovery of stroke patients; Rustoen, Howie, Eidsmo and Moum's (2005, p. 417) work advocating interventions supporting hope in patients with heart failure for a positive effect on intervention goals; and Walker's (2004, p. 8) research that concluded promoting hope in patient care is vitally important for promoting wellbeing in terminally ill patients. 
Finally, from a sociological perspective writers like Rycroft (1979) point out that

Hope is a social quality that is transmitted from individual to individual, from generation to generation, the sources of hope in any particular person are all those relationships which [s/he] has had in the past, which [s/he] is having in the present, which [s/he] envisages having in the future, and which endow [his/her] life with meaning and value (p. 12).

According to social philosopher Patrick Shade (2001), “connection with other humans, such that a sharing of concerns and abilities is possible, is important in both persisting and pursuing hopes" (p. 111). This type of connection also inspires courage, which is necessary when faced with failure and the risk that the difficulty inherent in hope contains. Shade (2001, p. 164) argues that the life of hope is infectious. Individual hopefulness leads to agency, which leads to vibrant communities of hope. For this reason, hope plays an important role in "the genesis and reconstruction of communities" (Shade, 2001, p. 200). What this means is that when we hope together our commitment to action is strengthened, and through the process of communicating our hopes to one another, our commitment to building just communities is invigorated.

Each of the above perspectives on hope offer insight into how important hope is to holistic wellbeing. It is reasonable therefore to assert that if hope is important 
to holistic wellbeing, and if holistic wellbeing is essential to contemporary early childhood education in New Zealand, then hope must be a subject of particular interest to early childhood education. Introducing a philosophy of hope to IECTE is therefore not a matter of introducing apples to oranges, but rather, it is an exercise in offering a new and useful perspective in a field that may have some natural affinity with what hope has to offer. The link between theories of hope and holistic wellbeing is useful to this thesis only insofar as it illustrates how hope theory is relevant to early childhood education in Aotearoa/New Zealand, whilst providing insight to some of the functions possible for hope as praxis. In the following chapter hope will also be used to inform a pedagogy for counteracting structural dissonance in IECTE programmes.

9.3 Hope, Bloch (1986) and Rortyan assumption.

This thesis adopts an approach to hope that integrates Ernst Bloch's (1986) notion of hope as concrete utopian function with Rortyan philosophical assumptions. The point of this section is to fuse (Gadamer, 1975) a peripheral philosophy of hope (Daniel, 1997; Hudson, 1982; Kellner, 1997) into the general and holistic notions of hope set out above, in order to expand the vocabulary available to this thesis in the following chapter. The first step in making this philosophical integration is to come to terms with Bloch's (1986) philosophy of 
hope, which is regarded by a number of scholars as notoriously difficult to understand, given the esoteric nature of his philosophical writing (Bloch, 1986; Daniel, 1997; Hudson, 1982; Kellner, 1997). It is worth surveying because of the unique and useful philosophical vocabulary that it has to offer.

In keeping with the philosophical assumptions that underpin this thesis parts will be rejected in the next section in a similar way to how parts of Weber (1949) were dropped in chapter four. The metaphysical and epistemological elements of Bloch's (1986) writing contradict the antimetaphysical and antiepistemological taken throughout this thesis. Following Rorty's (1999, p. 12) assertion that there are aspects of a writers vocabulary that hold back the formation of new understandings, and Gadamer's (1975) assertion that once the text has left the hand of its author it is open to new interpretations and applications, the rehabilitation of Bloch's (1986) writing is both philosophically and methodologically consistent with the scholarly approach taken throughout this thesis. That rehabilitation will be carried out in section 9.3.3.

There is much in Bloch's (1986) 1420-page Das Prinzip Hoffnung (The Principle of Hope) that is worthy of rehabilitation. Foremost among these is Bloch's (1986) conceptualisation of hope as concrete utopian function. Bloch's (1986) conception of hope as concrete utopian function is considered complicated and requires an introduction to some general concepts before it can be comprehended (Daniel, 
1997; Hudson, 1982; Kellner, 1997). It is perhaps due to the difficulty in Bloch's work, the Eurocentrism of his justifications and applications, and his radical utopian reading of Marxism that his work remains foreign to most New Zealand readers. However, Bloch's philosophy offers a new vocabulary to inspire action and challenge structural dissonance and thus can still be useful to IECTE programmes. Using Bloch's (1986) philosophical vocabulary is another example of border crossing (Dahlberg, Moss \& Pence, 1999), one that this thesis proposes has useful benefits, especially insofar as Bloch's (1986) philosophy has not-yet-been-used in early childhood studies in Aotearoa/New Zealand.

\subsubsection{Bloch: Some general definitions of hope}

There are four definitions that provide a useful introduction to Bloch's (1986) philosophy of hope. The first is process philosophy which Bloch (1986) gives a Marxist bent (Hudson, 1982). The idea of history as a process is central to understanding Bloch's idea of hope. By process he means movement through time. In Bloch's work, the future is the front of the world process, that is, the world as it moves through time. Bloch (1986) asserts "the Real is process" (p. 196), by this he means that reality is not premade, it is in the constant process of becoming other (and in the case of hope, becoming better). For Bloch, reality is not a closed affair or fatum, instead the real process of the world is an open oneone in which the future of the process has in no way been pre-determined. 
Similarly, the material of the present is also deep in the process of becoming other. Therefore, a Blochian understanding of IECTE would be to see it as a process of description and re-description (this perspective is not different to that already taken up by this thesis).

The second definition is Bloch's (1986) use of the word novum. Bloch did not intend a philosophy that consists of contemplation, for he believed that contemplation has as its object what has already become (it is backward looking). Instead he aimed to construct a conscious theory-practice: A philosophy that is embodied in human activity, or more specifically - in the material-dialectic of human hope and an unfinished world (Bloch, 1986, p. 200). On this point he claims, "Only thinking directed towards changing the world and informing the desire to change it does not confront the future (the unclosed space for new development in front of us) as embarrassment and the past as spell" (p. 8). Forward movement is exemplified by his concept of the novum (the objectively historically new). For Bloch (1986) it is novum that stands on the front of the world process, it refers to all that is radically new in human history and possibility. A novum is an unprecedented appearance of an object in the world - like the very first motor car, the very first printing press, the very first Froebel Kindergarten. 
The third definition is linked to both process and novum - the concept of front. Front is Bloch's word for that which is approaching, namely "Future, Front, Novum" (p. 8). In Bloch's (1986) system, these categories have been historically constant in the consciousness of humans as they dream forward and create new things (p. 7), in the world of objects as they display their tendency to change and be changed (p. 7), and in the works of poetry, literature, philosophy and science whose innovations he calls explosive dialectics (p. 8). These explosive dialectics emerge as an attempt to break through what has become, (these are the discourses someone like Thomas Kuhn (1962, p. 6) might call revolutionary, as opposed to normal - as per Rorty (1979)). Bloch (1986) concludes that "longing, expectation, hope therefore need their hermeneutics, the dawning of the In-Front-of-Us demands its specific concept of the Front" (p. 6): That hermeneutic is expressed in Bloch as the prefix not-yet.

Not-yet (nocht nicht) is a characteristic hermeneutic device for conversation of the novum (Bloch, 1986). According to Bloch (1986) what is needed is a forward signal "which enables us to overtake, not to trot behind. Its meaning is Not-Yet, and the task is to grasp it thoroughly" (p. 9). It is the not-yet-conscious in humanity that gives hope its pre-conscious anticipation of the better life that is to come. It is the not-yet-become that lies latent in the world of process that provides the real possibility for matter to become other. And, it is the not-yetbecome-good that gives hope its positive correlate in the not-yet-experienced 
and the not-yet-fully-worked-out, of an unfinished world. If, then, these are foundational concepts, what is hope? To this question Bloch (1986) gives two answers.

On the one hand, hope is both emotion and cognition. On the other hand hope is short hand for concrete utopian function. For Bloch (1986), hope is the most positive of the expectant emotions. The expectant emotions are anxiety, fear, fright, terror, hope and confidence, these are contrasted with what Bloch (1986) calls the "filled emotions of envy, greed and admiration" (p. 108). The difference between the two is that the former face the possibility of the novum, and the latter face only that which is no longer new. Bloch differentiates the expectant emotions as negative (anxiety, fear, fright, terror and despair) and positive (hope and confidence): each expectation decreases as certainty is aroused. In Bloch's (1986) philosophy “hope is thus ultimately a practical, a militant emotion, it unfurls banners. If confidence emerges from hope as well, the expectant emotion which has become absolutely positive is present, or as good as present, the opposite pole to despair" (p. 112).

For Bloch (1986), hope is also cognitive anticipation: Hope is "more essentially an act of a cognitive kind (and here the opposite is then not fear, but memory)" (p. 11). Bloch (1986) calls this cognitive aspect not-yet-conscious (consciousness of what has not-yet-become). Not-yet-consciousness appears as thinking, which 
Bloch (1986) defines as "venturing beyond" (p. 4), but more particularly it appears as a consciousness that is exemplified by daydreams: the waking dreams of a better life. According to Bloch (1986, p. 119), “all times of change are thus filled with Not-Yet-Conscious, even over filled." Hope is the not yet conscious element expressing itself in the waking dream of a better life that is possible, but has not yet become.

But Bloch goes a step further, and in doing so he creates a material dialectic of hope which casts human hope not above, but rather essentially entwined in a world that is in a rich process of becoming other: becoming better: "Thus the Not-Yet-Conscious in man belongs completely to the Not-Yet-Become, Not-YetBrought-Out, Manifested-Out in the world. Not-Yet-Conscious interacts and reciprocates with Not-Yet-Become, more specifically with what is approaching in history and in the world" (Bloch, 1986, p. 13). For Bloch, front, future and novum exist in the very material of the present, insofar as the present is a moment in a far greater unfinished process in which what is co-exists as what is to become. For Bloch (1986), hope is not only content (what is hoped for) but also function (how hope goes), experienced continually in the open process of becoming other, of becoming better (p. 4). 


\subsubsection{Bloch: Concrete utopian function}

A utopia is a place or space that does not exist. In more specific terms, it is an abstraction made up of language and images describing a perfect, or objectively better place and/or state of affairs. To manage this notion of utopia Bloch (1986) makes a distinction between abstract utopias and concrete utopias. Abstract utopias are made up of language and images describing a perfect, or better place and/or state of affairs. Abstract utopias do not move beyond symbolic into action that creates the better life that is possible for all. This notion is very similar to those put forward by Dahlberg and Moss (2005), Dewey (1902), Friere (1994) and Wertsch (1998). In Levitas (1990) this hope is concrete in the sense that the material world undergoes some form of change as a result of the commitment of humans through their activity.

For Bloch (1986) the utopian function consists of a dialectical relationship between not-yet-ontology (that which has not yet become of humankind) and real possibility (which is the unfinished world constantly pregnant with the possibility of the novum). Not-yet-ontology is Bloch's (1986) concept of being. Not-yet-ontology is being on the processual front of human experience and as such it "passes straight through Becomeness and beyond it; hunger becomes the force of production on the repeatedly bursting Front of an unfinished world" (Bloch, 1986, p. 308). This concept refers to the present moment and points out that that by the time you are conscious of the present it has already past. The 
present itself is empty (or in Bloch's words - dark). However, using Bloch's argument, it is possible also to conceive of the present as not only those moments that have passed us, but also those moments that are coming up, that have not yet formed themselves and so are full of the possibility of becoming other. According to Bloch (1986) when those moments in front of us are full of the possibility of becoming better - that is hope.

The other side of the dialectic is real possibility. Real possibility exists as a latency in the material of a world that is itself in the process of becoming other. For Bloch, the objectively real possible is the not-yet-become of matter: It is the latent changeability of the world in the open process of becoming other, of becoming better. Thus, "real possibility is the categorical In-Front-of-Itself of material movement considered as a process" (Bloch, 1986, p. 237). Examples of this are the seed and the tree, mountain building faults and erosion, the world shifting on its axis, movement in weather patterns, the latency in wood and ore to be shaped and used for innumerable things. Bloch's argument is that both humans and the world they live in are full of the possibility of becoming other, and in hope, better. In Bloch (1986) there is an ultimate state to which humans and the world tend and this process can be helped or hindered. In hope, the process of becoming other, of becoming better is helped as the tendency in humanity meets the latency of an unfinished world. The concrete utopian function is this dialectic working through its teleological process. The end of 
this process, according to Bloch (1986) is "something which shines into the childhood of all and in which no one has yet been: homeland" (p. 1376). A place where humans are no longer alienated from the world and the world is no longer alienated from humanity. It consists of the "naturalisation of humanity, humanisation of nature" (Bloch, 1986, pp. 131, 205, 209).

Bloch's mission was to provide a philosophy of hope to challenge backward looking philosophy and to create a method for reinterpreting social history as forward looking. Bloch wanted to move beyond abstract idealisms to say that hope is a principle at work in the material world as it meets the social worlds of human beings. It is precisely in the not of the present moment that Bloch finds the impulse toward what has not-yet-become of people and of the world. This is an attractive sentiment because it promotes an open ended philosophy were there is still so much that is not-yet thought of: Not-yet-conscious. To an ironist scholar working out of a reconceptualist perspective, this philosophy is more useful than closed conceptions of the world, or settled vocabularies.

\subsubsection{Rehabilitating Bloch}

In chapter three, the philosophical assumptions of this thesis were set out as anti-metaphysical/anti-essential and anti-epistemological/anti-foundational. This section applies those philosophical assumptions to Bloch's philosophy in order to extract the metaphysical and epistemological elements of his work, to 
make his vocabulary consistent with the philosophical assumptions that underpin this thesis. Bloch's (1986) concepts are still important to this thesis because the offer a vocabulary that cannot be found in any other philosophical perspective, for this reason his philosophy is worth rehabilitating through the fusion of the Rortyan perspective taken throughout this thesis.

The first step in rehabilitation is to reject Bloch's metaphysics, in particular his assertion that human hope is teleological (tending toward an ultimate and absolute end). If we reject the notion that there is some sort of ultimate reality (for Bloch this was Marxist homeland) then we rid ourselves of both Bloch's politics and the assumption that all of history is heading to an ultimate conclusion. Bloch wanted to show that the spirit of the world was moving in process toward its ultimate conclusion, but it was doing so through the material dialectic of humans and matter, rather than through ideas and idealism. By dropping this component from Bloch's framework we are able to conceive of an unfinished and unfinishable world, a world that is in process, a world that has at its front the novum, but a world heading in no preordained, unconditional direction, and therefore endlessly creative. This allows for the insertion of the Rortyan claim that constructing a more socially just society is about the best aim we humans can have. 
The second step is to drop Bloch's epistemology and his will to form a foundation upon which reality can be recognised as objectively real. From a Rortyan standpoint, the attempt to discover the essence of reality is a waste of time because reality is something we make, it is the product of popular metaphors, and those metaphors change with time and audience. Bloch (1986) argued that his dialectic method of identifying tendency in humanity and latency in the world acts as the gate-keeper of hope. He wished to carve away the abstract utopias of mere idealism and replaced it with his concrete utopia as a function for the realisation of "homeland" (Bloch, 1986, p. 1376) - his Marxist paradise. If his dialectic method is rejected and a hermeneutics of hope used in its place, then the presumption of gaining special insight into the nature of reality can also be set aside. From a Rortyan standpoint, this is an attractive proposition.

So what then is left? A Rortyan answer must surely be vocabulary. Bloch wished for an accurate description of reality. All that he managed, from a Rortyan perspective, was to create an alternative metaphor, complete with its own vocabulary and proposals for use. Formulae like novum, not-yet, not-yetconscious, not-yet-become are a fresh vocabulary to be picked up and applied. As far as this thesis is concerned, the concept concrete utopian function is an ungainly attempt at detecting ultimate truth and for that reason can be rejected. 
A rehabilitation of Bloch means picking up his concepts of novum, an

unfinished world, his characteristic hermeneutic not-yet, his concepts of not-yetconscious and not-yet-become and his assertion that concrete hope is the activity of changing the world.

\subsection{Theory of Hope.}

As a theoretical position, a Bloch/Rorty theory of hope is notable for rejecting the idea that there is an ultimate reality (and therefore any attempt to accurately represent that reality, or measure how well our assertions correspond to that reality). It also views hope as a verb that leads to changes in cognition, affect and matter. Most importantly, at least from an ironist's point of view, this theory of hope views the world (social and natural) as unfinished, full of the possibility of becoming better (more peaceful, more just), pregnant with the possibility of novum and enamoured with that which is not yet conscious and not yet become (in both word and deed). This section uses the term theory of hope as a generic term for the fusion of Blochian and Rortyan philosophies set out above. Later in the thesis this will be employed to constitute a pedagogy of enacted hope. 
The theory of hope developed through the integration of Rortyan assumptions and Blochian theory is an edifice for reinterpretation of the past, present and the future. As an edifice, this theory of hope opens out on to the possibility of alternative stories that are not yet conscious - new integrations that can be made and new ways to make the world a better, more peaceful, more just place. In education, this philosophy of hope entails moving beyond what is into what is becoming. Alternatively, it involves re-creation of what has already become through integrative conversation of what has not yet been considered, or the retrieval of what has become in the past but has not yet fully worked out its possibilities, to inform present and future situations.

This theory of hope entails an open system where vocabularies are picked up, put down and created in an effort to inspire and direct new constructive practices. The object of this theory of hope is the better life that is possible for all, which is achieved through the co-creation of contexts under the banner of social justice. Theory of hope is therefore a call to action and a call to difference. Not difference for its own sake, but difference for the sake of constructing a more peaceful less violent world. There may of course be a number of uses not yet thought of: that is an unavoidable facet of an open system. However, at least as far as this thesis is concerned, philosophy of hope lends itself to the creation of a praxis for social justice. It involves the radical negotiation of contexts from within the contexts themselves. For this reason, this theory of hope is useful for 
challenging the dissonance between socioculturalism and individualisation in IECTE programmes. On the one side it is amenable to sociocultural theory (albeit in a radical way), and on the other it challenges disembedding, standardisation and institutional dependence by opening the space for a notyet-achieved-socially-just institutional culture. Theory of hope, when used as a framework for pedagogy, opens up the possibility of the novum in IECTE programmes in Aotearoa/New Zealand.

This theory of hope radicalises socio-cultural theory by viewing culture as a negotiated event rather than a set of traditions to which one belongs or adheres. The up-shot of this view is that cultures are not closed systems, they are constantly being created and recreated both in the direction of tradition (what has already become) and the novum (that which is objectively new). The assumption here is that humans create cultures. This theory of hope assumes that there is still more to make of what is and that there are a multitude of cultures and cultural experiences that have not yet become, not yet even been thought of, or acted out. Using Bloch's terminology, theory of hope faces the front of socio-cultural contexts, to that space where the novum circulates awaiting entry into experience, whilst at the same time being formed and reformed through the collective experience of actors within their diverse contexts. When viewed through the lens of the theory of hope, culture is open to change. Participation does not involve moving from the periphery to the 
centre (as per Lave \& Wenger, 1991 and Wenger, 1998), nor does it involve undertaking an apprenticeship or initiation (as per Rogoff, 1990, 2003). Instead, participation is the radical co-construction of both context and content, and because of this it entails an unfinished and unfinishable process of becoming better (more peaceful, more just).

Theory of hope is, therefore, embedded as a form of social activity, but aimed toward the radicalisation of the context within which that social activity is embedded. Philosophy of hope avoids standardisation by drawing actors together in contexts and encouraging re-negotiation as a means to interdependence. This theory of hope challenges institutional dependency by requiring flexibility as a condition of institutional life wherein standardised dependencies are abolished in favour of democratic standards open enough to allow full participation in the content of what the standards themselves contain.

Theory of hope is therefore a radical social theory which would challenge contemporary hegemonies in IECTE programmes in Aotearoa/New Zealand within the current regulatory structure. It is also the realisation of the novum in sociocultural theory insofar as it localises culture to lived experience in diverse settings, allowing for the re-construction of those local cultures as a result of interactions and conversations between actors with diverse loyalties. When viewed in this way, theory of hope is exemplified by what has not-yet-become 
of culture. And, at its most socially useful, it means an interdependent pursuit of peace and justice that has not yet been achieved.

\section{Summary}

This chapter has constructed a theory of hope, ready for application to pedagogy in the following chapter. A general view of hope has been introduced and the notion of hope has been broadened by offering an holistic survey of hope's utility. Bloch's (1986) philosophy of hope has been introduced as a new vocabulary for IECTE studies, and has then been fused with the Rortyan assumptions that underpin this thesis, in order to make Bloch's vocabulary consistent with the philosophical assumptions used in this thesis. The following chapter uses the vocabulary worked out here to construction a pedagogy of enacted hope, as a suggestion for counteracting structural dissonance in IECTE programmes in Aotearoa/New Zealand. 


\section{Chapter 10}

\section{A pedagogy of enacted hope}

This chapter further advances a pedagogy based on the theory of hope developed in the previous chapter as a way to counter-act structural dissonance in IECTE programmes in Aotearoa/New Zealand. The first part of this chapter links hope and education to show that others have brought the two together previously. The second part of this chapter blends philosophy of hope with enactivist learning theory (Varela, Thompson \& Rosche, 1991) to construct a pedagogy of enacted hope. The final part explores some of the implications of using an enacted hope approach in IECTE programmes in Aotearoa/New Zealand. This chapter also presents data gathered in the focus groups to illustrate and evidence some of the points raised.

\subsection{Education and hope}

Education is the practice of encouraging not-yet-achieved qualities in human beings. For example, IECTE programmes aim to educate early childhood teachers to develop critical reasoning skills, a knowledge of best theory and practice, and a commitment to further professional training. Education programmes see future educators in the new admissions to training 
programmes, and it is through education that these students work toward their goals through a process of personal transformation. Education programmes such as IECTE deliver the hope of graduation and entry into the workforce among the many other idiosyncratic hopes that students may individually hold. This section looks at how hope and education are easy bedfellows.

The objects of early childhood education and IECTE programmes are overflowing with hope. Children have so much future in front of them - so much that has still not yet become of them. The younger the child, the more this is the case. For example, those that cannot yet walk have millions of steps on their horizon to realise. Those that cannot yet talk have millions of words to offer the world around them. From this vantage point, it seems reasonable to say that early childhood education deals with hope on a daily basis. It is also reasonable to say that Te Whäriki (Ministry of Education, 1996) is a document designed to keep hope alive, or better, to encourage the hope of building strong equitable and socially engaged communities. It achieves this by drawing upon socio-cultural themes of participation, co-creation and emancipated interest (interest that is free to experiment and explore the world). Curriculum-based early childhood education in Aotearoa/New Zealand holds open the door to that which is not yet possible, sees improvement as a signal of growth, and creates environments in which success is non-competitive and multifaceted 
(Ministry of Education, 1996). From this vantage point, early childhood education in Aotearoa/New Zealand deals in hope.

Hope and education are easy bedfellows combining to contribute to the cause of social justice on the world scene. Charity groups such as Education for Hope send children to school in Ethiopia in the hope that those children will one day become the architects of positive change in social and economic conditions in that country (www.educationforhope.com). Similarly, the charity Education and Hope provides a scholarship programme for children in Guatemala in the hope of breaking the cycle of poverty (www.educationandhope.com). In both cases, there is a firm belief in the ability of education to look forward to a better future and act on the possibility of its realisation.

In his book Pedagogy of Hope (1994), Paolo Freire revisited the themes set out in his classic Pedagogy of the Oppressed (1970) and reflected on his work and writing since that point. In this book, he expressed the importance of hope as a catalyst for social change, and described education as an essential element in bringing hope to the struggle for social justice. On this point he wrote "to attempt to do without hope... is tantamount to denying that struggle one of its mainstays" (Freire, 1994, p. 8). This insight into the connection between hope and action is confirmed by holistic perspectives on hope introduced in the previous chapter. It is also significant because it brings hope, education, action and social justice 
together into a single vision. This chapter uses a very similar approach by bringing philosophy of hope and enactivist learning theory together to counteract structural dissonance in the pursuit of more social justice in IECTE programmes in Aotearoa/New Zealand.

For Freire (1994) hope is more than just conceptual, it is a force to guide emancipatory action, for "without a minimum of hope, we can not so much as start the struggle" (p. 3). In Freire's (1994) writing, hope energises action, makes change for the better possible, and is an active ingredient in challenges to injustice:

Hope, as it happens is so important for our existence, individual and social, that we must take every care not to experience it in a mistaken form, and thereby allow it to slip toward hopelessness and despair. Hopelessness and despair and both the consequence and cause of inaction and immobilisation (p. 3).

In this tract, Freire (1994) distinguished between action and inaction in much the same way as Bloch (1986) used the terms concrete and abstract. Freire (1994), however, added a moral edge to his distinction by implying that certain hopes we may hold lead not to the better future that is possible, but rather to a future that is, by degree, worse. This thesis has pointed out that structural 
dissonance is not devoid of hope, and on this point I will make a similar distinction to that of Freire (1994) and Bloch (1986): If social justice is the only useful topic for philosophers to discuss (as suggested by Rorty, 1989), then it can be argued that there can be more and less useful expressions of hope. Hope and action for social justice, on this account, are a more useful expression of hope, and hope for individual success is less useful. Hope for social justice combined with inaction is even less useful still. This chapter is about bringing hope and action together in IECTE programmes in Aotearoa/New Zealand by suggesting that a pedagogy of enacted hope can counteract structural dissonance in those programmes.

Freire (1994) used hope to kindle the flame of revolution in both culture and pedagogy. Freire's (1994) pedagogy of hope, although it deals with a different form of injustice than this thesis (namely the injustice of poverty, sickness and death through inequality) is similar in motivation if not scale: both perspectives are deeply concerned that the world we live in is not just enough, we are also deeply committed to education as a powerful means toward social change, and finally, we are both convinced that hope is the key ingredient in making and energising that change. For Freire (1994) hope is the basis of our humanity and without it we succumb to despair and oppression. This thesis maintains that hope is a tool we can pick up and use in any number of ways: The best of these is the struggle for social justice. 
Other writers in the field of education have also specifically linked hope closely to education (e.g., Halpin, 2003; McInerney, 2004; Inglis, 2004; Thrupp \& Tomlinson, 2005). And, if hope is the practice of creating a better world that has not-yet-been achieved, then it is reasonable to say that most writers on the subject of education enlist hope as an active ingredient in the vision they hope to achieve (although they may not conceptualise hope in the way the writers mentioned above have done). In early childhood studies for example, writers like Dahlberg and Moss (2005), Cannella (1997) and MacNaughton (2005) have expressed this hope of making early childhood, early childhood settings and the participants within those settings more socially just.

In early childhood studies, Dahlberg \& Moss (2005) have argued that in these changing times of social ambivalence and fiscal uncertainty there is a marked absence of utopian thinking. Utopian thinking for Dahlberg and Moss is similar to what Bloch (1986) meant by concrete utopia: it is the practice of bringing hope's object to fruition through the means of human action on a world where change is possible. For Dahlberg and Moss (2005), utopian thinking involves critique of the status quo on the one hand and the radical reconstruction of social settings on the other. They argued that preschool settings have a role to play in the reconstruction of society along socially just lines through the reconceptualisation of those settings as sites for experimentation. To this end, they argue for what Santos (1998, as cited in Dahlberg and Moss, 2005, p. 182) 
called, a "destabilising subjectivity" wherein the status quo is challenged through the engagement of critical and imaginative thinkers. This critical engagement, aimed at aiding in the creation of a better life for children and adults is itself an expression of hope insofar as these authors are seeking to encourage relationships that have not-yet-been-achieved in ways that are notyet-conscious with the aim of constructing a socially just culture that has notyet-arrived but is hopefully appearing on the horizon.

From these examples it is reasonable to put hope and education together as a theoretical (and practical) exercise for the construction of socially just relations (personal and institutional). The next section continues on the theme of connecting hope, education and social justice

\subsubsection{The 'Robust Hope Project'.}

In her keynote address at the Early Childhood Intervention Conference in Australia, Christine Johnston (2006) set out a manifest for Robust Hope as a project comprised of two key elements:

1. "Hope itself is manifested in the potential for policy to create resilience, happiness and the imagining of a better future. 
2. The socio-cultural conditions of policy which create 'robustness' are manifested in a futures orientation, sustainability and a version of democracy which privileges equality over the liberty of the market" (p. 7).

The Robust Hope Project is a research project developed at the University of Western Sydney, which aims to express utopian possibilities in education and education policy in the face of neoliberal marketisation (Singh \& Sawyer, 2008). According to Sawyer, Singh, Woodrow, Downes, Johnson and Whitton (2007) the robust hope project "relies on a number of key resources: utopianism, an enhanced vision of democracy, agency, a futures orientation, a research-based approach, sustainability and resilience" (p. 228). What makes the hope robust is a commitment to democratic action aimed at constructing a better and more sustainable future combined with a commitment to construct a framework that can be used to critique policy in general and policy as it pertains to education specifically.

The Robust Hope Project is an exercise in hermeneutic interpretation whereby a particular set of ideas are brought into conversation with policy documents, or used to explain practices in specific education programmes (e.g., Indigo Preschool: Arthur \& Sawyer, 2009) or teacher education research (e.g., Sawyer et. al, 2007). The robust hope project aims to make policy makers accountable for their vision of the future by casting a critical gaze on the content of that 
vision in light of a commitment to democratic agency and sustainability. According to Sawyer et al. (2007), Robust Hope is "a metaphor for work to make a world in which projects of change count" (p. 239). For Halpin (2007), the Robust Hope Project offers a pedagogical impetus for all educational settings (not only early childhood) to embrace:

\footnotetext{
“Schools can only become significant sites of 'robust hope' if they... change and develop in ways that create cultures, curricula, pedagogues, support structures and opportunities for all students to interrogate their identities, identify new possibilities and build capacities and confidence to take risks and open up to new futures" (p. 245).
}

By drawing education and hope into a single vision the above authors, as architects of the Robust Hope Project, are expressing a perspective from which any attempt to separate hope from education is held as suspect. The architects of the Robust Hope Project constructed their theoretical framework using hope as a source of critical awareness whereas this thesis uses philosophy of hope to form a pedagogy within IECTE programmes based on an early critique highlighting structural dissonance (rather than a lack of hope). However, differences aside both projects believe that hope is a good thing, and both projects advocate putting that hope into action. The next section outlines the theory of enacted hope that the remainder of this chapter will suggest as a form 
of pedagogy that would be useful to counteract structural dissonance in IECTE programmes in Aotearoa/New Zealand.

\subsection{Enactivist learning theory}

In this section a pedagogy of enacted hope is constructed by fusing enactivist learning theory with the theory of hope worked out in the previous chapter. My thesis is that using a pedagogy of enacted hope in IECTE programmes can counteract structural dissonance and encourage social justice for student teachers in those programmes. This section begins with an introduction to enactivist learning theory (Varela, Thompson \& Rosch, 1991) and relates this to the philosophical assumptions of this thesis, at the completion of which a pedagogy of enacted hope is put forward.

\subsubsection{Enactivism.}

Enactivism is a theoretical approach to the science of mind (cognitivism) designed by Varela et al. (1991) and elaborated in their book The Embodied Mind. According to these authors, the aim of their book was "to build a bridge between mind in science and mind in experience by articulating a dialogue between these two traditions in Western cognitive science and Buddhist 
meditative experience" (p. xviii). Enactivism is the name given to this bridge or middle ground. It reflects a growing commitment that "cognition is not the representation of a pre-given world by a pre-given mind but is rather the enactment of a world and a mind on the basis of a history of the variety of actions that a being in the world performs" (Varela et al., 1991, p. 9).

This approach is similar to socio-cultural understandings of situatedness insofar as the authors assume that "to be human, indeed to be living, is always to be in a situation, a context, a world" (Varela et al., 1991, p. 59). From this perspective, it is possible for a room full of student teachers to be living in multiple worlds with multiple understandings of the universe and their place in it. On this point Varela et al. (1991) propose that "perception is not simply embedded within and constrained by the surrounding world; it also contributes to the enactment of the surrounding world" (p. 174). Thus, each of the student teachers in the classroom are enmeshed in the many worlds that they, through their actions and history of actions, have been instrumental in co-creating. The classroom is the place where these multiple worlds and multiple universes collide, combine and change.

Enactivism drops the mind/body distinction in favour of mutual codetermination: that notion that the mind and the world it perceives constantly create one another in a cyclic action of co-dependency. In other words this 
means that organisms and their environments have no intrinsic nature of their own, but rather exist as an interaction of conditions and histories whereby each side of the equation determines the other. Thus, "the enactive programme encompasses the temporality of cognition as lived history, whether seen at the level of the individual (ontogeny), the species (evolution) or social patterns (culture)" Varela et al., 1991, p. 213). More precisely, "organism and environment enfold into each other and unfold from one another in the fundamental circularity that is life itself" (Varela et al., 1991, p. 217).

Enactivism is anti-foundational or groundlessness. Varela et al. (1991) use Buddhist philosophies of sunyata (emptiness) and karuna (compassion) to formulate enactivism as a middle ground between Western cognitivism and Buddhism. In their explanation of Buddhism, the authors use Nagarjuna's (c. 200/1995) Mulamadhyamakakarika as the basis of their approach (Varela et al., 1991, p. 219). This thesis uses Dalai Lama's (1997) explanation of emptiness (sunyata) and altruism to explain both Nagarjuna (c. 200/1995) and Varela, et al. (1991). These concepts underpin the enactivist approach to cognitive science, enactivist learning theory, and the subsequent pedagogy of enacted hope elaborated in section 10.3 . 


\subsubsection{Sunyata and karunā.}

Buddhist scholars have a number of ways of talking about sunyata (emptiness) and those ways do not always reconcile with one another. For example, the Chittamatra school of Buddhism perceives the physical world as being empty of permanent form altogether, the Madhyamaka-Svatantrika school understands emptiness to mean that objects are only real insofar as they depend on perception for existence, and the Madhyamaka-Prasangika school maintains that emptiness means that all of reality is dependent on causes and conditions, and has no form in and of itself (Dalai Lama, 1997, pp. 99, 100). Varela, Thompson and Rosch (1991), Dalai Lama (1997) and this thesis use the Madhyamaka-Prasangika perspective on sunyata.

The notion of sunyata can be found in Nagarjuna's (c.200) classic Buddhist text outlining the middle path: Mulamadhyamakakarika in 18 in chapter XXIV:

Whatever is dependently co-arisen

That is explained to be emptiness.

That, being a dependent designation

Is itself the middle way (as cited in Garfield, 1995, p.49)

Dalai Lama (1997) identifies three meanings for dependent co-arising. First, there is the understanding that "conditioned things and events in the universe 
come into being only as a result of the interaction of various causes and conditions" (p. 12). This means that no thing or event has an intrinsic reality in and of itself, rather, everything is both relational and inter-relational. Second, all objects "can be understood in terms of how the parts compose the whole, and how the very idea of whole and wholeness depends upon the existence of parts" (Dalai Lama, 1997, p. 13). This means that all things (people included) are part of larger systems, and are also the combinations of the smaller parts of themselves. Thirdly, everything arises "solely as a result of the mere coming together of many factors that make them up" (Dalai Lama, 1997, p. 14). This means that everything that has come into being has done so because of numerous causes and conditions. From this vantage point sunyata or emptiness is not an absence, but rather a rejection of un-conditionality.

Sunyata is the philosophical equivalent to Rorty's (1989) notion of contingency explained in chapter 3. Enactivism as a philosophy is therefore antifoundational and anti-metaphysical insofar as it holds that no such thing as unconditioned reality to be found. Varela, Thompson and Rosch (1991) offer the following metaphor to describe their project: "Our guiding metaphor is that a path exists only in walking" (p. 241). The other side of enactivism determines how that path is to be laid down, but not the content. Laying down a path in walking depends on the generation of what the Dalai Lama calls "altruism" as a skilful means for embracing sunyata. 
According to the Dalai Lama (2005), altruism is a defining feature of Buddhist philosophy, and the best part in human experience. When this capacity is developed by people in their own lives it transforms into karunā. Karunā can be defined as any action that reduces the suffering of others, or the fountain of love and compassion. Varela et al. (1991) describe altruism as the warm side of groundlessness. Altruism in the Buddhist sense "has only one face, kindness to others" (Dalai Lama, 2005, p. 76). There are two general ways that kindness is understood in the Tibetan Buddhist tradition: helping others, and if that is not possible, then not causing harm to others. In this way, the interconnection between beings is organised for the pursuit of the best possible conditions for all beings. In the general Buddhist sense, the word being applies equally to humans, animals and insects. Altruism and the development of moral hope (hope for justice for others) are central aspects of Buddhist practice and Buddhist philosophy (Dalai Lama, 1997).

The ideal of enactivism is the generation of altruism in the construction of compassionate and socially just relationships, for the formation of causes and conditions that will lead to peace and happiness within ever larger systems (Varela, Thompson and Rosche, 1991). In this case enactivism is also a moral philosophy for the generation of benefit through ever larger social and ecological structures. In the next section, this philosophy of enactivism will be reconciled with the Rortyan assumptions that underpin this thesis. 


\subsubsection{Enactivism and Rortyan assumptions.}

Varela et al. (1991) use a conceptual map to describe cognitive science and its constituent parts. They use this map as a way of conceptualising who, in the Western tradition, is close to what they are calling enactivist. Philosophy is one of these parts, along with cognitive psychology, linguistics, neuroscience and research into artificial intelligence. At the centre of this map is cognitivism, which takes modern computers and operating systems as a model for cognition. They also identify two alternatives conceptualised as wider ecologies surrounding the centre. The first alternative is emergence or connectivism: approaches that explain cognition as a system of smaller more discrete component parts. The second alternative is enactivism, which describes cognition as an event of internal and external co-determination. Upon this map Varela, Thompson and Rosch (1991) situate a distinguished list of theorists, scientists and philosophers including Jerome Brunner, Mark Johnson, Noam Chomsky, Daniel Dennett and Richard Rorty. Their assertion is that Rorty's philosophy is situated firmly within the enactivist paradigm (Varela, Thompson \& Rosch, 1999, p. 7).

Enactivism and Rortyan assumptions use different vocabularies to make the same point regarding anti-essentialism. For example, where Rorty (1979) explains an absence of foundations/unconditionality, Varela et al. (1991) make use of a vocabulary of groundlessness. Where Rorty (1989) announces human 
descriptions of themselves, their world and their place in that world as contingencies of language, Varela et al. (1991) agree but instead use a language of multiple beginningless and endless conditions and causes. Furthermore, where Rorty (1989) talks of solidarity as the height of social utility condoning the expansion of the borders of those we call us until the category them disappears altogether, Varela et al. (1991) expound a philosophy of compassion based on a loving concern for the wellbeing of others and a will to bring about an end to suffering for all beings (karunā). From this perspective, Rorty (1979, 1989, 1999) and Varela et al. (1991) occupy the same philosophical position. The only difference appears to be the vocabulary that each picks up to describe their position, and the audience to whom their writing is addressed.

There is little, if any, conflict between the Rortyan philosophical assumptions used in this thesis and Varela et al. (1991) conception of enactivism. This lack of conflict allows this thesis to remain coherent in terms of not only how IECTE programmes can be re-conceptualised but also what that re-conceptualisation might look like.

\subsubsection{Enactivist learning theory}

Enactivist learning theory is an approach to pedagogical action that takes up the assumptions set out by Varela et al. Rosch (1991) and applies them to teaching and learning. The work of Brent Davis (1996) is significant in this regard. Davis 
(1996) offers valuable insight into how enactivism can be used as the basis for a theory on education. Along these lines, Sumara and Davis (1997) and Dawson (1999) offer further inroads into pedagogical applications for a practical pedagogy.

Davis (1996) described enactivist learning theory as a practice of occasioning performed understandings rather than discovering preformed knowledge. The thrust of enactivist pedagogy, according to Davis (1996), is the implication of ecologies and life histories in the structure of both learning and what is learned. However, the environment and individual historical structures/experiences are not determining agents in learning, instead:

Environmental patterns do not cause actions. Rather, they present an occasion for the person to act according to his or her structure. In such interactions, one's structure is necessarily affected and s/he thus emerges a different person. The other [people] involved in the interaction [are] similarly affected, and so [they] co-emerge (p. 10).

Education from an enactivist point of view is the ongoing process of coemergence whereby subjects, objects and environments undergo structural change as a direct result of human interaction. 
Davis's (1996) point is that for education the question of what cannot be separated from who we are. To this end Davis (1996) notes that "enactivist theorists on cognition offer a perspective that involves both becoming part of an ongoing existing world and the shaping of a new one" (p. 190). Enactivist learning theory focuses on events of learning. In those events, past (in terms of the collective past histories of the group), present (in terms of the task at hand), and future (in terms of emergent perspectives) coalesce into a pedagogical approach for the formation of not-yet formatted knowledge. From this perspective, "exactly where [learning] moves depends on such complex factors such as the structures of those present, the context, and what has been anticipated" (Davis, 1996, p. 235).

Enactivist learning theory takes up the notion of groundlessness and applies it to the formation of group specific grounds: localities. This is a similar approach to Rorty's (1979) presumption that the role of education is the creation of new edifices from which society and its constituents can be viewed. Enactivist learning theory is, therefore, "historical, situational, dynamic, intersubjective and consensual" (Davis, 1996, p. 8). Enactivist learning theory does not seek ever-fuller participation in a community of practice, but rather proposes that communities are formed through an ongoing praxis of conversation, integration and re-integration. Specifically, "emphasis is placed on cooperation over 
competition, ecologies over monologues, adequacy over optimality, movement over progress, and complexity over linearity" (Davis, 1996, p. 13).

Unexpected understandings are born out of the interaction/participation of formerly divergent personal structures within a group environment. In this way, "knowledge is recast as those patterns of acting that allow our structures to be coupled, thus entangling us in one another's existence and implicating us in one another's knowing" (Davis, 1996, p. 235). Along these lines, it is not possible to have a pre-formed curriculum guiding us to participation, rather, participation is the curriculum. It is enacted: "rather than attempting to teach toward a narrow, specific, and pre-stated understanding, [the enactivist] teaches from embodied understandings. Understanding [thus] is not a goal to achieve, but a quality to enact" (Davis, 1996, p. 239, brackets added).

Sumara and Davis (1997) carry on this metaphor to assert that "all our understandings are situated in and co-emerge with complex webs of experience" (p. 412). For IECTE, this means that the lives and life-stories of each person in each year group are as valid as theorists' and researchers' voices in determining the content of their education. This assertion is based on the assumption that "actions are not simply manifestations of (internal) understandings. They are themselves understandings" (Sumara \& Davis, 1997, p. 415). Dropping the distinction between internal and external in this way is 
similar to Rorty's (1979) prolonged attack on this distinction in Philosophy and the Mirror of Nature.

For Sumara and Davis (1997), from the enactivist perspective, "what is imagined, what is fantasized, what is guessed at, what is intuited, are not marginalised to the fringes of valued thought and resulting actions, but are understood as vitally contributing to the conscious experience of everyday life" (p. 417). For enactivist learning theorists, education is a lived event and as such it is as diverse as the participants in any given setting. To highlight this insight, one student teacher in the focus groups identified the figure of a good IECTE teacher as one who allows "you discuss how you are going to do it. I mean it seems like they haven't got a criteria for that whole morning, they come in with just that and they watch how everything unfold, and sometimes they don't finish off their brief because they've gone so far into... I mean they are actually watching what the students are doing and being open to seeing that we just can't finish it there because there are still some things going on." According to this student, good practice in IECTE teaching occurs when knowledge is enacted and allowed to emerge as a product of human interaction.

Sandy Dawson (1999) in her paper entitled 'The Enactive Perspective on Teacher Development: A path laid while walking' deepens the enactive commitment to education further. In this paper she states that "the thrust of 
enactivist work is to ... view the curriculum as being occasioned by the learner's experiences in their [learning] environment" (p. 149). It matters very little whether the learning environment means early childhood, primary, secondary or initial early childhood teacher education, the fact of the perspective remains, that "lived experience is crucial to the development of individual and shared awareness" (Dawson, 1999, p. 152).

In terms of the pedagogical work that defines a programme of study, Dawson (1999) offers the following interpretation: "it is the learner and the environment within which the learner is functioning that together poses the problem and specifies those paths that must be tread or laid down for their solution" (p. 155). In enactivist learning theory, there is a high degree of flexibility in learning programmes as participants and the programme they are involved in co-specify one another. Through that approach, "there is not a predetermined, pre-set curriculum but rather a curriculum that will be co-determined by the interactions amongst the members of the group" (Dawson, 1999, p. 159). Enactivist learning theory therefore establishes participation as not only a right, but also as ends and means of pedagogical action. As a result, external contexts are discounted in favour of local contexts - or in other words, the structural component of educational programmes emerges from the structure of the class group itself as they interact with contextual arrangements (e.g. themes, curriculum documents, policy etc.). 
In one focus group one respondent expressed her hopes in the following terms: "I think they need to be more flexible with the course, and adapt it depending on the group and the group's experience, and to recognise not just formal qualifications but life experiences as well, take those into account." This student is expressing a wish for a more enactive teacher education programme. Another student from a different group asked for a more responsive programme of study in which "students were to set courses right here and now" and allowed to follow their interests in the present moment. These students are talking about a teacher education programme that they themselves are key stakeholders in, where they are able to bring their experience and interests to the table and share with others to create unique learning opportunities that are greater than the sum of their parts. Dawson (1999) calls this a form of learning where "groups lay down their own path while walking. This path is co-determined; devised from a rich and growing set of possibilities" (p. 160).

Enactivist learning theorists like those introduced above understand teaching and learning to be a complex operation nestled within multiple layers of context and experience. They view cultural narrative as something that is constructed and reconstructed over and over in diverse contexts in the company of multiple and changing actors. Education, from this perspective, is therefore an evolutionary process resulting in a path of learning that "unfolds in a classroom and is particular to that context" (Davis, Sumara \& Luce-Kapler, 2000, p. 93). 
Enactivist learning theory makes the local environment and the actors within that environment the point of focus. Learning emerges out of interactions within that context. This is not to say that curriculum should be dropped, but rather, that interpretations of curriculum should be occasioned, rather than preordained, and pedagogical work should be co-created instead of externally controlled.

\subsection{Enacted Hope.}

Enacted hope is my neologism to describe open-ended learning processes that are focused on action for the betterment of others through the activities of emergent communities of learners. The previous chapter introduced a vocabulary of hope that can be used to challenge closed-ended conceptions of education and the world we live in (e.g., The Robust Hope Project). The previous section introduced enactivist learning theory as an alternative pedagogical perspective for use in IECTE programmes. This section brings the two together into unified vision for the creation of a socially just institutional structure in IECTE programmes in Aotearoa/New Zealand. Enactivism within this frame is the praxis of hope in education. 
As noted, Rorty (1989) described a liberal utopia where solidarity and irony can co-exist without contradiction. This was Rorty's (1989) brand of social dreaming. Hope, for Rorty (1999), is "the ability to believe that the future will be unspecifiably different from, and unspecifiably freer than the past" (p. 120). For Rorty (1999), hope is a condition for growth. Following this view Rorty (1999), argued that the role of universities (particularly the humanities) is to help students to see that their national narrative and past socialisation is openended, unfinished and full of the possibility of becoming other. This thesis is arguing a similar line, however, it is talking about IECTE programmes in New Zealand universities and I am arguing that it is the role of the programmes themselves to counteract structural dissonance in those programmes. This thesis proposes that one way this can be achieved is by picking up enactive pedagogy and using it to encourage an active hope for structural and social justice. Enacted hope is the expression that something more can be done to encourage social justice for student teachers in IECTE settings.

Enacted hope is the practice of putting social imagination into effect. It is the practice of holding open institutional structures to the point that aspirations to action emerge as they are occasioned by class groups, in local spaces. As a pedagogical perspective, enacted hope encourages classrooms to become emergent communities in which power to construct knowledge is shared by participants and organised by the will to construct socially just settings and 
institutional structures. The construction of knowledge is enacted through conversations aimed at serving and emancipating diverse others and measured in terms of how those conversations can be translated into action (that is, can have a real result in the practical sense of getting the job done). Enacted hope is, therefore, the practice of encouraging conversations of the better life that is possible whilst working together to bring those hopes to fruition.

Enactivism and the theory of hope worked out in the previous chapter share anti-foundational, anti-essentialist and altruistic underpinnings. At the level of praxis, enactivism shares a will to action with the notion of concrete utopia that was borrowed off Bloch (1986); furthermore, both enactivism and theory of hope are examples of open systems and each theoretical position is designed to encourage the novum (what has not yet become, not yet been achieved) in knowledge, practice and understanding. However, most importantly as far as this thesis is concerned, both enactivism and theory of hope do not merely open onto vistas of difference for the sake of difference itself. Rather, they open out directly onto the better life that is possible for all. In other words, they both face justice and peace, and their union is the praxis of forging these into an intersubjective experience. From this vantage point, the suggested pedagogy of enacted hope is a commitment to local effort to achieve the better life that is possible for all. 


\subsubsection{Enacted hope and socioculturalism}

Enacted hope is consonant with sociocultural assumptions of embeddedness, participation, co-construction and community. However, it adds a new inflection to each of these assumptions. Enacted hope understands embeddedness to be a form of embodiment that is open ended, mutually specified by environments and actors, and organised through a commitment to make the world a better (more just, more peaceful) place. From the perspective of enacted hope, sociocultural communities are communities enmeshed in an ongoing processes of emergence as not-yet-achieved possibilities are realised by actors through utopian activity, and moved beyond over the course of time. Culture in this frame is something that is not-yet-achieved, community is an ongoing conversation and context is a fluid concept that involves constant change as new actors enter the scene.

For example, imagine a group of student teachers in a classroom. From a sociocultural point of view they are embedded within a particular setting for a particular purpose using culturally mediated tools to carry out culturally significant (at least for the culture of the particular paper) tasks. From an enacted hope point of view, each student holds a part of the puzzle regarding the construction of knowledge, conversation of what can be done to make life better for fellow humans is the only purpose of the interaction. Interactions are allowed to emerge along themes (e.g., the principles of Te Whāriki (Ministry of 
Education, 1996), or domain knowledge etc.), but the content and output of the group is determined by the group itself as the actors co-emerge. Enacted hope differs from socioculturalism insofar as the context where embedding takes place is groundless, performed and specifically directed toward what-has-notyet-been-accomplished. Whereas, for socioculturalists like Lave and Wenger (1991), Vygotsky (1986) and Wertsch (1998) the context in which actors are embedded is more like a ground of settled cultural specificities which may or may not be directed toward the novum of what-has-not-yet-become.

Participation, from a sociocultural perspective, involves moving from peripheral to full participation in a particular social and/or institutional setting (e.g., Wenger, 1998) and it may also involve serving an apprenticeship leading to mastery and total inclusion into a communal body (e.g., Rogoff, 1990). Participation from a sociocultural perspective is about using cultural tools in culturally defined contexts for culturally defined purposes. Participation, from an enacted hope perspective, is a form of occasioning situations where the structure of the context in which participation occurs depends on the participants themselves. Rogoff (2003) wrote a similar interpretation of participants transforming culture and culture transforming participants, this approach assumes that culture offers a ground or foundation to be transformed. For enacted hope there is no such foundation implying a programme with minimal pre-formed structure. The educational culture in which people 
participate is the sum total of the participants themselves, and the qualities that they bring to the conversation. Furthermore, the will to bring about a state of affairs, knowledge or experience that is not-yet-conscious to individuals alone but rather a function of the group interaction marks enacted hope as a pedagogy useful for reproducing an open system on the one hand, and encouraging the construction of the novum for pedagogical action on the other.

Scaffolding (Wood, Bruner \& Ross, 1976) and tuakana-teina (Tangaere, 1997) notions of pedagogical practice assume that younger/less experienced students are encouraged by older/more experienced students to participate in a learning context or community. It is assumed that those older/more experienced students hold and impart knowledge essential to the learning community. This approach assumes that there is an essence of knowledge to be scaffolded or imparted to less experienced members of a learning community.

From an enacted hope perspective, there is no essence of knowledge to be imparted outside of the experiences of persons within a particular learning environment, and not-yet-achieved experiences that emerge as a result of the interaction of persons, themes, text and application (i.e., focus on making a better (more just, more peaceful) world. This approach disrupts the sociocultural dialectic of more and less knowledgeable and more and less experienced with an open dialogic that uses themes encourage the co- 
construction of knowledge through the relationships formed by individual participants in localised groups. Enacted hope drops the idea that there is an essence of knowledge to be imparted and picks up the metaphor of more or less useful for encouraging justice and peace in human interactions. Which is not to say that development, curriculum, pedagogy, culture and bi-culturalism, history and theory are no longer talked about in IECTE; rather, it means that they are talked about in a multitude of ways without privileging one narrative over the other, and where personal experience is equally important as the works of scholars and researchers in a given field of inquiry.

Co-construction is native to both sociocultural theory and enacted hope. Both perspectives encourage participants within educational contexts to recognise an undeniable right to shape and form the content of those contexts.

Socioculturalism holds the co-construction of contexts as an ideal closely linked to the praxis of participation (e.g., Rogoff, 2003). However, there are limits to the form that co-construction might take because of broader contexts and their apparently non-arbitrary elements (i.e., Graduating Teacher Standards). For example, from a sociocultural perspective learners are encouraged to follow their interests, work with others, learn/teach through modelling and become citizens of their learning environments. This occurs within a broader context of socio-cultural mores that are non-arbitrary; not open to co-construction or negotiation. For example, recognition of the Treaty of Waitangi (1840) and the 
assumption that it is a useful document, Graduating Teacher Standards (NZ Teachers Council, 2007), university policy, curriculum and professional standards, current best practice, course objectives and assessment prescriptions.

Enacted hope understands the above examples as arbitrary constructions that are open to negotiation within the local context of the group structure, with their importance being negotiated. This is not to say that the above examples should be rejected, but rather that they become open to interpretation, and reinterpretation as group understandings emerge out of personal accounts and interaction with a diverse literature associated with different subject areas. Understandings of those arbitrary events, how they can be best applied, or whether there are better ways of educating emerge as a result of groundless participation (see 10.3). What each social and cultural topic means is open, nonspecified, not-yet-achieved and full of the possibility of becoming other (and in hope, becoming better). The understandings that emerge are themselves arbitrary expressions of a time and place, and of the particular actors present, the texts consulted and the wider convictions of participants. In this way ground as an expression of foundation, essence or non-arbitrary certainty does not emerge from groundlessness, rather, that which emerges is occasioned and idiosyncratic to the group involved. 
Enacted hope creates a new inflection on embeddedness, participation, cocreation and community. This is largely a function of a commitment to groundlessness (anti-foundationalism) and a focus on that which has not-yetbecome of relationships, knowledge, education and interpretation. Enacted hope, of the sort suggested in this section, might therefore be understood as a radical form of socioculturalism, one that drops foundations and essences in favour of occasioned understandings, constructed realities and a commitment to social justice, peace, resulting in activity that aims to change the world for the better.

\subsubsection{Enacted hope and structural dissonance.}

Enacted hope overcomes individualisation by dropping the individualising agenda in favour of a groundless (anti-foundational) pedagogy for IECTE programmes. Specifically, enacted hope ruins the disembedding function of individualisation by re-embedding individuals in groups of people in localised learning environments that encourage participants to implicate their life experience and the communities to which they belong in the act of constructing knowledge. The main achievement of enacted hope in this regard is to make individual biographical patterns and the institutional structure of the educational context arbitrary (up for negotiation and/or reinterpretation). This arbitrariness challenges pre-formed notions of personhood and human understanding by encouraging groundless perceptions of a self that has not-yet- 
become, and knowledge that has not-yet-been achieved. Using enacted hope, as a pedagogy, directly challenges disembedding by making re-embedding a precondition for learning.

Life experiences communicated between students give rise to new approaches to pedagogical action that can not be situated in the individual alone.

Pedagogical work, in this approach, emerges as the generation of shared understandings and actions for the construction of a better world for all peoples. Education in this instance, equates to what Rorty (1979) has called edification (see also sections 2.1.1 and 4.1.3). Edification in terms of enacted hope means knowledge that emerges as a result of being embedded in local contexts. Pedagogy within this frame begins from the premise of groundlessness and involves laying down a path in walking (Dawson, 1999). These assumptions directly challenge the standardisation upon which the reproduction of individualisation depends. Standardisation may still occur (and necessarily so in the present institutional context), but it loses its power in the classroom itself, as the site where diverse histories, perspectives and interpretations coalesce, are valued, and are transformed as groups of learners define the content of their own emergent knowledge.

Avoiding standardisation is not the same as lacking structure. IECTE programmes would retain a structure based on themes (e.g. principles of Te 
Whāriki (Ministry of Education, 1996); domain knowledge; discourses of human development). Those themes are not essences to be internalised, nor are they foundations upon which knowledge is built, but rather, they are points of departure and points of return. This metaphor draws on the enactivist account of laying down a path in walking (Dawson, 1999). The thematic approach is useful here as part of the environmental structure with which personal structures in students may co-emerge to occasion understandings and interpretations that are not-yet-conscious, or pedagogical actions that have not-yet-been-achieved. From an enacted hope perspective, each theme contains a literature, and examples of interpretations and/or practices, but these are not foundations, they are opportunities for further conversation, further localised reconstruction.

The pedagogy of enacted hope draws together communities of learners, literature and themes and places the power to form knowledge and understandings in the hands of groups of actors within localised settings (i.e., particular classrooms). There is still standardisation in the learning programme but only insofar as there are themes that link to wider contexts (e.g., legislative, regulatory, curriculum) and the meta-theme of social justice. This is achieved by giving primacy to interactions within the group structure as communities of learners co-emerge and knowledge is occasioned from lived experiences and lived interaction with texts and teaching staff. Given this vision, there is no 
place for the standardisation of individuals and their learning programmes under the condition of enacted hope.

From the perspective of enacted hope, institutional dependency shifts to institutional interdependency. Pedagogical action (teaching), pedagogical work (assessed output) and pedagogical practice (teaching experience) would emerge as shared understandings of contextual requirements (i.e., Teacher's Council, university policy), as groups of learners actively work together to meet those requirements whilst engaging with themes and acting on emergent understandings. From this vantage point, it is conceivable that different groups of students within a single university will create different but also highly meaningful outcomes from other groups within the university. This diversity opens the door to inter-group dialogue and further emergent learning. The prospect of inter-group dialogue encourages a meeting of perspectives within the wider institution and across cohort years. In this way, interdependencies are formed in terms of intra-group emergence, inter-group emergence, multiple uses of textual sources and diverse orientations toward contextual requirements.

Enacted hope rejects disembeddedness, standardisation and institutional dependency by focusing on emergence, occasioned knowledge and interdependency. Of course, elements of individualisation will still exist (for 
example student ID numbers, personalised enrolment, individualised graduation, statutes for personal responsibility), but they will exist as a contingency rather than an organising principle. By switching pedagogical practice within IECTE programmes to one based on the paradigm of enacted hope this thesis proposes that the power of individualisation in the context of IECTE can be counteracted. Enacted hope is a praxis for social justice insofar as emergent communities of learners enjoy freedom to occasion their own learning within a flexible institutional structure. Furthermore, this approach does not contradict the socio-cultural content of IECTE programmes but rather offers support for embeddedness, participation, co-creation and community in the manner set out in the previous section.

The word structure has been used throughout this thesis to explore institutionalised rules and regulations and the rules and regulations of the context in which the institution is embedded. Within the perspective of enacted hope, structure has emergent properties and is co-determined by participants in contexts and the contexts themselves; thus structure is lived and it is local. This section has argued that the entire contextual structure of IECTE institutions need not change to yield an improvement, only the level of pedagogy: the level of the course outline, links to contextual requirements (e.g., Graduating Teacher Standards, curriculum), and teacher education praxis. External determinants such as Graduating Teacher Standards (NZ Teachers' Council, 2007) are 
internalised into the group structure and take on emergent qualities as understandings of what these mean, and how they are applied in courses, are occasioned as a result of conversation, interpretation and re-interpretation by actors within educational settings.

This section has introduced the pedagogical concept of enacted hope and advanced arguments on how taking this approach to teaching in IECTE programmes is on the one hand, not dissonant with sociocultural frameworks and on the other, able to counter-act structural dissonance.

\subsection{A pedagogy of enacted hope challenges structural dissonance in IECTE programmes in Aotearoa/New Zealand.}

This thesis now takes one last step in the direction of enacted hope by imagining what a course using a philosophy of enacted hope might look like. This section is intended as a move toward application but still hovers above current practices as a theoretical construction. In future, it is hoped that enactive and action research projects might take up some of the ideas developed here, and put them to the empirical test. 
One major difference between current practices and an enacted hope approach is that when using a pedagogy of enacted hope the course outline is developed over the duration of the study. In other words, the course outline emerges along with the group; it is an artefact of that emergence. There would still be individual enrolment in courses and university statutes on conduct and so on, that would still be up held, however these would be structural elements with which groups would engage directly and account for as a matter of shared responsibility. Courses would, therefore, necessarily include appreciation of regulatory requirements but seek room for movement within these requirements rather than being simply positioned by them.

Learning objectives would be replaced with themes to be covered and pedagogical work would be left open but with guidelines as to what counts and what does not count as pedagogical work. The themes and guidelines would become part of the environmental structure of IECTE courses. The pedagogical work required in each course would be like filling in the blanks in the course outline (e.g., what do the themes mean? What research and perspectives are available on these themes? Why are these themes important? What are alternative themes and why were those not specified? How can these themes be put into practice? How does this theme link with courses we have already taken?). The understandings used to fill in those gaps would emerge from 
dialogue between participants as they approach the environmental structure of the courses and the themes around which those understandings are organised.

Pedagogical work would involve reflecting upon and communicating personal beliefs on questions such as those suggested above. It would also involve a conversation between personal perspectives, research into the literature concerned with each theme, conversation with those literary perspectives, the creation of artefacts reflecting emergent understandings, imagination of practical applications of the theme in terms of working with children and their families and concrete activation of that theme in inter-group relationships and teaching practice with the aim of making the world (both human and material) better (that is, more just and more peaceful). This is quite an agenda, but the point here is that this agenda would be shared by all participants rather than handed down in a non-negotiable manner by unseen forces in the context of the university.

This vision of students, under the condition of enacted hope, is directed toward what has not yet been achieved in the context of each theme. It is expected that because each student in the group has a highly idiosyncratic personal history, and because emergence depends on those personal histories being brought into conversation with one another and with the task at hand, that the understanding that emerges will be one that has not-yet-been-achieved: a novum. This, in itself, 
challenges the university structure particularly in terms of the external control of courses and their content that this thesis has argued reproduces a context of individualisation. For example, this would cause issues with programme certification under the current Teachers' Council structure, and potential problems with CUAP and the Academic Board, as cohorts co-construct their own assessment schedules (although these could still be constructed to meet a specified criteria). The challenge would be in the localisation of control and the potential for a number of different approaches within particular papers and in particular year groups.

Using a pedagogy of enacted hope would disrupt the status quo in IECTE programmes in Aotearoa/New Zealand. From this perspective, enacted hope prompts a reconceptualisation of the structural elements that currently reproduce individualisation in the context of IECTE programmes. At the outset however, it may be possible for teacher educators to work with the emergent pedagogy set out above within the current structure of the papers they teach in. This will take imagination, a democratic orientation and a willingness to lay down their own path in walking. Stepping onto this path also takes a good measure of courage, especially where doing so runs counter to present organisational structures. Taking a similar approach to that used in the Robust Hope Project (i.e., Sawyer et. al, 2007) would offer evidence-based support for any pedagogical change, this would also have the follow-on effect of generating 
research based funding for teacher educators who are willing to make their own pedagogy the subject of their research.

At the conclusion of this chapter, enacted hope as a pedagogy for counteracting structural dissonance has arrived into consciousness (though in an embryonic form) but as a praxis it is not-yet-achieved. This thesis has argued that enacted hope is a pedagogical technology that is theoretically useful for the purposes of encouraging more just and peaceful relations between student teachers and the universities where they undertake their training. The challenge for the future is to translate these ideas into a practical programme (at first within present structures, and later as alternatives to present structures). What that challenge might look like or the steps that one might take to achieve that praxis is beyond the focus of this thesis, but it is certainly a subject open to future research.

Another point of interest for future consideration is the question of what an early childhood lecturer or tutor might look like from the perspective of enacted hope. In the perspective imagined here, lectures are replaced by workshop style tutorials where understandings emerge as groups of learners converge with one another, with structural requirements and with pedagogical themes. The role of the lecturer/tutor in this scenario is multifaceted. The teacher might potentially act as a conductor (like the conductor of an orchestra), except the music is not written in advance. In this role the teacher would be an expert in starting 
conversations and keeping them going. The teacher might be expert in constructing a sense of group cohesion and encouraging the development of group identity and safety, without cutting off the opportunity for change. They might initially draw people into conversation through questions and listen intently for opportunities for students to bring their life experiences to the discussion. The teacher might alternatively take on the guise of a bricoleur (Denzin \& Lincoln, 2005) intent on constructing an enacted bricolage. Again, in this role, the teacher would be less of an expert in content and more of an expert in encouraging connections and conversations whilst ensuring that the structural component of the course, and the theme around which emergence takes place, are given adequate voice. Given the discussion on enacted hope worked out above, whatever role the teacher would take, it is not a role that should be worked out in advance, but rather it is a path that should be laid down in walking, and in hope: laid down in the spirit of a better life that is possible for all involved. That is the spirit of moral hope.

\section{Summary}

This chapter has set out the philosophical assumptions, pedagogical theory and suggested application for a pedagogy of enacted hope. The concept of a pedagogy of hope has been reconciled with socioculturalism and has been shown to subvert individualisation processes. Consideration has been given to application in IECTE programmes and offered answers to some of the potential 
pitfalls in using this approach. The argument has been advanced that a pedagogy of enacted hope can counteract structural dissonance in IECTE programmes in Aotearoa/New Zealand. 


\section{Chapter Eleven}

\section{Conclusion}

This chapter is organised into two parts. The first part summarises the thesis and discusses some of the key arguments made through each of the chapters. The second part of this chapter identifies the limitations of the approach taken in this thesis as well as possibilities for further research.

\subsection{Summary of thesis.}

The main argument of this thesis is that there is structural dissonance in IECTE programmes in Aotearoa/New Zealand, and that something can be done about it.

All that an ironist scholar can hope for is that the vocabulary they have set out can gather support within the community for which it is intended. This thesis has created the term structural dissonance to make the point is that we can do better in our efforts to care for one another with IECTE programmes in Aotearoa/New Zealand. From the ironist perspective taken in this thesis, there are always new vocabularies that can be created, picked up and used - there are always more ways to go beyond the status quo and make life better (more 
peaceful, more just) for others. This thesis has been an ironist effort at keeping that possibility for further conversation going.

There is much more that can be said of structural dissonance as a concept; in this thesis I have limited my discussion to the contradiction between the sociocultural content of IECTE programmes and the cultural reproduction of individualisation in context of those programmes. This thesis, aside from being a complete text (see chapter 4 ) is also a collection of beginnings for further study including neo-pragmatic approaches to education, using structural dissonance to analyse other educational settings, improving the ecological hermeneutic method, and making an empirical study of the pedagogy of enacted hope.

This thesis has avoided stating that this is how it really is, or here is the truth and this is how I know it, or this is the best method to find out what is really happening in IECTE programmes. Philosophically speaking, it is not useful to make statements of this nature (though others may fundamentally disagree on this point). Dropping both metaphysics and epistemology from the outset cut off the need to make statements such as those above. Rather, this thesis has argued that for those interested in social justice, the thesis of structural dissonance offers a useful lens through which to view IECTE programmes in Aotearoa/New Zealand. 
The perspective set out in this thesis has had two primary motivations: The first is to reconceptualise IECTE in a unique and, hopefully, informative way. The second is to disrupt the idea of research as a search for certainty. This thesis has also attempted to show that theoretical research is an exercise in poetic reconceptualisation as much as it is an exercise in rational justification.

Beginning with the notion of structural violence did not seem appropriate for early childhood studies. Suggesting the concept of structural violence seemed in itself a form of violence. Softening this notion to structural dissonance seemed more useful to the potential audience of the ideas set out here. This is just to say, softer words can make more acceptable points sometimes. From a neopragmatic point of view the strength of the metaphor is not in its ability to accurately represent reality, but in its ability to add to the conversation regarding IECTE, as well as the potential to court agreement.

A major part of this project was introducing Rortyan assumptions to early childhood studies. This research found that this had been done in a partial way, but after reading re-reading many of Rorty's books I have sought to offered a concise and consistent approach to how his writing might be used in theoretic research. This thesis has picked some of the base philosophical arguments that Rorty offered, but there is a great deal more that can be written in the future, from a great deal more aspects of Rorty's writing that I have not covered in this 
thesis (e.g., critique of the Foucauldian left, see Rorty, 1998a). Understanding Rorty's philosophical assumptions and their implications for methodology and the structure of this thesis was in itself a major undertaking in this thesis.

The one-sided accentuation of the ideal type method allowed this thesis to side step issues of correspondence to reality or validity of method if certain of Weber's original assumptions were dropped. Using this approach has allowed the use concepts and vocabularies to interpret the content of IECTE programmes and the textual sources which construct the context in which those programmes are delivered. By focusing on forming relationships between the ideal types and IECTE programmes, using the medium of language, this thesis has taken the neo-pragmatic shift away from experience toward language use. Dropping the need for accurate representation has been a key element of the philosophical assumptions that have been adopted in this thesis.

Socioculturalism in IECTE programmes was an easy proposition to premise given the abundance of evidence available. However, this thesis has presented a multilayered approach that offers ecologically diverse justifications for socioculturalism in the content of IECTE programmes. Similarly, the chapter on individualisation picked this theme out of Beck's (1992) theoretical perspective and used his theses to reinterpret the context of IECTE programmes. Those 
elements of individualisation used in the ideal type were linked to the regulatory documents used in the context of those programmes.

The chapter on structural dissonance brought the ideal types of socioculturalism and individualisation together to argue a case for dissonance between these perspectives before showing where that dissonance occurs in the structure of IECTE programmes. The ecological hermeneutic was applied in this chapter to organise analysis and it was found that there is evidence of structural dissonance throughout the context of IECTE programmes in Aotearoa/New Zealand.

In part four, this thesis shifted from a hermeneutics of suspicion to a hermeneutics of understanding (Ricoeur, 1974), as attention turned from identifying structural dissonance to constructing a pedagogical approach that could counter act it. The chapter on hope integrated diverse discourses of hope into a general perspective within which a specific philosophy of hope could be situated. Bloch's (1986) vocabulary of hope was introduced as a reservoir of terms and concepts that could be used to reconceptualise contemporary perspectives on IECTE, particularly as they had not-yet-been-used in this field of research. By dropping the metaphysical and epistemological aspects of Bloch's (1986) work this thesis developed a philosophy of hope that could be integrated with pedagogy and applied to IECTE programmes. 
The final chapter of part four introduced educational approaches that have linked hope with education, to show that this type of fusion is not without precedent in educational literature. The next section introduced enactivist learning theory and related that perspective on pedagogy to the philosophical assumptions that underpin this thesis. The pedagogy of enacted hope was then constructed as an integration of the philosophy of hope worked out in the previous chapter and enactivist learning theory. Discussion of enacted hope centred around implications for IECTE programmes, consonance with socioculturalism and the ability to counteract structural dissonance. Though out the final parts of this chapter, indications of how a pedagogy for hope might be used in practice including challenges and considerations were explored.

This thesis has been about expanding contemporary conversations in IECTE to include a critique of structural dissonance, use of Rortyan assumptions and individualisation theory, and the introduction of a pedagogy of enacted hope. These four contributions have achieved the reconceptualist goal of offering new integrations (fresh border crossings) for both early childhood studies and IECTE. They have also met the ironist requirement to seek new vocabularies for the use in IECTE and early childhood studies in general.

At the conclusion of this thesis, however, it is very difficult to say " $\mathrm{X}$ has been found" or that "Y has been discovered". This difficulty is a function of the 
philosophical assumptions used throughout this thesis, and to turn against them at this point would be to court inconsistency at the final hurdle. Consistency between philosophical assumptions, methodology, analysis and reconstruction has been important throughout each chapter of this thesis: As the glue that holds the project together.

This thesis has attempted to maintain consistency has been assured throughout each of the parts and in each of the chapters. Hermeneutic methods of fusion have been employed in each chapter to integrate diverse texts in order to construct new and useful understandings and applications. The method of ecological hermeneutics has been used to organise analysis in a consistent manner, employing the ideal types (themselves constructed through hermeneutic fusion) to analyse content and context of IECTE programmes and their dissonance. Finally, the constructivist use of philosophical hermeneutics has been used to create a pedagogy of hope that is open to empirical testing in future, as discussed below.

Actual success, at least from the philosophical perspective adopted in this thesis, will be in whether aspects of this thesis or the thesis entire can find enough agreement within the community for which it is intended to be deemed useful enough to influence practice. Following Rorty (1989), however, that success may not be immediately measurable - as future audiences may find 
uses that contemporary audiences do not. From an ironist perspective, the idea that this thesis has created a final vocabulary for describing what is really going on in IECTE programmes is laughable. Rather, success from this the ironist perspective is a function of the degree to which common vocabularies have been dropped, new vocabularies picked up, and the possibility of further development left open.

\subsection{Limitations and possibilities.}

Adopting Rortyan philosophical assumptions has opened up possibilities in terms of methodology, analysis and reconceptualisation, but it has also closed off a number of possibilities. Foremost among those limitations has been an inability to use certain ways of speaking about what is being done, how it is being done, and why. For instance, using Rortyan assumptions, the term findings arouses suspicion. The assumption behind this word is that the thesis has discovered something that exists beyond mere appearance. This presupposes the philosophical assumptions that this thesis rejects (metaphysics and epistemology). The issue that arises then is one of validity and the reliability of results. Not insofar as these are questions that need to be answered, but insofar as they are questions to be replaced. 
This is a primarily theoretical thesis, and as such the limitation set by dropping the word findings or found is allayed by using words such as useful, constructed and argues. That said, it is a potential limitation that the arguments and the constructs set out in this thesis are not framed as findings or discoveries: If not in terms of structure to the over-all thesis, then in terms of ease of presenting positive/affirmative research outputs.

In terms of methodology; naming foreunderstandings and application at the outset of this thesis has served to explain the type of thesis being presented and the reason for presenting it. This thesis aimed to be consistent in its treatment of texts and the integrations set out throughout this thesis, however one potential weakness that arises is that no firm framework was used to define textual sources in absolute terms. This, of course, was a function of the philosophical assumptions used, particularly in the will to drop epistemology and pick up hermeneutics. The ideal types were used as frameworks, but they were hermeneutically constructed; created as fusions of chosen primary texts; of chosen parts of those texts. This, from some perspectives is a limitation when methods of knowing are expected to find absolute truth. However, if truth is viewed as a function of the sentences we use to gain consensus, then absolutism dissolves into particular purposes, in particular places, at particular times. 
Constructing the method of ecological hermeneutics offered a structure to the analysis and an innovation on hermeneutic method, but it did not account for the aspect of choice in the texts that were included for consideration. I attempted to include key texts into the analysis undertaken in each chapter: Where the word key means, accepted as important by the communities associated with the concepts, e.g., socioculturalism and Lave and Wenger (1991), Rogoff (1990, 2003), and Vygotsky (1978); individualisation and Beck (1992); hope and Bloch (1986); enactivism and Varela et al. (1991). But even in these attempts, as mentioned above, I have not been exhaustive. Primary texts have been consulted but the many potential uses of those texts have seldom been explored. Instead my own use of those texts has been highlighted, in relation to the foreunderstandings and application that guide this thesis. This approach is methodologically sound.

From the outset, this thesis was designed as a theoretical project in IECTE education; focused on textual analysis and hermeneutic fusion of diverse ideas into a coherent argument.

Constructing ideal types to stand for complicated sets of ideas is another potential limitation insofar as some aspects of a theory are left out while others are accentuated (recalling that Weber (1949) called the ideal type a one-sided accentuation in any case). The criteria for inclusion and exclusion was the major 
ideas of primary sources, however, arguments for how to know what is major or not were not possible given the philosophical assumptions used in this thesis. Comments like "this is more essential than that" would have created an inconsistency between the parts of this thesis. Rather, the ideas of theorists have been extracted from the original work and fused with the ideas of others to form groups of ideas that are were then used to analyse content and context. The possible limitation here is that the approach taken has not been exhaustive enough, however, the claim of being exhaustive, a true representation of reality, and infallible was never made, and could not be given the philosophical assumptions used in this thesis.

The final part of this thesis offered further reconceptualisation of IECTE programmes (in addition to using Rortyan assumptions and constructing structural dissonance as a critical concept) by creating a pedagogy of enacted hope and suggesting application to IECTE programmes. The greatest limitation of this approach is that at the end of the thesis enacted hope remains an abstraction. This is a limitation for those with an empirical bent. Of course the thesis argument would be much stronger with empirical evidence that the suggested programme actually works, but that would be a thesis in itself. The focus of this thesis has, from the outset, been theoretical construction. However, finishing with a theoretical construct in the context of this focus is not so much a limitation as the continuation of a theme. 
A further possibility for study exists in the current trend toward online and distance learning tuition. This is interesting because of the heightened degree of individualisation in programmes where the sociocultural elements of coming together in a shared physical space to learn a common subject matter are missing. It might be possible to see that structural dissonance is particularly poignant in these courses. That, however, will remain to be seen.

\section{Final summary}

This thesis has constructed the concept of structural dissonance as a critical tool for understanding IECTE programmes. It has used Rortyan assumptions throughout in order to ensure coherence and consistency between chapters and parts. Ideal types for socioculturalism and individualisation have been constructed and used to ainterpret the content and context of IECTE programmes. An ecological hermeneutic was been constructed to organise that analysis, and hermeneutic methods have been used to highlight structural dissonance in IECTE programmes in Aotearoa/New Zealand as a result. Finally a pedagogy of enacted hope has been constructed and suggested as a way to counter act structural dissonance in IECTE programmes in Aotearoa/New Zealand. 


\section{Appendix A}

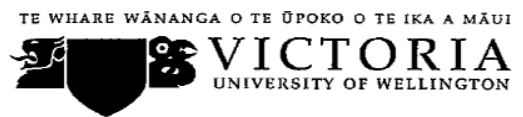

26 February 2007

Bradley Hannigan

34 Gibbs Road

RD1 Collingwood

Golden Bay

Dear Bradley

\section{RE: Ethics application AARP SEDS/2007/01}

I am pleased to advise you that your ethics application, 'Hope for a Generation: Individualisation, enacted hope and initial early childhood teacher education Aotearoa/New Zealand', with the amendments as required by the Ethics Committee, has been approved.

Yours Sincerely

2. A. honemgi

Dr Judith Loveridge

Convenor

Faculty of Education Ethics Committee 


\section{Appendix B}

\section{(VUW letterhead) \\ Participant Information Sheet for Focus Group Study.}

Researcher: Bradley Hannigan: School of Education Studies, VUW.

I am a PhD candidate at Victoria University of Wellington. I have previously been a tutor and lecturer in Early Childhood Education but no longer work in these roles. My PhD thesis studies the influence of individualisation in initial early childhood teacher education. I am assuming that individualisation, as a social process, exists in the practice of initial early childhood teacher education. Individualisation is a social process that reinforces individualism in institutions. Social theorists describe individualisation as a process that erodes citizenship. My research asks the question to what extent does individualisation influence initial early childhood teacher education in Aotearoa/New Zealand?

As part of my research I am inviting second and third year early childhood teacher education students to take part in focus groups to discuss their experiences in educational programmes. These focus groups will be audio taped, transcribed, and analysed to find out if individualising processes are referred to either directly or indirectly (that is, by referring to individualising processes by name, or using a language that is synonymous with individualisation).

I envisage that the focus groups will take around one hour, and depending on the number of interested respondents, there may be more than one focus group running. Focus groups will be held at the XXX Campus at a time convenient to participants (outside class time).

Participation in the focus groups will be confidential and will be reported in several of the chapters of my PhD thesis. All material collected will be kept confidential and no persons other than myself and my supervisors (Dr. Jim Neyland and Asso. Prof. Carmen Dalli) will hear or view the data collected. No names (other than pseudonyms) will be used at anytime in the research.

The thesis will be submitted for marking to the School of Education Studies, Victoria University of Wellington in 2010 and deposited in the University library thereafter. Tapes and transcripts will be destroyed seven years after the completion of this project. Findings from this research may be published in academic journals or presented at conferences. You may receive a summary report of findings for your verification if this is your wish (please indicate on the consent form). You may withdraw your input at any time prior to your verification of the research report. Your participation in this project is independent of your course work and in no way has a bearing on your assessment.

For further information you may contact:

Bradley Hannigan (peacenow@paradise.net.nz) Ph (03) 5248737

Jim Neyland (jim.neyland@vuw.ac.nz) Ph (04) 4635977

Carmen Dalli (carmen.dalli@vuw.ac.nz) Ph (04) 4635168

Bradley Hannigan, PhD Candidate, VUW. 


\section{Consent to Participation in Research}

Researcher: Bradley Hannigan, PhD candidate, Victoria University of Wellington.

(Please circle $\mathrm{Y}$ yes or $\mathrm{N}$ no as is appropriate).

I have been given and have understood an explanation of this research project. $\mathbf{Y} / \mathbf{N}$

I have had an opportunity to ask questions and have had them answered to my satisfaction. Y / N

I understand that I may withdraw my self from this project at any time (or any of the information that I have provided) before data collection and analysis has been verified, without any need for explanation or detriment to my self or my course of study. Y / N

I understand that all information I provide will be confidential and that my name will not be recorded or appear in any publication. $\mathbf{Y} / \mathbf{N}$

I understand that audio recordings and transcripts will be destroyed at the completion of the project. $\mathbf{Y} / \mathbf{N}$

I understand that I will have access to the group transcripts, for verification of content and analysis, before the thesis is submitted for assessment. Y / N

I understand that the data I provide will be reported in the researcher's $\mathrm{PhD}$ thesis, appropriate academic journals and at conferences. $\mathbf{Y} / \mathbf{N}$

I undertake to respect the opinions expressed by others in the group and their right to confidentiality. $\mathbf{Y} / \mathbf{N}$

I would like to receive a summary of the results of this research when it is completed. $\mathbf{Y} / \mathbf{N}$ (My contact address is

I agree/disagree to take part in this research. I have understood the terms and conditions set out above, and I have given my agreement of my own free will and without any form of duress.

Signed:

Date: 


\section{References.}

Achilles, E. (1999). Creating music environments in early childhood programs. Young Children, 54(1), 21-26.

Adorno, T.W. (2002). Essays on music (Trans. S. Gillespie). California: University of California Press.

Alloway, N. (1995). The contruction of gender in early childhood. Melbourne: Curriculum Corporation.

Altman, I., \& Rogoff, B. (1987). World views in psychology: Trait, interactional, organismic, and transactional perspectives. In D. Stokols \& I. Altman (Eds.), Handbook of environmental psychology: Vol 1 (pp. 7-40). New York: John Wiley \& Sons.

Ames, C. (1992). Achievement goals, motivational climate and motivational processes. In G.C. Roberts, Motivation in sport and exercise (pp. 161-176). Champaign, Ill.: Human Kinetics. 
Arnaert, A., Filteau, N., \& Sourial, R. (2006). Stroke patients in the acute care phase: Role of hope in self-healing. Holistic Nursing Practice, 20(3), 137146.

Arthur, L., \& Sawyer, W. (2009). Robust hope, democracy and early childhood education. Early Years, 29(2), 163-175.

Atkinson, W. (2007). Beck, individualization and the death of class: A critique. British Journal of Sociology, 58(3), 349-366.

Auckland University. (2007). BEd programme. Retrieved 07/07/07 from www.education.auckland.ac.nz.

Auckland University of Technology. (2007). BEd programme. Retrieved 07/07/07 from www.aut.ac.nz.

Bakhtin, M.M. (1981). The dialogic imagination (Trans. C. Emerson \& M. Holquist). Austin: University of Texas.

Bakhtin, M.M. (1984). Problems of Dostoevsky's Poetics (Trans. C. Emerson, Vol. 8). Minneapolis: University of Minnesota Press. 
Bakhtin, M.M. (1986). Speech Genres E Other Late Essays. (Trans. V.W. McGee no. 8). Austin: University of Texas.

Barash, D., \& Webel, C. (2002). Peace and conflict studies. Thousand Oaks: Sage Publications.

Bauman, Z. (1993). Postmodern ethics. Oxford: Blackwell Publishers.

Bauman, Z. (2001). The individualised society. Cambridge: Polity Press.

Beck, U. (1992). Risk society: Towards a new modernity. London: Sage Publications.

Beck. U. (2000). What is globalisation? Cambridge, UK: Polity Press.

Beck, U., \& Beck-Gernsheim, E. (2002). Individualisation. London: Sage Publications.

Beck, U. (2007). Beyond class and nation: reframing social inequalities in a globalizing world, The British Journal of Sociology, 58(4), 679-705. 
Betti, E. (1962). Hermeneutics as the general methodology of the geisteswissenchaften. In J. Bleicher, Hermeneutics as method, philosophy and critique. London: Routledge.

Bickmore-Brand, J., \& Gawned, S. (1990). Scaffolding for improved mathematical understanding'. In J. Bickmore-Brand (Ed.), Language in mathematics (pp. 43-58). Portsmouth: Heinemann.

Bland, R., \& Darlington, Y. (2002). The nature and sources of hope: Perspectives of family caregivers of people with serious mental illness. Perspectives in Psychiatric Care, 38(2), 61-69.

Bleicher, J. (1980). Hermeneutics as method, philosophy and critique. London: Routledge.

Bloch, E. (1953/1986). The principle of hope. Vol 1, 2, 3. (Trans. N. Plaice, S. Plaice \& P. Knight). Cambridge, MA: The MIT Press.

Bloor, M., Frankland, J., Thomas, M., \& Robson, K. (2001). Focus groups in social research. London: Sage Publications. 
Blossfeld, H.P., Mills, M., \& Bernardi, F. (Eds.). (2006). Globalization, Uncertainty and Men's Careers: An International Comparison. Cheltenham: Edward Elgar.

Bourdieu, P., \& Passeron, J. (1990). Reproduction in education, society and culture ( $2^{\text {nd }}$ ed.). London: Sage Publications.

Boutte, G. (2008). Beyond the illusion of diversity: How early childhood teachers can promote social justice. The Social Studies, 99(4), 165 - 174.

Boyer, E. (1990). Scholarship reconsidered: Priorities of the professoriate. Princeton: The Carnegie Foundation for the Advancement of Teaching.

Brandom, R. (2000). Rorty and his critics. Maldon: Blackwell Publishers.

Bronfenbrenner, U. (1979). The ecology of human development : Experiments by nature and design. Cambridge, Mass.: Harvard University Press.

Bredekamp, S. (Ed.) (1987). Developmentally appropriate practice in early childhood programs servicing children from birth through age 8. Washington, DC: NAEYC. 
Breen, R. (1997). Risk, recommodification and stratification. Sociology, 31, 473489.

Bruner, J.S. (1961). The act of discovery. Harvard Educational Review, 31, 21-32.

Bruner, J. S. (1975). The ontogenesis of speech acts. Journal of Child Language, 2, $1-19$.

Bultmann, R., \& Rengstorf, K. (1963). Hope. London: Black.

Butterworth, D. (1991). Gender equity in early childhood: The state of play Australian Journal of Early Childhood, 16(4), 3-9.

Cameron, M., \& Baker, R. (2004). Research on initial teacher education in New Zealand: 1993 - 2004. Wellington: New Zealand Council for Educational Research.

Cannella, G. (1997). Deconstructing early childhood education: Social justice and revolution. New York: Peter Lang. 
Cannella, G. S. (1999). The scientific discourse of education: Predetermining the lives of others - Foucault, education, and children. Contemporary Issues in Early Childhood, 1(1), 37-45.

Cannella, G. (2005). Reconceptualising the field (of early care and education): If 'western' child development is a problem, then what can we do? In N. Yelland, Critical issues in early childhood education, Berkshire: Open University Press.

Cannella, G., \& Viruru, R. (1999). Generating possibilities for the construction of childhood studies. Journal of Curriculum Theorizing, 15, 13-22.

Cannella, G., \& Viruru, R. (2004). Childhood and postcolonization: Power, education and contemporary practice. New York: RoutledgeFalmer.

Carr, M. (2001). Assessment in Early Childhood Settings: Learning Stories CA: Sage Publications.

Carr, M., \& May, H. (1993). Choosing a model. Reflecting on the development process of Te Whāriki: national early childhood curriculum guidelines in New Zealand. International Journal of Early Years Education, 1(3), 7-21. 
Carr, M., May, H. \& Mitchell, J. (1991). The development of an integrated early childhood programme, paper presented at the Proceedings of the Fifth Early Childhood Convention, Dunedin, New Zealand.

Carr, M., May, H., \& Podmore, V. (1998). Learning and Teaching Stories. New approaches to assessment and evaluation in relation to Te Whāriki. Paper presented at the Symposium for 8th European Conference on Quality in Early Childhood Settings.

Cazden, N. (1980). The definition of consonance and dissonance. International Review of the Aesthetics and Sociology of Music, 2, 123-168.

Chaiklin, S., \& Lave, J. (Eds.). (1993).Understanding practice: Perspectives on activity and context. Cambridge: Cambridge University Press.

Chang, H. (1994). The critical importance of cultural and linguistic continuity for infants and toddlers.' Zero to Three, Oct/Nov, 13-17.

Children's Protection Act, 1890.

Church, A. (2006). Creating community at group time. Scholastic Early Childhood Today, 21(1), 44-46. 
Cialdini, R., Trost, M., \& Newsome, J. (1995). Preference for consistency: The development of a valid measure and the discovery of surprising behavioural implications. Journal of Personality and Social Psychology, 69, 318-328.

Codd, J., Brown, M., Clark, J., McPherson, J., O'Neill, H., O'Neill, J., Waitere-Ang, H., \& Zepke, N. (2002). Review of future-focussed research on teaching and learning. Wellington: Ministry of Education.

Cohen, L. (2008). Foucault and the early childhood classroom. Educational Studies, 44(1), 7-21.

Cole, M. (1985). The zone of proximal development: Where culture and cognition create each other. In J.V. Wertsch (Ed.), Culture, communication, and cognition: Vygotskian perspectives (pp. 146-161). Cambridge: Cambridge University Press.

Collinge, J. (1994). Peace education across the curriculum: Some perspectives from New Zealand. Peace, Environment and Education, 5(1), 37-52. 
Cote, J.E., \& Schwartz, S.J. (2002). Comparing psychological and sociological Approaches to identity: identity status, identity capital, and the individualization process. Journal of Adolescence, 25, 571-586.

Cousins, N. (1989). Head first: The biology of hope. New York: EP Dutton.

Creswell, J.W. (1998). Qualitative inquiry and research design: Choosing among five traditions. Thousand Oaks, CA: Sage.

Croyle, R., \& Cooper, J. (1983). Dissonance arousal: Physiological evidence. Journal of Personality and Social Psychology, 45, 782-791.

Cullen, J. (1996). The challenge of Te Whāriki for future developments in early childhood education. Delta, 48(1), 113-125.

Cullen, J. (2001, September). Assessment dilemmas in socio-cultural curriculum. Keynote address to TRCC course: Strengthening the Links, Wellington.

Cullen, J. (2003). The challenge of Te Whāriki: Catalyst for change? In J. Nuttall, Weaving te whāriki: Aotearoa New Zealand's curriculum document in theory and practice. Wellington: NZCER. 
Dahlberg, G., \& Moss, P. (2005). Ethics and politics in early childhood education. London: RoutledgeFalmer.

Dahlberg, G., Moss, P., \& Pence, A. (1999). Beyond quality in early childhood education and care: Postmodern perspectives. London: Falmer Press.

Dalai Lama. (1997). The four noble truths. London: Thorsons.

Dalai Lama. (2002). How to practice: The way to a meaningful life (Trans. J. Hopkins). London: Rider.

Dalai Lama. (2006). Widening the circle of love (Trans. J. Hopkins). London: Rider.

Dalli, C. (1993). Is Cinderella back among the cinders? A review of early childhood education in the early 1990s. Presented at the NZARE conference held at the University of Waikato School of Education on 2-5 December.

Dalli, C. (1997). 'Early childhood centres as parental support: A personal perspective.' Childrenz Issues, 1(2), 21-24. 
Dalli, C. (2006). Re-visioning love and care in early childhood: Constructing the future of our profession. New Zealand Journal of Infant and Toddler Education. 8 (1), 5-11.

Damon, W. (1984). Peer education: The untapped potential. Journal of Applied Developmental Psychology, 5, 331-343.

Daniel, J. (1997). 'Reclaiming the 'terrain of fantasy': Speculations on Ernst Bloch, memory, and the resurgence of nationalism.' In J. Daniel \& T. Moylan (Eds.), Not yet: Reconsidering Ernst Bloch, London: Verso.

Davis, B. (1996). Teaching mathematics: Toward a sound alternative. New York: Garland Publishing.

Davis, B., Sumara, D., \& Luce-Kapler, R. (2000). Engaging minds: Learning and teaching in a complex world. Mahwah, N.J.: Lawrence Erlbaum Associates, Publishers.

Dawson, S. (1999). The enactive perspective on teacher development: A path laid down while walking. In B. Jaworski., T. Wood., S. Dawson (Eds.). Mathematics teacher education: Critical international perspectives. London: Falmer Press. 
Dayan, Y. (2005). Supervising early childhood students: From a behaviourist to a humanistic-democratic approach. Unpublished paper.

Dayan, Y. (2008). Towards professionalism in early childhood practicum supervision - a personal journey. European Early Childhood Education Research Journal, 16(2), 153-170.

Deleuze, G., \& Guattari, F. (1987). A thousand plateaus: Capitalism and schizophrenia (Trans. B. Massumi). London: Athlone Press.

Denzin, N., \& Lincoln, Y. (Eds.). (2005). The Sage handbook of qualitative research ( $3^{\text {rd }}$ ed.). Thousand Oaks: Sage Publications.

Derman-Sparks, L. (1989). Anti-bias curriculum: Tools for empowering young children. Washington: NAEYC.

Derrida, J. (1976/1997). Of grammatology (Trans. G. C. Spivak). Baltimore: Johns Hopkins University Press.

de Tocqueville, A. (1835). Democracy in America (Trans. H. Reeve). New York: George Dearburn \& Co. 
Dewey, J. (1900). The School and Society: Being Three Lectures by John Dewey, Supplemented by a Statement of the University Elementary School. London: P. S. King.

Dewey, J. (1902). The Child and the Curriculum. Chicago: University of Chicago Press.

Dewey, J. (1929). Experience and Nature (2 ${ }^{\text {nd }}$ ed.). La Salle: Open Court.

Dewey, J. (1938). Experience and Education. New York: Collier Books.

Dockett, S. (1997). Extending pretending: Adult roles in supporting children's play. Every Child, 3(1), 10-11.

Duffy, B. (1998). 'Talking with and listening to children.' In S. Smidt (Ed.), The early years: A reader (pp. 135-142). London: Routledge.

Duhn, I. (2006). Cartographies of childhood: mapping the modern/global child. A thesis submitted in fulfilment of the requirements for the degree of Doctor of Philosophy in Education. The University of Auckland, Aotearoa New Zealand. 
Duncan, S. F., \& Marotz-Braden, R. (1999). Using focus groups to identify rural participant needs in balancing work and family education. Journal of Extension [On-line], 37(1). Available at: http://www.joe.org/joe/1999february/rb1.html

Dunn, A., \& Cutting, J. (1999). Theory of mind, emotion understanding, language, and family background: Individual differences and interrelations. Child Development, 70(4), 853-865.

Dunn, J., \& Hughes, C. (1998). Young children's understanding of emotions within close relationships. Cognition and Emotion, 12, 171-190.

Durie, M. (1994). Whaiora: Māori health development. Auckland: Oxford University Press.

Eales, R. (1996). A Vygotskian approach to teaching art in the early Childhood curriculum. Paper presented at EDUVISION, Australian Art Educators' Conference, Dunedin, 9-16.

Eckhoff, A. \& Urbach, J. (2008). Understanding Imaginative thinking during childhood: Sociocultural conceptions of creativity and imaginative thought. Early Childhood Research Quarterly, 36, 179-185. 
Education and Hope. (2010). Education and Hope: Providing hope through education for the children of Guatamala. Retrieved 04/02/2010 from $\underline{\text { www.educationandhope.com }}$

Education for Hope. (2010). School and medical care for children in Ethiopia. Retrieved 04/02/10 from www.educationforhope.com

Elias. N. (1991). The society of individuals. New York: Continuum.

Elliot, A., \& Devine, P. (1994). On the motivational nature of cognitive dissonance: Dissonance as psychological discomfort. Journal of Personality and Social Psychology, 67, 382-394.

Epstein, J. (2006). In J. Elliot, 'Babies Need Tummy Time to Develop', http://news.bbc.co.uk/2/hi/health/5128144.stm. Retrieved 07/07/09.

Erikson, E. (1963). Childhood and society. New York: Norton.

Farquhar, S. (2008). Narrative identity: Ricoeur and early childhood education. A thesis submitted in fulfilment of the requirements for the degree of Doctor of Philosophy in Education. The University of Auckland, Aotearoa New Zealand. 
Faulks, K. (2000). Citizenship. London: Routledge.

Fenech, M., Sumison, J., \& Goodfellow, J. (2008). Regulation and risk: Early childhood education and care services as sites where the 'laugh of Foucault' resounds. Journal of Education Policy, 23(1), 35-48.

Ferge, Z. (2002). The changed welfare paradigm: The individualization of the social. Social Policy and Administration. 31(1), 20-44.

Festinger, L. (1957). A Theory of cognitive dissonance. Evanston: Row Peterson.

Festinger, L., \& Carlsmith, J. (1959). Cognitive consequences of forced compliance. Journal of Abnormal and Social Psychology, 58, 203-210.

Fleer, M. (1995). Staff-child interactions- a Vygotskian perspective (Vol. 1). Canberra: Australian Early Childhood Association Inc.

Fleer, M., \& Robbins, J. (2004). Yeah that's what they teach you at uni, it's just rubbish: The participatory appropriation of new cultural tools as early childhood student teachers move from a developmental to a sociocultural framework for observing and planning. Journal of Australian Research in Early Childhood Education, 11, 47-62. 
Foucault, M. (1972). The archaeology of knowledge and the discourse on language. New York: Pantheon.

Foucault, M. (1977). Discipline and punish: the birth of the prison. London: Penguin.

Foucault, M. (1980) Power/Knowledge: selected interviews and other writings 19721977. New York: Pantheon Books.

Foucault, M. (1991). Governmentality. In G. Burchell, C. Gordon, \& P. Miller (Eds.), The Foucault Effect: Studies in Governmentality, pp. 87-104. Hemel Hempstead: Harvester Wheatsheaf,

Freire, P. (1970). Pedagogy of the oppressed. New York: Continuum.

Freire, P. (1994). Pedagogy of hope: Reliving pedagogy of the oppressed (Trans. R.R. Barr). New York : Continuum.

Freud, S. (1923/1927). The ego and the id (Trans. J. Riviere). London: Hogarth Press.

Gadamer, H. (1975). Truth and method. New York: Continuum. 
Galtung, J. (1990). Violence and peace. In P. Smoker, R. Davies, \& B. Munske (Eds.), A Reader in peace Sstudies. Oxford: Pergammon Press.

Galtung, J. (1996). Peace by peaceful means: Peace and conflict, development and civilization. London: Sage Publications.

Galtung, J. (2004). Violence, war, and their impact: On visible and invisible effects of violence. http://them.polylog.org/5/fgj-en.htm. Retrieved 10/06/06.

Gerber, M. (2002). Dear parent: Caring for infants with respect. California: Resources for Infant Educarers.

Gerritsen, J. (2000). Diversity rules. New Zealand Educational Gazette, 79(2), 4-8.

Gibbons, A. (2006). The matrix ate my baby: technology and the child's play. A thesis submitted in fulfilment of the requirements for the degree of Doctor of Philosophy in Education. The University of Auckland, Aotearoa New Zealand.

Gillies, V. (2005). Raising the meritocracy. Sociology, 39(5), 835-853. 
Gillman, R., Dooley, J., \& Florell, D. (2006). Relative levels of hope and their relationship with academic and psychology indicators among adolescents. Journal of Social and Clinical Psychology, 25(2), 166-178.

Grace, D., \& Tobin, J. (1997). Carnival in the classroom: Elementary students making video. In J. Tobin (Ed.)., Making a place for pleasure in early childhood education (pp. 159-187). New Haven: Yale University Press.

Greenfield, P., Quiroz, B., Rothstein-Fisch, C., \& Trumbull, E. (2001). Bridging cultures between home and school. New Jersey: Lawrence Erlbaum Associates.

Grieshaber, S., \& Cannella, G. (2001). Embracing identities in early childhood education: Diversity and possibilities. New York: Teachers College Press.

Groopman, J. (2005). The anatomy of hope: How people find strength in the face of illness. Great Britain: Simon \& Schuster UK Ltd.

Guba, E., \& Lincoln, Y. (2005). ‘Paradigmatic controversies, contradictions, and emerging confluences'. In N. Denzin \& Y. Lincoln (Eds.)., The Sage handbook of qualitative research ( $3^{\text {rd }}$ ed.). Thousand Oaks: Sage Publications. 
Guylon, S., \& Tereni, L. (2005). Creating an empowering inside learning environment: An overview. Early Childhood Development, 2, 1-6.

Halpin, D. (2003). Hope and education: The role of the utopian imagination. London: RoutledgeFalmer.

Hamer, J. (2005). Exploring literacy with infants from a socio-cultural perspective. New Zealand Journal of Teachers' Work, 2(2), 70-75.

Hanna, P. (2006). Adults and children learning together. New South Wales: Pademelon Press.

Hanson, M. (2000). 'The beauty of dissonance.' Retrieved 05/11/07 from http://www.guitarnation.com/articles/hanson.dissonance.htm.

Hardcastle-Stanford, B. (1992). Gender Equity in the Classroom. In D. Byrnes \& G. Kiger. (Eds.)., Common Bonds: Anti-Bias Teaching in a Diverse Society. Wheaton: Association for Childhood Education International.

Hart, R. (1997). Children's participation: The theory and practices of involving young citizens in community development and environmental care. London: UNICEF, Earthscan Publications. 
Hayek, F.A. (1949). Individualism and economic order. Chicago: Chicago University Press.

Heater, D. (1999). What is citizenship? Cambridge: Polity Press.

Heidegger, M. (1962). Being and time (Trans. J. Macquarrie \& E. Robinson). New York: Harper and Row.

Helleiner, J. (2001). The right kind of children: Childhood, gender and "race" in Canadian postwar political discourse. Anthropologica, 43(2), 143-152.

Hirsch, E.D. (1967). Validity in interpretation. New Haven: Yale University Press.

Hodges, D. (2007). 'What is dissonance?' Retrieved 15/11/07 from http://www.guitarnoise.com/faq.php?id=143.

Holt, J. (1965). How children fail. Great Britain: Pitman Publishing.

Honig, A. (1983). Sex role socialisation in early childhood. Young Children, 44(4), 61-75. 
Hoy, D. C. (1978). The Critical Circle: Literature and History in Contemporary Hermeneutics. Berkeley: University of California Press.

Hudson, W. (1982). The Marxist philosophy of Ernst Bloch. New York: St Martins Press.

Husserl, E. (1936/1970). The crisis of European sciences and transcendental phenomenology (Trans. D. Carr). Evanston: Northwest University Press.

Inglis, F. (Ed.). (2004). Education and the good society. London: Palgrave MacMillan.

Irwin, K. (1994). Māori education, policy and teaching: Thinking globally, acting locally. In E. Halton (Ed.), Understanding teaching: curriculum and the social context of teaching (pp. 359-369). Sydney: Harcourt Brace.

Isaacs, S. (1930). Intellectual growth in children. London: Routledge.

James, W. (1907). Pragmatism : a new name for some old ways of thinking : popular lectures on philosophy. New York: Longmans Green. 
James, W. (1909). A pluralistic universe: Hibbert lectures a Manchester College on the present situation in philosophy. New York: Longmans Green.

Jipson, J., \& Johnson, R, (Eds.). Resistance and representation: Rethinking childhood education. New York: Peter Lang Publishing.

John-Steiner, V., \& Mann, H. (1996). Sociocultural approaches to learning and development: A Vygotskian framework. Educational Psychologist, 31, 191206.

Johnston, C. (2006). Robust hope: Finding a home for early childhood intervention in the new early years landscape. Early Childhood Intervention Australia (Victorian Chapter. Annual Conference Melbourne, 18th August.

Jolly Jumper ${ }^{\mathrm{TM}}$ (2009). www.jollyjumper.com.au. Retrieved 07/07/09.

Jones, L. (2002). Derrida goes to nursery school: deconstructing young children's stories. Contemporary Issues in Early Childhood, 3(1), 139-146. 
Jordan, E., Cowan, A., \& Roberts, J. (1995). Foucault - knowing the rules:

Discursive strategies in young children's power struggles. Early Childhood Research Quarterly, 10(3), 339-358.

Kant, I. (1785/1991). The metaphysics of morals (Trans. M. Gregor). Cambridge, New York: Cambridge University Press.

Kamberelis, G., \& Dimitriadis, G. (2005). Focus groups: Articulations of pedagogy, politics, and inquiry. In N. Denzin \& Y. Lincoln (Eds.)., The Sage handbook of qualitative research ( $3^{\text {rd }}$ ed.). Thousand Oaks: Sage Publications.

Kaomea, J. (2003). Reading erasures and making the familiar strange: Defamiliarising methods for research in formerly colonized and historically oppressed communities. Educational Researcher, 32(2), 67-85.

Katz, L. (1993). Dispositions: Definitions and implications for early childhood practices. Perspectives from ERIC/ECCE: a monograph series. Illinois: ERIC Clearinghouse on ECCE.

Keesing-Styles, L. (2000). Possibilities for partnership: Empowering parents to participate. Early Education, 24, 5-9. 
Kellner, D. (1997). Ernst Bloch, utopia, and ideology critique. In J. Daniel \& T. Moylan (Eds.), Not yet: Reconsidering Ernst Bloch, London: Verso.

Kelsey, L.J. (1891). Second annual report. Dunedin: Dunedin Free Kindergarten Association

Kessler, S.A., \& Swadener, B.B. (Eds.). (1992). Reconceptualizing the early childhood curriculum: Beginning the dialogue. New York: Teachers College Press.

Kierkegaard, S. (1849/1941). Fear and trembling and the sickness unto death (Trans. W. Lowrie). New Jersey: Princeton University Press.

King James Version. (2000). The holy bible. New York: Bartleby.com.

Kozulin, A. (2001). Interface between Vygotskian and mediated learning experience paradigms in teacher training. In R. Feuerstein (Ed.), Mediated Learning Experience in Teaching and Counseling. Jerusalem: ICELP.

Krueger, R., \& Casey, M.A. (2000). Focus groups: A practical guide for applied research (3rd ed.). Thousand Oaks, CA: Sage. 
Kublin, K., Wetherby, A., Crais, E., \& Prizant, B. (1989). Prelinguistic dynamic assessment: a transactional perspective. In A. Wetherby, S. Warren \& J. Reichle (Eds.), Transitions in prelinguistic communication (pp. 285-312). Baltimore: Paul H Brookes,

Kuhn, T. (1962). The structure of scientific revolutions. Chicago: University of Chicago Press.

Lantolf, J.P. (2000). Introducing sociocultural theory. In J.P. Lantolf, (Ed.), Sociocultural theory and second language learning (pp. 1-26). Oxford: Oxford University Press.

Lave, J. (1991). Situating Learning in Communities of Practice. In L. Resnick, J. Levine \& S. Teasley (Eds.). Perspectives on Socially Shared Cognition (pp. 63-83). Washington: APA.

Lave, J., \& Wenger, E. (1991). Situated learning: Legitimate peripheral participation. Cambridge, UK: Cambridge University Press. 
Lenz Taguchi, H. (2005). Getting personal: how early childhood teacher education troubles students' and teacher educators' identities regarding subjectivity and feminism. Contemporary Issues in Early Childhood, 6(3), 244-255.

Leont'ev, A.N. (1981). The problem of activity in psychology. In J.V. Wertsch (Ed.), The concept of activity in Soviet psychology (pp. 37-71). Armonk, NY: Sharpe.

Levinas, E. (1998). Entre nous: On thinking-of-the-other (Trans. M B. Smith \& B. Harshav). New York : Columbia University Press.

Levitas, R. (1990). The concept of utopia. London: Philip Allen.

Lukes, S. (1973). Individualism. New York: Harper \& Row.

Luria, A.R. (1976). Cognitive development. Cambridge: Harvard University Press.

Lynch, W. (1974). Images of hope: Imagination as healer of the hopeless. Notre Dame: University of Notre Dame Press. 
Maccoby, E.E., \& Jacklin, C.N. (1989). Gender segregation in children. In H.W. Reese (Ed.). Advances in child development and behaviour (pp. 239-287). New York: Academic Press.

Macfarlane, A. (2000). The value of Māori ecologies in a study of human development. In L. Bird \& W. Drewery (Eds.). Human development in Aotearoa: A journey through life, (pp 46-51). Auckland: McGraw-Hill.

Macfarlane, K., Noble, K., \& Cartmel, J. (2004). Pedagogy in the nursery: establishing practitioner partnerships in high-quality long day care programs. Australian Journal of Early Childhood, 29(4), 38-45.

MacNaughton, G. (1993). Gender, Power and Racism: A Case Study of Domestic Play in Early Childhood. Multicultural Teaching, 11(3), 12-15.

MacNaughton,G. (1996). Silenced voices: Learning about early childhood programs in the South East Asian region. Australian Journal of Early Childhood, 21(3), 33-39.

MacNaughton, G. (1997). Who's got the power? Rethinking gender equity strategies in early childhood. International Journal of Early Years Education, $5(1), 57-66$. 
MacNaughton, G. (2000). Rethinking gender in early childhood education. Sydney: Allen and Unwin.

MacNaughton, G. (2005). Doing Foucault in early childhood studies: Applying post-structural ideas. New York: RoutledgeFalmer.

MacNaughton, G., \& Smith, K. (2001). Foucault - action research, ethics and the risks of practicing freedom for early childhood professionals. Australian Journal of Early Childhood, 26(4), 32-39.

Mactier, D. (2006). Making meaning together: Emma's investigation of frost, hail and snow. Playcentre Journal, 126, 25-27.

Magnette, P. (2001/2005). Citizenship: The history of an idea (Trans. K. Long). Essex: ECPR Press.

Marshall, T.H. (1950). Citizenship and Social Class. In T.H. Marshall \& T. Bottomore, Citizenship and Social Class (pp. 3-51). London: Pluto.

Martin, C L., Eisenbud, L., \& Rose, H. (1995). Children's gender-based reasoning about toys. Child Development, 66, 1453-1471. 
Massey, S. (2008). Sexism, heterosexism, and attributions about undesirable behavior in children of gay, lesbian, and heterosexual parents. Journal of GLBT Family Studies, 3(4), $457-483$.

Massey University. (2007). BEd programme. Retrieved 07/07/07 from www.massey.ac.nz

Matsumoto-Grah, K. (1992). Diversity in the Classroom: A Checklist. In D. Byrnes \& G. Kiger. (Eds.)., Common Bonds: Anti-Bias Teaching in a Diverse Society. Wheaton: Association for Childhood Education International.

May, H. (1997). Discovery of early childhood: Mid eighteenth century Europe to twentieth century New Zealand. Wellington: Bridget Williams Books.

May, H. (2000). ECE2000@aotearoa.nz: Mapping the landscape of “the century of the child". New Zealand Annual Review of Education, 9, 117-132.

May, H. (2001). Politics in the playground: The world of early childhood in post-war New Zealand. Wellington: Bridget Williams Books Ltd.

May, H. (2004). Towards citizenry rights in early childhood. Delta, 56(1), 75-91. 
May, H. (2005). A right as citizen to a free [early childhood] education. Childrenz Issues, 9(2), 20-24.

May, H. (2009). Politics in the playground: The world of early childhood in New Zealand (2nd ed.). Dunedin: Otago University Press.

McArdle, F., \& McWilliam, E. (2005). From balance to blasphemy: Shifting metaphors for researching early childhood education. International Journal of Qualitative Studies in Education, 18(3), 323-336.

McCormack, L., Wong, M., \& Yogi, L. (2003). Individualisation in the inclusive preschool: A planning process. Childhood Education, 212-217.

McInerney, P. (2004). Making hope practical: School reform for social justice. Flaxton: Post Pressed.

Mead, G. H. (1934). Mind, Self, and Society. Chicago: University of Chicago Press.

Meade, A. (1982). Don't take that dress off James! Australian Journal of Early Childhood, 7, 37-42. 
Mendieta, E. (Ed.). (2006). Take care of freedom and truth will take care of itself: Interviews with Richard Rorty. Stanford: Stanford University Press.

Menand, L. (1997). Pragmatism: A reader. New York: Vintage Books.

Miedzian, M. (1991). Boys will be boys: breaking the link between masculinity and violence. New York: Doubleday.

Millei, Z. (2005). The Discourse of control: Disruption and Foucault in an early childhood classroom. Contemporary Issues in Early Childhood, 6(2), 128-139.

Minick, N., Stone, C.A., \& Forman, E.A. (1993). Integration of individual, social, and institutional processes in accounts of children's learning and development. In E.A. Forman, N. Minick, \& C.A. Stone (Eds.), Contexts for learning. Sociocultural dynamics in children's development (pp.3-16). New York: Oxford University Press,

Ministry of Education. (1996). Te whāriki: He whäriki mātauranga mō ngāa mokopuna o Aotearoa. Early childhood curriculum. Wellington: Learning Media. 
Ministry of Education. (1998). Quality in action. Te mahi whai hua.

Implementing the revised statement of desirable objectives and practices in New Zealand early childhood services. Wellington: Learning Media.

Ministry of Education. (1999). Health and physical education in the New Zealand curriculum. Wellington: Learning Media Ltd.

Ministry of Education. (2002). Pathways to the future: Ngā huarahi arataki.

Wellington: Ministry of Education.

Ministry of Education. (2004-2007). Kei tua o te pae/ Assessment for learning: Early childhood exemplars. Wellington: Learning Media.

Ministry of Education. (2007). Tertiary Education Strategy 2007-2012. Wellington: Author.

Ministry of Education. (2010). Tertiary Education Strategy 2010-2015. Wellington: Author.

Ministry of Education. (2011). Early childhood teacher education qualifications 2011. Wellington: Ministry of Education. 
Ministry of Health. (2000). New Zealand health strategy. Wellington: Author.

Ministry of Health. (2009a). Primary healthcare. Retrieved 14/06/2009 from www.moh.govt.nz/primaryhealthcare

Ministry of Health. (2009b). National immunisation register. Retrieved 14/06/09 from www.moh.govt.nz.dir

Ministry of Social Development. (2010). General student allowance criteria. Retrieved 09/07/10 from http://www.studylink.govt.nz/aboutstudylink/glossary/residency-status-or-type.html\#Permanentresident3

Mitchell, M., \& Reid-Walsh, J. (2002). Researching children's popular culture: The cultural spaces of childhood. London: Routledge.

Moll, L. (1990). Vygotsky and education. Cambridge: Cambridge University Press.

Moltmann, J. (1967). Theology of Hope. New York: Harper \& Row.

Morrow, G., \& Nigel, M. (2004). Parents and professionals working together: Turning the rhetoric into reality.' Early Years, 24(2), 163-176. 
Mozere, L. (2007). In early childhood: What's language about? Educational Philosophy and Theory, 39(3), 291-299.

Murphy, J. (1990). Pragmatism: From Peirce to Davidson. Boulder: Westview Press.

Nagarjuna. (c.200/1995). The fundamental wisdom of the middle way: Nagarjuna's Mulamadhyamakakarika (Trans. J. Garfield). New York: Oxford University Press.

New Zealand Education Act. (1989).

New Zealand Native Schools Act. (1867).

New Zealand Teachers' Council. (2004). Registered Teachers Code of Ethics. Wellington: Author.

New Zealand Teachers' Council. (2007). Graduating Teacher Standards. Wellington: Author.

New Zealand Teachers' Council. (2010). Guidelines for the Approval of Teacher Education Programmes. Wellington: Author. 
New Zealand Vice Chancellors' Committee. (2009). New Zealand vice chancellors' committee: Committee on university academic programmes (CUAP) functions and procedures 2009-2010. Wellington: Author.

Neyland, J. (2010). Rediscovering the Spirit of Education after Scientific Management. Rotterdam: Sense Publishers.

Noddings, N. (1999). Caring and competence. In G. Griffen (Ed.), The education of teachers (pp. 205-220). Chicago: National Society of Education.

Noddings, N. (2003). Caring: A feminine approach to ethics and moral education (2nd ed.). Berkeley: University of California Press.

Nordstrom, P.A., Wilson, L.L., Kelsey, T.W., Maretzki, A.N., \& Pitts, C.W. (2000). The use of focus group interviews to evaluate agriculture educational materials for students, teachers, and consumers. Journal of Extension, [On-line], 38(5). Available at: http://www.joe.org/joe/2000october/rb2.html 
Nuttall, J. (1997). The first years: The story of the Independent Development Trust. Cape Town: National Books Printers.

Nuttall, J. (Ed.). (2003). Weaving te whäriki: Aotearoa New Zealand's curriculum document in theory and practice. Wellington: NZCER.

Nuttall, J., \& Edwards, S. (2007). Theory, policy and practice: Three contexts for the development of Australasia's early childhood curriculum documents. In L. Keesing-Style \& H. Hedges (Eds.), Theorising early childhood practice: Emerging dialogues (pp. 3-22). Castle Hill, NSW: Pademelon Press.

O'Connell, J. (1999). Towards a definition of peace: Idea and process. In J. Calleja \& A. Perucca, Peace Education: Contexts and Values (pp. 25-38). Lecce: PensaMultimedia.

Organisation for Economic Co-operation and Development. (2001). What schools for the future? Paris: Author.

Olsson, L. (2009). Movement and experimentation in young children's learning: Deleuze and Guattari in early childhood education. New York: Routledge. 
Osgood, J. (2006). Deconstructing Professionalism in Early Childhood Education: resisting the regulatory gaze. Contemporary Issues in Early Childhood, 7(1), 5-14.

Otago University. (2007). Bed programme. Retrieved 07/07/07 from www.otago.ac.nz

Paley, V. (1986). On listening to what children say. Harvard Educational Review, 56(2), 122-131.

Parsons, T. (1978). Religion in postindustrial society: In action, theory and the human condition. New York: Free Press.

Partington, G. (1997). Teacher education and training in New Zealand. Auckland: Education Forum.

Peirce, C.S. (1878). How to make our ideas clear. Popular Science Monthly, 12, 286-302.

Peirce, C.S. (1904). A definition of pragmatism. In J. Hoopes (Ed.)., Peirce on signs: Writings on semiotic by Charles Saunders Peirce. Chapel Hill: University of North Carolina Press. 
Penn, H. (2004). Understanding early childhood: Issues and controversies.

Maidenhead: Open University Press..

Piaget, J. (1923/1926). Language and thought of the child. London: Paul Kegan.

Piaget, J. (1935/1971). The Science of Education and the Psychology of the Child.

London: Longmans.

Poest, C., Williams, J., Will, D., \& Alwood, M. (1990). Challenge me to move: Large muscle development in young children. Young Children, 45(6), 4-10.

Polkinghorne, J. (2002). The God of hope and the end of the world. London: SPCK.

Pollard, A. (1996). The social world of children's learning. London: Cassell.

Postman, N., \& Weingartner, C. (1971). Teaching as a subversive activity. New York: Delta Book Publishing.

Prochner, L. (2004). Early childhood education programs for indigenous children in Canada, Australia and New Zealand: an historical review. Australian Journal of Early Childhood, 29(4), 7-17. 
Pugh, G. (Ed.) (2001). Contemporary issues in the early years: Working collaboratively for children. London: Paul Chapman Publishing.

Putnam, H. (1995). Pragmatism: An open question. Oxford: Blackwell.

Reid, R. (2002). ‘Learning Stories: Narrative observations and learning dispositions'. Playcentre Journal, 113, 20-21.

Rhedding-Jones, J. (1995). What do you do after you've met poststructuralism? Research possibilities regarding feminism, ethnography and literacy. Journal of Curriculum Studies, 27(5), 479-500.

Rhedding-Jones, J. (1996) Positionings poststructural: Some Australian research in education, Nordisk Pedagogik [Nordic Journal of Research in Education], 16(1), 2-14.

Ricoeur, P. (1974). The conflict of interpretations. Evanston: Northwest University Press.

Ridgeway, A., \& Surman, L. (2004). Practice what we preach: Why reflective pedagogy? Journal of Australian Research in Early Childhood Education, 11(2), 1-13. 
Ritchie, J. (1994). Implementing a commitment to biculturalism in early childhood training. Journal for Australian Research in Early Childhood Education, 1, 122-132.

Ritchie, J. (1996). Anti-racism education within an early childhood education diploma programme. International Journal of Early Years Education, 4(1), $65-80$.

Ritchie, J. (2003). Bicultural development within an early childhood teacher education programme. International Journal of Early Years Education, 11(1), $42-56$.

Rogers, N. (2001). Theodor W. Adorno's poetics of dissonance: Music, language and literary modernism. PhD dissertation, University of Pennsylvania.

Rogoff, B. (1990). Apprenticeship in thinking: Cognitive development in social context. New York: Oxford University Press.

Rogoff, B. (1992). Three ways to relate person and culture: Thoughts sparked by Valsiner's review of Apprenticeship in Thinking. Human Development. $35,316-320$. 
Rogoff, B. (2003). The cultural nature of human development. Oxford: Oxford University Press.

Rorty, R. (Ed.). (1967). The linguistic turn: Essays in philosophical method. Chicago: University of Chicago Press.

Rorty, R. (1979). Philosophy and the mirror of nature. New Jersey: Princeton University Press.

Rorty, R. (1982). The consequences of pragmatism. Minneapolis: University of Minneapolis Press.

Rorty, R. (1989). Contingency, irony and solidarity. Cambridge, UK: Cambridge University Press.

Rorty, R. (1990). Pragmatism as anti-representationalism. In J. Murphy, Pragmatism: From Peirce to Davidson. Boulder: Westview Press.

Rorty, R. (1991a). Objectivism, relativism and truth: Philosophical papers (vol. 1 ). Cambridge, UK: Cambridge University Press. 
Rorty, R. (1991b). Essays on Heidegger and others: Philosophical papers (vol. 2). Cambridge, UK: Cambridge University Press.

Rorty, R. (1998a) Achieving our country: Leftist thought in twentieth-century America. Cambridge, Mass.: Harvard University Press.

Rorty, R. (1998b). Truth and progress: Philosophical papers (vol. 3). Cambridge, UK: Cambridge University Press.

Rorty, R. (1999). Philosophy and social hope. London: Penguin.

Rorty, R. (2007). Philosophy as cultural politics: Philosophical papers (vol. 4). Cambridge, UK: Cambridge University Press.

Rousseau, J.J. (1762/1974). Emile (Trans. B. Foxley). London: Dent Everyman Library.

Royal Tangaere, A. (1997). Learning Māori together: Kōhanga Reo and home. Wellington: NZCER. 
Rustoen, T., Howie, J., Eidsmo, I., \& Moum, T. (2005). Hope in patients hospitalised with heart failure. American Journal of Critical Care, 14, 417425.

Ryan, S., \& Ochsner, M. (1999). Traditional practices, new possibilities: transforming dominant images of early childhood teachers. Australian Journal of Early Childhood, 24(4), 14-21.

Rycroft, C. (1979). Steps to an ecology of hope. In R. Fitzgerald (Ed.), The sources of hope, Australia: Pergamon Press.

Saltmarsh, S. (2009). Becoming economic subjects: Agency, consumption and popular culture in early childhood. Studies in the Cultural Politics of Education, 30(1), 47-59.

Sapon-Shevin, M. (1996). Celebrating diversity, creating community. In S. Stainback \& W. Stainback (Eds.), Inclusion: A guide for educators. Maryland: Paul Brookes Publishing Co.

Sawyer, W., Singh, M., Woodrow, C., Downes, T., Johnston, C., \& Whitton, D. (2007). Robust hope and teacher education policy. Asia-Pacific Journal of Teacher Education, 35(3), 227-242. 
Saxe, L. (1991). Lying: Thoughts of an applied social psychologist. American Psychologist, 46(4), 409-415.

Schwartz, S., Cote, J., \& Arnett, J.J. (2005). Identity and agency in emerging adulthood: Two developmental routes in the individualization process. Youth Society, 37(2), 201-229.

Sellars, M. (2009). A Rhizo-poiesis: A children's play(ing) of games. Complicity: An international Journal of Complexity and Education, 6(2), 91103.

Sellars, M., \& Honen, E. (2007). Putting rhizomes to work: (E)merging methodologies. NZ Research in Early Childhood Education Journal, 10, 145154.

Shade, P. (2001). Habits of hope: A pragmatic theory. Nashville: Vanderbilt University Press.

Sheerer, M. (1997). Using Individualization and Scaffolding to Improve Inservice Programs. Early Childhood Education Journal, 24(3), 201-203. 
Singh, M., \& Sawyer, W. (2008). Democracy and robust hope: Queensland's education and training reforms for the future. Education, citizenship and social justice, 3, 223-237.

Siu, K. \& Lam, M. (2005). Early childhood technology education: A sociocultural perspective. Early Childhood Education Journal, 32(6), 353358.

Skinner, B.F. (1968). The Technology of Teaching. New York: Appleton-CenturyCrofts

Slavin, R.E. (1983). When does cooperative learning increase achievement? Psychological Bulletin, 94, 429-445.

Slavin, R.E. (1987). Developmental and motivational perspectives on cooperative learning: A reconciliation. Child Development, 58, 1161-1167.

Smiley, P.A., \& Dweck, C.S. (1994). Individual differences in achievement goals among young children. Child Development, 65, 1723-1743.

Smith, A.B. (1996). The early childhood curriculum from a sociocultural perspective. Early Child Development and Care, 115, 51-64. 
Smith, A.B. (1998). Understand children's development ( $4^{\text {th }}$ ed.). Wellington: Bridget Williams Books.

Smith, A. B. (2006). How can collaboration improve the wellbeing of children in Aotearoa/New Zealand?' Editorial. Childrenz Issues, 10(2), 3-4.

Smith, A.B. (2007). Children's rights and early childhood education: links to theory and advocacy. Australian Journal of Early Childhood, 32(3), 1-9.

Smoker, P., Davies, R., \& Munske, B. (1990). A reader in peace studies. Oxford: Pergamon Press.

Snyder, C. (1994). Psychology of hope: You can get there from here. New York: The 'Free Press.

Snyder, C. (2000). Handbook of hope: Theory, measures, and applications. New York: Academic Press. 
Spodek, B. \& Saracho, O. N. (1994). Early childhood education and early childhood special education: A look to the future. In B. Spodek \& O.N. Saracho (Series Ed.) and P. L. Safford (Vol. Ed.), Yearbook in early childhood Education: Vol. 5. Early childhood special education (pp. 242-246). New York, NY: Teachers College Press.

Stewart, J. \& Rawhiti, L. (2004). Creating tertiary retention programmes for indigenous peoples in NZ - moving toward a holistic approach: Incentives, outcomes and issues raised by the variety of programmes at Victoria University of Wellington, NZ. Journal of Australian and New Zealand Student Support Services Association, 24, 26-46.

Stotland, E. (1967). A preliminary statement to a theory of attitude structure and change. New York: McGraw-Hill.

Strathdee, R. (2005) Commentary: A critical reflection on the research-led teacher education reforms in New Zealand. New Zealand Journal of Educational Studies, 40(1), 221-227.

Sumara, D., \& Davis, B. (1997). Enactivist theory and community learning: Toward a complexified understanding of action research. Educational Action Research, 5(3), 403-422. 
Swadener, E.B., \& Kessler, S.A. (1991). Reconceptualizing early childhood education: An introduction. Early Education and Development, 2(2), 85-94.

Swick, K., \& Freeman, N. (2004). Nurturing Peaceful Children to Create a Caring World: The role of families and communities. Childhood Education, 81(1), 2-7.

Taylor, C. (1989). Sources of the self: The making of the modern identity. Cambridge, Mass. : Harvard University Press.

Te One, S. (2003). The context for Te Whäriki: Contemporary issues of influence. In J. Nuttall (Ed.), Weaving Te Whāriki: Aotearoa New Zealand's early childhood curriculum document in theory and practice (pp. 17-50). Wellington: NZCER.

Te One, S. (2008). Children's participation rights in a New Zealand kindergarten. Paper presented at NZARE conference, Palmerston North.

Te One, S. (2009). Perceptions of children's rights in three early childhood settings: A thesis submitted to the Victoria University of Wellington in fulfilment of the requirements for the degree of Doctor of Philosophy in Education. Unpublished PhD thesis. 
Terhardt, E. (1974). Pitch, consonance, and harmony. Journal of the Acoustical Society of America, 55, 1061-1069.

Terreni, L. (2005). Scaffolding Alex: Actively supporting young children in the visual arts. New Zealand Journal of Teachers' Work, 2(1), 43-48.

Tharp, R., \& Gillmore, R. (1988). Rousing minds to life: Teaching, learning, and schooling in social context. Cambridge: Cambridge University Press.

Thrupp, M., \& Tomlinson, S. (2005). Introduction: Education policy, social justice and'complex hope'. British Educational Research Journal, 31(5), 549565.

Tobin, J. (1997). The missing discourse of pleasure in the classroom. In J. Tobin (Ed.)., Making a place for pleasure in early childhood education (pp. 138). New Haven: Yale University Press.

Tozzo, S.G., \& Golub, S. (1990). Playing nurse and playing cop: Do they change children's perceptions of sex-role stereotypes? Journal of Research in Childhood Education, 42, 123-129.

Treaty of Waitangi. (1840). 
Trifonas, P.P. (2006). Deconstruction and the philosophy of childhood. JCT, 22(3), 113-118.

Tronto, J. (2006). The ethics of care: Personal, political, and global. New York: Oxford University Press.

Tudge, J.R.H., \& Rogoff, B. (1989). Peer influences on cognitive development: Piagetian and Vygotskian perspectives. In M.H. Bornstein \& J.S. Bruner (Eds.), Interaction in human development (pp. 17-40). Hillsdale, NJ: Erlbaum.

University of Canterbury. (2007). BEd programme. Retrieved on 07/07/07 from www.canterbury.ac.nz

Varela, F., Thompson, E., \& Rosch, E. (1991). The embodied mind: Cognitive science and human experience. Cambridge: The MIT Press.

Victoria University of Wellington. (2007). BEd programme. Retrieved 07/07/07 from $\underline{w w w . v u w . a c . n z}$

Villegas, A., \& Lucas, T. (2002). Preparing culturally responsive teachers: Rethinking curriculum. Journal of Teacher Education, 53(1), 20-32. 
Viruru, R. (2001). Early childhood education : postcolonial perspectives from India. California: Thousand Oaks.

Vygotsky, L. (1978). Mind in society: The development of higher mental processes. Cambridge: Harvard University Press.

Vygotsky, L. S. (1981). The genesis of higher mental functions. In J.V. Wersch (Ed.), The concept of activity in soviet psychology. Armonk: M. E. Sharpe.

Vygotsky, L.S. (1986). Thought and Language (Trans. A. Kozulin). Cambridge, MA: MIT Press.

Vygotsky, L. \& Luria, A. (1994). Tool and symbol in child development. In R. van der Veer, \& J. Valsiner (Eds.), The Vygotsky reader. Oxford: Blackwell.

Waikato University. (2007). BEd programme. Retrieved 07/07/07 from $\underline{\text { www.waikato.ac.nz }}$

Walker, C. (2004). Promotion of hope vital in care of dying patients: nonspecialist palliative nurses encouraged to read research into terminal illness. Nursing Standard, 19(10), 8. 
Walkerdine, V. (1988). Counting girls out: Girls and mathematics. London:

Falmer.

Walsh, D.J. (1993). Art as Socially Constructed Narrative: Implications for Early Childhood Education. Arts Education Policy Review, 94, 18-23.

Weber, M. (1949/1969). 'Objectivity in social science and social policy'. In R.

Rogers, Max Weber's Ideal Type Theory, New York: Philosophical Library.

Weber, M. (2002). The Protestant Ethic and "The Spirit of Capitalism" (Trans. P. Baehr \& G.C. Wells). UK: Penguin Books.

Wein, C., Coates, A., Kealing, B., \& Bigelow, B. (2005). Designing the environment to build a connection to place. Young Children, 16-24.

Weis, L., Altbach, P., Kelly, G., \& Petrie, H. (Eds.). (1991). Critical perspectives on early childhood education. Albany, N.Y.: State University of New York Press.

Weiten, W. (1998). Psychology: Themes and variations ( $4^{\text {th }}$ ed.). Pacific Grove: Brooks Cole Publishing. 
Wenger, E. (1998). Communities of Practice: learning, meaning and identity. New York: Cambridge University Press.

Wenger, E., McDermott, R., \& Snyder, W. (2002). Cultivating communities of practice: a guide to managing knowledge. Cambridge, MA: Harvard Business School Press.

Wertsch, J.V. (1984). The zone of proximal development: Some conceptual issues. In B. Rogoff \& J. V. Wertsch (Eds.), Children's learning in the "zone of proximal development." San Francisco: Jossy-Bass.

Wertsch, J.V. (1985). Vygotsky and the social formation of mind. Cambridge, MA: Harvard University Press.

Wertsch, J. (1991). Voices of the mind: a sociocultural approach to mediated action. London: Harvester Press.

Wertsch, J. (1998). Mind as action. Oxford: Oxford University Press.

Westburg, N. (2003). Hope, laughter, and humour in residents and staff at an assisted living facility. Journal of Mental Health Counselling, 25(1), 16-33. 
White, J. (2007). Authoring the metaphoric act: The ethical encounter of 'teaching' young children in dialogic activity. Peer reviewed abstract submitted to the International Interdisciplinary Conference (May, 2007): "Perspectives and Limits of Dialogism in Mikhail Bakhtin", University of Crete, Greece.

White, J. \& Nuttall, J. (2007). Expanding intersubjectivity: The potential of Bakhtinian dialogism to inform narrative assessment in early childhood education. The First Years/Nga Tau Tuatahi: New Zealand Journal of Infant and Toddler Education, 9(1).

Wilde, O. (1891). The soul of man under socialism. St. Louis: Hermann Schwarz.

Wood, D., Bruner, J., \& Ross, G. (1976). The role of tutoring in problem solving. Journal of Child Psychology and Psychiatry, 17, 89-100.

Woodhouse, B.B. (2008). Individualism and Early Childhood in the U.S.: How Culture and Tradition Have Impeded Evidence-Based Reforms. Journal of Korean Law, 8, 135-160. 
Woodrow, C., \& Brennan, M. (2001). Interrupting dominant images: Critical and ethical issues. In J. Jipson \& R. Johnson (Eds.). Resistance and representation: Rethinking childhood education. New York: Peter Lang Publishing.

Wulf, C. (1992). Education for peace. Peace, Environment, and Education, 8, 3-10.

Zinchenko, V.P. (1985). Vygotsky's ideas about units for the analysis of mind. In J.V. Wertsch (Ed.), Culture, communication, and cognition: Vygotskian perspectives (pp. 94-118). Cambridge: Cambridge University Press. 